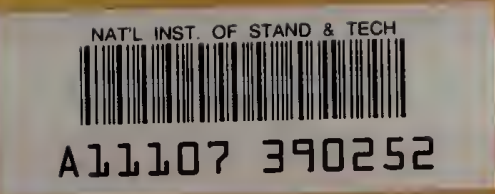

NBS

PUBLICATIONS

NBSIR 83-2732(R)

\title{
Use of Hazard Pictorials / Symbols in the Minerals Industry
}

U S. DEPARTMENT OF COMMERCE National Bureau of Standards Center for Building Technology Illuminating Engineering Group Building Physics Division Washington, DC 20234

Sponsored by QC S. Department of Interior 100 lashington, DC 20241 .456 

...

USE OF HAZARD PICTORIALS/SYMBOLS

Belinda Lowenhaupt Collins

U.S. DEPARTMENT OF COMMERCE

National Bureau of Standards

Center for Building Technology

Illuminating Engineering Group

Building Physics Division

Washington, DC 20234

September 1983

Sponsored by

Bureau of Mines

U.S. Department of Interior

Washington, DC 20241

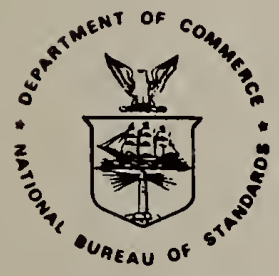

U.S. DEPARTMENT OF COMMERCE, Malcolm Baldrige, Secretary NATIONAL BUREAU OF STANDARDS, Ernest Ambler, Director 



\section{ABSTRACT}

This report documents a three-phase research effort on the evaluation of the effectiveness of safety symbols and hazard pictorials for use in mining and milling operations. In the first phase, applicable codes and standards were reviewed, along with documentation of typical mining hazards, to determine relevant safety messages. This phase included site visits to eight mine sites to document existing sign practice and common mining hazards. In the second phase, the effectiveness of two sets of symbols for 40 different safety messages was evaluated with 267 miners from 10 sites at disparate geographical locations. This evaluation also included an assessment of the effectiveness of six different symbol surround shapes and colors. Symbols which were the most effective, according to the suggested criteria, were those which depicted both the person and the hazard or protective gear, and which were more representational, rather than highly abstract. Based upon this research, a set of 40 symbols was suggested for further graphic refinement, additional evaluation, and eventual use. In the third phase, these symbols were assessed in an inmine evaluation at 2 sites. This evaluation indicated that the symbol signs were generally well understood and conspicuous, with no problems of durability, or poor contrast arising during the three-month evaluation. A Handbook for using symbol signs in mines concludes the report.

Key words: communication; hazard; mining; pictogram; safety; signs; standards; symbols; visual alerting; warnings. 


\section{FOREWORD}

Th1s report is one of a serles documenting National Bureau of Standards research and analysis efforts in support of the Bureau of Mines (BoM)/National Bureau of Standards (NBS) Hazard P1ctorlal/Safety Symbol Evaluation Program. Th1s report is a deliverable product under BoM Contract Number J0113020 entitled, "Use of P1ctorials/Symbols in the Minerals Industry,".

It was administered under the direction of Twin Citles Mining Research Center, Minneapolis, Minnesota with Guy Johnson acting as the Technical Project officer. Phil Silas was the contract administrator for the Bureau of Mines. This report summarizes the research completed as part of the contract during the period of January 1981-January 1983.

\section{ACKNOWLEDGEMENTS}

The author wishes to acknowledge the help of the many people who were essent1al to the completion of this report. The cooperation of the many miners who part1clpated so wlllingly is deeply appreclated, along with the mining companies who allowed the use of their personnel and facilitles. In addition, the following people furnished invaluable support during the course of the profect:

Guy Johnson, Bob Mattes, and Mike Sapko, of the Bureau of Mines, provided continulng support and use of mine facilities; Dr. Nell Lerner contributed extensively to the research planning, code review and documentation, and statistical analysis; Dr. Austin Adams also provided invaluable assistance during the stat1st1cal analysis; and Ms. Karen Lister, Mr. Albert Hattenburg, Dr. Mary Natrella, and Mr. George Turner, of the National Bureau of Standards provided insightful and helpful comments on the document. Finally, I would like to thank the Word Processing Unit for their competent job in typing the many versions of the final report. 


\section{EXECUTIVE SUMMARY}

Extensive highway research has demonstrated that, when chosen appropriately, symbols can communicate information more rapidly and of ten, more effectively, the words. Greater use of symbols for safety and hazard warning messages, however, requires that they be understandable to the intended audience. The present project was designed to assess the effectiveness of safety symbols and hazard pictorials for mine-safety communication.

In the first phase of a three-phase evaluation, requirements for safety signs in mines were determined by a series of site visits which assessed existing practice, a hazard analysis which reviewed mine accident and fatality statistics, and a code review which tabulated symbol and sign requirements in existing national and international codes. From this first stage, a set of 40 messages (referents) applicable to mine safety signs was developed. At the same time, one to two symbols were selected for further evaluation for each message, (based upon previous research and code recommendations).

In the second phase, the understandability of the selected symbols was assessed with 267 miners at 10 different mine sites in the United States. Miners indicated their understanding of a symbol's meaning by completing a four-choice multiple response form. At each site, miners were split into two groups so that the performance of more than one symbol for a message could be compared. In addition, the degree of danger (perceived hazardousness) indicated by six different surround shapes was determined by a ranking procedure for several different interior images. The results from the second phase indicated that statistically significant differences in performance occurred between symbols for 72 percent of the referents for which 2 symbols were studied. An analysis of variance revealed significant site and age differences as well. For 34 referents, at least one symbol was identified correctly by 85 percent or more of the miners participating. Symbols which performed below this level included: Laser, Radiation, General Warning, Flammable, Fire Alarm Call Point, and No Exit. Many of these latter symbols are either highly abstract or represent unfamiliar concepts. Correctly identified symbols can be characterized as more pictorial, often depicting a person plus an action, or piece of gear, or hazard. Although problems emerged for some of the more abstract hazard-warning symbols, symbols for personal protective gear, prohibited actions, and fire/ safety equipment were generally correctly identified. The results of the rankings for the perceived hazardousness of surround shape indicated that the diamond and octagon were seen as most hazardous and the square and circle as least hazardous. Red, yellow, and orange were ranked as the most appropriate colors for hazard warning.

In the third phase, a subset of 20 symbols was selected for an in-mine evaluation, based upon the results from the second phase. This evaluation, which took place at 2 mine sites in the Eastern United States, included further assessment of the understandability of the 40 "best" symbols, determination of confusions within, and conspicuity of, the subset of installed symbols, and determination of physical parameters such as contrast and durability. Although the in-mine evaluation revealed continuing problems with the Flammable symbol, 
the overall performance of the symbol signs was generally good. The need for additlonal word messages on some hazard-warning signs was ldentifled.

Based on the three evaluation phases, a handbook was written for using symbol signs in mines. Th1s handbook, wh1ch concludes the report, provides suggestions for symbol sign configuration, location, and testing at mine sites. In summary, the overall evaluation of safety symbols in mines indicated that symbols are a generally effective means of communicating safety and hazard information. A set of some 25-30 symbols 18 suggested, along with a handbook containing general guldelines for the use of symbol signs in mines. 


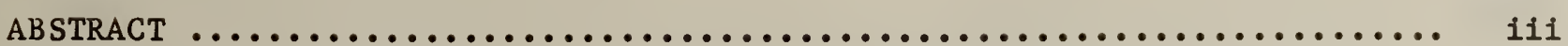

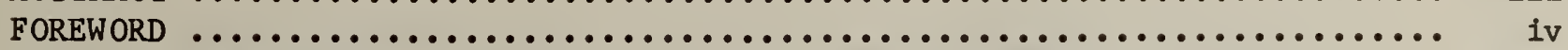

ACKNOWLEDGEMENTS

EXECUTIVE SUMMARY $\ldots \ldots \ldots \ldots \ldots \ldots \ldots \ldots \ldots \ldots \ldots \ldots \ldots \ldots \ldots \ldots \ldots \ldots \ldots \ldots \ldots \ldots \ldots$

1. INTRODUCTION $\ldots \ldots \ldots \ldots \ldots \ldots \ldots \ldots \ldots \ldots \ldots \ldots \ldots \ldots \ldots \ldots \ldots \ldots \ldots \ldots \ldots$

1.1 FRAMEWORK FOR THE STUDY OF SAFETY SYMBOLS AND HAZARD PICTORIALS 1

1.1 .1 Background Research ............................ 2

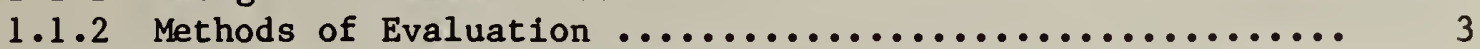

1.2 WORKPLACE SAFETY SYMBOL RESEARCH $\ldots \ldots \ldots \ldots \ldots \ldots \ldots \ldots \ldots \ldots \ldots \ldots \ldots$

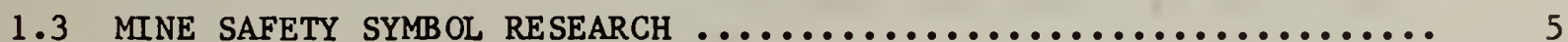

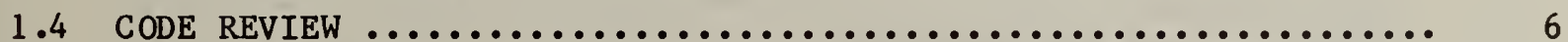

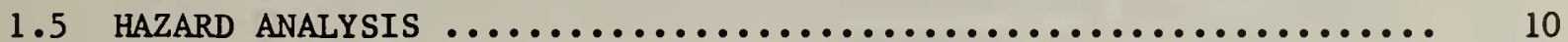

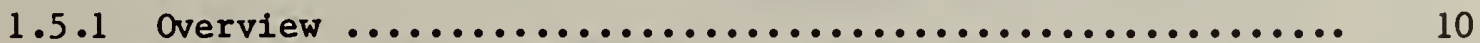

1.5 .2 Detailed Hazard Analysis $\ldots \ldots \ldots \ldots \ldots \ldots \ldots \ldots \ldots \ldots \ldots \ldots \ldots \ldots$

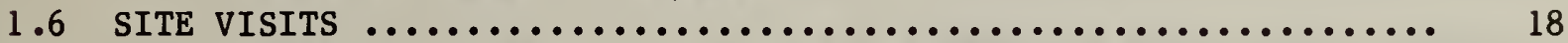

1.6 .1 Hazard Information from Site Visits $\ldots \ldots \ldots \ldots \ldots \ldots \ldots \ldots . . . \ldots$

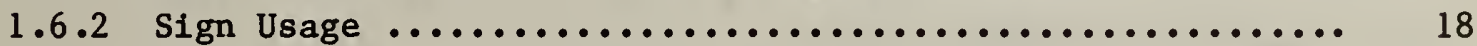

2. SELECTION OF REFERENT MESSAGES AND CANDIDATE SYMBOLS ........... 25

2.1 SELECTION OF REFERENT MESSAGES $\ldots \ldots \ldots \ldots \ldots \ldots \ldots \ldots \ldots \ldots \ldots \ldots \ldots \ldots . \ldots \ldots$

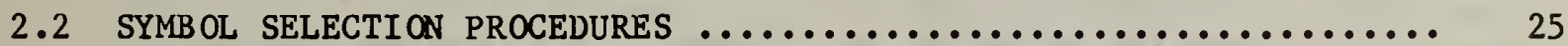

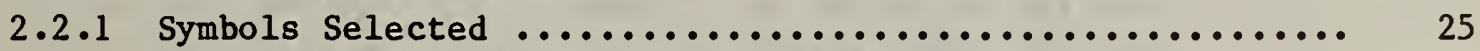

2.2.2 Rationale for Specific Symbol Selection ............. 27

2.2 .3 Surround Shape Concerns ......................... 28

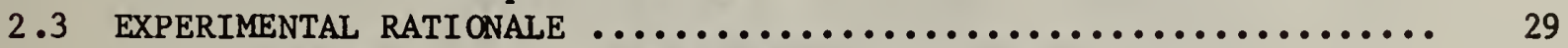

2.3 .1 Evaluation of Understandability ................... 29

2.3.2 Perceived Hazardousness of Surround Shape ............. 31

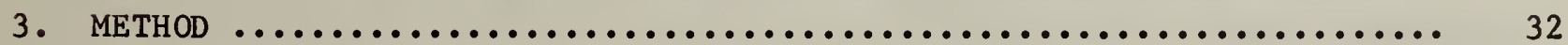

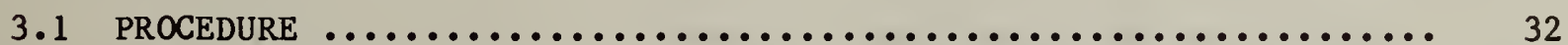

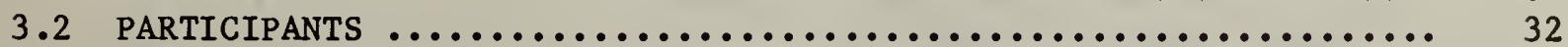

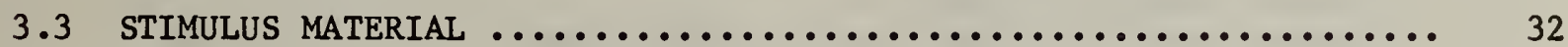

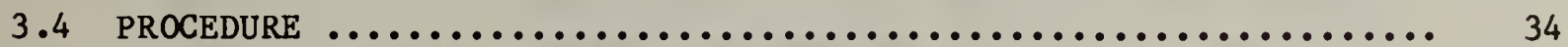

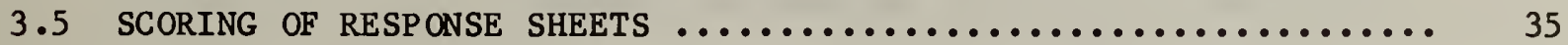

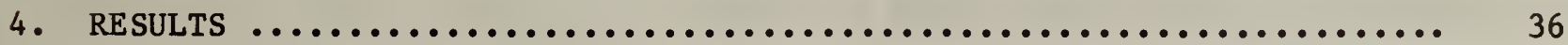

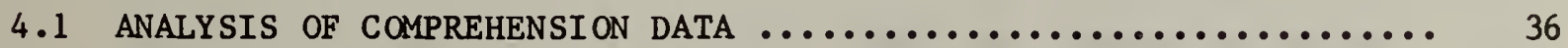

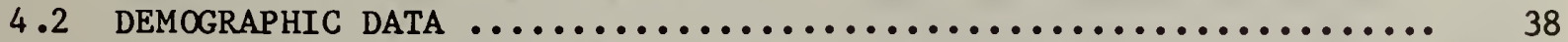

4.3 PERFORMANCE OF INDIVIDUAL SYMBOLS $\ldots \ldots \ldots \ldots \ldots \ldots \ldots \ldots \ldots \ldots \ldots \ldots \ldots \ldots$

4.4 RESULTS AND DISCUSSION OF INDIVIDUAL SYMBOLS $\ldots \ldots \ldots \ldots \ldots \ldots \ldots \ldots . . \ldots$

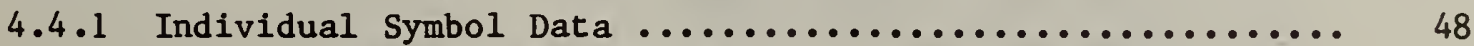

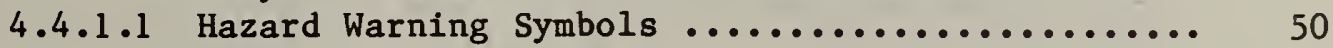

4.4 .1 .2 Prohibition Symbols ..................... 70 


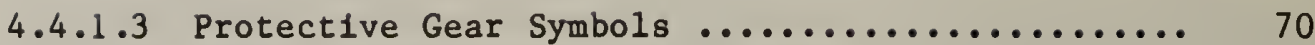

4.4.1.4 Safety Equipment and Fire Emergency Symbols .... 76

4.4.1.5 Egress Related Symbols .................. 87

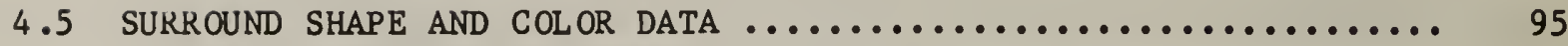

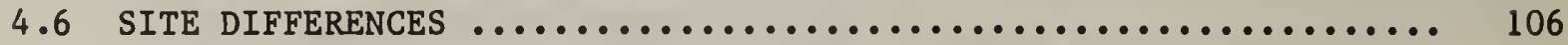

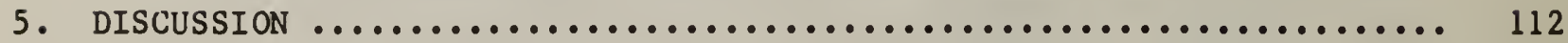

5.1 COMPARISON WITH PREVIOUS RESULTS ..................... 112

5.2 FACTORS WHICH APPEAR TO AFFECT SYMBOL EFFECTIVENESS $\ldots \ldots \ldots \ldots \ldots 112$

5.3 SURROUND SHAPE AND BACKGROUND COLOR DATA ................ 117

5.4 DISCUSSION OF SITE DIFFERENCES $\ldots \ldots \ldots \ldots \ldots \ldots \ldots \ldots \ldots \ldots \ldots \ldots \ldots \ldots \ldots$

5.5 SELECTION OF A PRELIMINARY SYMBOL SET $\ldots \ldots \ldots \ldots \ldots \ldots \ldots \ldots \ldots \ldots \ldots$

6. IN-MINE SYMBOL SIGN EVALUATION $\ldots \ldots \ldots \ldots \ldots \ldots \ldots \ldots \ldots \ldots \ldots \ldots \ldots \ldots \ldots$

6.1 SELECTION OF SYMBOL SIGNS $\ldots \ldots \ldots \ldots \ldots \ldots \ldots \ldots \ldots \ldots \ldots \ldots \ldots \ldots \ldots \ldots \ldots$

6.2 EVALUATION OF SYMBOL SIGN EFFECTIVENESS $\ldots \ldots \ldots \ldots \ldots \ldots \ldots \ldots \ldots \ldots \ldots$

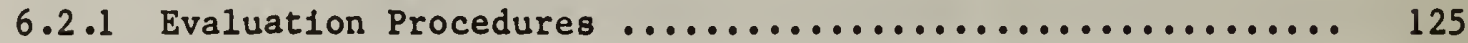

6.2 .2 Evaluation of Understandability--Both Sites .......... 127

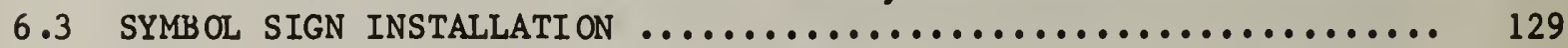

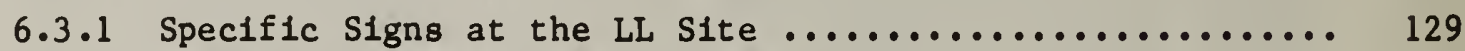

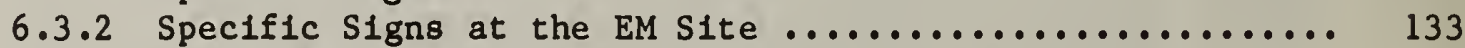

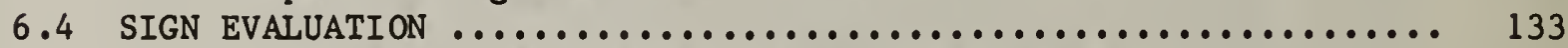

6.4.1 Evaluation of Physical Characteristics .............. 133

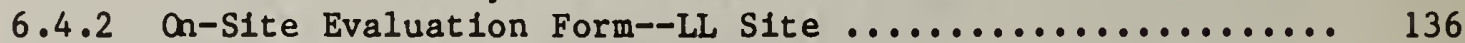

6.4 .3 Comments from the EM Evaluation .................... 140

6.5 GEINERAL CONCLUSIONS FROM THE ON-SITE EVALUATION $\ldots \ldots \ldots \ldots \ldots \ldots . . \ldots 140$

7. RECOMMENDATIONS ....................................... 143

7.1 SUGGESTIONS FOR IMPROVEMENT IN SYMBOLS $\ldots \ldots \ldots \ldots \ldots \ldots \ldots \ldots \ldots \ldots$

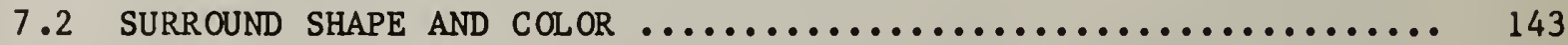

7.3 CRITERIA FOR EVALUATING SYMBOL EFFECTIVENESS $\ldots \ldots \ldots \ldots \ldots \ldots \ldots \ldots$.

7.4 DEVELOPMENT OF A SET OF RECOMMENDED SYMBOLS $\ldots \ldots \ldots \ldots \ldots \ldots \ldots \ldots \ldots$

8. HANDBOOK FOR USING SYMBOLS SIGNS IN MINES .................. 147

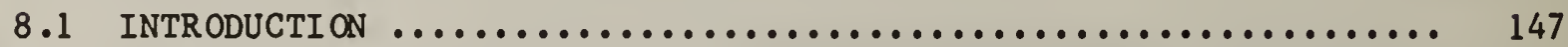

8.2 CURRENT STANDARDS FOR SYMBOL SIGNS $\ldots \ldots \ldots \ldots \ldots \ldots \ldots \ldots \ldots \ldots \ldots \ldots \ldots$

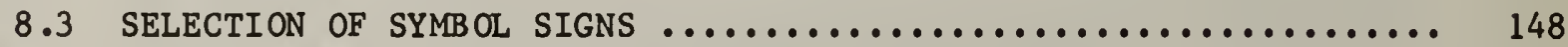

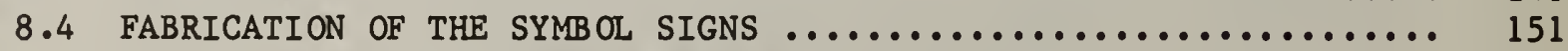

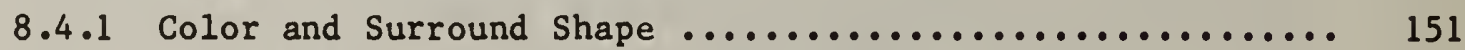

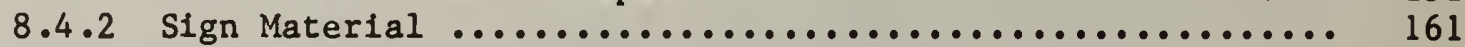

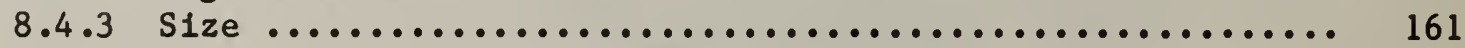


TABLE OF CONTENTS

$\underline{\text { Page }}$

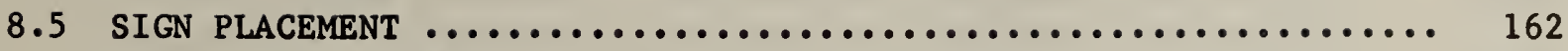

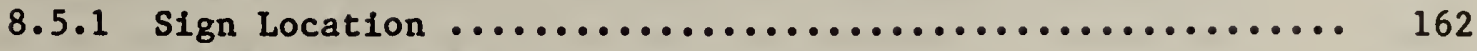

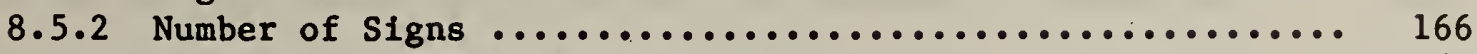

8.6 SYMBOL EVALUATION--SUGGESTED PROCEDURES $\ldots \ldots \ldots \ldots \ldots \ldots \ldots \ldots \ldots \ldots \ldots$

8.7 ADDITION OF WORD MESSAGES $\ldots \ldots \ldots \ldots \ldots \ldots \ldots \ldots \ldots \ldots \ldots \ldots \ldots \ldots \ldots \ldots \ldots . \ldots \ldots$

8.8 GENERAL RECOMMENDATIONS $\ldots \ldots \ldots \ldots \ldots \ldots \ldots \ldots \ldots \ldots \ldots \ldots \ldots \ldots \ldots \ldots \ldots \ldots$

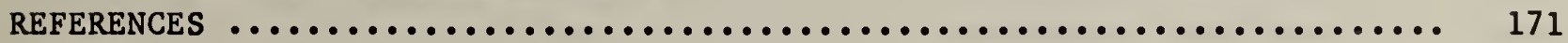

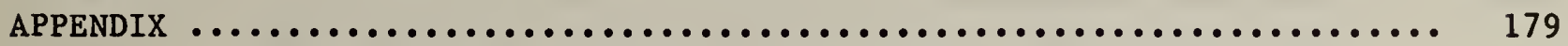


Table 1. Mine Safety Messages from the Code of Federal Regulations .... 7

Table 2. Synthesis of International Safety Symbol Codes ............. 9

Table 3. Coding Sign Practices from International and U.S. Safety

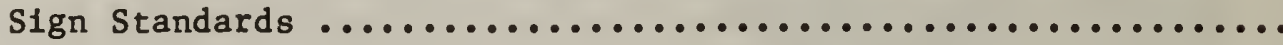

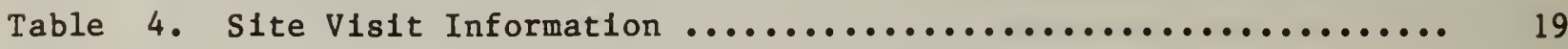

Table 5. Safety Sign Messages Observed at Eight Mine Sites ........... 21

Table 6. Referent Messages for Mine Safety Symbols ................. 26

Table 7. Data Collection Locations $. . . \ldots \ldots \ldots \ldots \ldots \ldots \ldots \ldots \ldots . . . \ldots \ldots$

Table 8. Overall Percentage of Correct Answers and Mean Confidence Ratings for All Symbols $\ldots \ldots \ldots \ldots \ldots \ldots \ldots \ldots \ldots \ldots \ldots \ldots . . . \ldots \ldots$

Table 9. Site Data Analyses ............................... 39

Table 10. Summary Age Data $\ldots \ldots \ldots \ldots \ldots \ldots \ldots \ldots \ldots \ldots \ldots \ldots \ldots . \ldots \ldots, 40$

Table 11. Occupation Categories and Frequencies from All Sites

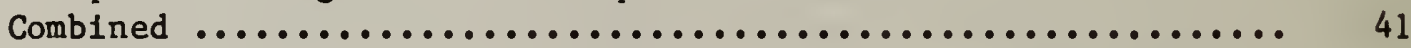

Table 12. Statistical Analysis Data for All Symbols and Across Sites ... 45

Table 13. Comparison of Percentage Correct and Confidence Ratings

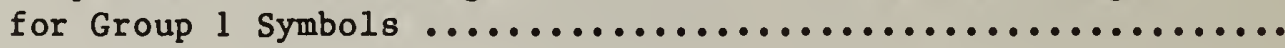

Table 14. Comparison of Percentage Correct and Confidence Ratings

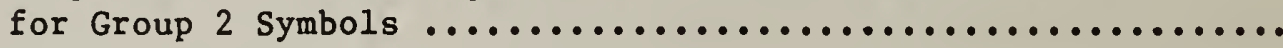

Table 15. Ranking Data for Hazard Symbols - Totals for All Sites ...... 96

Table 16. Ranking Data for Explosion - Totals for Each Site .......... 97

Table 17. Ranking Data for Entanglement - Totals for Each Site ........ 98

Table 18. Ranking Data for Poison - Totals for Each Site ............. 99

Table 19. Ranking Data for General Warning - Totals for Each Site ..... 100

Table 20. Ranking Data for Surround Alone - Totals for Each Site ...... 101

Table 21. Ranking Data for First Ald - Totals for Each Site .......... 102

Table 22. Ranking Data for Hard Hat - Totals for Each S1te........... 103 


\section{LIST OF TABLES (Continued)}

$\underline{\text { Page }}$

Table 23. Ranking Data for Safety Information Symbols - Totals for

All Sites ........................................ 104

Table 24. Site Comparison Data .............................. 108

Table 25. Percentage of Correct Response for Each Site .............. 110

Table 26. Mean Confidence Rating Data for Correct Answers for All

Subjects at Each Site .............................. 111

Table 27. Comparison with Previous Symbol Research ................. 113

Table 28. Image Content--Ordered According to Percentage Correct

Responses--Group 1 ............................. 115

Table 29. Image Content-Ordered According to Percentage Correct

Responses--Group 2 .............................. 116

Table 30 . Preliminary Selection of Images ....................... 122

Table 31. Percentage Correct and Confidence Rating Data for Final

Symbol Set for Both Sites ......................... 128

Table 32. Ranking Data for Surround Shapes for Hazard Symbols - LL

Site ........................................ 130

Table 33. Sign Location and Luminance Measurements -- LL Site ........ 131

Table 34. Sign Location and Luminance Measurements - EM Site ........ 132

Table 35. Confusion/Conspicuity Data ......................... 138

Table 36. Mine Safety Messages from the Code of Federal Regulations .... 149

Table 37. Categories of Safety Messages Used in the Handbook ......... 152

Table 38. Minimum Sizes Suggested for Symbols by the Treasury Board of Canada ........................................ 163

Table 39. Different Symbolic Information for a Single Hazard ........ 165

Table 40. A Suggested Matching Procedure ......................... 167

Table 41. General Suggestions for Using Safety Symbols at Mine Sites ... 170 


\section{LIST OF FIGURES}

Page

F1gure 1. Fatal mine accidents--1980 est1mates ................... 12

F1gure 2. Est1mated infury data--NFDL and NUL--1980 ............ 13

Figure 3. ANSI $81 \mathrm{gn}$ format for hazard-warning s1gns ............... 22

Figure 4. Distribution of age by site for four age groups .......... 43

Figure 5. Percentage of correct responses as a function of mean confldence rating ................................ 49

F1gure 6. Flammable hazard $\ldots \ldots \ldots \ldots \ldots \ldots \ldots \ldots \ldots \ldots \ldots \ldots \ldots \ldots \ldots \ldots \ldots \ldots \ldots . . \ldots$

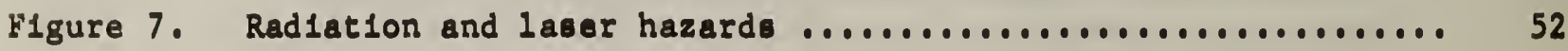

F1gure 8. Explosion hazard $\ldots \ldots \ldots \ldots \ldots \ldots \ldots \ldots \ldots \ldots \ldots \ldots \ldots \ldots \ldots \ldots \ldots \ldots \ldots$

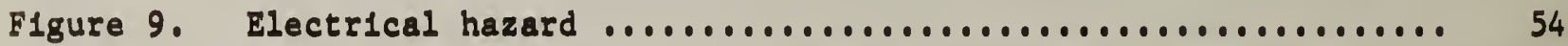

Figure 10. Corrosion hazard ............................... 55

F1gure 11. Poison hazard ................................. 57

F1gure 12. Fork $11 f t$ truck hazard $\ldots \ldots \ldots \ldots \ldots \ldots \ldots \ldots \ldots \ldots \ldots \ldots \ldots \ldots . \ldots . \ldots$

F1gure 13. slip hazard $\ldots . \ldots \ldots \ldots \ldots \ldots \ldots \ldots \ldots \ldots \ldots \ldots \ldots \ldots \ldots \ldots \ldots \ldots \ldots$

F1gure 14. Fall from elevation hazard ......................... 60

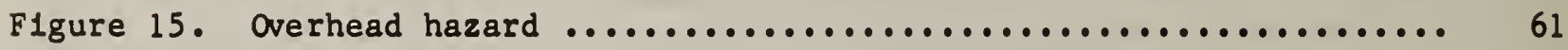

Figure 16. General warning $\ldots \ldots \ldots \ldots \ldots \ldots \ldots \ldots \ldots \ldots \ldots \ldots \ldots \ldots \ldots \ldots \ldots \ldots . \ldots \ldots$

Figure 17. Trip hazard $\ldots \ldots \ldots \ldots \ldots \ldots \ldots \ldots \ldots \ldots \ldots \ldots \ldots \ldots \ldots \ldots \ldots \ldots \ldots \ldots . \ldots . \ldots$

Figure 18. Pinch point and hot surface hazards $\ldots \ldots \ldots \ldots \ldots \ldots \ldots \ldots \ldots \ldots$

F1gure 19. Crush hazard ................................. 66

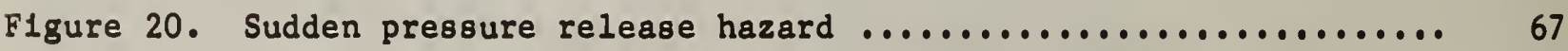

F1gure 21. Sever/cut hazard $\ldots \ldots \ldots \ldots \ldots \ldots \ldots \ldots \ldots \ldots \ldots \ldots \ldots \ldots \ldots \ldots \ldots$

F1gure 22. Entanglement hazard ............................ 69

F1gure 23. Do not touch ................................ 71

$x 11$ 


\section{LIST OF FIGURES (Continued)}

$\underline{\text { Page }}$

Figure 24 . No smoking $\ldots \ldots \ldots \ldots \ldots \ldots \ldots \ldots \ldots \ldots \ldots \ldots \ldots \ldots \ldots \ldots \ldots \ldots \ldots \ldots . \ldots \ldots$

Figure 25 . No open flame $\ldots \ldots \ldots \ldots \ldots \ldots \ldots \ldots \ldots \ldots \ldots \ldots \ldots \ldots \ldots \ldots \ldots \ldots \ldots$

Figure 26. Head protection required ........................... 74

Figure 27. Hearing protection required ........................ 75

Figure 28. Eye protection required $\ldots \ldots \ldots \ldots \ldots \ldots \ldots \ldots \ldots \ldots \ldots \ldots \ldots \ldots \ldots$

Figure 29. Foot protection required $\ldots \ldots \ldots \ldots \ldots \ldots \ldots \ldots \ldots \ldots \ldots \ldots \ldots \ldots . \ldots$

Figure 30 . Hand protection required ........................... 79

Figure 31 . Respiratory protection required ...................... 80

Figure 32. First aid location $\ldots \ldots \ldots \ldots \ldots \ldots \ldots \ldots \ldots \ldots \ldots \ldots \ldots \ldots \ldots \ldots$

Figure 33 . Safety shower location $\ldots \ldots \ldots \ldots \ldots \ldots \ldots \ldots \ldots \ldots \ldots \ldots \ldots \ldots \ldots \ldots$

Figure 34 . Eyewash location ............................... 84

Figure 35. Fire extinguisher and hose and reel location ............ 85

Figure 36. Fire alarm call point $\ldots \ldots \ldots \ldots \ldots \ldots \ldots \ldots \ldots \ldots \ldots \ldots \ldots \ldots \ldots$

Figure 37. Exit $\ldots \ldots \ldots \ldots \ldots \ldots \ldots \ldots \ldots \ldots \ldots \ldots \ldots \ldots \ldots \ldots \ldots \ldots \ldots \ldots \ldots . \ldots . \ldots$

Figure 38 . Emergency exit $\ldots \ldots \ldots \ldots \ldots \ldots \ldots \ldots \ldots \ldots \ldots \ldots \ldots \ldots \ldots \ldots \ldots \ldots$

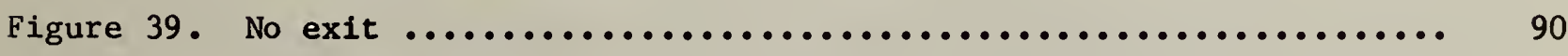

Figure 40. Do not enter .................................... 92

Figure 41 . Keep door open $\ldots \ldots \ldots \ldots \ldots \ldots \ldots \ldots \ldots \ldots \ldots \ldots \ldots \ldots \ldots \ldots \ldots \ldots \ldots$

Figure 42. Keep door closed ................................ 94

Figure 43. Rated hazardousness of surround shape .................. 105

Figure 44. Preferred background color for selected symbols .......... 107

Figure 45. Symbols fabricated as signs for in-mine evaluation.......... 126

Figure 46. Photographs of symbol signs as installed at the LL site ..... 134 


\section{LIST OF FIGURES (Continued)}

$\underline{\text { Page }}$

Figure 47. Photographs of symbol signs as installed at the EM site .... 135

Figure 48 . an-site evaluation form ........................ 137

Figure 49. Photographs comparing symbol signs with adjacent word signs . 142

Figure 50. Symbols suggested for safety messages ................. 153

F1gure 51. Typical symbol configuration ....................... 157

F1gure 52. Examples of symbol configuration for each category ........ 159 


\section{INTRODUCTION}

\subsection{FRAMEWORK FOR THE STUDY OF SAFETY SYMBOLS AND HAZARD PICTORIALS}

Traditionally, hazard warnings and safety instructions have been provided by written English signs within the United States. Such signs are designed to call the workers' attention to a hazard, inform them of the nature of the hazard, and provide information for avoiding the hazard or for following specified safety precautions. The importance of worker safety is underscored by the statistic that 13,000 persons were killed in work accidents, with disabling injuries numbering $2,200,000$, at a cost of approximately $\$ 30.2$ billion in 1981 (National Safety Council, 1981). In mines alone, a total of 237 miners were killed in 1981 and 172 miners in 1982, (Mine Safety and Health Administration, 1981; 1982.) A total of 23,990 accidents (nonfatal occurrences with lost workdays) were reported for coal, metal, non-metal, stone, and sand and gravel mines for 1981 . In all workplaces, injuries are most likely during the first month of the first year on the job (National Safety Council, 1979; Bureau of Labor Statistics, 1979). The need to warn the new miner or worker, then, is particularly acute.

Written signs, while commonly used, may not be the best way of providing safety or hazard information, however. The use of pictorial, or symbolic signs has become increasingly common, because such signs can provide essential information more rapidly (Janda and Volk, 1934), more accurately (Walker, Nicolay and Stearns, 1965), and at a greater distance (Smith and Weir, 1978) even under conditions of distraction or interference (King 1971, 1975; E11s and Dewar 1979). Symbol signs also can be smaller than written signs, while encoding the same information, making them suitable for equipment as well as for environmental signs (Forbes, Gervais, and Allen, 1963; Green 1979). Symbol signs also have the advantage of providing information without the use of a particular written language. In addition, they may be more effective in altering behavior (Forbes, et al., 1963). The use of symbolic signs, often without accompanying word legends, is now mandated by the Department of Transportation (DOT) for interstate highways in the United States (DoT, 1979).

The advantages of developing a uniform system of hazard pictorials and safety symbols for mining applications are numerous. The mechanization of modern mining has sparked the need for safety messages which are readily detectable and understandable by a moving operator. In addition, there is a need to communicate information to those who are not fully literate or whose native language is not English. Estimates of illiteracy vary widely from about 2 to 64 million adult Americans (Kirsch and Guthrie, 1977-1978), while the Bureau of the Census reported (Washington Post, 1979) that five million of the eight million people in the U.S. whose native language was not English claimed to have difficulty in speaking or understanding English. For these people, symbols could be the only visual warning for preventing accidents. These facts, when combined with the data which indicate that symbols can be more effective than word signs, reinforce the need to develop a workable system of hazard pictorials and safety symbols for mining applications.

Simply selecting a pictorial to convey a safety message from existing catalogues such as Dreyfuss (1972) or Modley and Myers (1976) is not sufficient, however. 
Symbols are more effective than word signs if, and only if, they communicate their message to the intended user. Although the designer of a symbol may understand 1ts message perfectly, it does not necessarily follow that others will. Collins and Lerner (1982) found that several internationally proposed life-safety symbols communicated messages that were opposite to their intended message to a large number of people. Before symbols are selected for mining applications, their effectiveness in communicating the intended message to members of a mining population must be evaluated. A symbol which does not have good understandability will fall to communicate necessary safety information.

\subsubsection{Background Research}

Numerous evaluations of symbol effectiveness have been performed. These are reviewed in detail elsewhere (Collins, 1982) but a brlef overview is provided as a framework for the evaluation of mine-safety symbols and hazard pictorials.

Experimental assessments of symbol effectiveness have concentrated upon symbols for h1ghways, vehicles, machinery, and public information. The bulk of the research has focused on highway applications, beglnning with a study by Janda and Volk (1934) who determined that subjects responded faster to symbol signs than to word signs. Walker, Nicolay, and Stearns (1965) determined that symbol slgns were 1dentifled more accurately than word 81gns. King (1975) found that subjects 1dentifled symbols more accurately when their response was delayed and an interference task included. This experiment attempted to simulate an actual driving condition in which the interval between viewing a sign and acting upon it is occupied with a driving task -- a condition similar to many mining operations during which a miner must see and act upon a sign's message while continuing to perform a customary mining operation. In another experiment on highway symbols, Dewar, E11s, and Mundy (1976) found that reaction time was always shorter for symbols under both normal and degraded viewing conditions. In a laboratory study, Johnston, Cole, Jacobs and Gibson (1976) determined that selected symbols were visible at a greater distance than their word-sign counterparts.

Other experiments have concentrated upon assessing the meaningfulness of individual highway symbols (Bralnard, Campbell, and Elkins, 1961; Griffith and Actkinson 1978). Still another series of experiments assessed the effectiveness of selected symbols in actually changing behavior. Forbes, Gervals, and Allen (1963) determined that a red " $x$ " was most effective in controlling traffic lane use, in a series of lab and field studies. This symbol, demonstrably superior to a comparable word sign in changing behavior, also could be smaller and more flexibly positioned - another important consideration for mining applications. Dewar and Swanson (1972) also translated laboratory research into effective highway signage, by demonstrating that positive, rather than prohibitory symbols were more effective in altering driving behavior.

Many of the studies of automotive and machine symbols concentrated on measuring the understandability of a specific set of symbols. In an evaluation of farm and industrial machine symbols, Cahill (1975, 1976) found wide variability in the performance of individual symbols, although experience and context improved 
performance somewhat. She noted that more graphic, pictorial representations of the intended message were better understood, while symbols denoting continuing activities such as "Engage" or "Hours Running" were poorly understood. Such "conceptual" messages appear to have poor initial understandability even to experienced users. Wiegand and Glumm (1979), in an evaluation of automotive control symbols, concurred with Cahill's results, noting that knowledge of the understandability of a set of symbols can be used to indicate where graphic redesign or additional education is necessary.

Other studies of automotive symbols assessed symbol performance by having subjects touch the appropriate controls (Heard, 1974) or having them indicate familiarity with and appropriateness of a set of proposed symbols (Green and Pew, 1978). Green (1979) suggested that a valuable way to develop specific symbols for a message is to have the user draw them - a technique known as the production method. This technique is especially valuable in situations where common symbols do not exist for a particular message.

Evaluation of public information symbols (Easterby and Zwaga, 1976; Freedman and Berkowitz, 1977; Freedman, Berkowitz and Gallagher, 1976; Mackett-Stout and Dewar, 1981; Zwaga and Boersema, 1981), also indicated a wide range of comprehension among selected symbols, with pictorial symbols being more understandable than abstract ones. Studies of safety symbols have concentrated upon symbols for consumer products (Easterby and Hakie1, 1977, a, b, c; 1981) fire safety (Collins and Lerner, 1982; Lerner and Collins, 1980a), and industrial safety (Lerner and Collins, 1980b; Collins, Lerner and Pierman, 1982). Easterby and Hakiel (1981) determined that the color Red was preferred for flammable hazard signs while Black was selected for poison. Their data also indicated that subjects preferred symbols which described the hazard to those which prohibited the action or prescribed a particular action (to avoid the hazard). In addition, symbols which were more visually complex (perhaps, more representational) performed better than more abstract, graphically simpler signs. They concluded that the content of the image, rather than the color, primarily determines sign comprehension. Their data also indicated that subjects older than 55 performed consistently more poorly than all other age groups, a finding confirmed by Lerner and Collins (1980) and Hulbert, Beers, and Fowler (1979). For fire safety signs, Lerner and Collins (1980) found that certain important symbols for egress were not only not understood, they also received a significant number of critical confusions (opposite-to-correct answers). Again, these poorly performing images were among the most abstract studied.

\subsubsection{Methods of Evaluation}

Understandability or meaningfulness has been assessed by numerous methods. One of the most common methods is simply to ask people to write down a brief definition of the meaning of a sign (Brainard et al., 1961; Walker et al., 1965; Cahi11, 1975; Easterby and Zwaga, 1976; Collins and Lerner, 1982). In addition to indicating the understandability of the symbol, wrong answers from the definition procedure provide insight into the kinds of confusions and misunderstanding associated with a particular symbol. Another commonly used method is a matching procedure in which people select the answer from a list of answers 
which best "matches" the symbol's meaning (Brainard et al., 1961; Griffith and Actkinson, 1978; Wlegand and Glumn, 1979). Hulbert, Beers, and Fowler (1979) used a multiple cholce procedure with 1mmediate knowledge of results in an assessment of highway signs. Other researchers asked subjects to gulde themselves along a highway or through a bullding relying upon symbolic information (Freedman et al; 1976; Forbes et al; 1963; Dewar and Swanson, 1972); or touch the appropriate control (Heard, 1974). St11l others asked for assessments of rated meaningfulness or preference (Green and Pew, 1978; Collins, Lerner, and Pierman, 1982; Easterby and Hak1el, 1981). Mackett-Stout and Dewar (1981) suggested the use of an "efficiency index" derived from data on legibility distance, comprehension, and preference, for a more comprehensive evaluation. In addition, measures such as speed of detection or recognition have been obtained with and without the addition of distracting tasks.

This brief overview indicates that the performance of symbols can be assessed along several dimensions by a variety of methods. The performance dimensions include understandability or comprehension (what does it mean?), detectability (can it be seen?), discrimination (1s it confused with other symbols, particularly in the same set?), conspicuity (does 1t attract attention?), and behavior (do people perform the correct action in response to the sign?). Because symbols are used primarily to replace or supplement written signs, it is essential that they be understood - that they communicate their intended message. Once a symbol's understandability has been determined, Its performance on the other evaluation dimensions should then be assessed. For mining operatlons, both detectab1lity and consplculty (or sallence) are also critical, part1cularly for moblle equipment operators. The focus of the present report, however, 18 on understandability - or the determination of the relative meaningfulness of two sets of symbols for a serles of safety messages.

\subsection{WORKPLACE SAFETY SYMBOL RESEARCH}

A previous study conducted by the National Bureau of Standards (Collins, Lerner and Pierman, 1982; Lerner and Collins, 1980b) examined the relative understandability of different safety symbols for a set of 33 referents. A total of 89 candidate images were studied. In the study by Collins et al. (1982), 222 employees from industrial sites at four different geographical locations provided short, written definitions of the meaning of one image for each referent. In the second portion of the study, particlpants were shown all the candidate images for a given referent, and asked to choose the one that best conveyed the intended meaning to them. They also indicated the reasons for their choice. In addition, 75 participants who were nalve to the worksplace also participated in a pilot study.

The understandability of the symbols, in terms of percentages of correct and incorrect definition answers, varied widely for the thiry-three referents, as well as for the candidate images studied for each referent. Desplte standardized use for many years, symbols for Radiation, Laser, and Biohazard were frequently misidentified. On the other hand, symbols for Protective Gear, First Aid, and Emergency Equipment were generally correctly defined. The different candidate images for the various hazard referents, showed the greatest range in terms of percentage of correct definition, with responses to each of 
the three 1mages for Entanglement, Electricity, Corrosion, and Overhead Hazard being quite different. Referent messages for which all candidate images received less than 85 percent correct responses Included Radiation, Laser, Blohazard, General Warning, Posion, Combustible, Eyewash, Exit, No Exit, and No Entrance. The first four referents were particularly poorly understood.

Generally, the preference data supported the understandability data, with the image receiving the highest percentage of correct answers also being the most preferred. Participants also typically expressed strong preferences for one of the candidate choices with significant differences occurring in all but two cases (Eyewash and General Warning). They also provided insightful comments about the reasons for their choices, including ideas about the visibility, pictorial nature, and probable effectiveness of the various images proposed for each referent.

Although the study by Collins et al. (1982) assessed the relative understandability of a number of workplace safety symbols, it did not assess stereotypes or perceived hazards associated with either symbol color or surround shape. Nor did it assess many of the hazards associated with mining and mining equipment, or use members of a mining population. Rather, it provided an initial assessment with industrial personnel of the understandability of graphic images for 33 referents - as these images appeared in sign catalogues and standards. These data do provide a basis for comparing the performance of industrial and mining personnel, since many of the referents and symbols studied are common to the two studies. A comparison of the two sets of data will be given in Section 5.1 .

\subsection{MINE SAFETY SYMBOL RESEARCH}

Throughout the preceding section, the focus has been on research into the effectiveness of symbolic messages. Generally, reseachers began their investigations with an existing set of symbols suggested for a particular application. For example, Freedman et al. (1976) evaluated a set of symbols proposed by the American Institute of Graphic Arts (AIGA, 1974) for use in transportation facilities, while Heard (1974) evaluated three sets of symbols proposed by the International Organization for Standardization (ISO) for automotive displays. In the case of safety symbols, however, no one set of symbols has been recommended for use within the United States.

As a result, the assessment of symbolic images for mining environments required a determination of the most important and most prevalent safety and hazard warning messages used in mines. This determination involved first an assessment, given in Section 1.4, of existing international, national, and industrial standards for safety symbols, particularly for mines. Secondly, it included a hazards analysis, given in Section 1.5 , to determine the nature and frequency of mining accidents. Thirdly, it involved site visits, given in Section 1.6 , to a number of mines and discussions with mining personnel. Finally, it included inputs from voluntary standards writing groups within the United States such as the American National Standards Institute (ANSI) Z535 Committee on Safety Signs and Colors, the Construction Industry Manufacturers Association (CIMA), and the Society of Automotive Engineers (SAE). A list of important 
afety messages and ymbols was developed from these sources. The selection of safety mesuages and symbols is described in section 2 , along with the

\section{experimental rationale. In sections 3,4 , and 5 an evaluation of the} understandability of symbols for each of 40 messages with miners from 10 mine sites is presented. An analysis of the percelved hazardousness of surround shape and color is also presented in these sections. Section 6 presents results from an in-mine evaluation of a subset of the recommended symbols while section 7 provides recommendations based upon all phases of testing. Section 8 presents a handbook for guidance in using symbol signs in an actual mine.

\subsection{CODE REVIEW}

Both national and international codes containing information about sign and symbol messages related to safety information and hazard warnings were reviewed. The code applicable to mining operations, The Code of Federal Regulations, Title 30 , makes no provision for the specific use of symbols but does list the situations for which signs are required. Table 1 presents the general messages required and the relevant cltations for sign requirements in mines from Title 30, Mineral Resources, of the Code of Federal Regulations (July 1, 1980 rev1sion). Parts 55, 56, 57, 75 and 77 all concern mine safety standards. The paragraphs cited 1nclude all references to the use of safety-related signs and labels. Communications, which were not considered, include references to alarus, diagrams and maps, control panels, and communication and signaling devices.

Parts 55 (Health and Safety Standards - Metal and Nonmetallic Open Pit Mines), 56 (Health and Safety Standards - Sand, Gravel, and Crushed Stone Operations), and 57 (Health and Safety Standards - Metal and Nonmetallic Underground Mines), coinprise Subchapter N - Metal and Nonmetallic Mine Safety of the Code of Federal Regulations, Title 30 . The three parts are parallel in construction and similar in content. The paragraphs of each part that refer to sign use are presented in table 1. This table indicates all relevant paragraphs, and Indicates which of the three parts include that paragraph. For Part 57, some paragraphs refer to surface operations only or to underground operations only; where the requirement is so restricted, it is noted in the table. Subchapter 0 - Coal Mine Health and Safety contains two relevant parts: Part 75 "Mandatory Safety Standards - Underground Coal Mines," and Part 77, "Mandatory Safety Standards, Surface Coal Mines and Surface Work Areas of Underground Coal Mines."

Other codes reviewed included the European Economic Commission (EEC) proposed directive for "Safety Signs at Work in Coal Mines" (1979) which contains specific recommended symbols for mining applications. Other safety codes and standards reviewed are aimed at more general industrial applications, rather than mines specifically. Nevertheless, many of the messages included are similar to those found in the Code of Federal Regulations and the EEC Directive and so are included here. These include the EEC Directive for Safety Signs at Places of Work (771576) (1977), and various ISO (International Organization for Standardization) proposed standards--DIS 3864.3 (1978); ISO 3461 (1980a); and DP 6309 (1978).) The Canadian Standards Association (1977) provides referents with suggested image content, but no specific imagery, while the Treasury Board 
Table 1. Mine Safety Messages from the Code of Federal Regulations

\section{GENERAL MESSAGE}

No Entry,

Restricted Entry

Hazard, Danger

(general)

No Smoking

No Open Flame

Explosive

Blasting Switch,

Safety Switch

Burn Rate of Fuse

Flammable Liquid

Compressed Gas

Hazardous Material

Toxic Material

Location of Fire-Fighting

Equipment

Location of Self-Rescuer

Electrical Danger

Electricity Lock-Out

Electricity Disconnect

Traffic Control

\section{RELEVANT CITATIONS}

$55.3-5,55.6-103,56.3-5,57.6-103$

$57.3-5,57.5-28,56.6-103,57.20-20$,

$57.21-43,75.303,75.1711-3,77.1303(\mathrm{~g})$

$55.20-11,56.20,57.20-11,75.303$

$55.4-2,55.6-110,55.8-5,56.4-2$, $56.6-110,56.8-5,57.4-2,57.6-110$, $57.8-5,77.1102$

$55.4-2,55.8-5,56.4-2,56.8-5,57.4-2$, $57.8-5,77.1102$

$55.6-20(1), 55.6-43,55.6-159(\mathrm{~b})$, $56.6-20(1), 56.6-43,56.6-159(\mathrm{~b})$, $57.6-20(1), 57.6-29,57.6-43,57.6-159(\mathrm{~b})$, $77.1301(\mathrm{c})(9), 77.1301(\mathrm{e}), 77.1302(\mathrm{c})$

$77.1303(\mathrm{hh})$

$77.1303(v)$

$77.1103(a)$

75.1106-3

$55.16-4,56.16-4,57.16-4,77.208(c)$

$55.20-12,56.20-12,57.20-12$

$55.4-23,56.4-23,57.4-23$

$75.1712-2(f), 75.1714-2(g)(2)$

$55.12 .21,56.12-21,57.12-21,77.511$

$55.12-16,55.12-17,56.12-16,56.12-17$, $57.12-16,57.12-17,75.511,77.501$

$75.601,75.809,75.904,77.600$

$55.971,56.971,57.971,77.1600(\mathrm{~b})$ 
Table 1. (Cont1nued)

\section{GENERAL MESSAGE}

Traffic Control

Tra1n Crossing

Parked Vehicle Hazard

Projection from Vehicle

Men Working (In shaft)

Emergency Stop (holst)

Speed (holst)

Maximum Load (holst)

Unsafe Equipment

Fall Hazard

Obstruction

Egress

Keep Door Open/Closed

Shelter Hole

Reduced Clearance

Reduced Overhead Clearance

\section{RELEVANT CITATIONS}

$55.971,56.971,57.971,77.1600(\mathrm{~b})$

$55.9-59,56.9-59,57.9-59$

$55.9-68,56.9-68,57.9-68,77.1607(0)$

$55.9-49,56.9-49,57.9-49,77.1607(t)$

55.19-107, 56.19-107, 57.19-107, $55.19-108,56.19-108,57.19-108$

$55.19-13,56.19-13,57.19-13$

$77.1908(k)$

$77.1402-2$

$55.9-73,56.9-73,57.9-73$

$55.11-12,56.11-12,57.11-12$

$57.9-104$

$57.11-51(b), 75.1704,77.1101(c)$

$55.21-57,56.21-57,57.21-57$

$57.9-111$

$55.9-83,56.9-83,57.9-83,75.1403-8(\mathrm{~b})$, $77.1600(\mathrm{c}), 77.1605(\mathrm{~h})$

$55.9-60,56.9-60,57.9-60,55.11-10$, $56.11-10,57.11-10,75.1403-10(\mathrm{c})$, $77.1600(c)$ 
Table 2. Synthesis of International Safety Symbol Codes

$\underline{\text { Referent Message }}$

Flammable

Laser

Radiation

Electrical

Corrosion

Explosion

Poison

Forklift Truck

Overhead Hazard

Moving Machinery

General Warning

Hard Hat

Eye protection

Ear protection

Respiratory protection

Hand protection

Foot protection

First aid

No smoking

No open flame

Exit

No Exit

No Entrance

Not drinking water

Do not extinguish with water

Sound your hooter

Locomotive in area
Suggested Image Content

Flames from horizontal surface

Sunburst with radiating line

Three blades around circle

Zig-zag or lightning bolt with arrow

Test tubes dripping acid on hand, bar

Exploding object with radiating particles

Skull and Crossbones

Person in forklift truck

Crane load breaking

Two rotating gears

Exclamation point

Front view of head with hard hat

Front view of head with safety glasses

Front view of head with ear protectors

Front view of head with respirator

Two hands with gloves

Side view of safety boot or shoe

Cross

Circle, slash, lighted cigarette

Circle, slash, lighted match

Variations of person moving, door, arrow

Person moving, door, circle, slash

Person walking, circle, slash

Circle, slash, faucet, water, cup

Circle, slash, bucket, water flames

Horn

Picture of locomotive 
of Canada (1980) provides actual symbollc 1magery. Table 2 presents referents and Image content as suggested by these codes.

As noted in the review of CFR, Title 30, applicable U.S. standards do not usually address the use of symbols. In addition to the codes for mines, these Include the ANSI Z35.1 (1972) and Z53.1 (1979) standards for Safety Signs, and for Safety Colors, respectively; the Occupational Safety and Health Administration (OSHA) standards (CFR, 1981) from which reference to symbols was deleted; and the National Fire Protection Association (NFPA) life safety code (for exit signs) (Sharry, 1978).

The NFPA Standard on Symbols for Fire Fighting operations (1980) provides symbols for 10 fire messages, while two DoT-sponsored publications by the American Institute of Graphic Arts (AIGA) (1974; 1979) provide extensive symbology directed toward public information signs. Similarly the DoT Manual on Uniform Traffic Control Devices (DoT, 1979) provides both Informational and warning symbols for highway applications.

An industry standard, SAE (1979), provides for the use of the hazard alert triangle, while two industry publications, FMC (1978) and Westinghouse (1981), provide both symbol and sign layout information. Table 3 provides documentation of some current international and U.S. conventions for color coding and sign type.

\subsection{HAZARD ANALYSIS}

\section{5 .1 Overview}

The MSHA Mine Injuries and Worktime Quarterly (1980; 1982) was reviewed to determine the kinds of injuries and fatalities occurring in mines. Percentage occurrence of both fatalities and injuries (non-fatal days lost [NFDL] and no days lost [NDL] were combined) were computed for all mines. These data are presented in figures 1 and 2. These figures allow both fatality and injury percentages to be compared with each other for all mines and for each mine type.

As is common in accident data, fatalities and injuries do not appear to occur with equal frequencies in the same situations. The majority of injuries are in the areas of material handling, hand tools, slips and falls, machinery, and powered haulage (in that order), while the majority of fatalities are in powered haulage, roof falls, machinery, electricity, falling materials, and explosions. Furthermore, the percentage of fatalities seems to vary more between mine types than does that for injuries, although this varlability might be reduced by weighting the data with an hours-worked measure, such as MSHA uses in its more detalled annual injury reports for each mine type. It is also interesting to note that the percentage of injuries occurring in mills and processing plants is quite high. While this category only accounted for 6.8 percent of the coal injuries, it accounts for 28.2 percent of the metal injuries, 56.6 percent of the nonmetal injuries, and 36.5 percent of the stone injuries (MSHA, 1980) (Preliminary 1982 figures indicate 6.2 percent infuries for coal, 15.5 for netal, 13.4 for nonmetal and 10.9 for stone. Sand and gravel injury data were not broken down into location.) Use of more effective signing techniques is 
Table 3. Coding Practices from International and U.S. Safety Sign Standards

\begin{tabular}{|c|c|c|c|}
\hline & ISO/EEC & CANADIAN & U.S. \\
\hline Shape & Prohlbltion & $\begin{array}{l}\text { Prohibition } \\
\text { Danger }\end{array}$ & $\begin{array}{l}\text { - Danger } \\
\text { - Stop } \\
\text { - Fire \& Emergency }\end{array}$ \\
\hline Orange & - & $m$ & $\begin{array}{l}\text { - Dangerous Machine } \\
\text { - Energized Equipment } \\
\text { - Warning - Proposed }\end{array}$ \\
\hline Yellow & Warning & Caution & $\begin{array}{l}\text { Caution } \\
\text { - Storage for } \\
\text { Flammables } \\
\text { - Containers for } \\
\text { Explosives, } \\
\text { or Unstable } \\
\text { Materials } \\
\text {-Radiation }\end{array}$ \\
\hline Green & Information & $\begin{array}{l}\text { Emergency } \\
\text { Information }\end{array}$ & $\begin{array}{l}\text { - Safety Information } \\
\text { - First Aid \& }\end{array}$ \\
\hline Blue & Mandatory Action & Miscellaneous & $\begin{array}{l}\text { - Information } \\
\text { - Bulletin Boards } \\
\text { - Railiroad }\end{array}$ \\
\hline Black & & Mandatory Actlon & \\
\hline
\end{tabular}




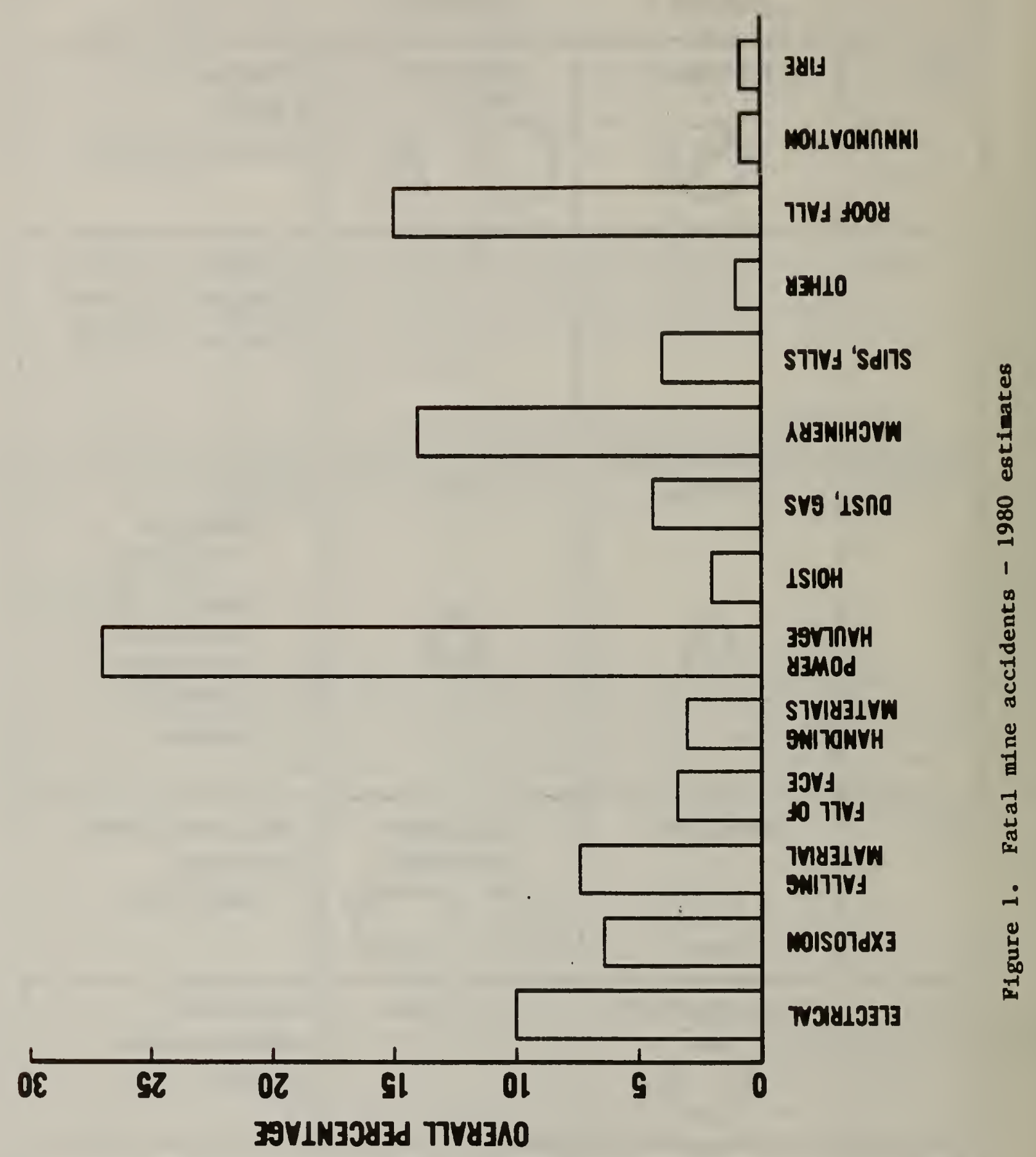


particularly feasible in milling and processing plants, since the operational area does not change location on a continuous basis.

Examination of the accident data for cosl mines (MSHA, 1979) reinforces the need to provide safety messages and symbols related to cuts/punctures, contusions/brulses, and strains/sprains, both in terms of hazard warnings and reminders to wear personal protective gear. (A potential accident-producling situation may be indicated by warning of the hazard, by requiring protective gear, or by prohibiting a particular action.) In addition, Shep1ch, Schlick, and Thirumalal (1978) point out the need to warn Inexperienced miners in particular, due to thelr high rate of 1nfuries. These authors noted that in 1978 , over 30 percent of the miner population $(160,000$ miners) were elther new entrants or relocated and untralned miners. Furthermore, over one-third of the fatal infuries Involved miners with less than 1 year's fob experlence.

\subsubsection{Detafled Hazard Analysis}

Nineteen "Yellow Jackets", or in-depth studies of specific types of mine accldents, produced by the Health and Safety Analysis Center (HSAC) of MSHA, were also reviewed in deta11. (See the reference section for the 11st of t1tles.) These studles examined the kinds of accldents, the causes, the personnel involved, and trends over several years. The present review concentrated upon determining those altuations for which 1mproved hazard pictorlals and algnage could be approprlate in warning personnel of a hazardous situation. These situations w1ll be discussed; sltuations requiring equipment modification, specialized tralning or changes in practices are outside the scope of this report.

The common factors 11 sted as occurring for many "Mantrip" accidents and Injurles for all mine types for 1978 and 1979 Included poor separation of vehicles and non-posted, non-enforced speed 11m1ts. Factors listed for haulage-related fatalities and injurles for surface metal and non-metal mining included failure to heed warning signs, excessive speed, unmarked railroad crossings and failure to yield right of way. Powered haulage accounted for 41 percent of the injuries in surface mining for metal, non-metal and sand and gravel in 1978-79, as well as 18.5 percent of the fatalities in surface coal mines from 1973-76 and 29 percent of the fatalities in metal/non-metal mining for 1972-75. For this latter category, job inexperience was a contributory factor with 44 percent of the coal fatalities and 34 percent of the metal/non-metal (M/NM) fatalities occurring among those w1th less than 1 year of on-the-job experience and 72 percent of coal fatalities occurring among those with less than 5 years. In all these cases, clear and consistent signage 1ndicating road conditions and speed limit information would be appropriate. Signs related to safe operating practices such as seat belt usage, do not leave running equipment unattended, setting brakes, blocking vehicles, lowering blades, and no riding on buckets, blades, etc., are appropriate for both haulage and machinery accidents. Warning signs of unsafe, unstable ground, berms, low or insufficlent clearance and similar hazardous (and often temporary) conditions are another Important category of potential signage related to mobile equipment. 
Other accident/injury categories covered by the "Yellow Jackets" treat moving machinery including conveyors, front end loaders, bulldozers, draglines, crushers, scrapers, lifts, cranes and drills. Front end loaders and conveyors accounted for 49.5 percent and 18 percent respectively of the 138 machinery fatalities in M/NM surface mining fron 1972 to 1975 . These fatalities could again be related to job inexperience ( 34 percent with less than 1 year experience and 66 percent with less than 5 years). Failure to de-energize conveyors accounted for 14 percent of these injuries and working under elevated equipment for 5 percent.

Need for signs related to lock-out procedures recurred throughout the "Yellow Jackets" reviewed. Another set of contributing causes for M/NM fatalities included failure to wear protective eyeglasses, protective gear for falling objects, safety lines, life jackets, safety harness, and safety gloves. Symbolic reminders of the need to wear personnel protective gear are appropriate for all mine types.

An analysis of injuries in all types of M/NM mining for 1975 and 1976 noted failure to wear proper safety gear and failure to shut off or lock-out machinery as major injury factors. Gear included both eye and foot protection. Again, the group experiencing the most injuries ( 34 percent) were those with less than 1 year job experience. (The authors note that the total number of persons and staff hours representing various experience categories are not available for calculating an overall frequency rate.) Recommendations appropriate for signage include: warning to stay clear of suspended loads, wear hard hats, wear suitable footgear, wear face shields/goggles/glasses, wear protective gloves, and wear seat belts. Other recommendations include posting speed limits, and repairing and maintaining equipment only when power is off or machinery blocked. Appropriate signs would include those for entanglement, protective gear, as well as reminders to shut-off/lock-out moving equipment, load equipment properly, and use safe operating modes.

Conveyor injuries were studied in a separate analysis of $\mathrm{M} / \mathrm{NM}$ mines for 1975-76. Routine maintenance and repairs accounted for 59 percent and 23 percent of the injuries, respectively. Generally, the injury related to catching fingers, hands, arms, and upper extremities in a moving belt. While guards are used during normal operations, they may of ten be circumvented during maintenance. Symbolic reminders of entanglement, pinch, crush, and sever hazards would be appropriate for curbing conveyor injuries. Reminders to wear hard hats also would be appropriate since 18 percent of the injuries were the result of rocks falling from the conveyor. Finally, a lock-out symbol to warn against energizing a belt during repair is needed, since both fatalities and injuries occurred during conveyor repair.

Under slusher injuries, failure to wear safety equipment accounted for about 10 percent of the injuries. Again, about half the injuries occurred to those with less than 1 year of job experience. Recommendations for reducing slusher injuries which would be translated into signage included the need to secure the slusher properly, the need to avold working in the same area as the slusher, and to wear proper protective gear. Because about one third of the injuries 
occurred to those with more than five years experience, additional training and reminders of safe working practices may also be in order.

Electrical accidents accounted for a noticeable percentage of mining fatalities and infuries. For coal, 2854 electrical infuries occurred between 1974 and 1979 and some 50 fatalities in M/NM mining between January 1972 and August 1977. Injurles typically occurred while working on varlous electrical systems and junction boxes with a lesser number occurring for energized circuits on mining and haulage equipment. Hands and eyes were most frequently injured due to arcing near hands and face. Signage-related recommendations include the use of protective gloves or cable handling devices, and the need to Identify lock out, nip point, and disconnect switches. For M/NM mines about 60 percent of the fatalities occurred to those with less than 3 years job experience. Most of the fatalities occurred to maintenance personnel ( 78 percent). A general conclusion was that fatalities are caused by unsafe actions in the vicinity of lethal voltages or by improper repair/connection of electrical wires or by working on a clrcult belleved to be de-energlzed. Because many of the fatalities Involve persons not trained as electriclans, there is a great need for signs to Indicate hazards and correct precautions for avolding hazards. These could Include symbols for danger of electric shock, electrocution, gloves, proper handling equipment, and lock-out.

An analysis of pinch point infuries for $M / N M$ mines in 1978-79 indicated that victims were caught by conveyors, belts, rollers, pulleys, gears, etc., with conveyors, V-belts, and pulleys accounting for about 60 percent of the injuries. Activities typically included cleaning in and around equipment ( 30 percent), using hand tools around moving machinery ( 16 percent), working on V-belts ( 13 percent), energizing equipment without warning (12 percent), and catching handtools in equipment ( 16 percent). Occupations included mill/plant operator ( 26 percent), ut1lity/laborer ( 24 percent), mechanic/repalr ( 20 percent) and supervisors ( 7 percent). The following conclusions relevant to signage were reached: victims reached behind guard, falled to block unit against movement, falled to follow proper lock-out procedures (so that equipment could be energized by persons other than victim), and used handtools around moving machinery with exposed pinch-points. Conclusions reached in a study of handtool injuries in M/NM mining from 1977-79 included the need to remind personnel to wear safety glasses, face and dust masks, to 1nstruct on the safe use of handtools, and the need not to drop tools on fellow employees. Cuts, lacerations and punctures accounted for 33 percent of the injuries, strains and sprains for 23 percent, contusions and bruises for 19 percent, and dust/metal in the eyes for 10 percent. Malntaining equipment in good condition was noted as another problem.

Another class of injuries studied was that of back injuries, occurring primarily during handling and lifting materials such as cables/hoses, timbers/posts, and contalners. An analysis of such injuries in coal mining for 1978-79 and in M/NM mining for 1977-79 noted that training on proper lifting procedures had not reduced back infuries appreclably, since 82 percent of those suffering infuries claimed that they had followed correct lifting procedures. Recommendations for reducing back injuries included relocating materlal closer to use point, reducing large quantities of material to smaller amounts, using longer shovels, tongs, etc., and providing more instruction on correct lifting 
procedures. Symbol signage reminding people to follow proper procedures might also be effective.

Another related category of injuries studied for $M / N M$ mines was that of slips and falls. Some 5800 injuries due to slips and falls occurred during 1977-78, with falls from machinery being the most common type of injury at a work site. Falls from stationary elevations such as ladders, platforms, scaffolds and catwalks accounted for about 10 percent of the injuries (with half of those being from ladders). Slipping and falling during walking accounted for about 12 percent of the injuries at the worksite and fully 50 percent of those injuries occurring away from the worksite were due to ice and water on walking surfaces and falls on stairs or ramps. Causal factors included improper mounting/ dismounting from machinery, jumping from machinery, and oil, ice, grease, etc. on ladders and other working surfaces. Signage possibilities include reminders of proper mounting/dismounting techniques, use of safety belts where appropriate, and marking of openings in ground or floor with warning signs.

Comparison of injury rates for different coal seam heights indicated greater likelihood of disabling injury for low coal (seam height less than 36 in.). This may be due to poorer lighting and decreased visibility for low coal, uncomfortable or cramped working positions leading to more disabling injuries, low clearance, increasing difficulty of handling materials, problems associated with low coal conditions including fewer canopied coverings on equipment, and tendency for low coal mines to be smaller and perhaps to have less fully developed safety programs. Recommendations did not include anything relevant to signage, although increased attention to signage used in low coal might prove worthwhile. Similarly, the analysis of falls of ribs, roof, and face accidents for coal did not indicate many opportunities for improved signage, as these accidents tend to occur at or near the face area, often where supports are not installed and where permanent signage is impractical. Safety signs could be profitably used at the entrance to a coal mine, in processing areas, or in changing facilities, however.

Thus, review of the "Yellow Jackets" underlined the need for signs for personal protective gear, hazard warning, such as electrical and entanglement, unsafe practices (especially lock-out indications) and traffic signage.

Because the Department of Transportation (1979) already provides a system of symbols for highway signage which is readily adaptable to the mine environment, this need will not be considered further here. For the other hazards, referents or meanings not considered in the various codes which should be considered include: lock-out indicators, life lines/jackets and similar protective gear, do not jump from machinery/platforms, cut, sever, crush, and hole or open pit hazards (slip, trip and fall).

The Code of Federal Regulations Title 30 (1980) requires signs for the following messages for which symbols currently exist: No Entry/Restricted Entry, General Hazard, No Smoking, No Open Flame, Explosives, Location of Fire Fighting Equipment, Electrical Danger, Fall Hazard, and Exit. Other CFR Messages which should be considered for symbolization include: Electricity lock out, limited horizontal clearance, keep door open/closed, shelter hole, and reduced vertical clearance. 


\subsection{SITE VISITS}

\subsubsection{Hazard Information from Site V1sits}

Visits to eight different mine sites also provided information about perceived common hazards and necessary safety information from the perspective of the individual site safety and mining personnel. Safety personnel universally mentioned injuries related to slipping, tripping, and falling, lifting and straining, conveyors and entanglements, lock-out/tagout procedures, as well as explosion, fire, and potential electrical hazards. Problems related to chemical processing such as corrosion, poison, and chemical burns, cropped up in those mines with mills and processing plants attached. Signage tended to be related to the major, infrequently occurring hazards rather than the more minor, but ubiquitous hazards such as slip, trips, and falls, or pinching, crushing, and severing. Because the latter can occur anywhere, they are much more difficult to warn against. Nevertheless, there was a wide range of different potential hazards in the eight sites visited.

Safety personnel also expressed interest in pictorial signage as a way of communicating information rapidly and getting the miners attention. Table 4 presents information from these visits, including the mine type, approximate size, percelved hazards, and general sign use (as observed). This is by no means an exhaustive survey of current mine hazards and 81 gn practices, but combined with the MSHA hazards data, it provides some indication of the various sorts of situations that could require symbol signs.

\subsubsection{Sign Usage}

As noted in 1.6 .1 , site visits were made to eight different mine sites to determine the types of signs currently used, obvious hazards, and perceived signage needs. These mines included two sand and gravel operations, two openpit copper, one underground molybdenum, one underground coal, one open-pit coal, and two oil shale facilities. At several sites, the milling operations as well as the mines were visited.

The site visits revealed extensive use of word signs with very few symbol or symbol plus word signs. (This is encouraging in that miners will not have to "unlearn" a set of symbols which differs from any recommended sets.) The symbols* actually observed at the sites included: Iso Radiation, Iso Electrical, cross for First Aid, hand for Stop, man with circle and slash (at woman's dressing room), arrows for Direction, and circle, slash, and cigarette for No Snoking. Sign messages typically referred to hazards, prohibited actions, protective gear, and exit. Table 5 presents frequently observed messages from the mine site visits related to hazard or safety information. Signs related to traffic control -- both rail and self-propelled -- were also observed, along with informational signs such as women's and men's restrooms/changing areas.

* See figures in section 4 for the appropriate imagery. 
Table 4. S1te V1sit Information

\begin{tabular}{|c|c|c|c|}
\hline Type of Mine & Approximate S1ze & Typical Hazards & Observed S1gn Usage \\
\hline $\begin{array}{l}\text { Sand and Gravel } \\
\text { Mine \& Mill }\end{array}$ & $\begin{array}{l}85 \text { miners } \\
\text { some } 1111 \text { terate } \\
\text { some Spanish speaking }\end{array}$ & $\begin{array}{l}\text { Dust } \\
\text { conveyor belt, pinch, crush, } \\
\text { sever } \\
\text { noise } \\
\text { high voltage } \\
\text { slips \& falls } \\
\text { mobile equipment - } \\
\text { Increased hazards during } \\
\text { maintenance }\end{array}$ & $\begin{array}{l}\text { few signs used } \\
\text { word format - homemade } \\
\text { legibility problems due to } \\
\text { dust \& dirt } \\
\text { dim lighting levels Inside } \\
\text { mill \& packaging area } \\
\text { Symbols: none }\end{array}$ \\
\hline $\begin{array}{l}\text { Open Pit Copper } \\
\text { Mine \& Mill }\end{array}$ & $\begin{array}{l}400 \text { miners } \\
\text { some Spanish speaking }\end{array}$ & $\begin{array}{l}\text { Explosion } \\
\text { fire } \\
\text { slips falls } \\
\text { overhead hazards } \\
\text { mobile equipment } \\
\text { chemical - corrosion } \\
\text { poison }\end{array}$ & $\begin{array}{l}\text { ANSI word signs - purchased } \\
\text { primarily "danger" category } \\
\text { extensive use of signs to } \\
\text { mark every possible hazard } \\
\text { mine - mud \& dirt a problem } \\
\text { mill - problems of durability } \\
\text { due to corrosion - frequent } \\
\text { sign replacement } \\
\text { problems of "red" fading } \\
\text { outside } \\
\text { Symbols: radiation; DoT } \\
\text { highway symbols on haulogy } \\
\text { roads }\end{array}$ \\
\hline $\begin{array}{l}\text { Underground } \\
\text { Molybdenum } \\
\text { mine \& shops }\end{array}$ & $\begin{array}{l}1500 \text { ( } 3 \text { shifts) } \\
\text { about } 15 \text { percent } \\
\text { Spanish speaking } \\
\text { no real literacy problem } \\
\text { generally young }\end{array}$ & $\begin{array}{l}\text { Pire including vehicle } \\
\text { explosion } \\
\text { underground fueling } \\
\text { mobile equipment } \\
\text { roof falls } \\
\text { pinch point, crushing } \\
\text { dust/noise } \\
\text { slips falls }\end{array}$ & $\begin{array}{l}\text { 1llumination (cap lamp) } \\
\text { metal halide lighting in } \\
\text { shops \& control facilities } \\
\text { ANSI word sign format } \\
\text { signs } 10 \text { - } 10 \text { ft off floor } \\
\text { because of dust spraying } \\
\text { extensive signage, perhaps } \\
\text { some visual clutter } \\
\text { Symbols: "hand" for stop, } \\
\text { "no men" at woman's changing } \\
\text { room }\end{array}$ \\
\hline $\begin{array}{l}\text { Open Pit Copper } \\
\text { mine \& mill } \\
\& \\
\text { shops }\end{array}$ & $\begin{array}{l}3000 \text { miners } \\
\text { experienced work force }\end{array}$ & $\begin{array}{l}\text { Slips \& falls from equipment } \\
\text { blasting/explosives } \\
\text { h1gh voltage } \\
\text { mov1ng equipment } \\
\text { flying particles } \\
\text { entanglement, crushing } \\
\text { noise } \\
\text { respirable dust } \\
\text { chemlcal burns } \\
\text { radiat1on } \\
\text { overhead hazards } \\
\text { strains, prains }\end{array}$ & $\begin{array}{l}\text { Sign use concentrated In } \\
\text { repalr/maintenance shops } \\
\text { \& concentrator/crusher } \\
\text { areas } \\
\text { Word signs - handmade } \\
\text { Some dust \& weathering } \\
\text { problems } \\
\text { Symbol: radiation symbol in } \\
\text { conveyor belt area }\end{array}$ \\
\hline
\end{tabular}


Table 4. (Continued)

\begin{tabular}{|c|c|c|c|}
\hline Type of Mine & Approximate S1ze & Typlcal Hazards & Observed S1gn Ueage \\
\hline $\begin{array}{l}\text { Industrial Sand } \\
\text { Mine o M111 }\end{array}$ & $\left\{\begin{aligned} 75 & \text { miner } \\
3 & \text { hifts } \\
\text { no } & \text { literacy problem }\end{aligned}\right.$ & $\begin{array}{l}\text { Slips of falls } \\
\text { conveyor belt inquiries } \\
\text { dust } \\
\text { nolse } \\
\text { explosives } \\
\text { some chem1cals } \\
\text { f1re, burns } \\
\text { lockout fallure }\end{array}$ & $\begin{array}{l}\text { ANSI word lgns } \\
\text { Many signs, generally located } \\
\text { on or near hazard } \\
\text { Protective gear at entrance } \\
\text { to site } \\
\text { Some rust dirt but } \\
\text { generally leg1ble lgns } \\
\text { Symbol: ISO l1ghting } z 1 g-z a g\end{array}$ \\
\hline $\begin{array}{l}\text { Underground } \\
\text { Coal Mine } \\
\text { \& M111 }\end{array}$ & $\begin{array}{l}400 \text { miners } \\
\text { no 11teracy problem } \\
\text { young workforce }\end{array}$ & $\begin{array}{l}\text { Fall of roof \& rib, objects } \\
\text { sl1ps f falls } \\
\text { entanglement, pinching, } \\
\text { crushing (conveyor belts) } \\
\text { electrical } \\
\text { f1re } \\
\text { explosion } \\
\text { 1mproper lifting } \\
\text { mob1le equipment }\end{array}$ & $\begin{array}{l}\text { relatively few s1gns used } \\
\text { underground } \\
\text { h1gh voltage most frequent } \\
\text { 81gn } \\
81 g n s \text { - homemade } \\
\text { problems of poor contrast } \\
\text { due to dust o poor color } \\
\text { cho1ce } \\
\text { escapeway s1gns 1n yellow o } \\
\text { white } \\
\text { 11lumination by cap or } \\
\text { vehicle light } \\
\text { Symbols: none }\end{array}$ \\
\hline $\begin{array}{l}\text { Open P1t } \\
\text { Cosl }\end{array}$ & $\begin{array}{l}100 \text { miners } \\
\text { young workforce } \\
\text { some literacy problems }\end{array}$ & $\begin{array}{l}\text { Mobile equipment } \\
\text { falls from equipment }\end{array}$ & $\begin{array}{l}\text { protective gear } 81 \mathrm{gn} \text { at } \\
\text { entrance to mine } \\
\text { relatively few word elgns } \\
\text { Symbols none }\end{array}$ \\
\hline $\begin{array}{l}\text { Underground } \\
\text { o1l Shale } \\
\text { demonstration } \\
\text { mine } \\
\text { mine } \\
\text { construction } \\
\text { site }\end{array}$ & $\begin{array}{l}100 \text { totel } \\
\text { young workforce }\end{array}$ & $\begin{array}{l}\text { Electrical hazard } \\
\text { explosion hazards } \\
\text { flammable materials } \\
\text { slips falls } \\
\text { construction hazards } \\
\text { chem1cal - corrosion } \\
\text { - polson }\end{array}$ & $\begin{array}{l}\text { ANSI word format generally } \\
\text { Used limited o1gnage under } \\
\text { ground } \\
\text { Hazard warning s1gns } \\
\text { generally located on or } \\
\text { near hazard } \\
\text { Protective gear - entrance to } \\
\text { site or hazard area } \\
\text { Few legibllity problems } \\
\text { Symbol: electrical } 218 \mathrm{zag}\end{array}$ \\
\hline
\end{tabular}


Table 5. Safety Sign Messages Observed at Eight Mine Sites

\section{Hazard}

High Voltage, Electrical

Radiation

Hazardous Area

Combustible, Flammable

Explosive, Blasting

Slip

Corrosion

Oxidizers In Use

Poison

Overhead Crane In Operation

Falling Material

Keep Clear of Pit

Stay Clear of Moving Machinery

$\underline{\text { Protective Gear }}$

Wear Hard Hat

Wear Safety Glasses

Wear Safety Shoes

Respirator Required

Self Rescuer Required

Ear Protection Required

Life Jackets Required $\underline{\text { Prohibition }}$

No Smoking

No Open Flame

Do Not Start

Do Not Operate Past This Point

Egress

Exit

Escapeway

Stop

Automatic Fire Door

Restricted Area

Authorized Personnel Only

Safety

Eyewash

Fire Extinguisher Location

Fire Hose

First Ald

Shelter Area 
DANGER - BLACK \& WHITE

- RED OVAL

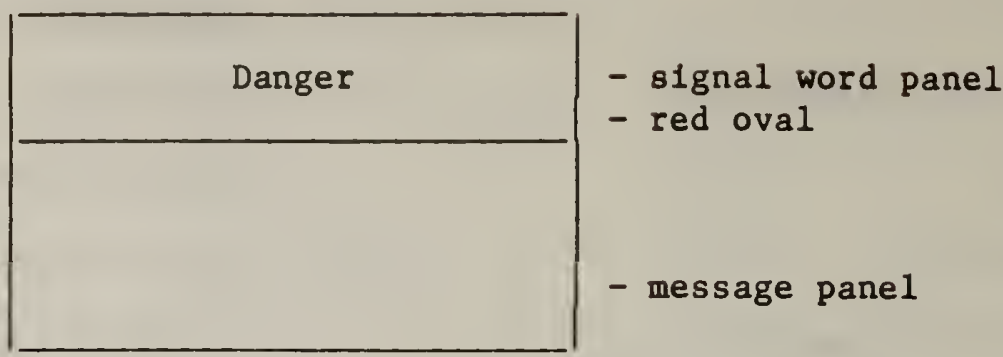

CAUTION - BLACK \& YELLOW

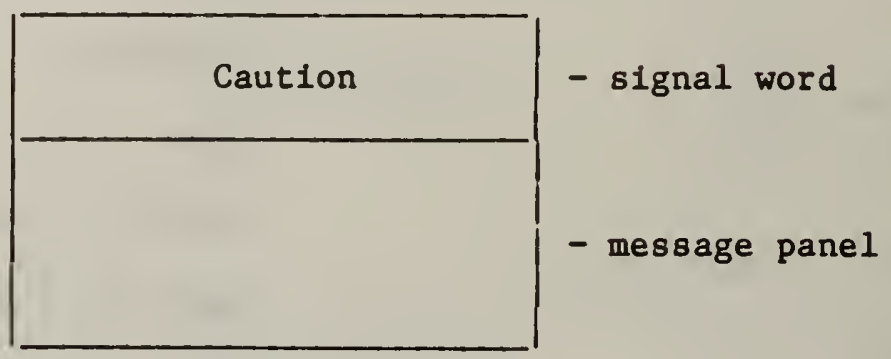

EXAMPLE

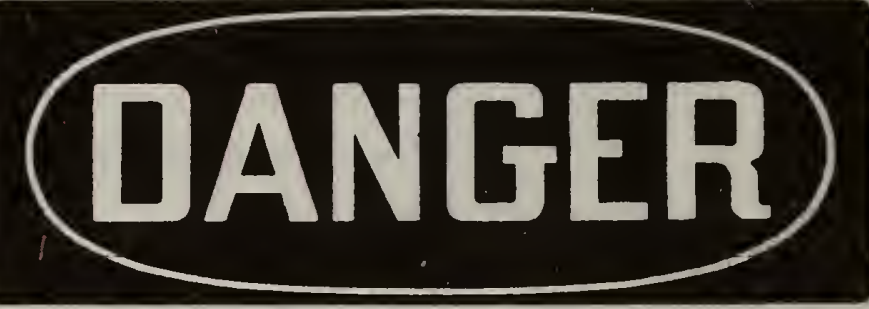

- red background

- white letters

XANTHATE-QRGANIC

- white background

IRRITANT - DO NDT

APPLY HEAT - DD

NDT MIX WITH ACID

Figure 3. ANSI sign format for hazard-warning signs 
The only consistently observed sign format was the ANSI Danger and Caution word signs. These were used fairly extensively, of ten with quite long messages manufacturers except where the safety personnel felt auxiliary protective equipment or "no smoking" signs might be necessary. In other mines, however, the signs were clearly homemade, using idiosyncratic colors and formating. For example, in one mine, the escapeway signage was presented in yellow and white with poor legibility.

Problems of sign legibility were abundant. In one operation, the signs were so badly corroded as to be almost illegible, while other signs (including a radiation sign) were obscured by dust. Since mining operations typically involve moving and crushing large quantities of material, as well as chemical processing, problems of dust, dirt, corrosion, and weathering are not surprising. They do suggest, however, that signs may need careful monitoring, cleaning, and frequent replacement. In underground operations, additional problems arise because of the low lighting levels. Where cap lamps are used, signs are visible only if the miner turns the lamp toward them. As a result, the signs should be in an area typically illuminated within the normal sweep of a cap lamp. Placement at the ceiling or the floor would appear to be ineffective. Retroreflective and/or fluorescent materials should be considered for critical signs. Where general mine lighting was used, light levels varying widely from about 1-150 fc were observed. Positioning of the sign with respect to the lighting also varied widely. As a result, observations of low contrast - resulting in less likelihood of detection - were common. Light sources included fluorescent, mercury, tungsten, and high pressure sodium, with most mines using a variety of sources depending on the location. In addition, signs were located anywhere $2 \mathrm{ft}$ off the ground, on an inaccessible area of a piece of equipment, or 10 $15 \mathrm{ft}$ above the ground. For example, spraying to reduce dust requires that signs be placed high above the floor. Lower placement increases the likelihood of sign obscuration by the dust-reducing agent. In addition, the likelihood that miners may be moving rapidly in motorized vehicles past a sign increases the need for legible signs.

The amount and extent of signage varied widely from mine to mine. In one mine, very few signs were used and these related primarily to escapeways, voltage dangers, and rail traffic indicators. In another, every conceivable hazard was marked, sometimes with more than one sign. The latter approach can result in visual clutter and confusions. The miner does not know what is the most critical message to attend first. In such over-signed installations, the attentiongetting value of the individual sign is 1ost. On the other hand, the danger of under-signing is that an important safety message is left unsaid. Another issue is the repetition of a message - at what intervals do signs need to be placed to warn of recurring hazards, such as entanglement in a conveyor belt? Still another is that of multiple hazards - a refueling area must be marked to warn of flammable and explosive hazards as well as no smoking and no open flame. Similarly, certain chemicals may be explosive, flammable, corrosive, and poisonous at the same time. Although ANSI standards exist for labeling chemicals, there are no comparable guidelines for signing a mine or a mill. Determining the most dangerous hazard in terms of potential injury and economic cost would appear to be a viable starting point - particularly if signs for this hazard would tend to keep people away from it. Anecdotal evidence suggests, for 
example, that more attention 18 paid to a "danger - blasting" sign than to a "danger-keep out" s1gn.

Another set of concerns relates to the durability of a sign. Problems related to dust and dirt could be solved by cleaning on a regular basis, although in some dusty sites that might prove burdensome. On the other hand, corrosion and weathering w1ll eventually require replacement of the s1gn, sometimes on a monthly basis. Obviously the material composition of the sign 18 important. Consideration of the relative performance of vinyl, plastic, and metal signs needs to be made. Vandalism is yet another problem. In one mine, the safety officer noted that signs present a challenge in terms of how quickly they could be defaced or destroyed. Pictorial signs could present a new outlet for creative, artistic vandalism.

Although a previous study of industrial signs (Collins et al., 1982) indicated widespread use of color coding to indicate areas for personal protective gear, fire equipment, and selected production facilities, such coding was infrequently observed for mine operations. One site did code the location of fire extinguishers with a patch of yellow located above them, however.

In summary, there appears to be some consistency across mine sites of the sign messages observed (due most likely to the commonality of hazards) but not in formating, positioning, amount, or color coding. Development of a suggested set of plctorlal signs could Increase consistency between sites. In addition, mine safety personnel expressed interest in a set of pictorials and symbollc signs for mine safety. They mentioned the desirabllity of being able to purchase slgns related to their needs from existing sign catalogues. Th1s could decrease rellance upon homemade slgns of dublous deslgn, durabllity, and leg1b1lity. As a result, the development of a set of pictorials and symbols for mine hazards appears to have potentlal acceptance from the mine safety community. 


\section{SELECTION OF REFERENT MESSAGES AND CANDIDATE SYMBOLS}

\subsection{SELECTION OF REFERENT MESSAGES}

After reviewing the wide range of symbols and referents (messages) collected from sign and symbol standards, sign catalogues, sign manufacturers, mine hazard analysis, mine site visits and previous research, forty referents were selected for further experimental study. The study was intended to determine those symbols that were understandable and that could be effective with a mining population. The 40 referents, presented in table 6 , represent safety situations and hazards which appear to be frequently occurring and dangerous. The referents are given in intentionally general form (e.g., "danger Entanglement Hazard.") At some point, further discrimination among the possible messages for a particular safety referent may be required (e.g., "danger of entanglement in a conveyor belt", or "a continuous miner", or "a shuttle car"). Some of these messages were also studied in an earlier experiment on safety symbols (Collins et al., 1982), although additional hazard warning messages were included to represent a broader selection of possible mining hazards. Data from the present experiment will be compared with the previous study wherever common symbols were studied. This will allow the responses of different workplace samples to be compared.

Referents from five different categories of safety messages are included. Hazard warning messages are intended to warn of a particular hazard or danger. The hazard messages selected represent the major kinds of injuries reported in section 1.3 , or are among the messages given in the various international/ national standards. The prohibition referents indicate various prohibited actions. "Do not touch", an addition to the various international standards, appears useful as a general cautionary/prohibitory message. Personal protective gear referents indicate the need to wear various types of safety equipment typically found in mining and milling. Egress-related messages refer to "exit" and "no exit", including "keep door open/closed". Finally, the safety instruction messages refer to both first aid and fire emergency information.

\subsection{SYMBOL SELECTION PROCEDURES}

\subsubsection{Symbols Selected}

A total of 72 symbols were tested for the forty referents. These symbols are presented in section 4-Results, along with the data for each message. Two symbols was tested for each referent, except where symbols were already standardized or no alternative symbol for a concept was located. One symbol per referent was studied for each group of miners to avoid confusions between symbols. Symbols were selected to represent a range of symbolic approaches, such as hazard alone/hazard with person; abstract/representative; detailed/ simple; black and white/colored, because these factors are thought to affect overall symbol understandability.

Symbols were obtained from a variety of sources including national and international standards, sign/symbol catalogues, and product manufacturers. Several symbols were modified or redrawn from their original sources, usually to simplify an otherwise graphically complicated image. 
Table 6. Referent Messages for Mine Safety Symbols

HAZARD WARNINGS

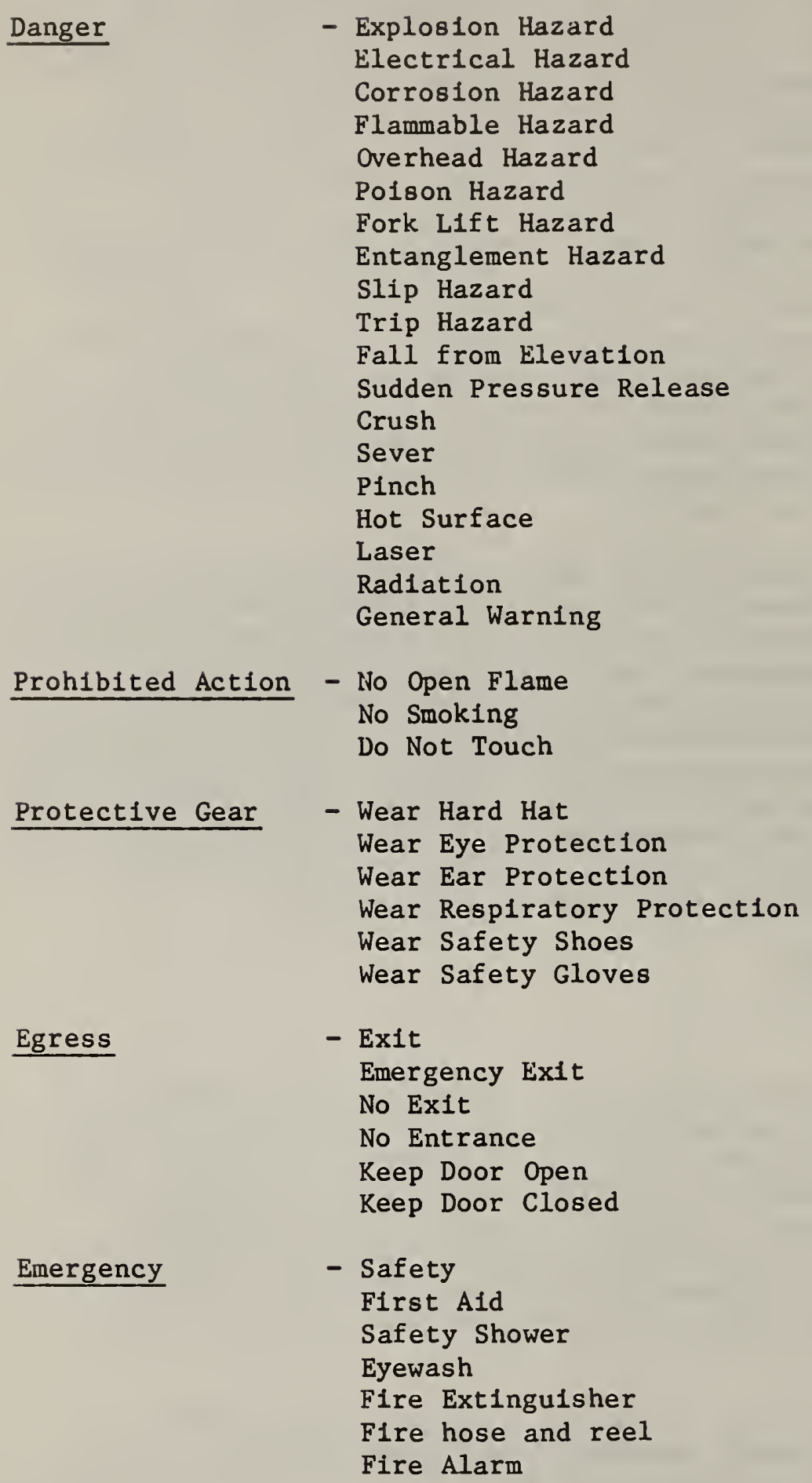




\subsubsection{Rationale for Specific Symbol Selection}

About 60 percent of the 72 symbols studied in the present experiment were also evaluated in the earlier workplace symbols experiment. In that study, the number of symbols located for a given referent varied from two to well over 40 or 50 , since there was no standard set of safety symbols in the United States. As a result, selecting a symbol for evaluation necessarily required decreasing the number of symbols to a smaller, more manageable set, if further research with a large number of subjects was to be practical. A ranking procedure was used to reduce the large set of symbols to a more manageable set for further study. In a ranking procedure, subjects order a set of images according to how well they believe that each image conveys the intended meaning of the referent. Use of this procedure allows an ordered selection of a limited set of symbols for more detailed research. It also suggests that the set of images tested will be at least somewhat meaningful. As a result, ISO TC-145-SC1 recommended rank-ordering as the best procedure for reducing the size of a set of 1mages. Easterby and Zwaga (1976) followed this procedure with small groups of subjects in two countries to select three sets of public information symbols. Similarly, Heard (1974) and Green (1979) had subjects rank-order images for automotive displays and controls according to meaningfulness, before proceeding with further symbol evaluation.

For the workplace symbol study (Collins et al., 1982) the ranking procedure was used to select the final set of images to be evaluated for each referent. About 30 representatives of the safety and graphic design communities rank-ordered images in terms of their appropriateness for each referent. Participants rankordered only the five best images for each graphic concept, although in some cases as many as 20-30 images were presented. They then rank-ordered the graphic concepts to determine which concept best conveyed the referent. Thus, a two-stage process of ranking both symbolic images and graphic concepts was used to select one to five images for each referent.

The set of images selected by the rank order procedure for further experimental study represented a range of concepts. Images that participants ranked as the best representation for each referent were generally included. These selections were modified by the following factors: the need to include those safety symbols suggested by the International Organization for Standardization (ISO) in the final testing, and the desire to select as graphically diverse a set of images as possible. In addition, only one image was selected for further testing for six referents because these images were already widely standardized. These referents included Laser, No Smoking, Biohazard, Radiation, Fire Extinguisher, and Hose and Reel connection.

In the present experiment, the initial selection of images was based on the results from the Collins et al., (1982) study. Where common referents existed, two images which were either well understood or preferred were selected for further study with the mining population. In a number of cases, however, the data from this earlier research indicated that only one of the images tested was reasonably successful. This was particularly true for Overhead Hazard, Poison, Slip, Trip, and Emergency Exit. In these cases, a second image was selected for study based on comments given by the industrial subjects, the 
earliar ranking data, and ouggestion by the ANSI and CIMA ymbol ubcommittees. In addition, the subcomittees suggested the need for the following referents: Sudden Pressure Release, Crush, Sever, P1nch, and Hot Surface. Symbols for these referents were also supplied by these subcomittees. Additional Exit symbols were selected based upon prellminary results from an NBS experiment on exit symbol visibility (Collins and Lerner, 1983). The CFR reviow also suggested the need for symbols for Keep Door Open/Closed. In the case of Personal Protective Gear symbols, almost all the symbols studied in the earlier experiment were well understood, although those symbols showing the gear on a person seemed to be slightly more preferred and better understood. Because the ISO symbols using this approach (which were used in the earlier experiment) are somewhat outmoded, a newer set developed by the Treasury Board of Canada (1980) was selected instead.

The final set of 1mages selected represented the following sorts of general concepts: hazard (abstract or representatlonal); hazard consequences; proh1bited actions; protective gear (by 1tself, or on human form); and safaty devices. The 1mages also varied along the following dimensions: complexity simplic1ty; abstraction - representation; presence - absence of human f1gure(s); and activity - inactivity. The use of color and surround shape also varied, and was determined by currently existing standards. Th1s meant that the hazard Bymbols were generally presented as a black figure on a triangular yellow background; the prohibition symbols as a black figure on a circular white surround with a red circle and slash; personal protection as a white figure on a solld blue disk; safety Information as a white 1mage on a square green background; and fire Information as a white 1mage on a square red background. Egress symbols varled in color between green and white, black and white, red and white, and red, white and black. In addition, some of the hazard symbols were presented as black figures on a square white background, or as white figures on a red background. In general, however, the majorlty of the symbols followed the coding conventions given by ISO TC 80 (1979).

\subsubsection{Surround Shape Concerns}

The various international standards typically use an auxlliary coding system to indicate the category to which the symbolic message belongs. Generally, the following system is used internationally (ISO, 1979; EEC, 1977; 1979):

o hazard - black figure, yellow background, black triangular surround,

- protective gear (mandatory action) - white figure, solid blue circular disk

- prohibition - black figure, white surround, red circle and slash

- egress \& safety - white figure, square green surround

o fire - white figure, square red surround

The Canadian Standards Association (1977) uses color for the hazard category to indicate the level of hazard. Red indicates danger and yellow, caution. A black disk, rather than a blue disk, is used for protective gear. A standard by the Standards Association of Australia (1980) recommends the use of a diamond surround to indicate the presence of a hazard, as does the U.S. DoT (1979) for highway caution signs. 
The use of surround shape and color appears to be a viable means of indicating additional, complimentary information about the symbolic image. In the case of hazard symbols, however, at least four different surround shape coding strategies have been used in the United States. There is the internationally used triangle, the diamond used by the Department of Transportation (DoT, 1979), the square used by the FMC Corporation (1978), and the circle occasionally used by the Nutheme Corporation (1975). In addition, DoT (1974), in conjunction with the United Nations (UN), places the hazard warning symbol in the upper half of a diamond. Thus, the user in the U.S. is potentionally exposed to at least four, if not five, different coding strategies.

The triangle has been criticized because it can limit the size of the interior image. As a result, the square has been suggested (FMC, 1978). Yet, several researchers (Cochran, Riley and Douglas, 1981) have suggested that angular "pointy" shapes convey the idea of danger of hazard better than rounder, less angular shapes.

Few researchers, however, have actually determined whether the prospective user is aware of the intended message behind all the coding systems. Do triangles, squares, diamonds, circles, and the like convey any information about the likelihood of danger or hazard? Has the American user become aware of the coding systems used in the highways - (the symbol system probably viewed by the largest number of persons) - or have American users become familiar with international practice - or do the various surround shapes make little, if any, difference?

Consequently, as a supplement to the main study on the relative understandability of safety symbols, a study on the perceived hazardousness of surround shape was conducted. The six surround shapes most frequently used in both safety and highway symbol sign systems were selected. These were the circle, square, triangle, diamond, octagon, and inverted triangle. Because these shapes are usually presented with an interior image, which may influence perceived hazardousness, the effect of different interior images was also studied. Thus, the six shapes were presented both alone and with four different interior hazard images. These four images were those for explosion, poison, entanglement, and general warning, which represented a range of direct personal involvement, hazard severity, abstraction, and probable consequences. Two additional safety images were presented: the cross for first aid and the hard hat.

\subsection{EXPERIMENTAL RATIONALE}

\subsubsection{Evaluation of Understandability}

To be effective, a symbol must be understood; it must communicate the desired meaning to those who encounter it. While understandability is a critically important criterion by which to evaluate a symbol, it is not the only one. A symbol should also be detectable at a given distance under specific light levels. A symbol should be discriminable, or distinguishable from other symbols within a particular set. A symbol should be recognizable, or be remembered and identified under different circumstances. A symbol should be graphically satisfactory and command attention. Finally, a symbol should alter behavior in the intended direction and facilitate conformance with the message. A fully 
effective symbol performs well in each of these areas. Understandability, however, is the key which unlocks the whole process of communicating safety messages. As a result, the priority for the research on safety symbols presented in the present report is the determination of the relative understandability of several images selected for each referent. In this way, the most understandable image could be recommended for a given referent.

Understandability or comprehension has been assessed by a number of different procedures. Perhaps the most commonly used is simply to ask a person to give a short definition of the meaning of a symbol (definition procedure). Other techniques have involved asking a person to match a symbol to a definition (or vice versa) (matching procedure) or to select the correct definition from a set of alternative cholces (multiple-choice procedure). While the definition procedure has been widely used, it poses numerous problems. These include difficulties in scoring or determining exactly what subjects meant by their answers and the assumption that subjects are verbally facile enough to be able to write down a reasonable (and readable) answer. The latter problem emerged as significant at several of the workplace sites studied; there was no reason to assume that miners might have less trouble with a definition procedure than industrial personnel. Answers obtalned with a multiple cholce procedure with confidence ratings (to be discussed later) were shown to correlate highly with answers obtained from a definition procedure in an earlier NBS study (Lerner and Collins, 1980a). Use of a multiple cholce procedure for determining "understandability" was therefore used for the study of mine hazard pictorials and safety symbols. This procedure was used with some confidence because it used as incorrect cholce alternatives those "wrong" and "partially correct" answers given in the earlier workplace symbols project. These answers, which are tabulated in the report by Collins et al. (1982), formed the source of the choice alternatives used in the multiple choice response form. A major attempt was made to include serious confusions among the choice alternatives for each referent, because previous NBS research indicated that some symbols communicate messages which are opposite to the intended one. In particular, where appropriate, a "critical confusion" or an opposite-to-correct choice was deliberately included.

The multiple cholce procedure was combined with a confidence rating procedure in which subjects provided a rating of their confidence in the correctness of each choice alternative for a given symbol. This procedure, which was previously shown to provide an index of guessing and confusions, provides additional information about the effectiveness of a given symbol.

Thus, the relative understandability of two symbols was compared for 32 referents. (Eight symbols were assessed individually). The comparison is made in terms of the percentage of correct answers for each symbol, as well as of the confidence ratings for the four alternative cholces. Various other statistical analyses are also made for the various types of data. These results are discussed in section 4. 


\subsubsection{Percelved Hazardousness of Surround Shape}

Although symbol surround shape and color were not shown to affect symbol understandability in any consistent manner in the earlier workplace symbol research (Collins et al., 1982), they may influence the perceived hazardousness of a symbol, and provide additional safety coding information.

In the second portion of the mine-safety symbol experiment, participants were given an opportunity to rate the perceived hazardousness of the different surround shapes commonly used for safety messages. These shapes included triangle, square, circle, octagon, diamond, and inverted triangle. Each of the six shapes was presented for a single image. Six different images were used--four Hazard, one Personal Protective Gear, and one Safety Instruction. In addition, the surround shapes alone were also presented. Participants were asked to rank order the six images according to the degree of hazard or danger indicated by the symbol. They were also asked to select the background color (red, green, blue, yellow, orange, and black) that best conveyed the symbol message. Part II was thus designed to assess whether specific surround shapes and colors were associated with different types of safety messages and hazard warnings. (See Appendix for samples of the ranking sheets.)

Data obtained from the present study are designed to provide information on miners' comprehension of selected safety symbols, confusions related to specific symbol messages, and the coding value of surround shape and color. They will be compared with applicable data on industrial safety symbols, to provide an indication of safety symbol effectiveness for different types of industrial and mining populations. 
3. METHOD

\subsection{PROCEDURE}

The experimental study consisted of two parts, one on symbol understandability (part 1) and one on percelved hazardousness of surround shape (part 2). In the first part, participants selected a multiple choice answer from a set of four alternatives, and rated their confidence in the correctness of each of the four alternative choices. Part 1 was designed to assess the relative understandability of the two candidate symbols for each message. In the second part, participants rank-ordered each of $s i x$ surround shapes in terms of perceived hazardousness. Participants also indicated the most appropriate background color for the most "hazardous" surround shape. Part 2 was designed to test the hypothesis that all surround shapes are perceived as equally dangerous.

\subsection{PARTICIPANTS}

A total of 271 people participated in the experiment including 16 females. These people came from elght different testing locations, involved in both surface and underground mining. The locations included two coal mines (BC and EM), one open-p1t copper (BT), one industrial sand (WED), two oil shale (OS), one oil shale mine construction site (CO), and one college mine-safety class (MT). (Data from the three oll shale sites and mine-safety class will be analyzed statistically as one site (OS).) Table 7 presents information on the data collection locations. The various sites were chosen to represent a broad range of different mining occupations in a wide geographical distribution, although no attempt was made to get a random sample (due to the difficulty of gaining access to different sites). Participants were typically miners or personnel likely to be working at a mine site and hence subject to possible mining hazards. Testing sessions were generally held as part of a safety training meeting. Although color deficiences occur in 8 to 10 percent of caucasian males (Rubin and Walls, 1969), color vision of the participants was not measured, because it was not believed to be essential for understanding a symbol's message. Color is, nevertheless, belleved to play an important role in facilitating sign detectability, discriminability and conspiculty (Glass et al., 1983).

With the exception of the varlous oil shale and mine safety class sites, both groups of symbols were administered at each site. One hundred thirty-five miners saw symbols from group 1, while 136 viewed symbols from Group II. Data from 4 miners were excluded from part 1 due to scoring problems, making the total number of participants for part 1 to be 267 . No miner saw both group 1 and group 2 symbols. Elght symbols were, however, common to the two groups. Since part 2 followed directly after part 1, a total of 271 people were potential participants. The number (N) of actual participants was lower due to statistical restrictions which will be discussed in 4.5 .

\subsection{STIMULUS MATERIAL}

For part 1, each symbol was initially silk-screened into a $30 \mathrm{~cm} \mathrm{x} 30 \mathrm{~cm}$ (12 in $x 12$ in) placard. Color slides were then photographed individually from each placard. Symbols were tested using the color and surround shape given in the 
Table 7. Data Collection Locations

$\begin{array}{lllc}\text { S1te } & \text { Location } & \text { Mine Type } & \text { Number of Participants } \\ \text { BC1* } & \text { Kentucky } & \text { Coal } & 26 \\ \text { BC2** } & \text { Kentucky } & \text { Coal } & 24 \\ \text { EM1 } & \text { Pennsylvania } & \text { Coal } & 10 \\ \text { EM2 } & \text { Pennsylvania } & \text { Coal } & 16 \\ \text { BT1 } & \text { Montana } & \text { Open-pit Copper } & 36 \\ \text { BT2 } & \text { Montana } & \text { Open-pit Copper } & 35 \\ \text { WED1 } & \text { Illinois } & \text { Sand \& Gravel } & 24 \\ \text { WED2 } & \text { Illinois } & \text { Sand \& Gravel } & 20 \\ \text { OS1 } & \text { Colorado } & \text { O11 Shale } & 24 \\ \text { OS2 } & \text { Colorado } & \text { Oil Shale } & 6 \\ \text { MT1** (OS1) } & \text { Montana } & \text { College Mine Safety Class } & 20 \\ \text { CO2*** (OS2) } & \text { Colorado } & \text { Oil Shale Construction } & 30 \\ & & & \end{array}$

* 1 refers to Group 1 symbols

** 2 refers to Group 2 symbols

*** MTl was combined with OS1 and and $\mathrm{CO} 2$ with OS2 for statistical comparisons due to the smallness of the OS2 site. OS1 and OS2 were used for subsequent statistical comparisons. 
or1ginal source. A total of 72 symbols were shown in part 1. (See figures 6-42 for a representation of each symbol studied.)

In part 2, the six surround shapes were drawn to a constant size using ISO guidelines (1980a). The interior images were then placed within each of the six surrounds. Participants were given a random set of seven sheets. On each sheet, all of the six surround shapes were used, in random order, to surround one interior image. One sheet showing only the surround shapes alone was included as well. The seven sheets were drawn in black and white and then photocopied.

\subsection{PROCEDURE}

Each experimental session consisted of the following sets of events: a) participants read and signed the Research Participant Agreement and the Privacy Act Advisory Statement (see Appendix for example); b) instructions for the use of the multiple choice form in part 1 were given and a practice example worked; c) participants completed the 40 item multiple choice sheet, for part 1 of the study; d) instructions for part 2, (perceived hazardousness of surround shape and color), were given; e) participants rated surround shapes and color; f) participants were debriefed as to the meaning of each symbol, and given a chance to comment and provide suggestions for improvement. The entire session including a break between parts 1 and 2 required about 1 to $11 / 2$ hours.

Observers participated in groups of 4-30 people at locations chosen by the safety office. The testing session typically occurred during a safety-training session, to minimize disruptions to production. Typically, 2-4 testing sessions were held at each site so that an equal number of participants could view the two sets of symbols. Each set of symbols was presented in a different random order to minimize order effects. In part 1 , symbols were presented at a rather slow rate (about $30 \mathrm{sec}$ per symbol - or when everyone had finished responding). Participants were instructed to circle the correct cholce alternative for each symbol and then rate their confidence on a scale of one to five in the correctness of each of the four answers. They were also instructed that the session was a test of the symbols, not of them, but that all forms were to be completed individually. (Participants were informed that their participation was voluntary and that they were free to terminate the test at any time.)

After part 1 was completed, participants were given part 2. They were instructed to rank order each symbol according to how much danger, or hazardousness, the symbol indicated to them using a scale from one to six (with one being most and six being least hazardous). They were also asked to c1rcle the background color that was most approprlate for the shape ranked as number one. Participants were also asked to indicate their age, sex, fob title, and years of mining experience. 


\subsection{SCORING OF RESPONSE SHEETS}

The number of correct, incorrect, and no responses were tabulated for each syubol. The confidence ratings given for each of the four answers were also tabulated in part 1. These tabulations were then computerized for further summary and analysis. In part 2, rankings given for each surround shape were tabulated, along with the frequency of each color selection. Statistical analyses will be described in detall in section 4. 
4. RESULTS

\subsection{ANALYSIS OF COMPREHENSION DATA}

The data on symbol understandability were analyzed using the SPSS [1975] set of statistical programs on the NBS UNIVAC $1100 / 82$ to test for statistical significance. The percentage of correct responses for each symbol was calculated across sites for both group 1 and group 2. In addition, the distribution of responses across the four cholce alternatives was tabulated for each of the 72 symbols studied. Similarly, the distribution of confidence ratings was also tabulated for the four answers, and a mean confidence rating calculated for each choice alternative. Table 8 presents the percentage of correct answers and the mean confidence rating for the correct answer for both version 1 and 2 of each symbol. A mean confldence rating for the correct cholce was also calculated for only the correct participants. This measure is termed "CCONF". Individual results for each symbol w1ll be discussed in detall in section 4.4 .

Statistical comparisons were made for several measures of overall performance. These included one-way analyses of variance (ANOVA) which were calculated to assess the effects of age and site on both percentage correct and confidence ratings ( $\mathrm{CCONF}$ ).

Although data were collected in at least elght separate location, for the purposes of stat1stical comparisons, several groups of participants were combined 1nto a larger groups. Thus, a new site group, OS1, was created which contained OS and MT. S1milarly, OS2 contained CO and OS. The OS1 and OS2 s1te groups are unique in that everyone was not from the same mine site, but rather were from 4 geographic locations in Western Colorado and Montana. Nevertheless, for purposes of comparison they will be referred to as the OS sites. Furthermore, some participants in both OS site groups were somewhat less famillar with mining per se, as they contained some mine construction workers ( $\mathrm{C} O$ ), and minesafety students (MT). Neither group, however, can really be considered naive to mining, as they either worked at a mine site or had received training in mine safety. (Thus, the statistical analysis focused on sites EMI and 2, BTI and $2, \mathrm{BCl}$ and 2 , WEDl and 2 , and OSI and 2.)

Three statistical analyses were made for the overall data. These were an analysis of variance (ANOVA) for the number of correct responses, and mean CCONF, as a function of site, and of the number of correct responses as a function of age. The overall number of correct responses and mean correct confidence rating (CCONF) were calculated for each s1te. The ANOVA for each revealed a significant site difference, attributable to the BC site. Personnel in the four other sites typically identified about 32 of the 40 symbols correctly. For the BC group, however, the mean number of correct responses was closer to 28. Similarly, the mean confidence rating given by correct subjects for the correct answer at the $B C$ site was about 3.10 , in comparison with a range of 3.8 to 4.2 for the other sites.

The analysis of variance of the number of correct responses as a function of age also was statistically significant. Two age categories stand out in this analysis; the older subjects (aged 50-61) whose mean number of correct responses 
Table 8. Overall Percentage of Correct Answers and Mean Confidence Ratings for All Symbols

\begin{tabular}{|c|c|c|c|c|c|c|c|c|}
\hline \multirow{2}{*}{ Number } & \multirow[b]{2}{*}{ Symbol } & \multicolumn{2}{|c|}{ Version 11} & \multicolumn{5}{|c|}{ Version $2^{2}$} \\
\hline & & Percentage* & Mean Confidence & Rating & Percentage & Mean & Confidence & Rating \\
\hline 1 & Flammable & 57.5 & 3.68 & & 64.1 & & 3.91 & \\
\hline 2 & Laser & 30.4 & 2.70 & & --- & & --- & \\
\hline 3 & Radiation & 37.7 & 3.10 & & --- & & --- & \\
\hline 4 & Explosion & 91.7 & 4.56 & & 92.3 & & 4.49 & \\
\hline 5 & Electrical & 96.2 & 4.77 & & 51.6 & & 3.64 & \\
\hline 6 & Corrosion & 86.4 & 4.75 & & 71.3 & & 4.15 & \\
\hline 7 & Poison & 90.0 & 4.67 & & 81.5 & & 4.17 & \\
\hline 8 & Fork Lift Truck & 95.3 & 4.71 & & 94.5 & & 4.72 & \\
\hline 9 & Slip & 83.6 & 4.39 & & 99.2 & & 4.77 & \\
\hline 10 & Fall & 95.3 & 4.67 & & 91.5 & & 4.40 & \\
\hline 11 & Overhead Hazard & 70.7 & 4.21 & & 97.7 & & 4.67 & \\
\hline 12 & General Warning & 59.4 & 2.98 & & --- & & ---- & \\
\hline 13 & Trip & 97.0 & 4.78 & & 80.8 & & 4.16 & \\
\hline 14 & Pinch & 88.2 & 4.34 & & $-\infty$ & & $-\infty$ & \\
\hline 15 & Hot Surface & 91.8 & 4.43 & & $-\infty$ & & --- & \\
\hline 16 & Crush & 74.2 & 4.05 & & 90.6 & & 4.28 & \\
\hline 17 & Sudden Pressure & & & & & & & \\
\hline & Release & 89.2 & 4.22 & & 31.0 & & 2.71 & \\
\hline 18 & Sever/Cut & 82.9 & 4.11 & & 89.2 & & 4.42 & \\
\hline 19 & Keep Door Open & 89.7 & 4.23 & & 96.8 & & 4.38 & \\
\hline 20 & Do Not Touch & 95.5 & 4.59 & & 89.6 & & 4.32 & \\
\hline 21 & Keep Door Closed & 83.1 & 3.98 & & 71.1 & & 3.89 & \\
\hline 22 & Head Protection & 96.9 & 4.68 & & 97.7 & & 4.65 & \\
\hline 23 & Hearing Protection & 96.2 & 4.75 & & 96.1 & & 4.69 & \\
\hline 24 & Eye Protection & 96.9 & 4.70 & & 96.2 & & 4.61 & \\
\hline 25 & Foot Protection & 88.8 & 4.15 & & 97.7 & & 4.70 & \\
\hline 26 & Hand Protection & 92.2 & 4.49 & & 95.3 & & 4.58 & \\
\hline 27 & No Smoking & 95.8 & 4.89 & & $-\infty$ & & $-\infty$ & \\
\hline 28 & No Open Flame & 95.4 & 4.85 & & 94.5 & & 4.69 & \\
\hline 29 & First Aid & 84.2 & 4.52 & & 95.9 & & 4.59 & \\
\hline 30 & Safety Shower & 65.6 & 3.91 & & 86.9 & & 4.41 & \\
\hline 31 & Eye Wash & 91.3 & 4.32 & & 68.5 & & 3.90 & \\
\hline 32 & Exit & 72.1 & 3.78 & & 91.5 & & 4.35 & \\
\hline 33 & Emergency Exit & 89.3 & 4.18 & & 55.7 & & 3.30 & \\
\hline 34 & No Exit & 81.1 & 4.29 & & 69.5 & & 4.00 & \\
\hline 35 & Do Not Enter & 93.8 & 4.43 & & 80.5 & & 3.89 & \\
\hline 36 & Fire Extinguisher & 96.2 & 4.86 & & $-\infty$ & & -- & \\
\hline 37 & Hose \& Ree1 & 92.3 & 4.62 & & --- & & --- & \\
\hline 38 & Alaram Call Point & 56.0 & 3.60 & & 64.3 & & 3.82 & \\
\hline 39 & Entanglement & 80.3 & 4.01 & & 92.3 & & 4.48 & \\
\hline 40 & Respiratory & & & & & & & \\
\hline & Protection & 70.6 & 4.13 & & 83.2 & & 4.49 & \\
\hline
\end{tabular}

\footnotetext{
* For correct alternative only

1 Number of participants for version $1=136$

2 Number of participants for version $2=131$
} 
was 28.9 , and those people who falled to report their age. Their mean number of correct responses was 28.1 , as compared with an overall mean of about 32 correct responses for the other age categories. See table 9 for comparisons.

\subsection{DEMOGRAPHIC DATA}

Demographic data on age, sex, and job title were obtained for miners at each of the elght locations studied. These locations included two coal mines (BC and $E M$ ), one copper (BT), one industrial sand (WED), two oil shale (OS), one oil shale mine construction site ( $\mathrm{CO}$ ), and one college mine-safety class (MT).

The summary age data for all locations are given in table 10. The summary data include mean age, $N$, (number of participants reporting age) median age, modal age, and age range. These data are presented for group 1, group 2, and combined groups for all locations. A total of 256 participants reported their age. Fifteen participants, about 5.5 percent of the whole sample, falled to report their age or sex. This included six people from group 1 and nine from group 2, primarily from the EM, WED, and BT locations.

The mean age of all particlpants studied was 34.76 years. For those participants who recelved group 1 slides, it was 34.79 ; for those recelving group 2 slides, 1 t was 34.34 . The age range was 20-61, while the median age was 32.2. Only 16 females particlpated out of a total group of 256 . Their mean age was 27.8 as opposed to the mean male age of 35.3 . There were several differences in mean age between locations, with BT participants being noticeably older with a mean age of 42.4 , and MT belng younger with a mean age of 24.5 . BC and $\mathrm{CO}$ were also somewhat younger than the overall mean, with mean ages of 30.6 and 30.5 respectively. There were no age differences greater than 1.5 years between groups 1 and 2 at any given location, except the oil shale locations.

Table 10 presents the overall age distribution of participants from each of the locations as well as from the total sample. Figure 4 presents the age data grouped into four age categorles: 20-30,30-40, 40-50, and 50-61, for all particlpants and then for the individual locations. This figure demonstrates clearly that the majority of the participants ( 70.1 percent) were under 40 , but that the distribution varied widely from location to location for each age group. These variations were most marked for the youngest group which contained 1.5 percent of the BT participants and 90 percent of the MT participants. The BT participants, as noted earlier, had a greater concentration in the two older categories (40-50,50-61) than the other locations, while BC tended to have a lesser concentration (and MT had none) in these categories.

The number of female participants, 16 or 5.9 percent of the total sample, is too small to make any statement about sex-related differences. The women were also concentrated in two locations which might reasonably be expected to be less famlliar with mine safety messages (MT and $\mathrm{CO}--$ a safety class and a mine construction firm).

Table 11 presents a summary of 57 job title/occupation categories as reported by the participants. A total of 265 participants reported their job title, although two of these were too illegible to decipher or categorize. About 61 
Table 9. Site Data Analyses

SCORE DATA

\begin{tabular}{lccc} 
SITE & MEAN SCORE & STD. DEV. & N \\
\cline { 2 - 3 } BC1 & 27.62 & 8.36 & 26 \\
BC2 & 28.71 & 4.16 & 24 \\
BT1 & 23.36 & 5.24 & 36 \\
BT2 & 31.60 & 6.92 & 35 \\
EM1 & 32.70 & 3.16 & 10 \\
EM2 & 33.25 & 3.80 & 16 \\
OS1 & 31.57 & 7.35 & 44 \\
OS2 & 32.92 & 3.14 & 36 \\
WED1 & 31.50 & 5.19 & 20 \\
WED2 & 33.05 & 4.12 & 267 \\
Total & 31.47 & 5.93 & \\
ANOVA - F $=2.639$ & 81g. & .01 leve1 \\
\multicolumn{4}{c}{ CCONF DATA }
\end{tabular}

Mean Confidence Rating - Correct Answer

Correct Subjects Only

SITE MEAN SCORE $\underline{\text { STD. DEV. }}$

$\begin{array}{lrrr}\text { BC1 } & 3.09 & 1.31 & 26 \\ \text { BC2 } & 3.10 & 1.17 & 24 \\ \text { BT1 } & 4.08 & .89 & 36 \\ \text { BT2 } & 3.77 & 1.06 & 35 \\ \text { EM1 } & 3.94 & .64 & 10 \\ \text { EM2 } & 4.07 & .46 & 16 \\ \text { OS1 } & 3.94 & .91 & 44 \\ \text { OS2 } & 4.13 & .64 & 36 \\ \text { WED1 } & 4.22 & 1.06 & 20 \\ \text { WED2 } & 4.11 & .78 & 20\end{array}$

$\begin{array}{llll}\text { Total } & 3.85 & 1.005 & 267\end{array}$

ANOVA $-F=4.77 \quad$ 81g. .05 level

AGE DATA

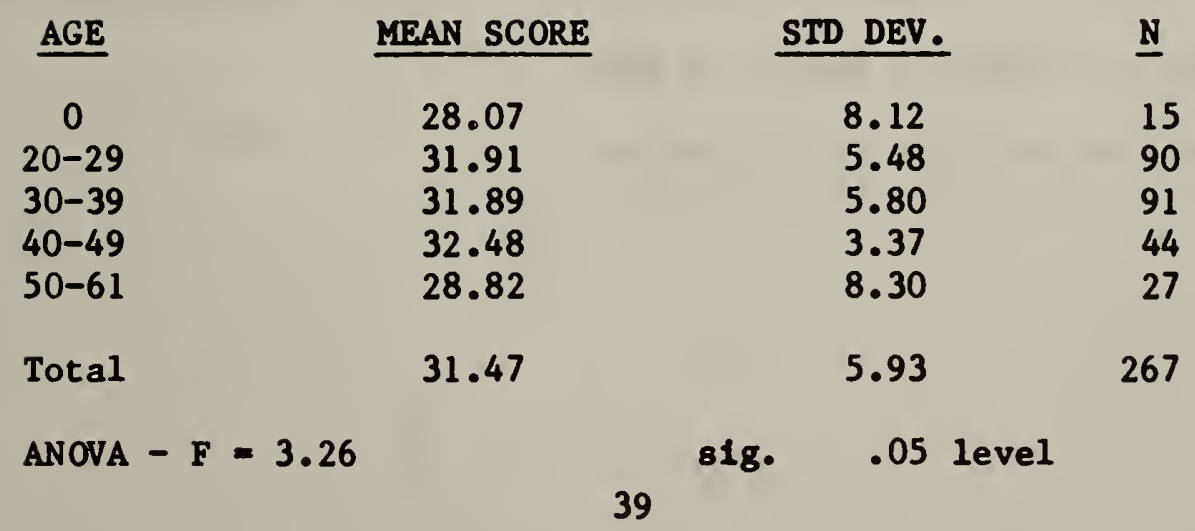


Table 10. Sumary Age Data

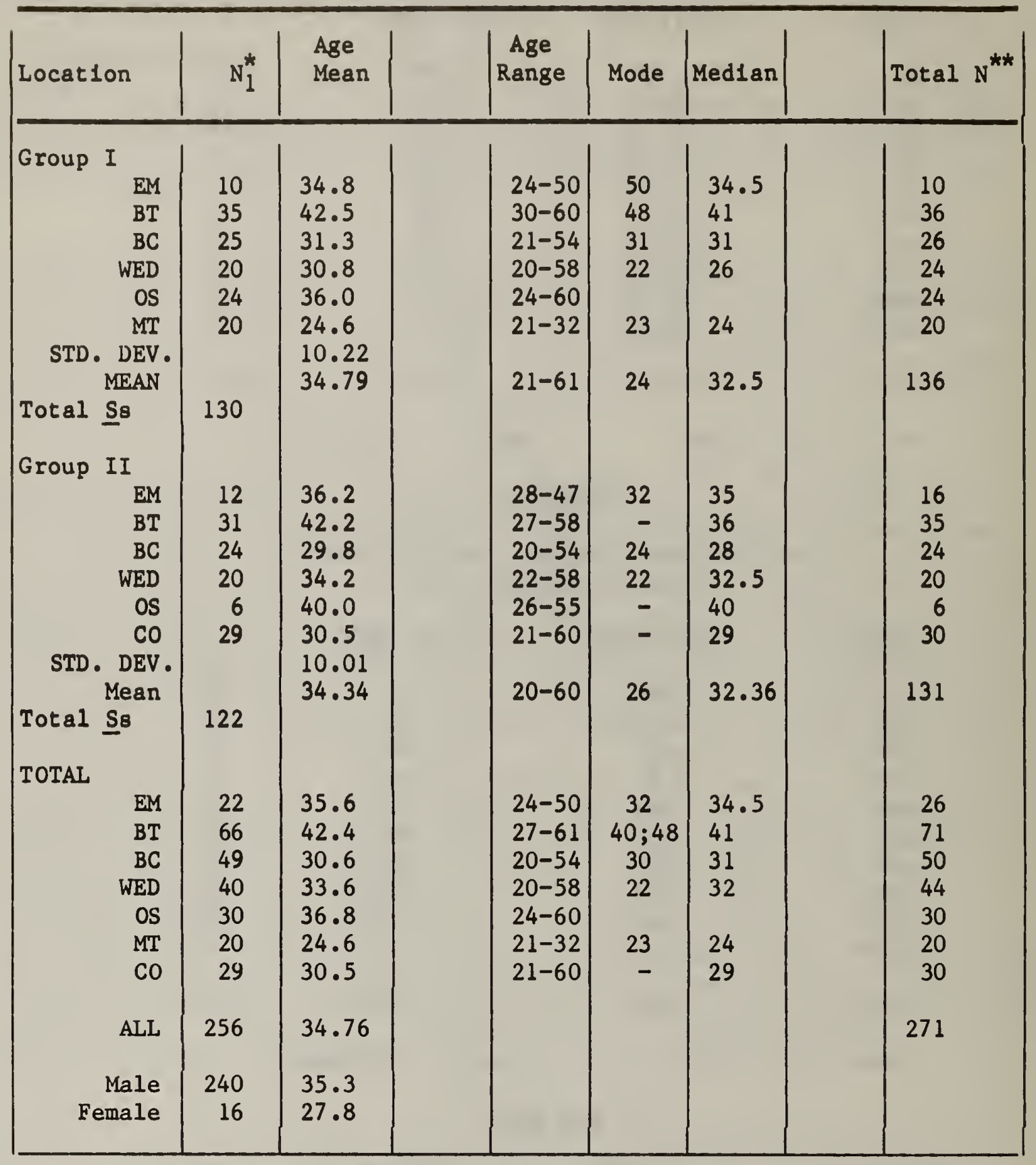

* $N_{1}=$ Number of subjects reporting age

** $\mathrm{N}$ - Number of subjects participating 
Table 11. Occupation Categories and Frequencies from

A11 Sites Combined

Category

Miner

Foreman

Saf ety/Tralning

Student

Mechanic

Electrician

Steelworker

Engineer

Mobile Equipment Operator

Machinist

Van/bus driver

Supervisor/manager

Beltman

Teamster

Roof-bolter

Maintenance

Botlermaker

Motorman

Warehouse/Supplies

Laborer

Ut111ty

Millpacker

Cost-survey \& engineering

Construction

Deadwork

Miner helper

Screen utility, tester, brusher

Sandbagger

Mill, crusher operator

Flotation operator

Welder

Surface truck operator

Weighmaster, weigher

Clean-up, car cleaner

Tireman

Carpenter

Geological technician

Rigging draftsman

Medic

Rodman

Power plant trainee

Scale loader

Coal passer

Crane operator

Footman

Number

20

17

16

13

13

11

11

11

9

9

9

9

8

8

6

5

5

4

4

4

4

4

4

3

3

3

3

3

3

3

2

2

2

2

2

2

2

1

1

1

1

1

1

1 (mining, environ., structural, fleld, boller-room) (underground) 
Table 11. (Continued)

Category

Grinding floor operator Dredge operator

Mason

Processing

Surveyor

Serviceman

Floating man

Logger

Woodworker

Secretary

Computer techniclan

Industrial hyglenist

Dental hyglenist

Industrial Techniclan

P.R.

Photographer

TOTAL

Two were too 1llegible to categorize

Number

1

1

1

1

1

1

1

1

1

1

1

263 
percent of the total sample could be categorized into thirteen categories, including the general "miners" category, which comprised anywhere from 8-20 people. The other categorles, while quite diverse, do not contaln a large number of participants. It 1s, of course, difficult to determine whether different terms for simflar occupations were used at different sites. Furthermore, some of the students were classified in occupations such as dental hygenist, carpenter, and woodworker, rather than student, although both classifications are equally applicable. The occupations reported represent a reasonably wide varlety of mine site activities, with the possible exception of the mine safety students. Th1s latter category might well be more representative of the new m1ner, however.

Although differences between jobs probably determine symbol comprehension, at least to a limited extent, no one job title in the present sample contalns enough participants to make stat1stically meaningful inferences. Consequently, general analysis of the data concentrated on age and site differences.

\subsection{PERF ORMANCE FOR INDIVIDUAL SYMBOLS}

The performance of the individual symbols will be discussed in terms of several measures - overall percentages of correct responses, mean confidence rating for the correct cholce by all subjects, and by subjects giving correct answers only (CCONF), most frequently chosen and highest rated alternatives, chi square $\left(x^{2}\right)$ analysis of the difference in cholce frequencies for the correct cholce, and t-test analysis of the difference in mean confidence ratings for the correct choice from all subjects.

Based upon the above analyses the difference in performance between the two candidate 1mages selected for the 32 referents was statistically significant (at or beyond the .05 level) for 23 referents. These referents include the following 23 messages: Electrical, Corrosion, Polson, S11p, Trip, Fall, Overhead Hazard, Crush, Sudden Pressure Release, Do Not Touch, Door Closed, Foot Protection, No Open Flame, F1rst Aid, Safety Shower, Ex1t, Emergency Ex1t, No Ex1t, Do Not Enter, Door Open, Entanglement, Eyewash, and Respirator. In nine cases, no significant differences between cand1date 1mages emerged, while for elght referents only one 1mage was assessed. See table 12 for the chi square and t-test data.

Tables 13 and 14 present the symbol referents ordered in terms of percentage correct and confidence ratings. The two tables demonstrate that as the percentage correct response 1ncreases so does the mean confidence rating. Thus symbols receiving 90 percent correct responses had mean confldence ratings of 4.5 or more, while symbols with only 30-70 percent correct had much lower confidence ratings - (generally below 3.5 to 4.0 ). As a result confidence ratings above 4.5 can be considered "high", while confldence ratings below 3.5 can be consldered "low".

The data in tables 13 and 14 can be examined to see those instances where a confidence rating was noticeably different from that for symbols with a similar percentage of correct identification. In group 1, symbols for which the confidence ratings were noticeably lower 1ncluded: Laser, Entanglement, Exit, 
Table 12. Statistical Analysis Data for All Symbols Across Sites

\begin{tabular}{|c|c|c|c|c|}
\hline Referent & $t$-test & S1g. & $x$-test & $81 \mathrm{ig}$ \\
\hline Flammable & -1.43 & .155 & .861 & .3533 \\
\hline Explosion & .73 & .465 & .001 & .9709 \\
\hline Electricity & 8.80 & .000 & 64.108 & .0000 \\
\hline Corrosion & 5.45 & .000 & 7.749 & .0054 \\
\hline Poison & 4.52 & .000 & 3.142 & .0763 \\
\hline Forklift & -.13 & .900 & .000 & .9885 \\
\hline slip & -3.81 & .000 & 18.419 & .0000 \\
\hline Fall & 2.63 & .009 & .975 & .3236 \\
\hline Overhead & -4.08 & .000 & 32.627 & .0000 \\
\hline $\operatorname{Tr} 1 \mathrm{p}$ & 6.02 & .000 & 15.666 & .0001 \\
\hline Crush & -1.64 & .102 & 10.785 & .0010 \\
\hline Sud. Pres. Rel. & 9.22 & .000 & 88.550 & .0000 \\
\hline Cut & -1.81 & .071 & 1.611 & .2043 \\
\hline Open Door & -1.05 & .296 & 3.862 & .0494 \\
\hline No Touch & 2.20 & .028 & 2.416 & .1201 \\
\hline Close Door & .55 & .586 & 4.593 & .0321 \\
\hline Head Protection & .31 & .759 & .000 & .9917 \\
\hline Ear Prot. & .77 & .444 & .081 & .7753 \\
\hline Eye Prot. & 1.00 & .320 & .000 & .9907 \\
\hline Foot Prot. & -4.64 & .000 & 6.564 & .0104 \\
\hline Hand Prot. & -.83 & .407 & .600 & .4387 \\
\hline No Open Flame & 2.04 & .043 & .001 & .9771 \\
\hline First Aid & -.62 & .535 & 8.265 & .0040 \\
\hline Safety Shower & -3.57 & .000 & 14.829 & .0001 \\
\hline Eyewash & 2.74 & .007 & 19.438 & .0000 \\
\hline Exit & -3.69 & .000 & 15.200 & .0001 \\
\hline Emergency Exit & 4.78 & .000 & 34.545 & .0000 \\
\hline No Exit & 1.85 & .066 & 3.987 & .0458 \\
\hline No Entrance & 3.82 & .000 & 9.035 & .0026 \\
\hline Alarm & $-1 \cdot 34$ & .180 & 1.468 & .2256 \\
\hline Entanglement & -3.44 & .001 & 6.868 & .0088 \\
\hline Respirator & -2.92 & .004 & 4.891 & .0270 \\
\hline
\end{tabular}


Table 13. Comparison of Percentage Correct and Confidence Ratings for Group 1 Symbols

Referent

Laser
Radiation
Alarm Call
Flammable
General Warn
Shower
Respirator
Overhead
Exit
Crush

Entanglement

No Ex1t

Cut/Sever

Door Closed

Slip

First Ald
Corrosion
P1nch
Foot
Sud. Pres. Rel
Emergency Exit
Door Open
Polson
Eyewash
Explosion

Hot Surface

Hand

Hose

No Entrance

Fall

Forklift

No Open Flame

Do Not Touch

No Smoking

Electrical

Ear

Ext1ngulsher

Head

Eye

Tr1p

\section{(2)* \\ (3)}

(38)

(12)

(30)

(40)

(16)

(39)

(34)

(18)

(21)

(9)

(29)

(6)

(17)

(33)

(19)

(7)

(31)

(4)

(15)

(26)

(37)

(35)

(10)

(8)

(28)

(20)

(27)

(5)

(23)

(36)

(22)

(24)

(13)
\% Correct Confidence Rating

30.4

37.7

56.0

57.5

59.4

65.9

70.6

70.7

72.1

74.2

80.3

81.1

82.9

83.1

83.6

84.2

86.4

88.2

88.8

89.2

89.3

89.7

90.0

91.3

91.7

91.8

92.2

92.3

93.8

95.3

95.3

95.4

95.5

95.8

96.2

96.2

96.2

96.9

96.9

97.0
2.70

3.10

3.60

3.68

2.98

3.91

4.13

4.21

3.78

4.05

4.01

4.29

4.11

3.98

4.52

4.52

4.75

4.34

4.15

4.22

4.18

4.23

4.67

4.32

4.56

4.43

4.49

4.62

4.43

4.67

4.71

4.85

4.59

4.89

4.77

4.75

4.86

4.68

4.70

4.78

* Symbol number 
Table 14. Comparison of Percentage Correct and Confidence Rating Data for Group 2 Symbols

Referent

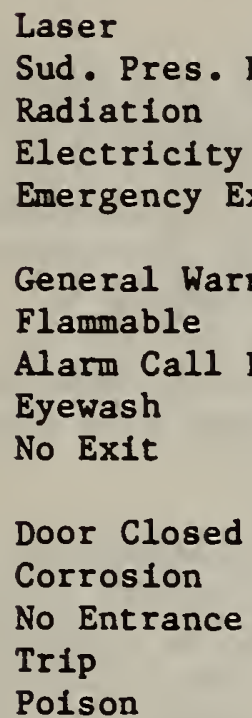

Respirator

Shower

Pinch

Cut/Sever

Do Not Touch

Crush

Exit

Fall

Hot Surface

Explosion

Entanglement

Hose

Forklift

No Open Flame

Hand

No Smoking

First Aid

Ear

Extinguisher

Eye

Door Open

Foot

Head

overhead

slip

* Symbol number
Mean

$z$ Correct Confidence Rating

$(2) *$

(17)

(3)

(5)

(33)

30.4

31.0

2.70

2.71

37.7

51.6

44.7

3.10

3.64

3.30

49.4

2.98

64.1

64.3

68.5

69.5

3.91

3.82

3.90

4.00

(34)

(21)

(6)

(35)

(13)

(7)

71.1

3.89

4.15

3.89

4.16

80.8

81.5

$4.17^{\prime}$

4.49

83.2

4.41

86.9

88.2

89.2

4.34

4.42

4.32

(18)

89.6

90.6

91.5

91.5

91.8

92.3

4.28

4.35

4.40

4.43

4.55

(4)

92.3

4.48

4.62

4.72

4.69

4.58

95.3

95.8

4.89

4.59

4.69

4.86

4.61

96.2

96.8

97.7

97.7

97.7

99.2
4.38

4.70

4.68

4.67

4.77 
Eyewash and Do Not Touch. In group 2, simllar symbol included: Laser, Sudden Pressure Release, Fire Alarm Call Point, No Entrance, Crush, Exit, and Keep Door Open. These symbols can be considered to be ones for which the part1c1pante were less sure of the correct meaning and for which some guessing may have occurred.

Other symbols are noteworthy in that the confidence ratings were higher than those for symbols with similar percentages of correct identifications. For group 1, these symbols included: Flammable, Alarm Call Point, Overhead, Slip, First Ald, Corrosion, Polson, Hose and Reel, No Open Flame, Extinguisher, and No Smoking. For group 2 the symbols included: Electricity, Corrosion, Respirator, No Smoking, and Extinguisher. It appears that those people who identified these particular symbols correctly tended to be very certain of their response. While these distinctions are arbitrary and dependent upon the symbols tested, they do indicate situations where either guessing may have occurred or where some particlpants were very certain of their answers.

A correlation coefficient of 0.92 was found between the percentage of correct responses and mean confidence ratings for group 1 symbols, and of 0.96 for group 2 symbols. Figure 5 plots the mean confidence rating as a function of the percentage correct for each symbol. (Each symbol is 1dentified by an arbitrary number given in table 8.) These data demonotrate further that symbols which recelve high percentages of correct responses also typlcally recelve high mean confidence ratings (confidence ratings could range from 1 to 5 ). Symbols for which low confldence ratings are given for high percentages of correct responses Indicate instances where participants were somewhat unsure of the correct response or when another alternative appeared plausible. In addition, selection of an incorrect cholce alternative 18 another Indication of confusion about a symbol's meaning. Such cholces w1ll be termed confusions. When the choice is an opposite-to-correct one, it will be termed a critical confusion. These instances will be discussed in detall for each symbol.

\subsection{RESULTS AND DISCUSSION FOR INDIVIDUAL SYMBOLS}

\subsubsection{Individual Symbol Data}

Each figure for a given referent reports the test data in terms of percentage of correct answers, mean confidence rating for correct answers for all subjects, and for subjects who selected the correct answers (CCONF), and frequency of selection and mean confidence rating from all participants each cholce alternative. The figures also present the choice alternatives given to all participants, as well as a black and white reproduction of each symbol. (Symbols were generally tested in the appropriate 253 safety color. The color for each symbol as tested is given in the figures). Each figure also presents statistical data when the performance of two symbols was compared, in terms of significance levels $(p<.05, .01$, or .001 , and $N S=$ not significant. The text also indicates If a symbol were suggested by ISO TC80, by terming the symbol as the "ISO symbol." 


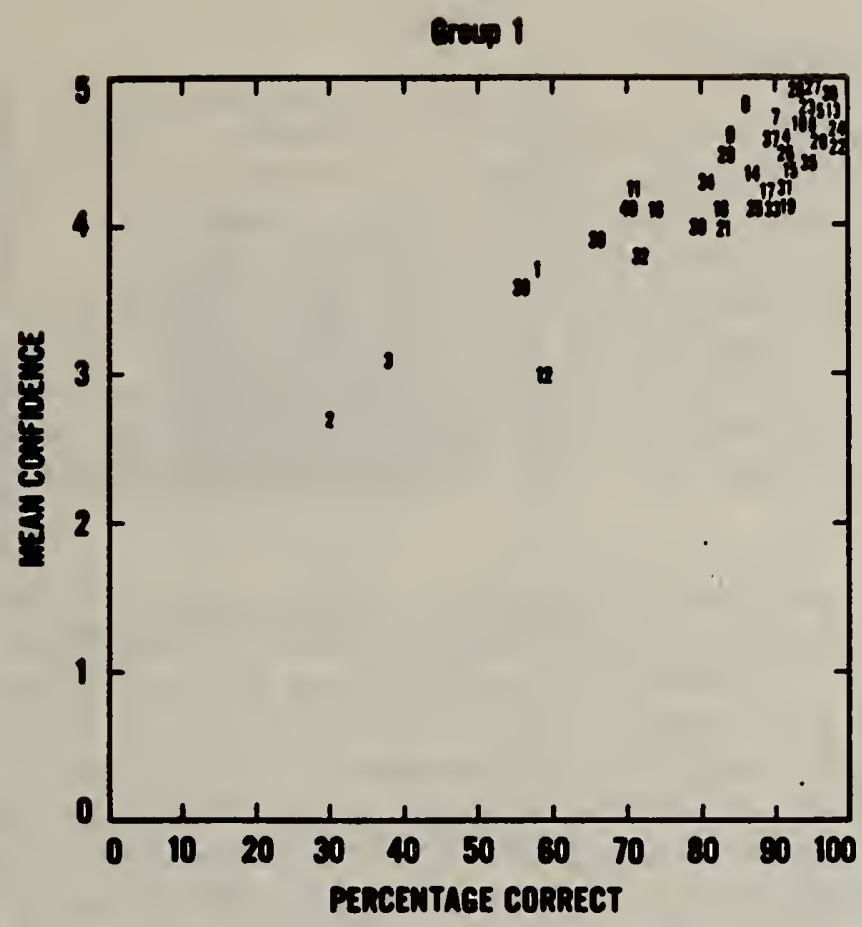

$\sin 2$

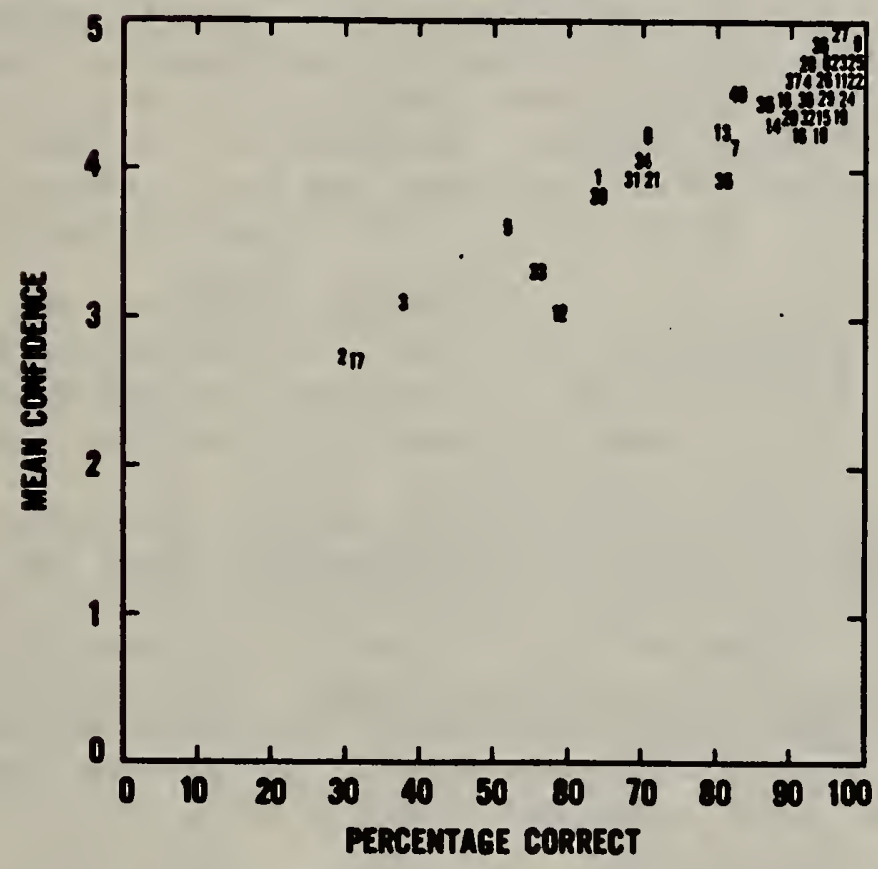

Figure 5. Percentage of correct responses as a function of mean confidence rating 


\subsubsection{Hazard Warning Symbols}

Data for the first referent to be reported, Flammable, figure 6 , indicate that neither symbol was well understood. Even the ISO candidate 1mage, \#2, was correctly identified by only 64 percent of those responding. It recelved a relatively low confidence rating, 3.9, as well. Performance for 1mage 1 was even poorer, with 57.5 percent correct 1dentification, and a mean confidence rating of 3.68 . In fact, alternative $C$, "fire permitted," emerges as a critical confusion (or opposite-to-correct response) for both symbols. Th1s answer was chosen by 20.8 percent for 1mage 1 , and by 20.3 percent for 1mage 2. Cholce "a", "excessive heat area" was also selected by a high percentage of people for both 1 mages 1 and 2 .

Data for both Radiation and Laser, figure 7, 1ndicate that these two symbols continue to be poorly understood with correct identifications of 38 percent and 30 percent, respectively. Mean confldence ratings for the correct answer for both symbols were among the lowest given for any symbol -- around 3.0 . The Radiation symbol, In fact, recelved more answers ( 47.5 percent) for rotating fan blades than for radiation, with a similar mean confidence rating (also of 3.0). In addition, 14 percent 1dentified the radiation symbol as "fallout shelter" - a critical confusion. Laser similarly recelved more answers related to solar power ( 47.6 percent) with higher confidence ratings ( 3.23 ) than for "laser hazard". There was also a high percentage of answers (19.8) related to radiation hazard as well as to flying particles (11 percent). Clearly, neither of these two symbols successfully communicated the intended message. This poor performance may be somewhat attributable to the infrequent or localized occurrence of these two hazards in mining operations as well as to the abstract graph1c representation of the 2 symbols. Nevertheless, the data suggest that training and/or word messages should accompany any use of these symbols to communicate hazard warnings, since their inltial comprehension 18 so poor.

In contrast, both candidate symbols for Explosion, figure 8, had a high percentage of correct answers (above 90 percent) and reasonably high confidence ratings. Symbol 1 obtalned only 6 percent responses related to fire, while symbol 2 recelved 4 percent responses related to bomb shelter location.

A statistically significant difference emerged between candidates 1 and 2 for Electrical Hazard, figure 9 , for both the percentage correct and confidence rating data. Image 1 , showing a whole body being electrocuted, recelved 96.2 percent correct answers, in contrast to 51.6 percent for 1mage 2, the ISO lightning bolt. Image 1 recelved a mean confidence rating of 4.77 and 1mage 2 , a mean rating of 3.36 . Th1s latter symbol also recelved 46.8 percent answers for "lightning strike likely," (compared with 0.7 percent for 1mage 1) and a mean confidence rating of 3.32 , (compared with 1.8 for 1mage 1 ).

For Corrosion, figure 10, the ISO 1mage (1) (showing both a hand and a bar being corroded) recelved a higher percentage of correct responses, 86.4 percent, compared w1th 71.3 percent for the more stylized 1mage of 2 . Image 1 also recelved a significantly higher confidence rating of 4.75 compared with 1mage 2, with a mean confidence rating of 4.15 . Confusions for both symbols were with the cholce "emergency hand wash location," with 10 to 20 percent 

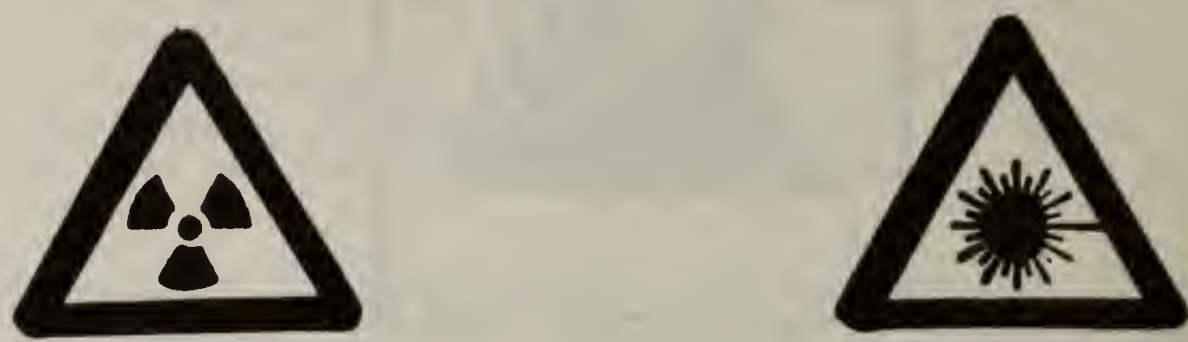

1

2

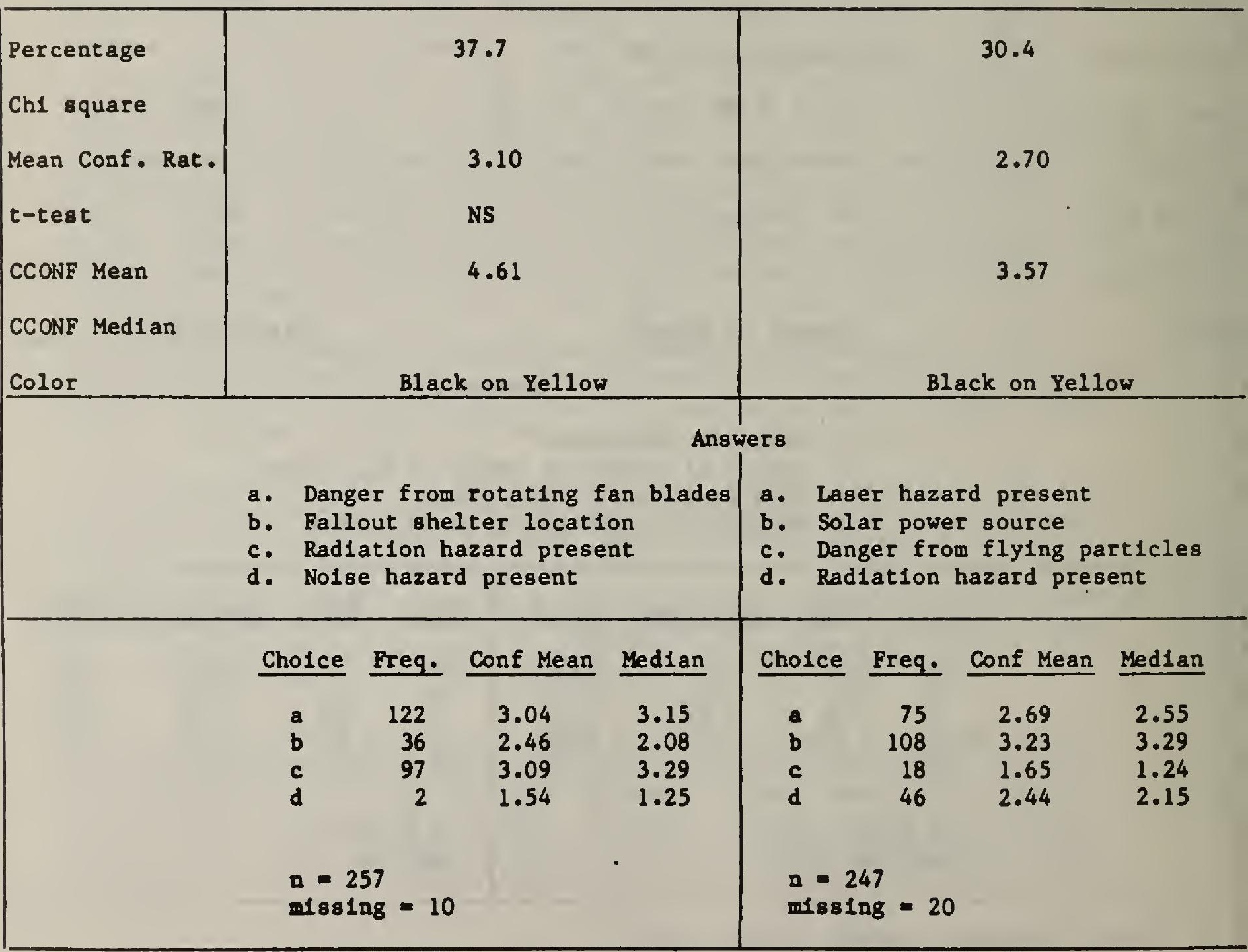


Figure 8

Explosion Hazard

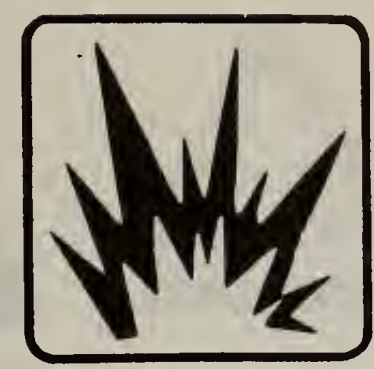

1

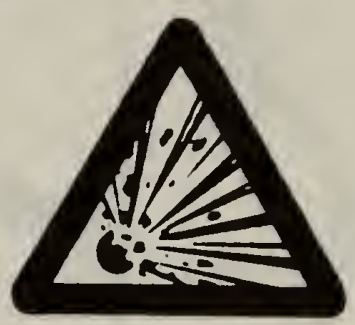

2

\begin{tabular}{|c|c|c|c|c|c|c|c|c|}
\hline $\begin{array}{l}\text { Percentage } \\
\text { Chi square } \\
\text { Mean Conf. Rat. } \\
\text { t-test } \\
\text { CCONF Mean } \\
\text { CCONF Median } \\
\text { Color }\end{array}$ & $\begin{array}{l}\text { Choice } \\
\text { a } \\
\text { b } \\
\text { c } \\
\text { d } \\
\\
\text { n }= \\
\text { mls8: }\end{array}$ & $\begin{array}{ll}\text { a. } & \mathrm{Da} \\
\text { b. } & \mathrm{Bo} \\
\text { c. } & \mathrm{Br} \\
\text { d. } & \mathrm{Da}\end{array}$ & $\begin{array}{l}\text { NS } \\
4.76 \\
\text { NS } \\
4.62 \\
4.78 \\
\text { on White } \\
\end{array}$ & $\begin{array}{l}\text { Med1an } \\
4.76 \\
1.46 \\
1.08 \\
1.98\end{array}$ & $\begin{array}{l}\text { Ins } \\
\text { In area } \\
\text { Choice } \\
\begin{array}{l}\text { a } \\
b \\
c \\
d\end{array} \\
\text { a }=1 \\
\text { mis81 }\end{array}$ & 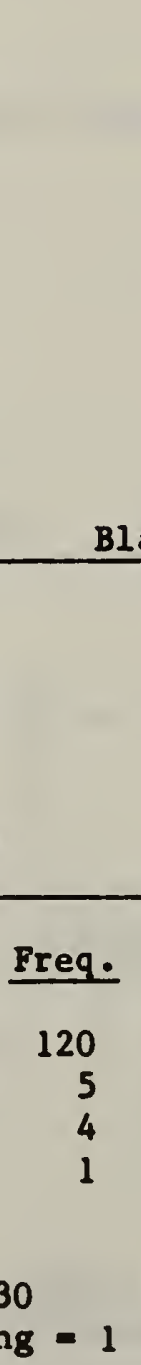 & $\begin{array}{c}92.3 \\
4.49 \\
4.55 \\
4.74 \\
\text { ck on Yell }\end{array}$ & $\begin{array}{c}\text { Med1an } \\
4.71 \\
2.42 \\
1.27 \\
1.25\end{array}$ \\
\hline
\end{tabular}


Tigure 9

Blectrical Haeard
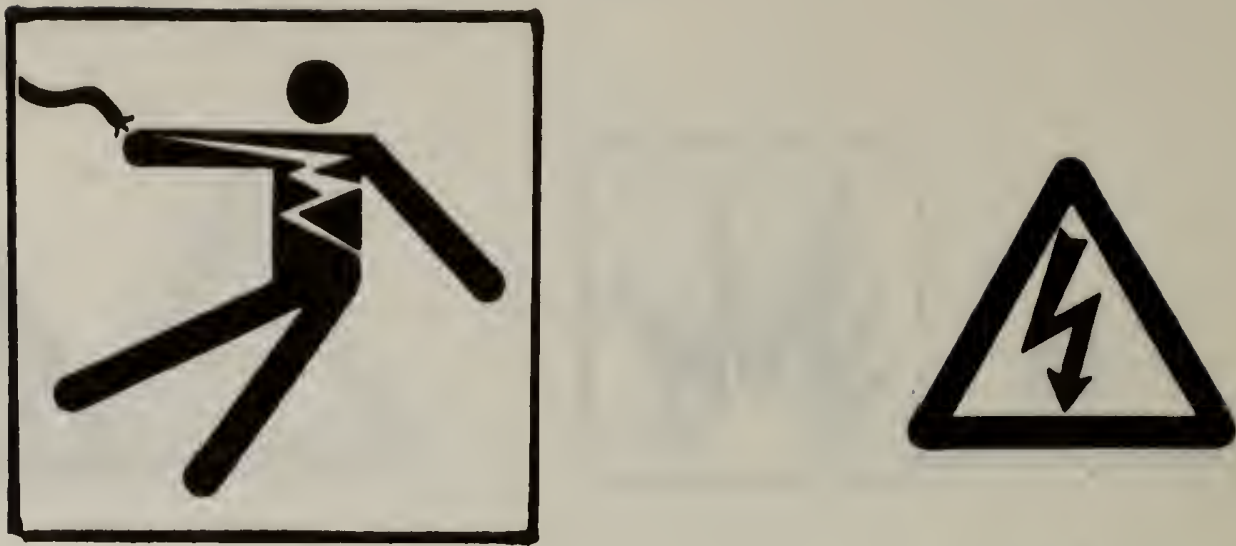

1

2

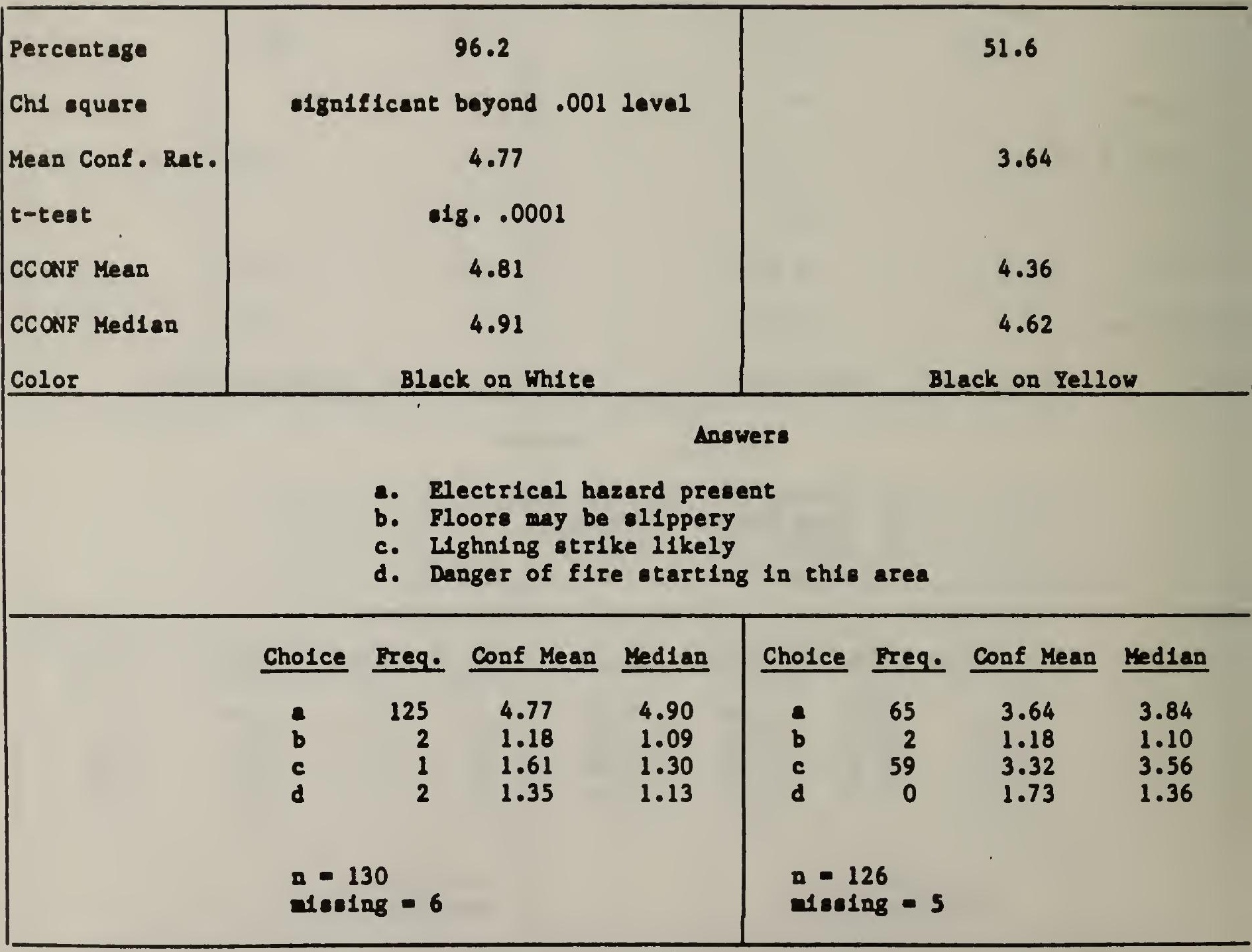


Figure 10

Corrosion Hazard

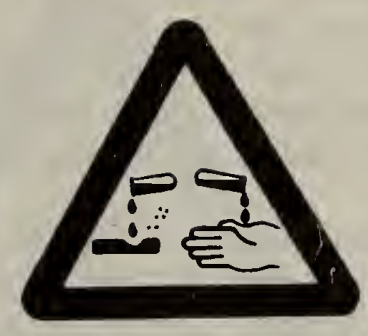

1

Percentage
Chi square
Mean Conf. Rat.
t-test
CCONF Mean
cConf Median
Color

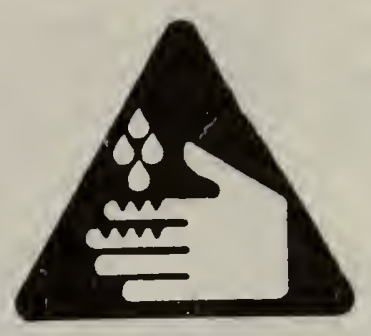

2

\begin{tabular}{|c|c|}
\hline 86.4 & 71.3 \\
$81 \mathrm{~g} . .01$ & \\
4.75 & 4.15 \\
$818 . .0001$ & \\
4.82 & 4.58 \\
4.89 & 4.72 \\
Black on Yellow & White on Red \\
\hline
\end{tabular}

\section{Answers}

a. Energency hand wash location

b. Corrosive hazard may cause chemical burns

c. First ald location here

d. Hazardous machinery used here

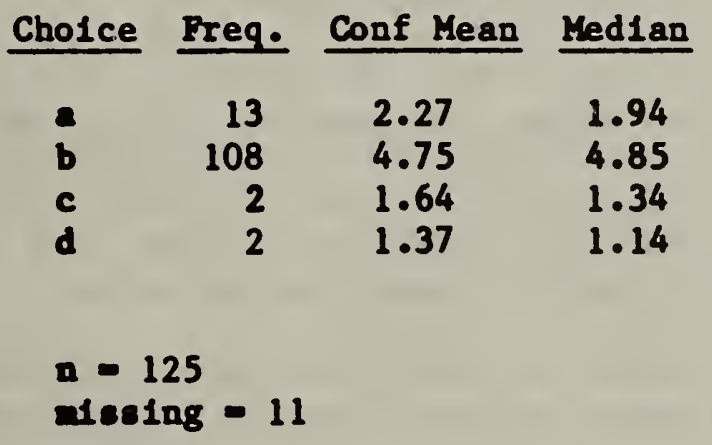

Cho1ce Preq. Conf Mean Median

$\begin{array}{rrrr}\text { a } & 27 & 2.78 & 2.74 \\ \text { b } & 92 & 4.15 & 4.47 \\ \text { c } & 6 & 1.81 & 1.41 \\ \text { d } & 4 & 1.32 & 1.12\end{array}$

n $=129$

alssing - 2 
selecting this answer. This choice also recelved a mean confidence rating of 2.27 from group 1 particlpants and 2.78 from group 2.

Statistically significant differences for both percentage correct and mean confidence rating emerged between images 1 and 2 for Poison, figure 11 . The familiar skull and crossbones was correctly identifled by 90 percent of the participants, while image 2 was identified by only 81.5 percent. Similarly image 1 received a mean confidence rating of 4.67 while 2 received one of 4.17 . About 19 percent of those responding indicated that image 2 meant "nuclear hazard present". This answer also recelved a mean confidence rating of 2.52 .

There were no significant differences between the two images studied for Fork Lift Truck, figure 12, with both images recelving about 95 percent correct responses and mean confidence ratings of 4.7. No real confusion emerged for either image, although answer "d", "warehouse storage location" received mean confidence ratings of around 2.1. Both images communicated the message successfully, however.

Image 2 for Slip, figure 13, recelved 99.2 percent correct answers, compared with 83.6 percent for 1mage 1. Image 2 showed the whole body slipping and falling, while 1mage 1 showed only the feet. Image 2 also recelved a higher mean confidence rating, 4.77 vs. 4.39. Both measures were significantly different according to the chi square and t-test statistics. For 1mage 1 , 14.8 percent picked "keep area clean", while giving it a mean confidence rating of 2.47. Although no one chose this answer for 1mage 2, it did receive a somewhat higher confidence rating of 1.89. No other answers recelved very high confidence ratings.

Image 1 for Fall From Elevation, figure 14, recelved a slightly higher percentage of correct answers ( 95.3 vs 91.5$)$ and also had a significantly higher confidence rating of 4.67 compared with 4.40 . No real confusions emerged for elther image, however.

Larger and significant differences in percentage correct were elicited for the two images for Overhead Hazard - 97.7 percent for 1mage 2, and 70.7 percent for image 1, figure 15. Mean confidence ratings were also significantly different for the two 1mages - 4.67 versus 4.21. Image 1 recelved 8.9 percent answers for "loading zone" and 17.9 percent for "check gear before hoisting". These two choices were given mean confidence ratings of 2.56 and 2.14 respectively.

Only one image was studied for General Warning, figure 16. It, however, received a low percentage of correct answers, 59.4 percent, and a correspondingly low mean confidence rating, 2.98. In addition, 16.6 percent of the total participants, failed to respond to this symbol. The answer, "yleld ahead" was selected by 24 percent of the participants and received a mean confidence rating of 2.27. "Danger from falling objects" was selected by about 12 percent of the participants and recelved a mean confidence ratings of 1.78 . Performance was almost as poor for this symbol as for laser and radiation.

Statistically significant differences occurred for the two images for Trip, Figure 17. Image 1, showing a person tripping over an object, was correctly 
P1gure 11

Po1son Hazard
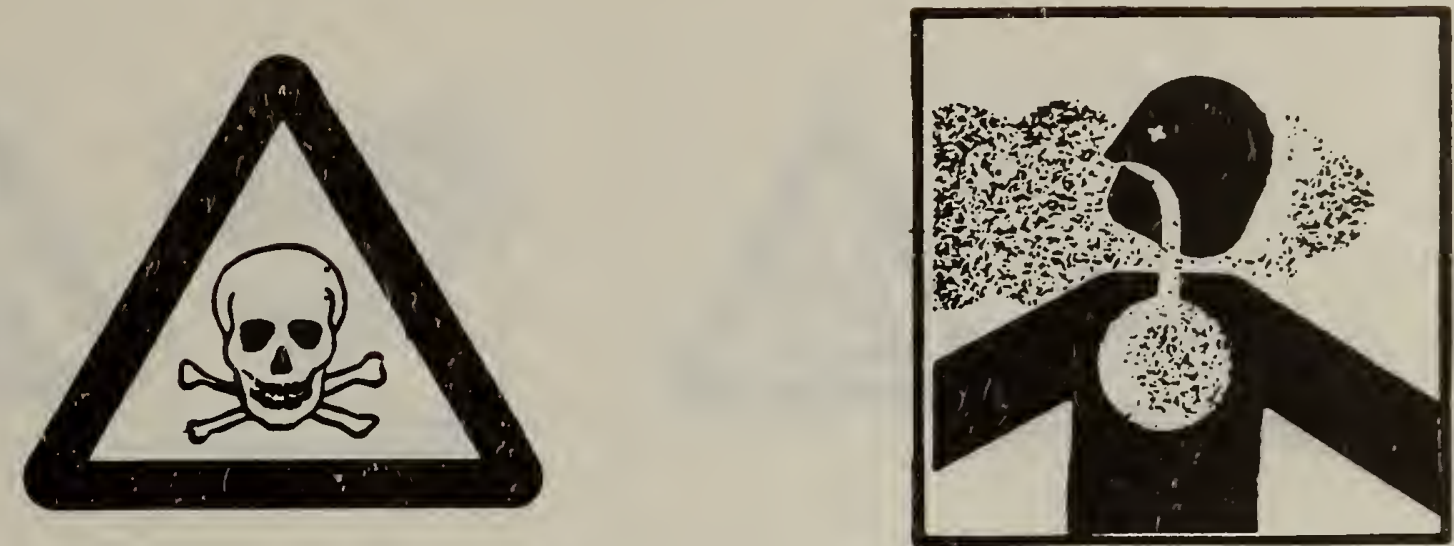

1

2

\begin{tabular}{|c|c|c|c|c|c|c|c|c|}
\hline \multirow[t]{3}{*}{$\begin{array}{l}\text { Percentage } \\
\text { Ch1 square } \\
\text { Mean Conf. Rat. } \\
\text { t-test } \\
\text { CCONF Mean } \\
\text { CCONF Median } \\
\text { Color }\end{array}$} & \multicolumn{4}{|c|}{$\begin{array}{c}90.0 \\
\text { NS } \\
4.67 \\
\text { 818. } .001 \text { level } \\
4.79 \\
4.90 \\
\text { Biack on Yellow }\end{array}$} & & . & $\begin{array}{c}81.5 \\
4.17 \\
4.30 \\
4.60 \\
\text { ack on Whit }\end{array}$ & e \\
\hline & & $\begin{array}{l}\text { a. } P 0 \\
\text { b. Wr } \\
\text { c. } \mathrm{Y1} \\
\text { d. } \mathrm{Ne}\end{array}$ & $\begin{array}{l}\text { Loon hazard } \\
\text { tch out for } \\
\text { eld to elde } \\
\text { clear hazar }\end{array}$ & $\begin{array}{l}\quad \text { An } \\
\text { present } \\
\text { safety } \\
\text { rly pede } \\
\text { d presen }\end{array}$ & $\begin{array}{l}\text { ers } \\
\text { rards } \\
\text { rlans }\end{array}$ & & & \\
\hline & $\begin{array}{c}\text { Cholce } \\
\text { a } \\
\text { b } \\
\text { c } \\
\text { d } \\
\text { n = } \\
\text { nies }\end{array}$ & $\begin{array}{r}\text { Preg. } \\
117 \\
8 \\
2 \\
3 \\
\end{array}$ & $\begin{array}{c}\text { Conf Mean } \\
4.67 \\
1.89 \\
1.22 \\
1.79\end{array}$ & $\begin{array}{l}\text { Med1an } \\
4.86 \\
1.39 \\
1.06 \\
1.36\end{array}$ & $\begin{array}{c}\text { Cholce } \\
a \\
b \\
c \\
d \\
\text { n }\end{array}$ & $\begin{array}{r}\text { Preq. } \\
101 \\
0 \\
0 \\
24 \\
\\
25 \\
\text { ng }=6\end{array}$ & $\begin{array}{c}\text { Conf Mean } \\
4.17 \\
1.57 \\
1.11 \\
2.52\end{array}$ & $\begin{array}{l}\text { Med1an } \\
4.48 \\
1.29 \\
1.03 \\
2.30\end{array}$ \\
\hline
\end{tabular}


P1gure 12

Fork L1ft Truck Bazard
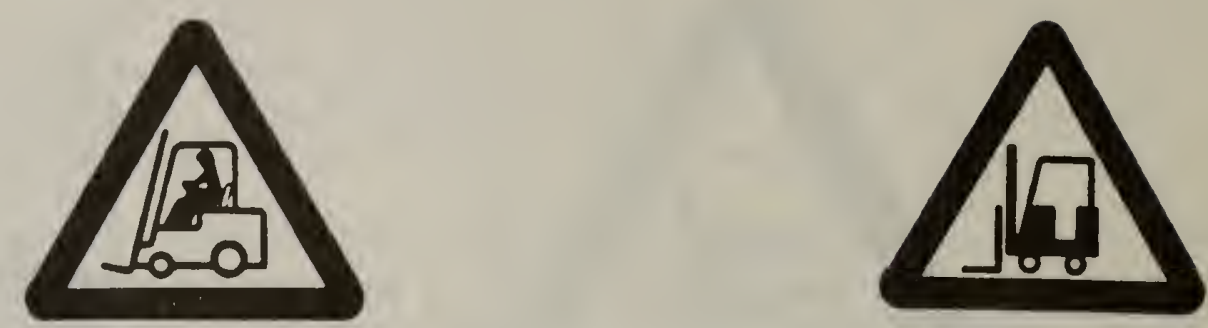

1

2

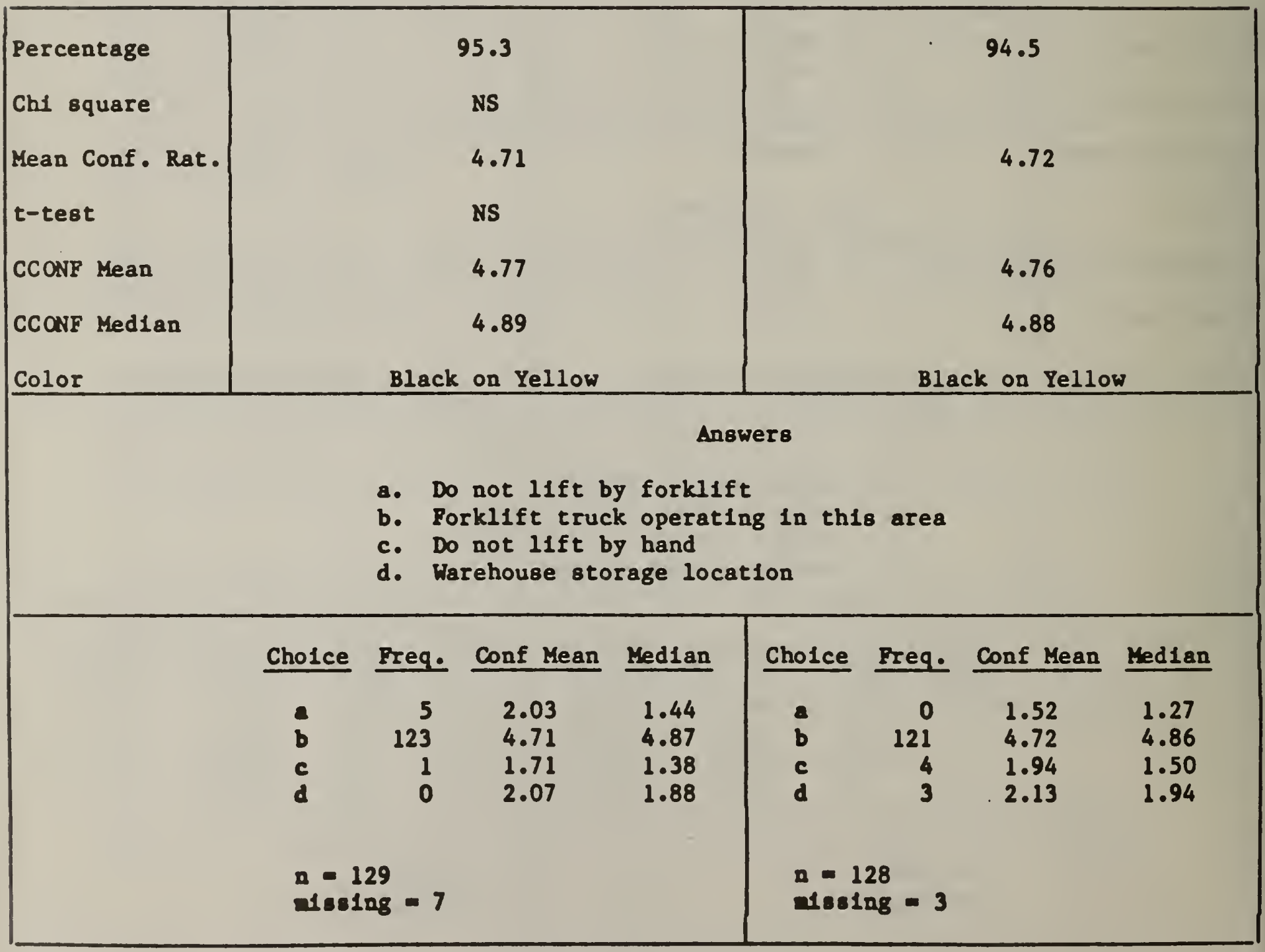




\section{Figure 13}

Slip Hazard
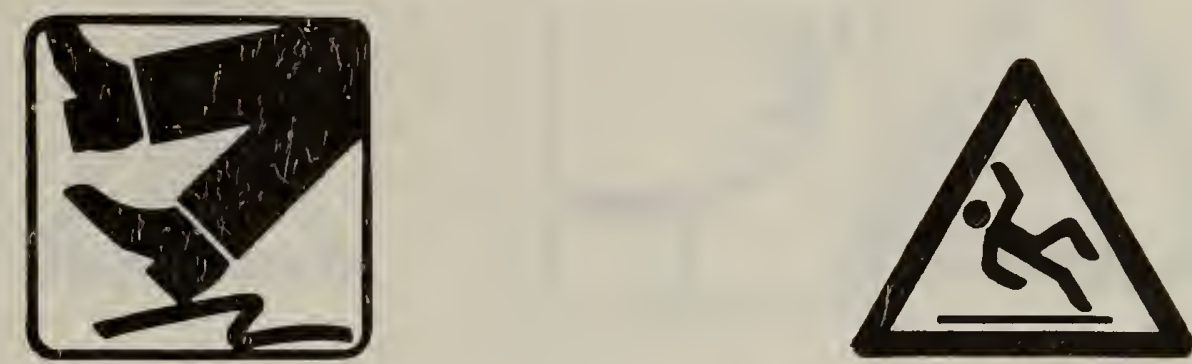

1

2

\begin{tabular}{|l|c|}
\hline Percentage & 83.6 \\
Ch1 square & 81gnificant beyond .05 level \\
Mean Conf. Rat. & 4.39 \\
t-test & $818 \cdot .0001$ \\
CCONF Mean & 4.67 \\
CCONF Median & 4.81 \\
Color & Black on White \\
\hline & \\
& a. Reep area clean \\
& b. Wear boots In area \\
c. Danger of polsonous snakes in area \\
d. Slippery floors In area
\end{tabular}

Choice Freq. Conf Yean Median

Choice Freq. Conf Mean Median

$\begin{array}{lrrr}\text { a } & 19 & 2.47 & 2.28 \\ \text { b } & 0 & 1.40 & 1.17 \\ \text { c } & 2 & 1.28 & 1.10 \\ \text { d } & 107 & 4.39 & 4.71 \\ & & & \\ \text { n }=128 & & \end{array}$

$\begin{array}{lll}a & 0 & 1.89\end{array}$

1.62

$\begin{array}{llll}b & 1 & 1.44 & 1.22\end{array}$

$\begin{array}{llll}\text { c } & 0 & 1.08 & 1.04\end{array}$

$\begin{array}{llll}\text { d } & 130 & 4.77 & 4.88\end{array}$

a $=131$

Assing $=0$ 
P1gure 14

Pall From Elevation thard
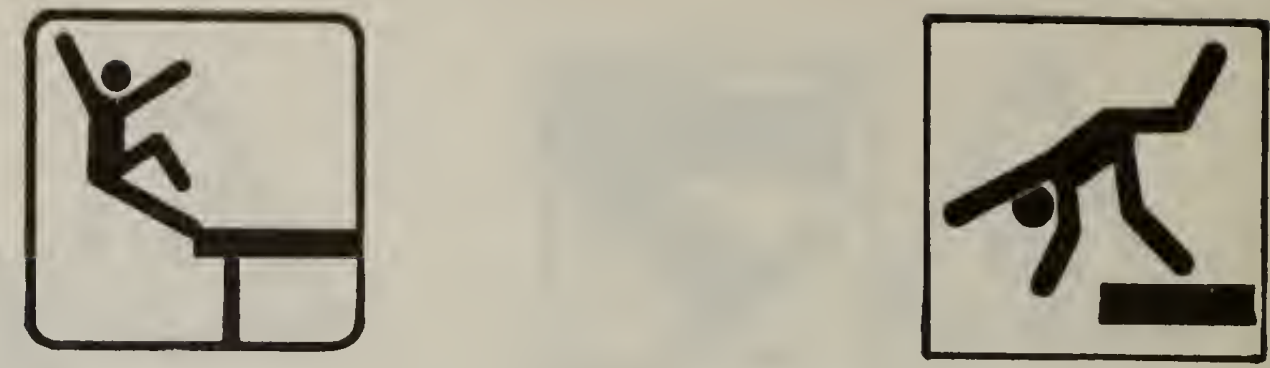

1

2

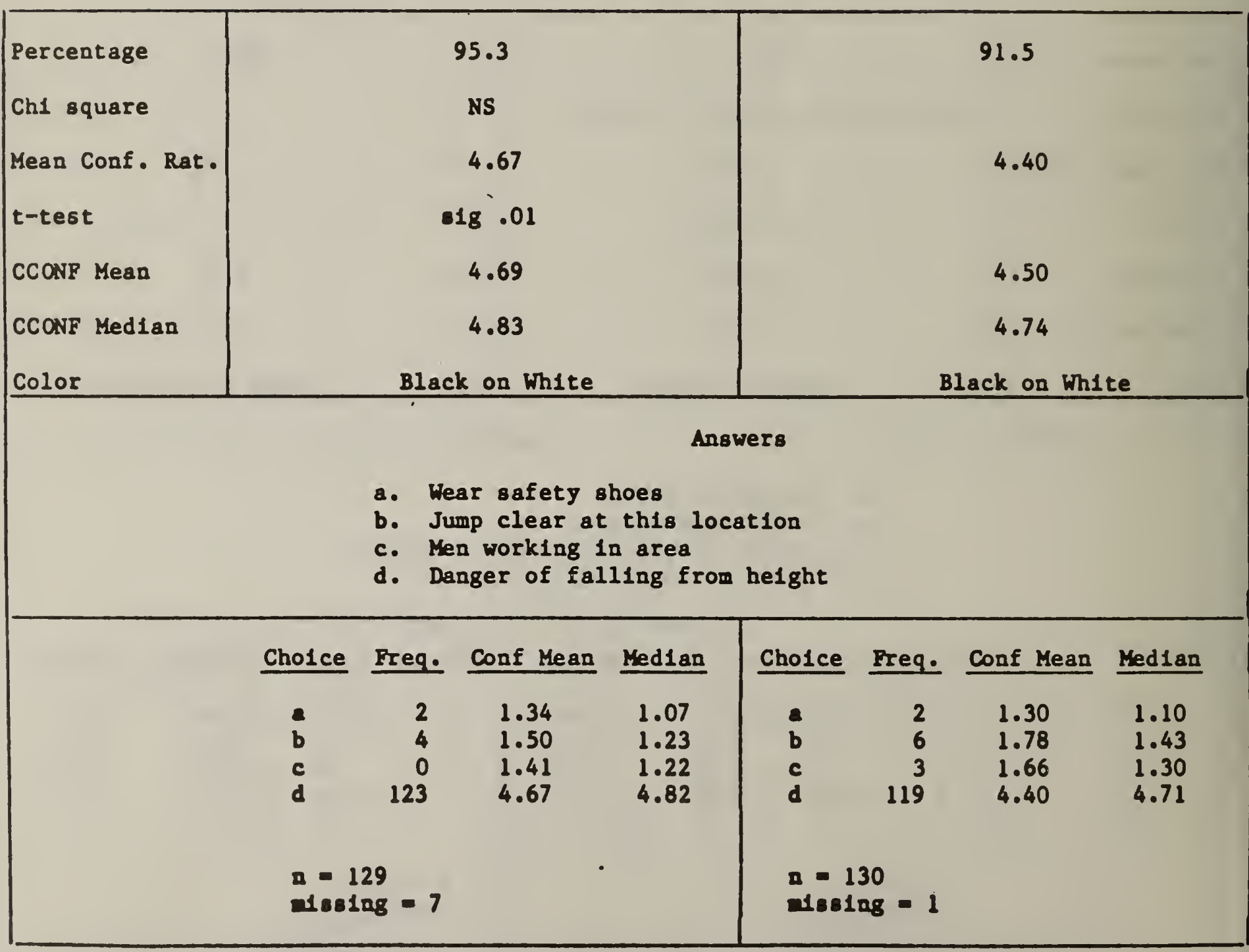


P1gure 15

Overhead Hazard
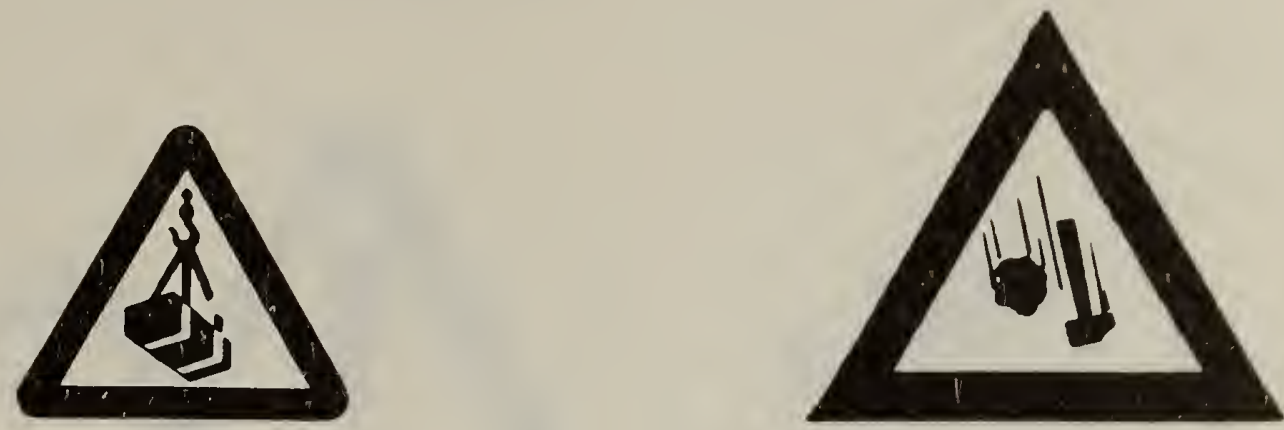

1

2

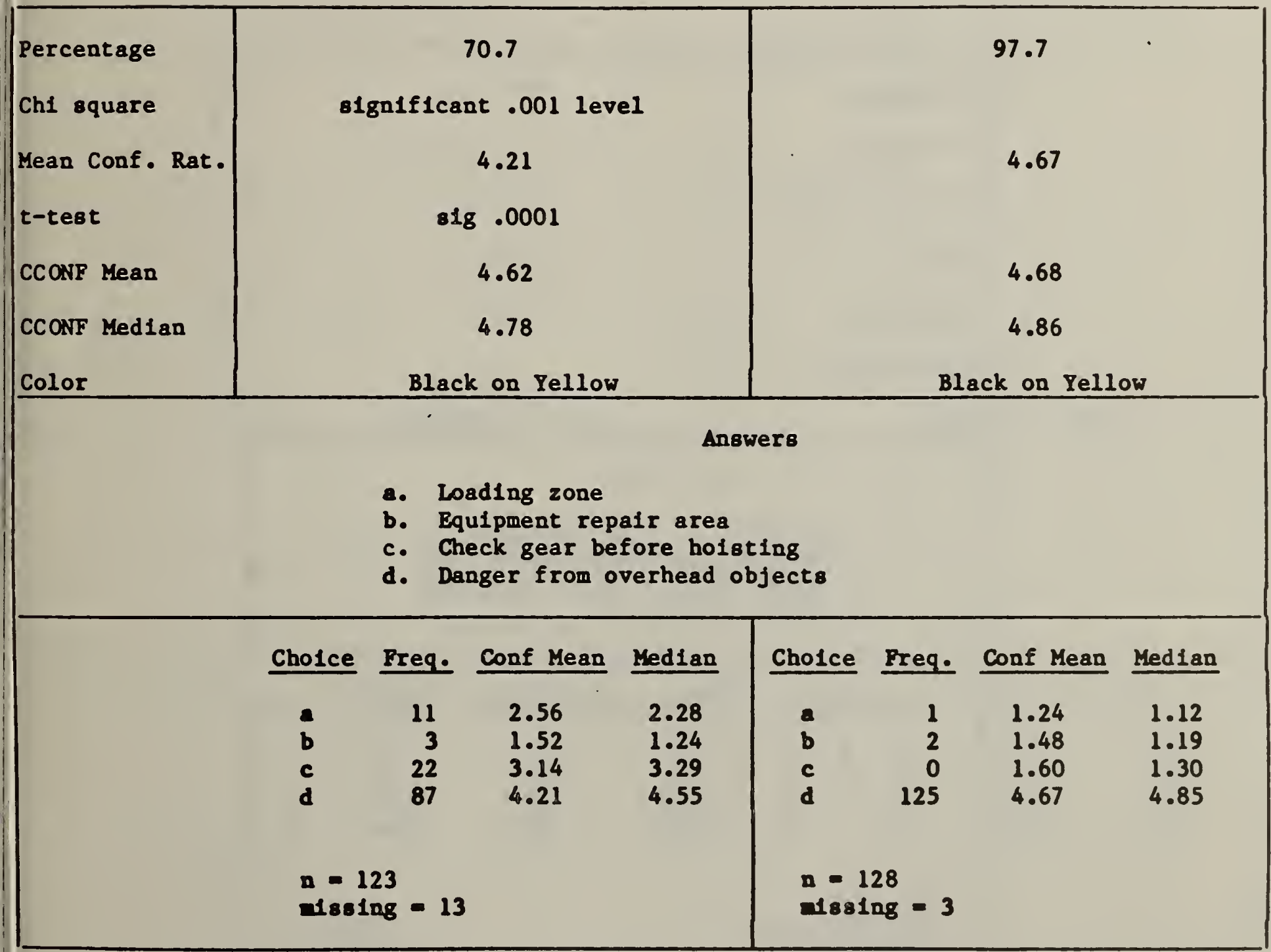


General Warning

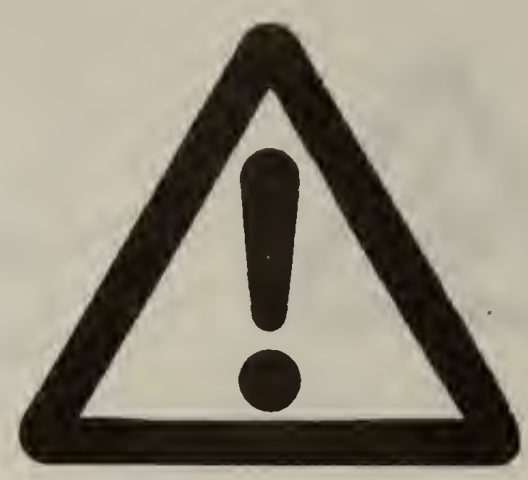

1

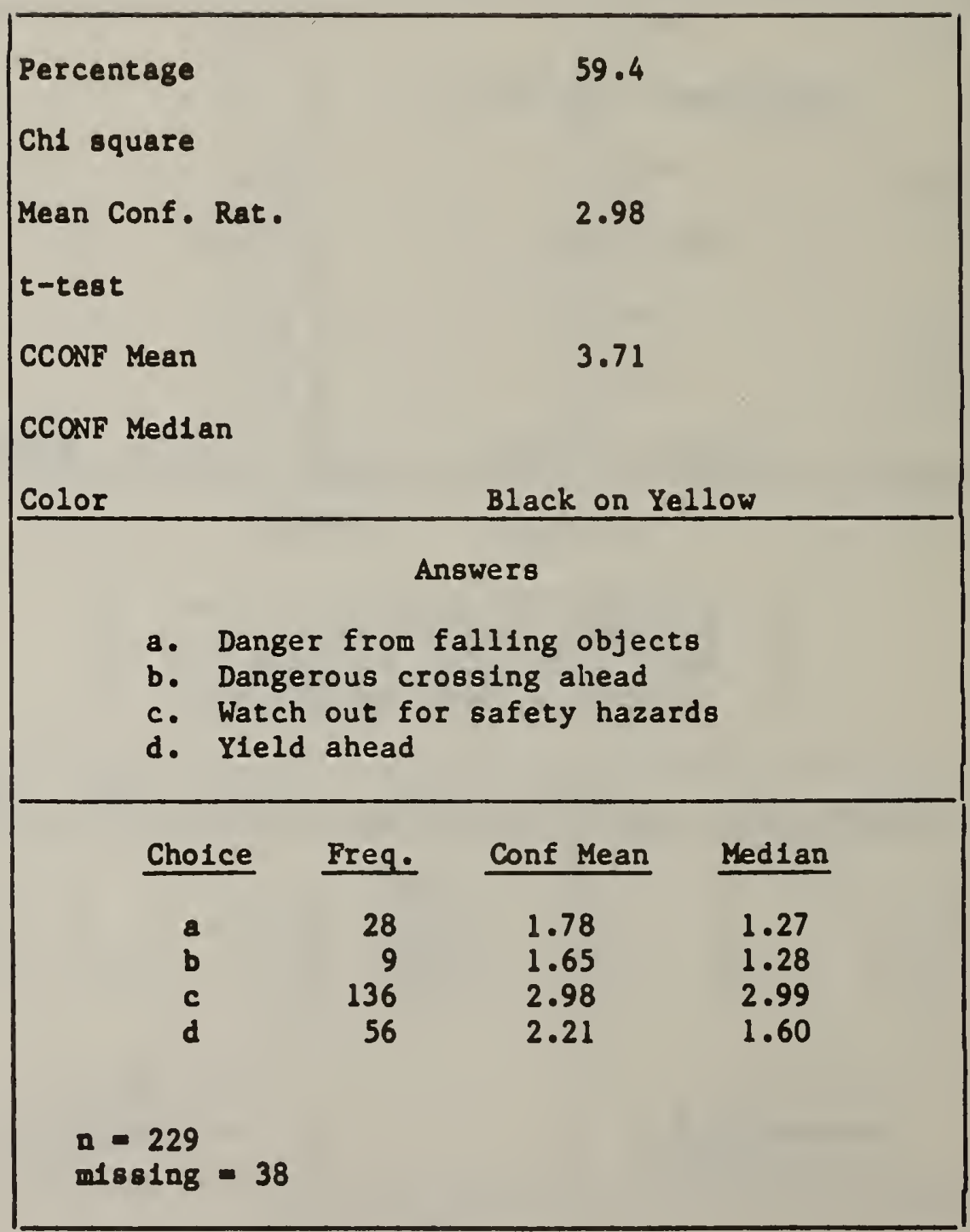




\section{F1gure 17}

Tr1p Hazard
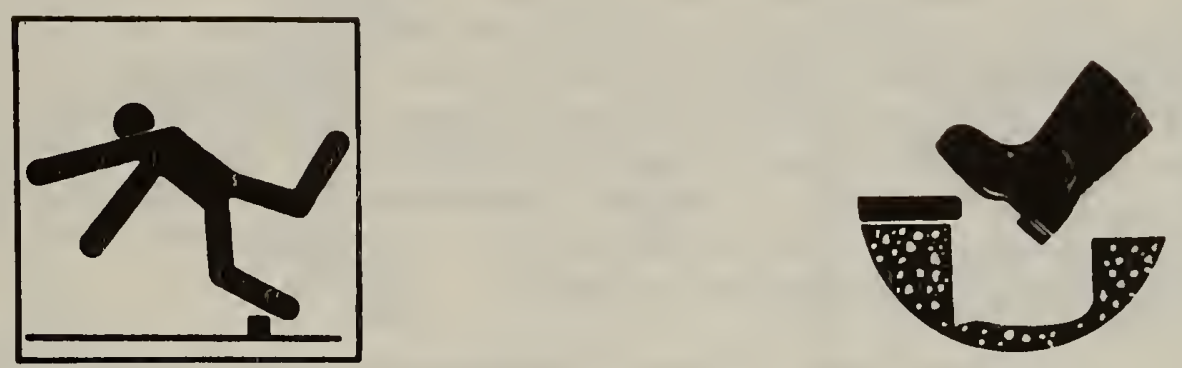

1

2

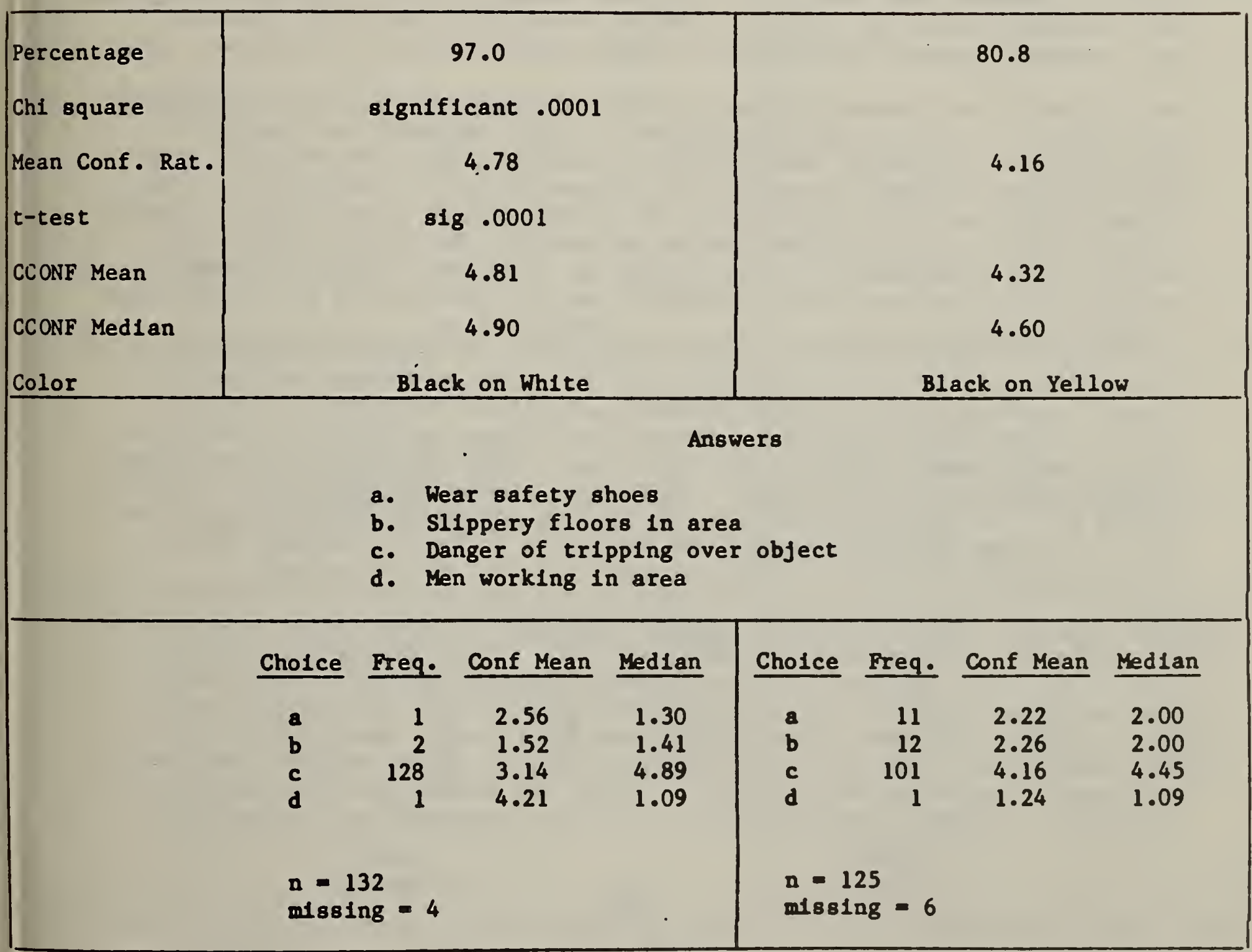


identified by 97 percent of the participants, but image 2 was identified correctly by only 80.8 percent. The mean confidence ratings, of 4.78 and 4.16 , also were significantly different. Confusions for image 2 were related to "wear safety shoes" and "slippery floors" (about 9 percent), with mean confidence ratings of around 2.2 .

The only image studied for Pinch, figure 18 , was identified correctly by 88.2 percent of the participants. It also recelved a mean confidence rating of 4.34. Some confusion arose with the cholce, "wear protective gloves", which was selected by 9 percent of the participants. Hot surface, figure 18, also recelved a high percentage of correct answers ( 91.8 percent) and a confidence rating of 4.43. Answer c, "danger from sharp objects on surface" was selected by about 8 percent of those responding. No other answer emerged as plausible, judging by the low confidence ratings.

The two Images for Crush, figure 19, recelved significantly different percentages of correct answers, with image 1 recelving 74.2 percent correct answers and image 2, 90.6 percent. A small difference occurred in the mean confidence ratings, 4.05 versus 4.28 . Twenty-four percent selected "pinch point" for Image 1 and gave 1 t a confidence rating of 3.27 . Only two percent selected this answer for image 2. "Danger from flying particles" appeared to be a reasonable choice for image 2 to elght percent of the participants.

Image 1 for Sudden Pressure Release, figure 20, performed signficantly better, than image 2. It was identifled correctly by 89.2 percent, but received a relatively low confidence rating of 4.22. Serious confusions arose for image 2 , which recelved a higher percentage of choices (64.3) for "danger from bright lights," than for the correct answer (31.0), and a much higher mean confidence rating ( 3.57 vs 2.71). Differences in response between the two images were statistically significant, but the fairly low confidence rating for image 1 suggests that even this graphic rendition was not particularly well understood.

In contrast, 1mage 2 for Cut or Sever, figure 21, was identifled correctly by 89.2 percent of the participants and received a mean confidence rating of 4.42 . A small percentage of people ( 10 percent) identifled this image as "pinch point". Image 1 was identified correctly by 82.9 percent of the participants and received a mean confidence rating of 4.11. About 14.6 percent identified this image as meaning Pinch Point. This answer also received a mean confidence rating of 2.69 . It is interesting to note that the single change from a hand to a foot being severed decreased the percentage of correct answers, lowered the mean confidence rating, and increased the number of confusions.

Similarly, for Entanglement, figure 22, Inclusion of a hand in the gears, image 2 , increased performance on all three measures. This image was identified correctly by 92.3 percent, recelved a mean confidence rating of 4.48 , and had a low percentage (6.2) of wrong answers (and this for the answer, "protective gear required"). Image 1, which performed significantly more poorly, depicted the gears alone. Only 80.3 percent identifled this image correctly and gave it a low mean confidence rating of 4.01. About ten percent selected "wear protective gear" for image 1 while another 5.4 percent selected "oll gears while 
P1nch Hazard

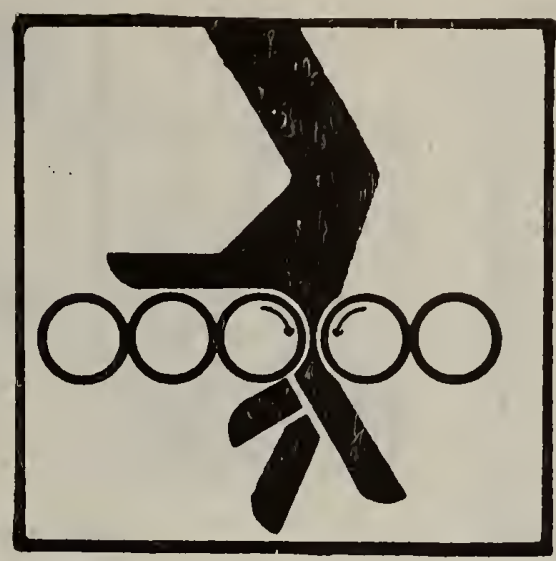

1
Hot Surface Hazard

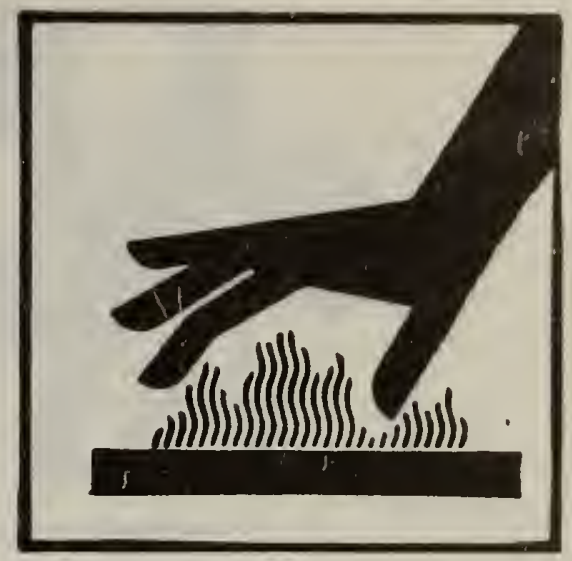

2
4.43

4.54

Black on White

80.8

88.2

$4 \cdot 34$

4.50

Black on White

Answer8

a. Do not wear gloves

b. Bot surface may burn you

c. Danger from sharp objects on ourface

d. Place hand here

Cholce Breq. Conf Mean Med1an

Cholce Freg. Conf Mean Median

$\begin{array}{rrrr}\text { a } & 225 & 4.34 & 4.73 \\ \text { c } & 2 & 1.39 & 1.17 \\ \text { d } & 7 & 1.28 & 1.09 \\ & 21 & 2.03 & 1.57\end{array}$

n $=225$

aseing $=12$ 


\section{Crush Bazard}

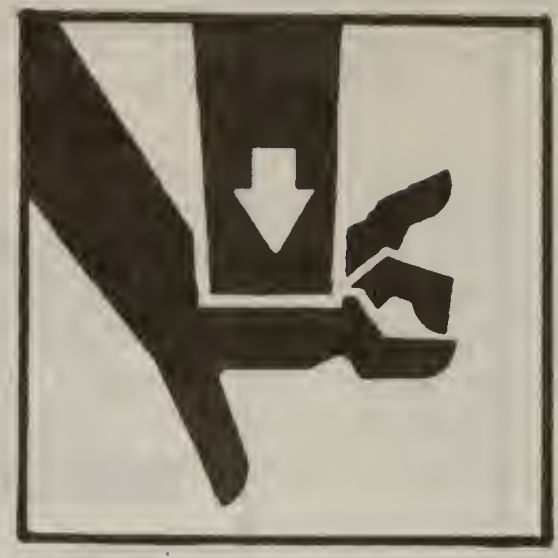

1

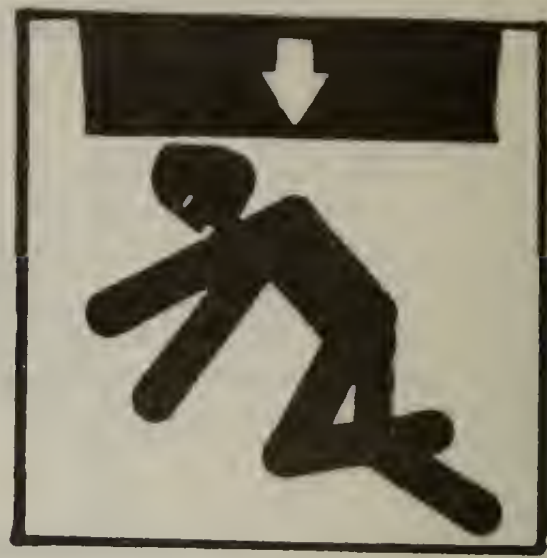

2

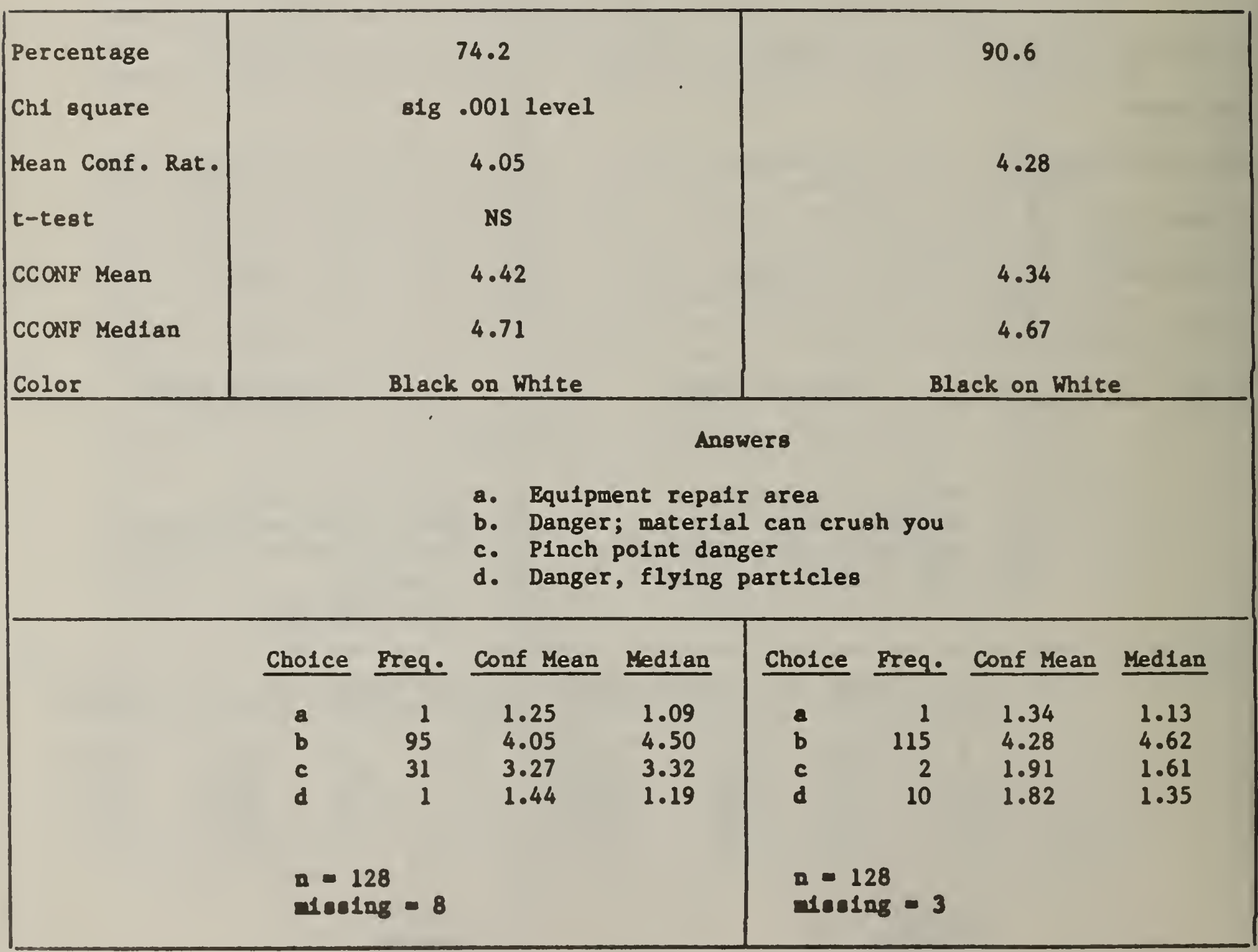




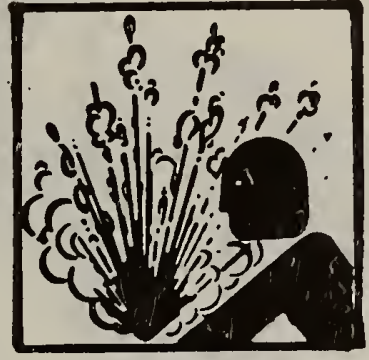

1

t-test

CCONF Mean

CCONF Median

Color significant beyond .0001

4.22

0.001

89.2
olgniflcant beyond .0001
4.22
0.001
4.36
4.58
Black on White

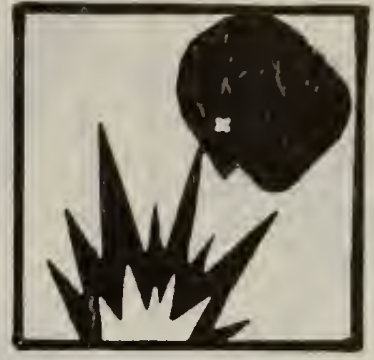

2

\section{Answers}

a. Danger of sudden pressure release

b. F1re may start here

c. Hazardous nuclear material

d. Danger from bright 11ghts

Cholce Preq. Conf Mean Median

$\begin{array}{rrrr}\text { a } & 116 & 4.22 & 4.52 \\ \text { b } & 5 & 1.93 & 1.57 \\ \text { c } & 4 & 1.77 & 1.35 \\ \text { d } & 5 & 1.51 & 1.20\end{array}$

n $=130$

assing - 6
Cho1ce Freq. Conf Mean Median

$\begin{array}{rrrr}\text { a } & 39 & 2.71 & 2.81 \\ \text { b } & 2 & 1.60 & 1.35 \\ \text { c } & 4 & 1.94 & 1.59 \\ \text { d } & 81 & 3.57 & 3.98\end{array}$

n -126

as81ng $=5$ 
P1gure 21

Bever Bazard

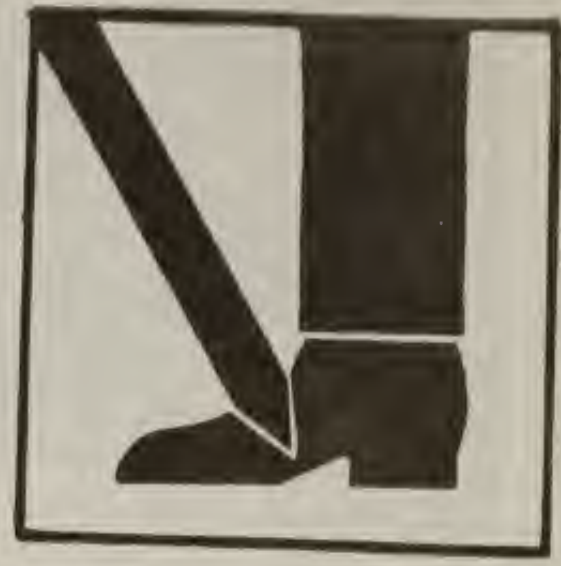

1

2

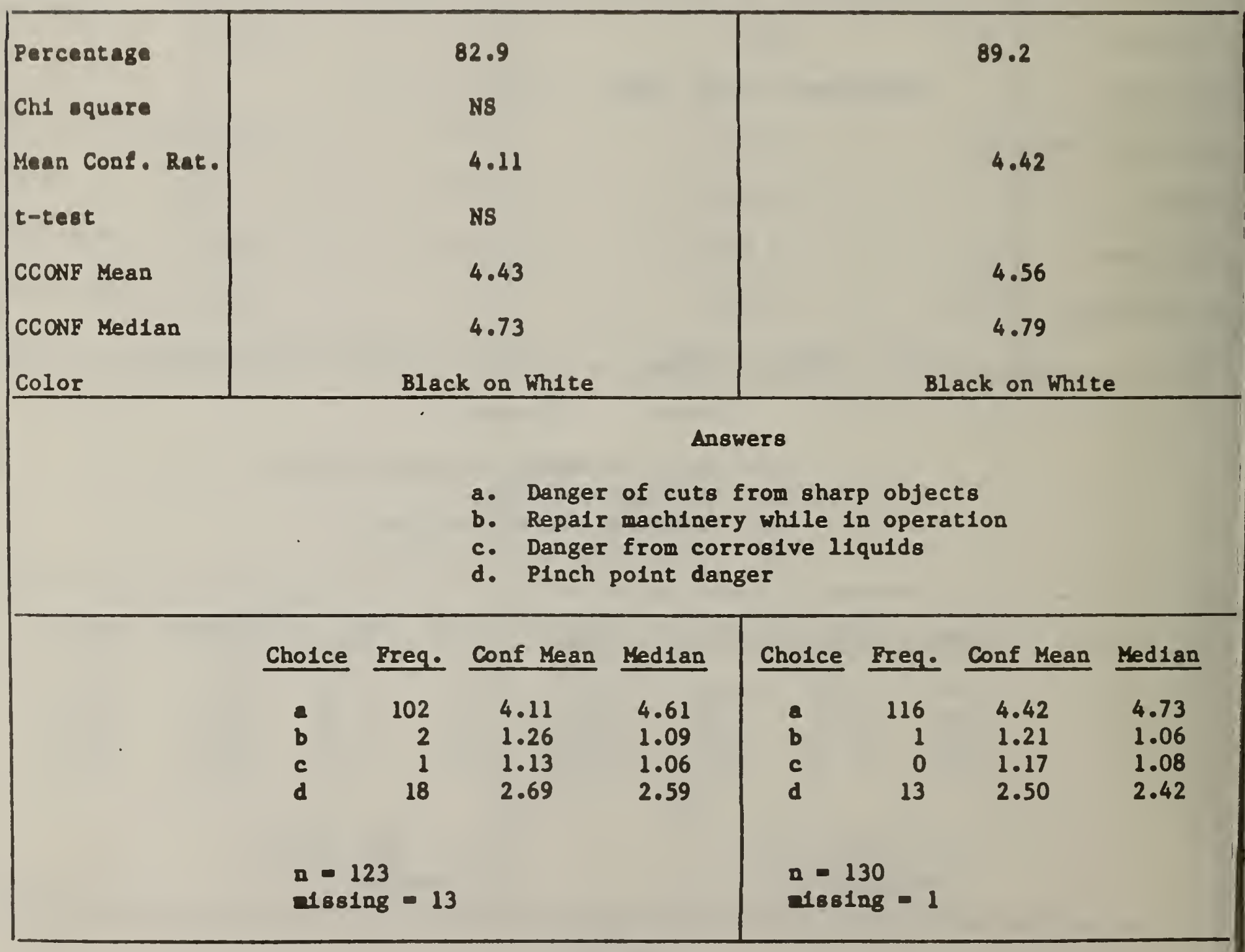


P1gure 22

Entanglement Hazard
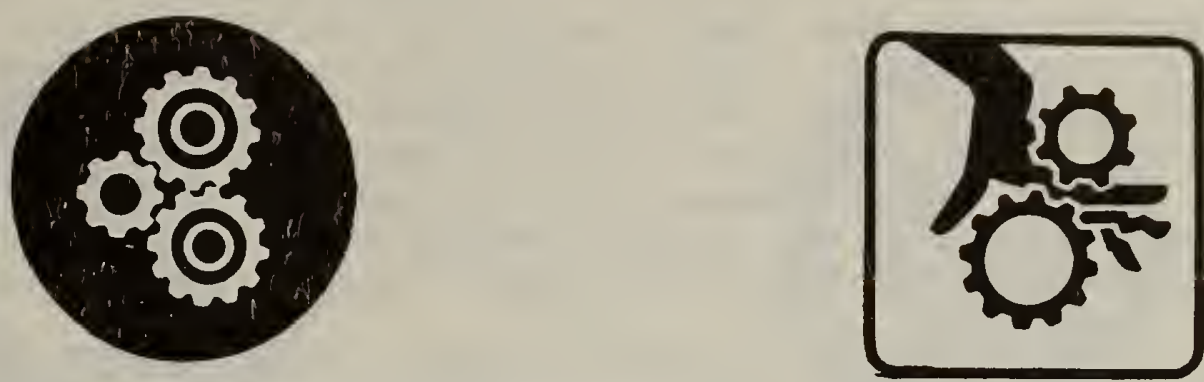

1

2

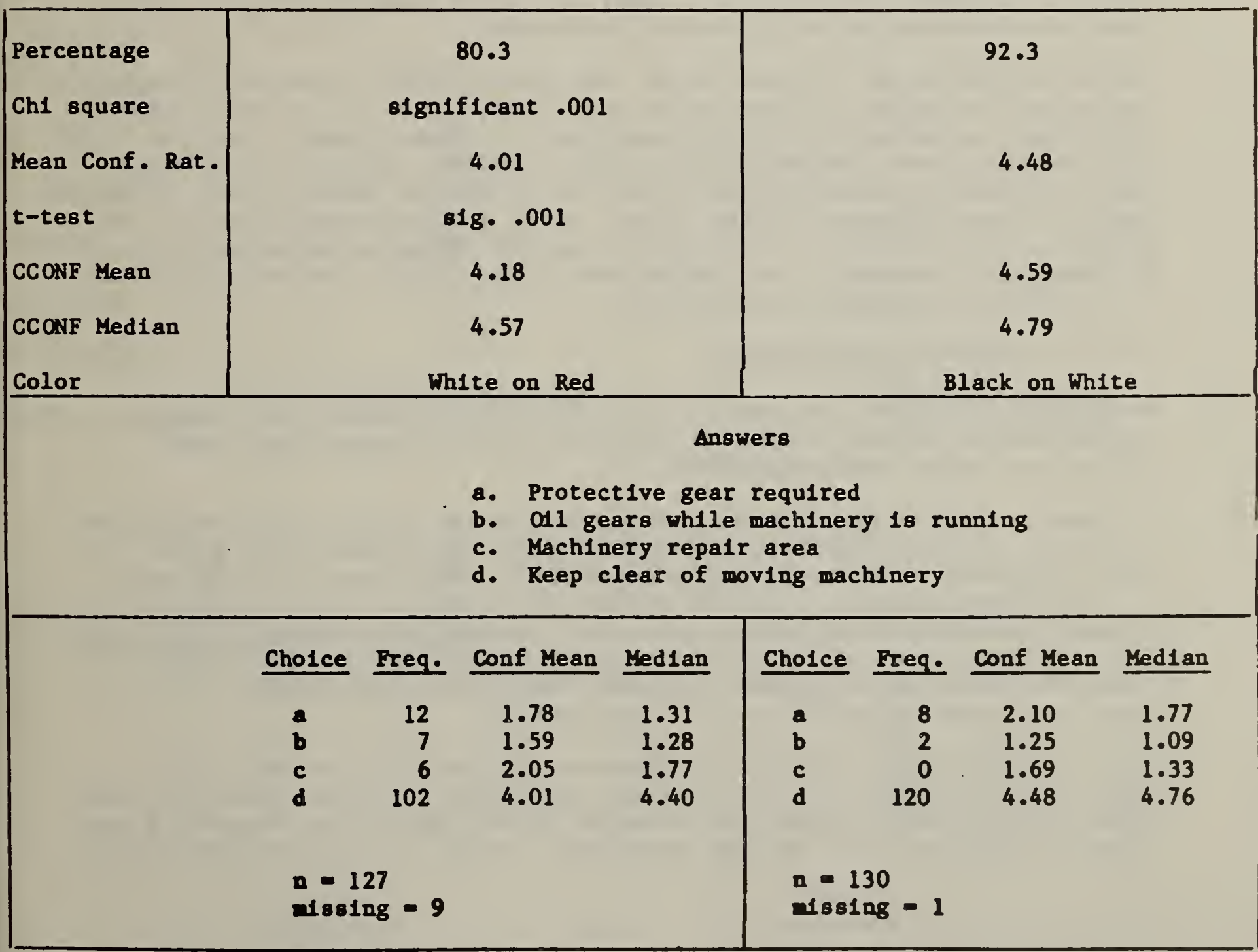


machinery is running". Addition of the hand to the gear graphic appears to have a noticeable, positive effect upon the effectiveness of this message.

\subsubsection{Prohibition Symbols}

For the first of the prohibition referents, Do Not Touch, figure 23, both candidate images were identified correctly by about 90 percent or more of those participating. Image 1 showing the whole hand received a significantly higher mean confidence rating ( 4.59 versus 4.32$)$ and a higher percentage of correct answers. Confusions for both images arose primarily for the answer, "do not lift objects manually," with a higher percentage (6.4) occurring for image 2. Although both images communicate their message well, use of the whole hand, rather than just a finger, appears to be more effective.

The circle, slash, and cigarette imagery for No Smoking, figure 24, was correctly identified by 95.8 percent of the participants. This image also received one of the highest mean confidence ratings -4.89 . Confusions, 2 percent, did arise for "smoking permitted"; however, this answer received a very low confidence rating $(1.18)$. This low rating suggests that the confusions may have been due to misreading the choices.

Similarly, the use of a circle, slash, and flame or match, resulted in high percentages of correct answers for No Open Flame, figure 25. No statistically significant differences emerged between the two images. Image 1 received 95.4 percent correct responses, and a mean confidence rating of 4.85 , while image 2 received a slightly lower percentage of correct answers, 94.5 percent, and lower mean confidence rating, 4.69. Only a few confusions arose for "no danger of fire" for image 2 ( 3 percent), and for "fires permitted in this area" for image 1 ( 2 percent). Both images thus appeared quite successful in terms of the three performance measures used.

\subsubsection{Protective Gear Symbols}

In general, all images for personal protective gear performed well, perhaps because miners are all required to wear such gear and because the images studied are highly representational.

For Head Protection Required, figure 26, both images received high percentages of correct answers- -96.9 percent for image 1, and 97.7 percent for image 2 . Mean confidence ratings were also high- -4.68 for image 1 and 4.65 for image 2. Wrong answers were elicited from only 1-2 percent of those responding. The answer, "Construction workers in the area," received mean ratings of 2.11 and 2.21 for images 1 and 2. Some miners commented that neither image showed the attachment for a cap lamp common to mining hard hats. Nevertheless, both images performed quite well on the three measures.

Similarly, both 1mages for Hearing Protection, figure 27, performed well. Image 1 was identified correctly by 96.2 percent and received a mean confidence rating of 4.75 , while image 2 was selected by 96.1 percent and received a confidence rating of 4.69. Minimal confusions ( 3.0 and 1.6 percent) were elicited 


\section{Pigure 23}

Do Not Touch
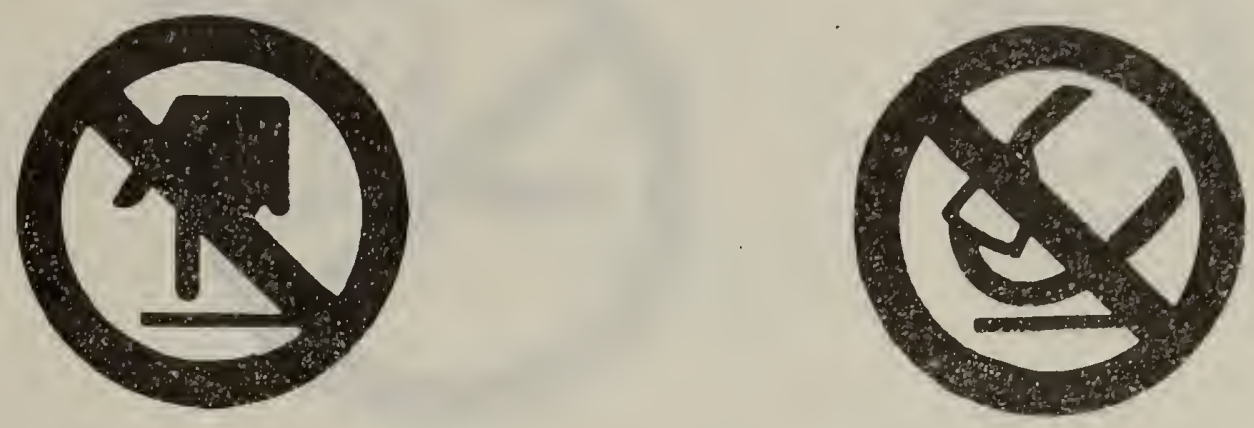

1

2

\begin{tabular}{|l|c|c|}
\hline Percentage & 80.3 & 89.6 \\
Ch1 square & NS & 4.32 \\
Mean Conf. Rat. & 4.59 & \\
t-test & $81 \mathrm{~g} . .05$ & 4.47 \\
CCONF Mean & 4.62 & 4.77 \\
CCONF Median & 4.82 & Black, White, Red \\
\hline Color & Black, White, Red & \\
\hline
\end{tabular}

Answers

a. Do not touch

b. Do not lift objects manually

c. Wear protective shoes

d. First ald location

\section{Cholce Preq. Conf Mean Median}

$\begin{array}{lrrr}\text { a } & 126 & 4.59 & 4.81 \\ \text { b } & 4 & 1.58 & 1.20 \\ \text { c } & 2 & 1.20 & 1.07 \\ \text { d } & 0 & 1.20 & 1.07 \\ & & & \\ \text { n }=132 & & & \\ \text { alse1ng }=4 & & \end{array}$

Cholce Freg. Conf Mean Median

$\begin{array}{rrrr}\text { a } & 112 & 4.32 & 4.73 \\ \text { b } & 8 & 1.47 & 1.19 \\ \text { c } & 3 & 1.20 & 1.08 \\ \text { d } & 2 & 1.54 & 1.22\end{array}$


Figure 24

No Smoking

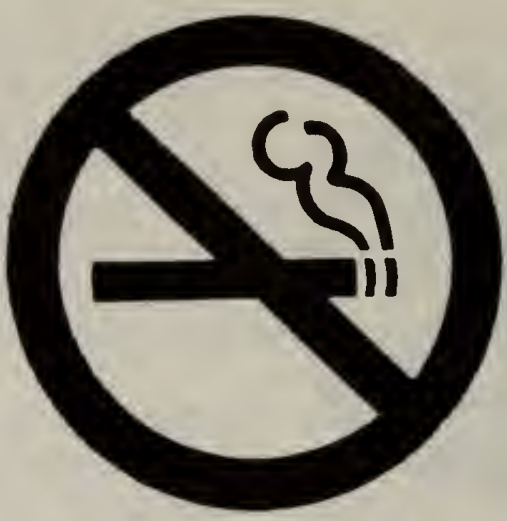

1

Percentage

95.8

ChI square

Mean Conf. Rat.

4.89

t-test

CCONF Mean

4.94

CCONF Median

Color

Black, White, Red

\section{Answer8}

a. Smoking permitted

b. Do not discard cigarettes here

c. Smoke only cigars

d. No smoking allowed

Cholce Freq. Conf Mean Median

$\begin{array}{llll}a & 6 & 1.18 & 1.05\end{array}$

$\begin{array}{llll}\text { b } & 3 & 1.98 & 1.54\end{array}$

$\begin{array}{llll}\text { c } & 2 & 1.20 & 1.07\end{array}$

$\begin{array}{llll}\text { d } & 249 & 4.89 & 4.97\end{array}$

n $=260$

aseing $=7$ 
F1gure 25

No Open Flame
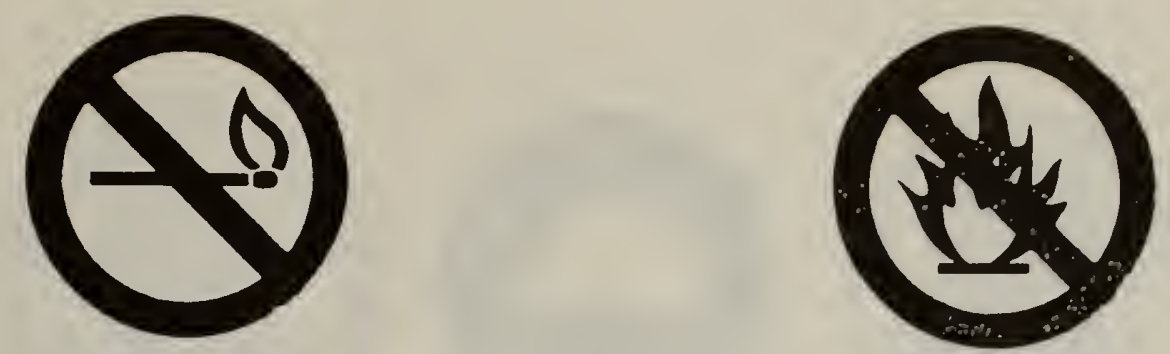

1

2

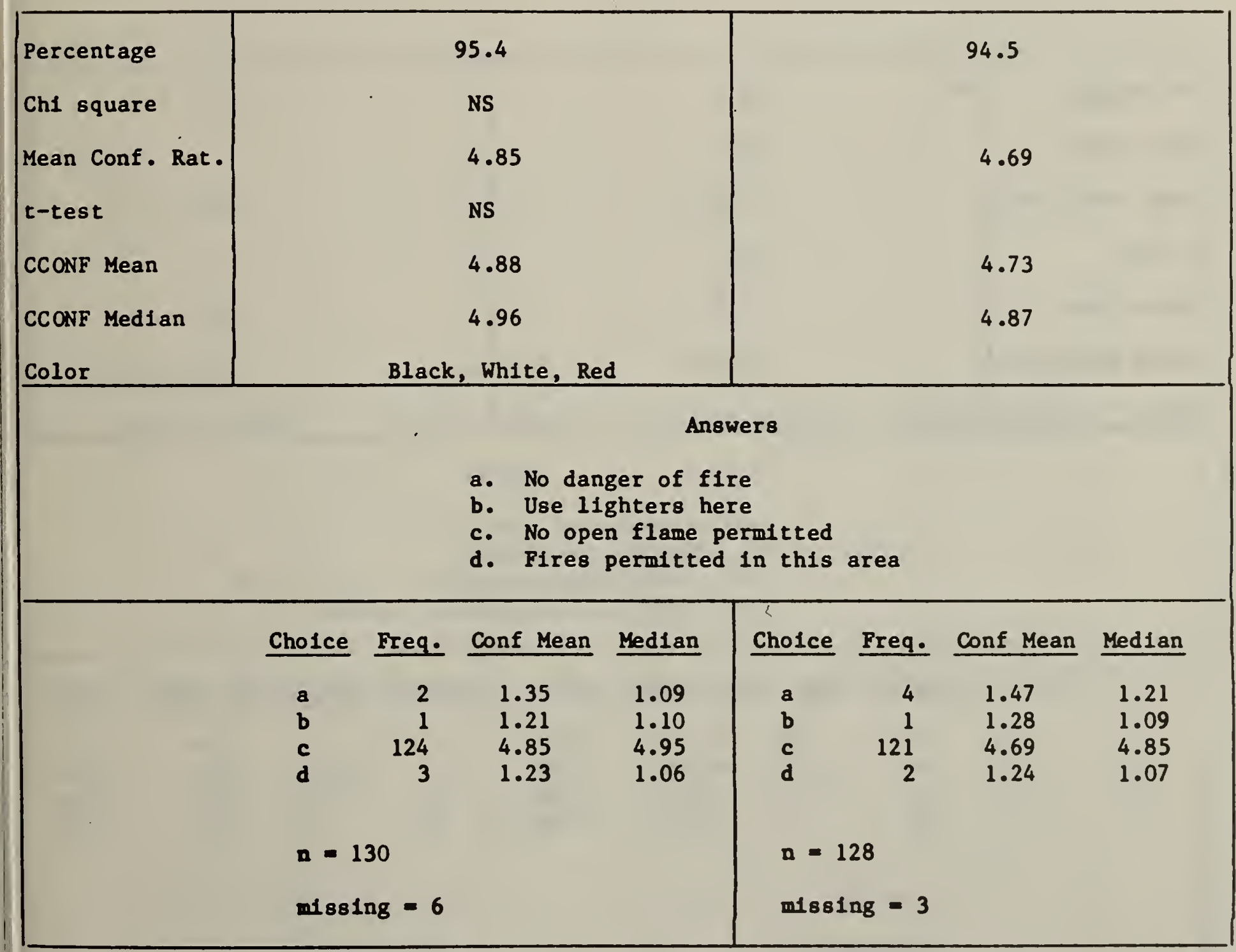




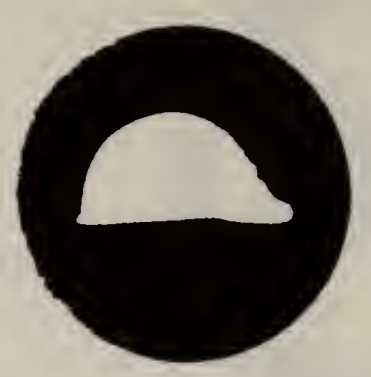

1

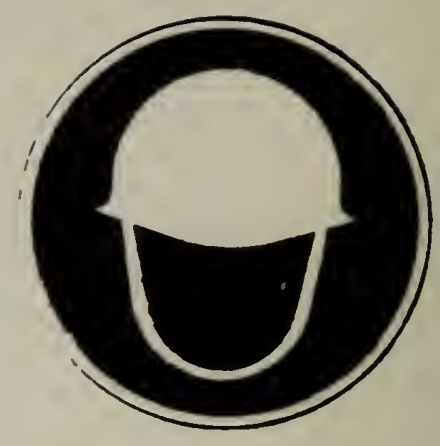

2

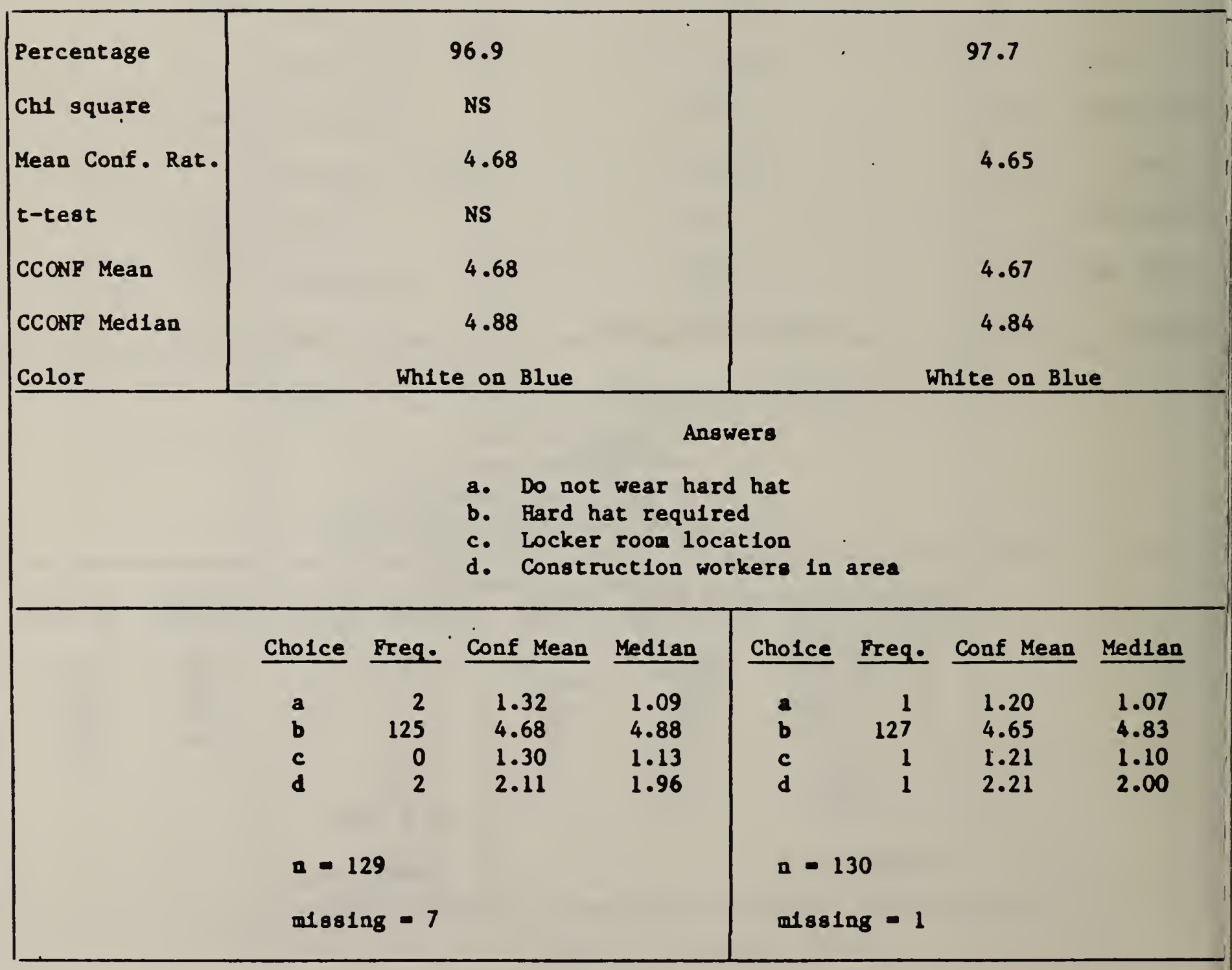




\section{P1gure 27}

\section{Hearlng Protect1on Required}

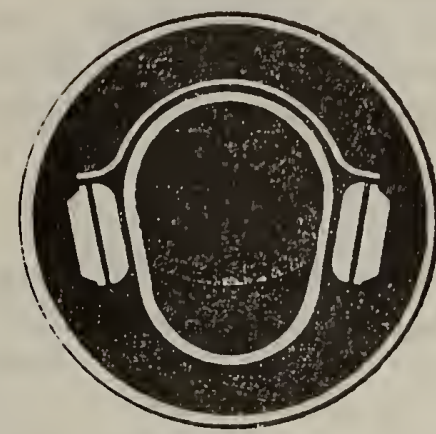

1

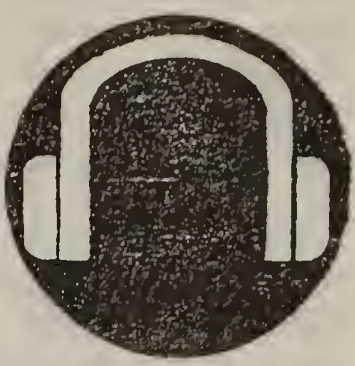

2
Percentage

Cht square

Mean Conf. Rat.

t-test

CCONP Mean

CCONF Median

Color

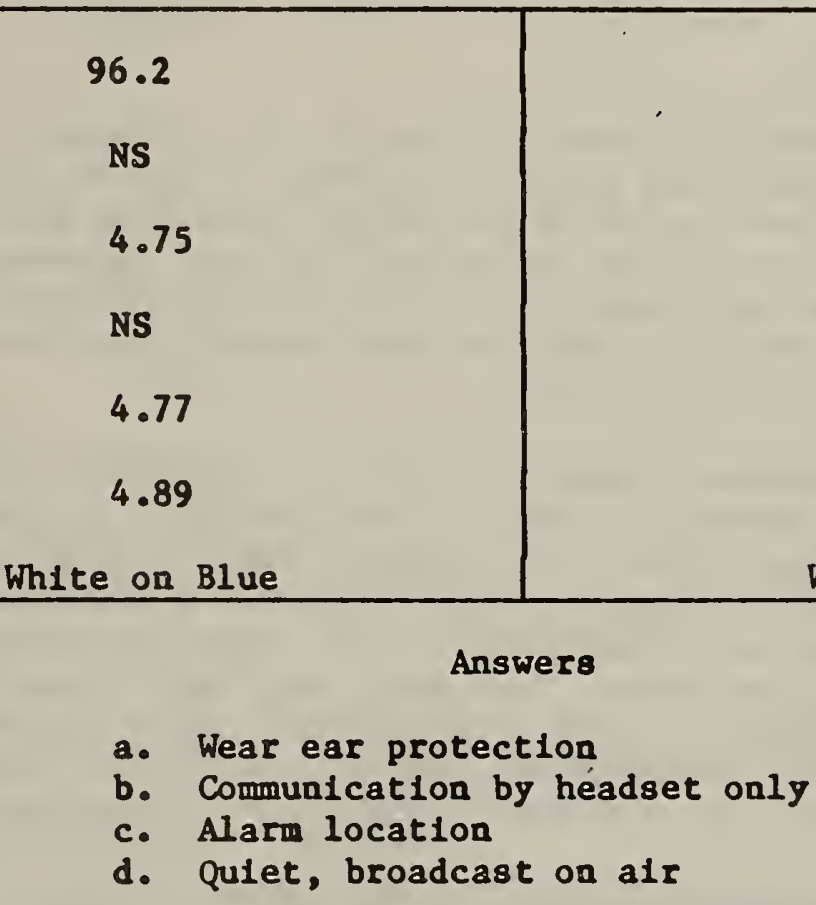

Cholce Freq.: Conf Mean

$\begin{array}{rrrr}\text { a } & 127 & 4.75 & 4.89 \\ \text { b } & 4 & 2.25 & 2.14 \\ \text { c } & 1 & 1.34 & 1.13 \\ \text { d } & 0 & 1.58 & 1.30\end{array}$

n $=132$

mfssing $=4$
Cholce Freq. Conf Mean Median

$\begin{array}{lll}\text { a } & 124 & 4.69\end{array}$

b 22.29

c $\quad 1 \quad 1.26$

d $\quad 2 \quad 1.64$

4.87

2.12

1.11

1.29 
by answer 2 "communications by headset only" which also received mean confidence ratings of about 2.2 .

For Eye Protection, figure 28, both images were generally identified correctly with 96.9 percent correct responses for image 1 and 96.2 percent for image 2 . Mean confidence ratings were also high--4.70 for image 1 and 4.61 for image 2 . The frequency of wrong answers was small, with only four incorrect answers for image 1 and five for image 2. Image 2 did receive higher confidence ratings for all incorrect answers than did image 1 .

For Safety Shoes Required, figure 29, image 2 performed significantly better with 97.7 percent correct responses and a mean confidence rating of 4.70 , compared with 88.8 percent correct and 4.15 for 1mage 1 . Image 2 also received only three incorrect answers. Image 1 recelved about 5 percent responses for the answers, "rubber boots required", and "leave shoes here." The incorrect alternatives for image 1 all received higher mean confidence ratings, as well. Again several miners commented that image 2 was a more realistic depiction of safety footgear. Certainly, it recelved a significantly higher percentage of correct answers.

For Hand Protection Required, figure 30, both images recelved a high percentage of correct answers ( 92.2 percent for 1mage 1 and 95.3 percent for 1mage 2) and high confidence ratings ( 4.49 for image 1 and 4.58 for 2 ). In addition, image 1 , showing one glove alone, received 7 percent responses for answer d, "stop here" and a mean confidence rating of 2.04--the highest for any of the choice alternatives. Similar confusions were reported for the image of one glove alone in Collins et al. (1982).

Images for Respirator, figure 31, did not perform as well as those for the other protective gear messages. Image 2 recelved 83.2 percent correct responses, and a mean confidence rating of 4.49 , while 1mage 1 received 70.6 percent correct responses, and a confidence rating of 4.13. A significant difference between the images occurred for both the $\chi^{2}$ and $t$-test measures. Confusions arose for both images for the answer "face mask required," which was chosen by 27.8 percent and 15.2 percent of the participants, and recelved mean confidence ratings of 3.59 and 3.74. Although an apparently plausible alternative, this answer does not indicate the need for respiratory or breathing protection.

\subsubsection{Safety Equipment and Fire Emergency Symbols}

Images for both safety equipment location and fire emergency messages were studied. With the exception of Safety Shower and Fire Alarm Call Point, all images were generally identified correctly.

A significant difference in the percentage of correct responses emerged between images 1 and 2 for First Aid, figure 32. Image 2 recelved 95.9 percent correct responses, while 1mage 1 recelved only 84.2 percent. The mean confidence ratings, 4.59 and 4.52 respectively, were about the same for both, however. Confusions arose for image 1 with the answer "safety training location" ( 10.5 percent response and mean confidence rating of 2.41.) Although the frequency of selecting this answer was much lower for image 2 ( 1.6 percent), the mean 
P1gure 28

Eje Protection Required

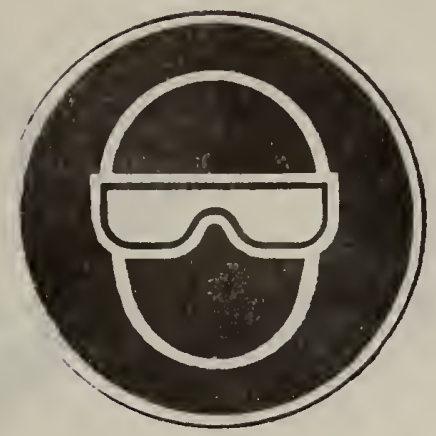

1

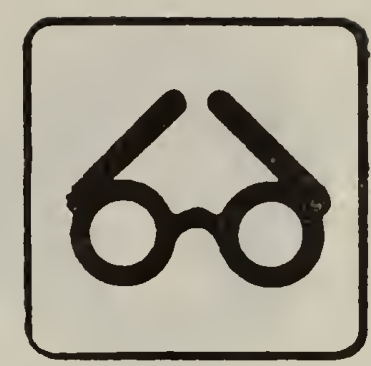

2

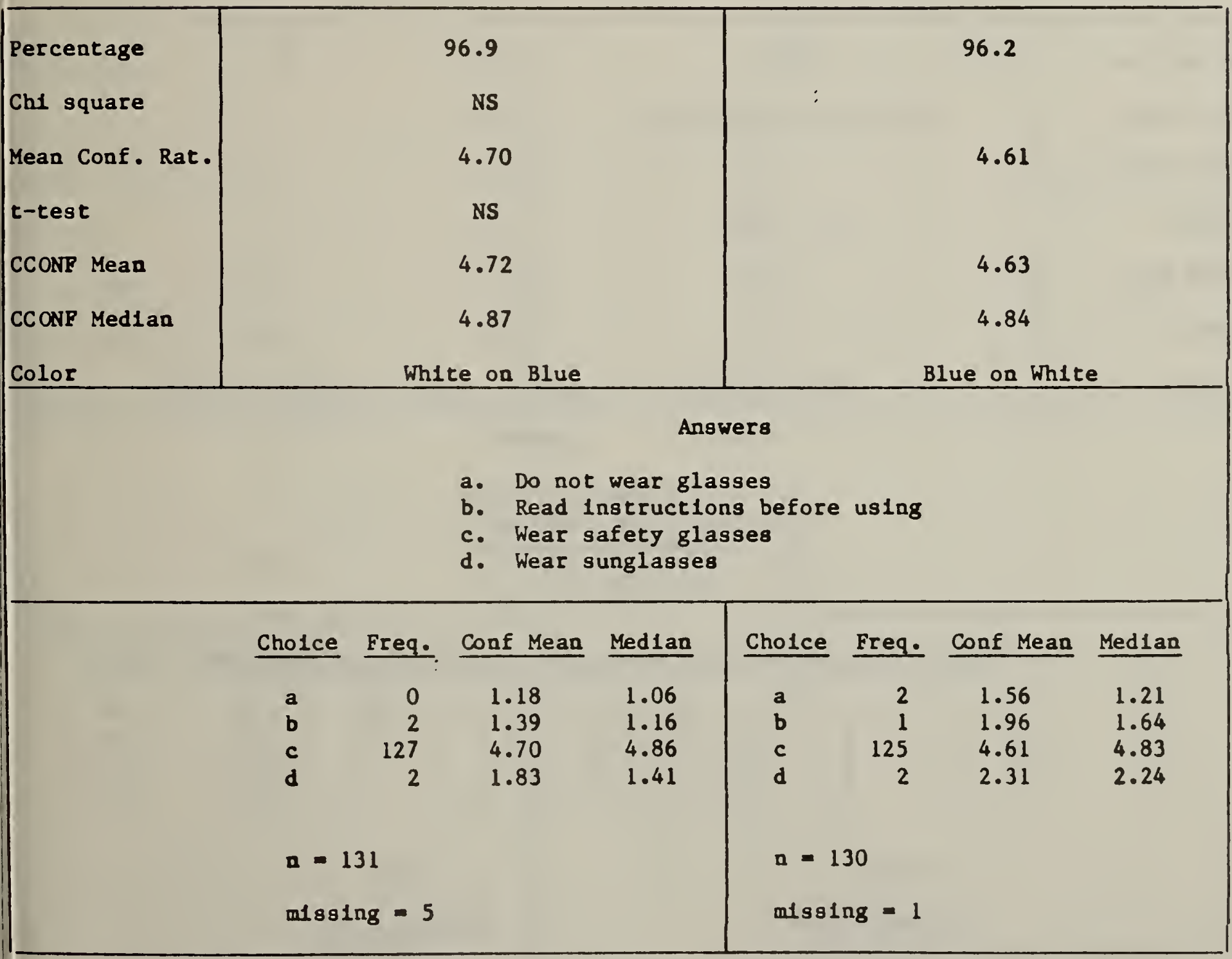




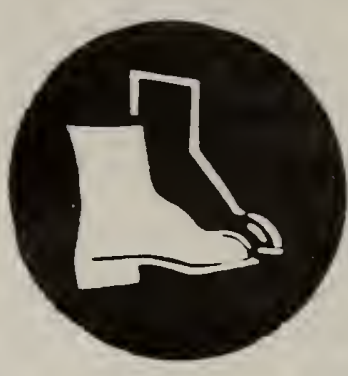

1

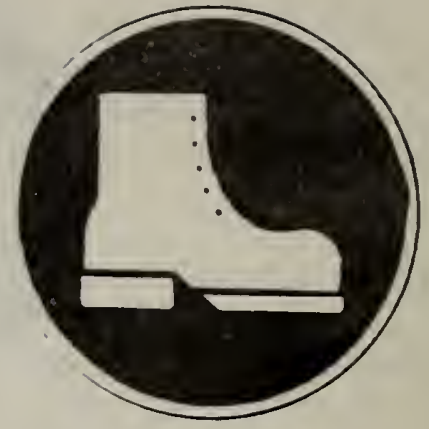

2

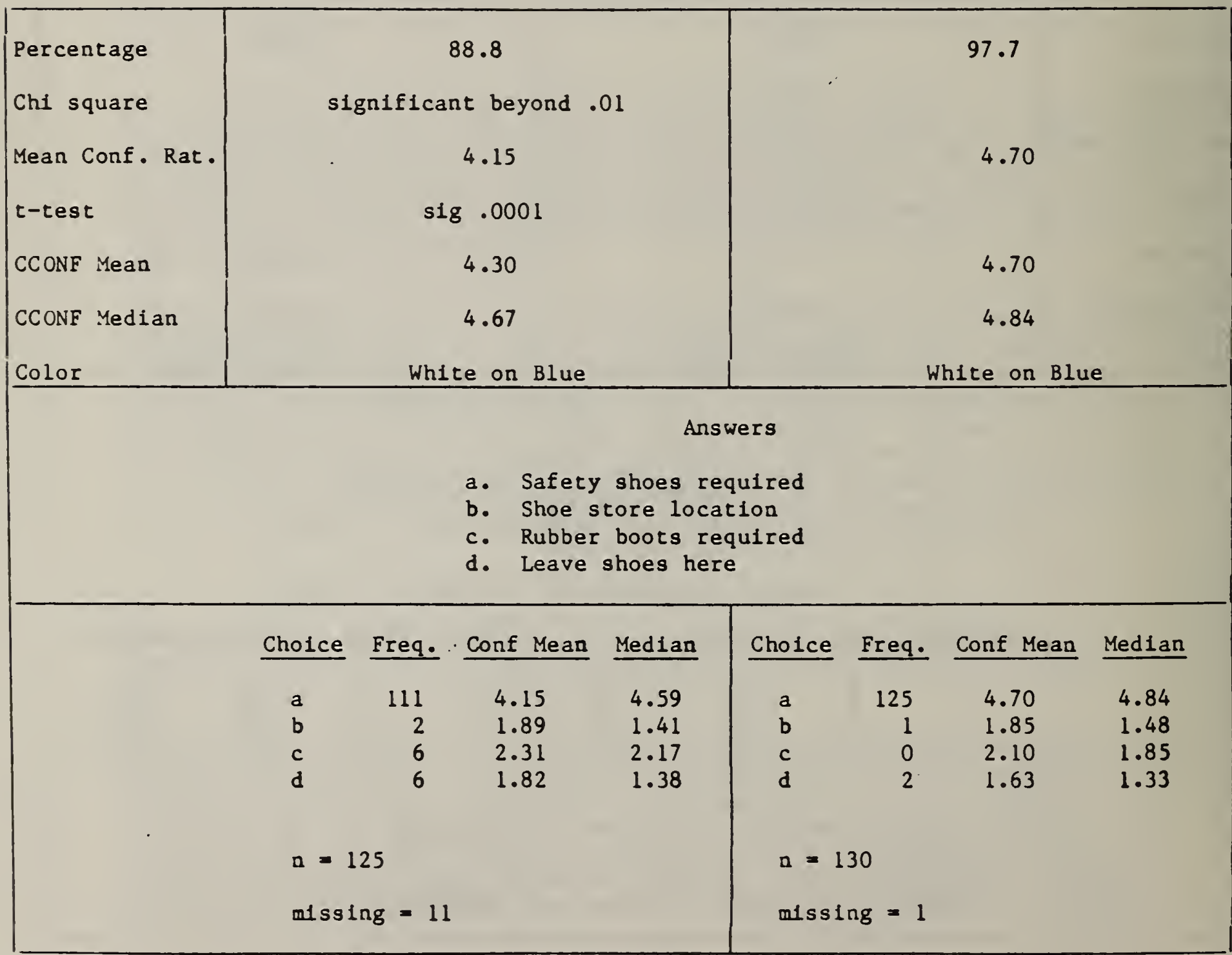


P1gure 30

Band Protection Required
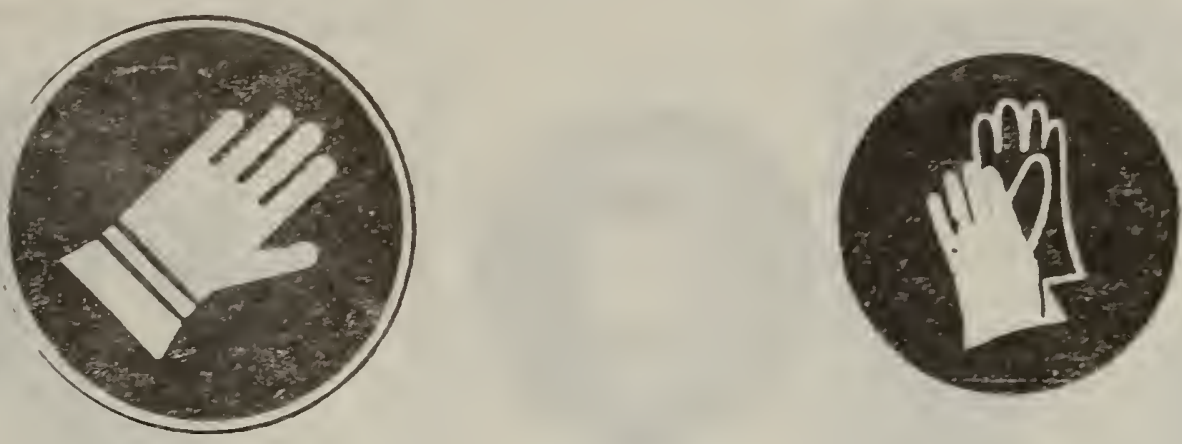

1

2

\begin{tabular}{l|c|c}
\hline Percentage & 92.2 & 95.3 \\
Cht square & NS & \\
Mean Conf. Rat. & 4.49 & 4.58 \\
t-test & NS & \\
CCONF Mean & 4.62 & 4.59 \\
CCONF Median & 4.82 & 4.79 \\
Color & White on Blue & \\
\hline
\end{tabular}

\section{Answers}

a. Turn this way

b. Safety gloves required

c. Wash hands here

d. Stop here

Cholce Freq... Conf Mean Median Cholce Freq. Conf Mean Median

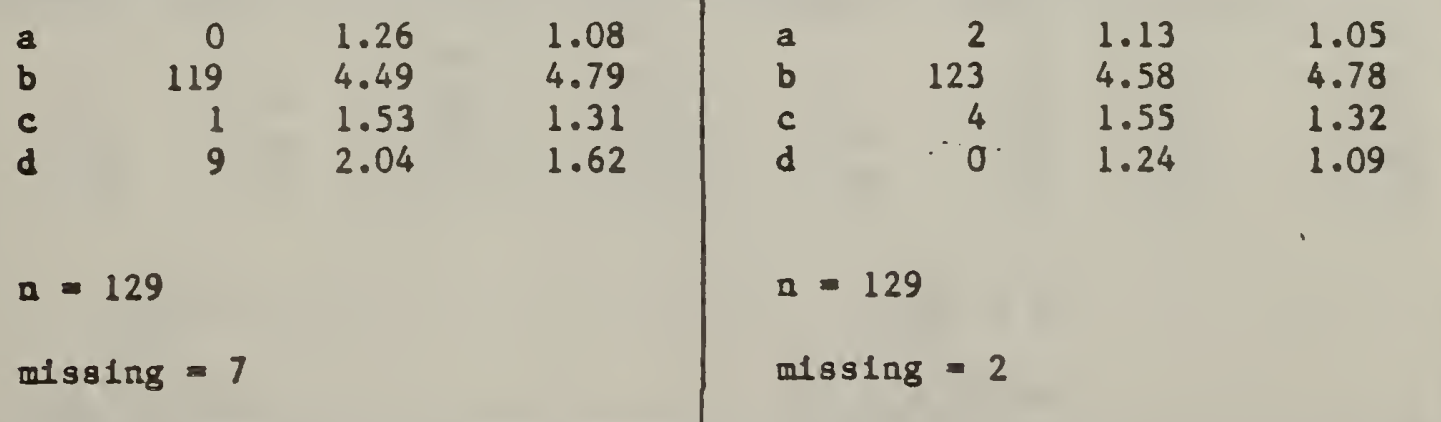


Figure 31

Respiratory Protection Required
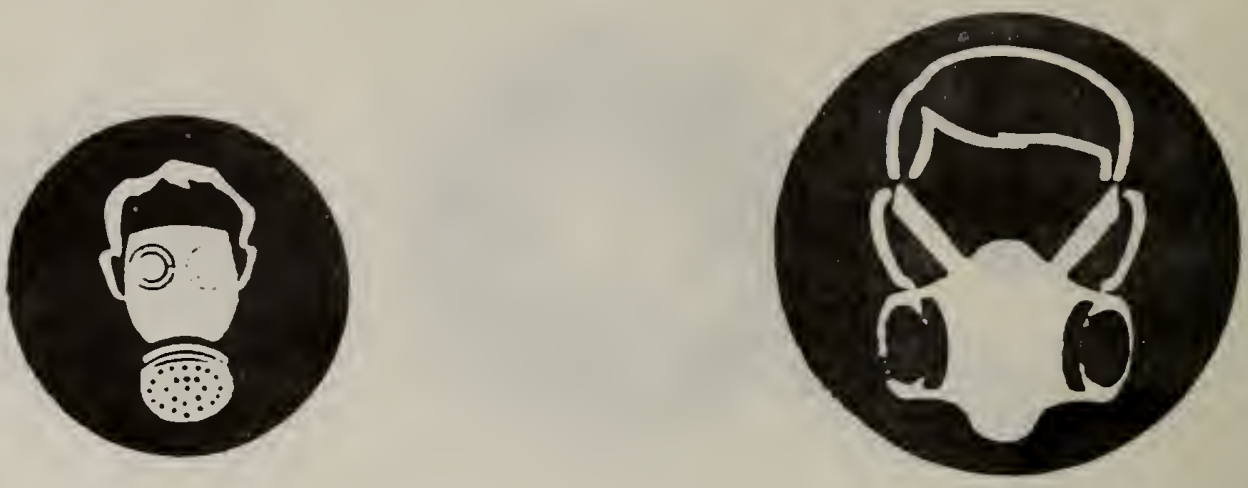

1

2

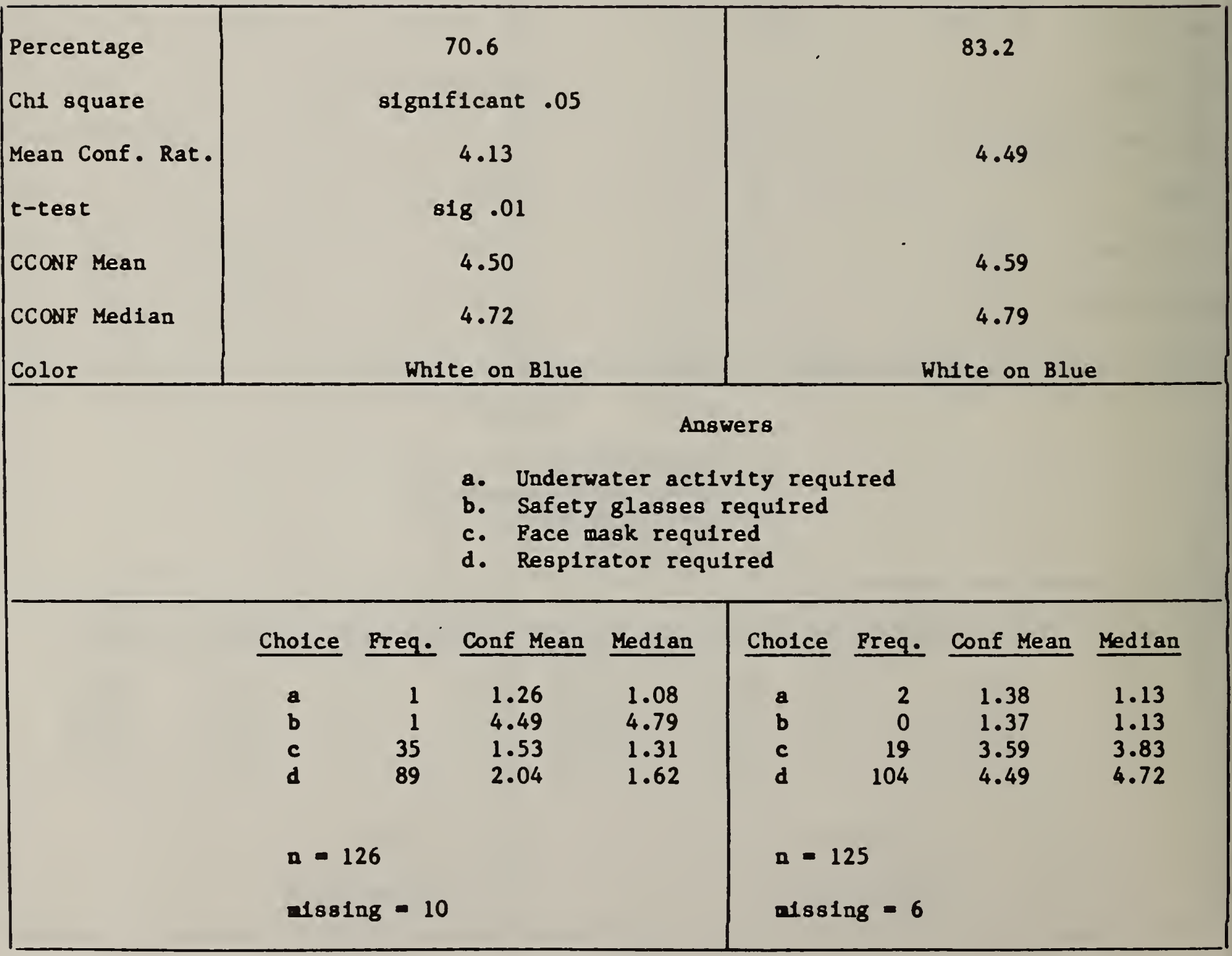


Pigure 32

Firet Ald Location
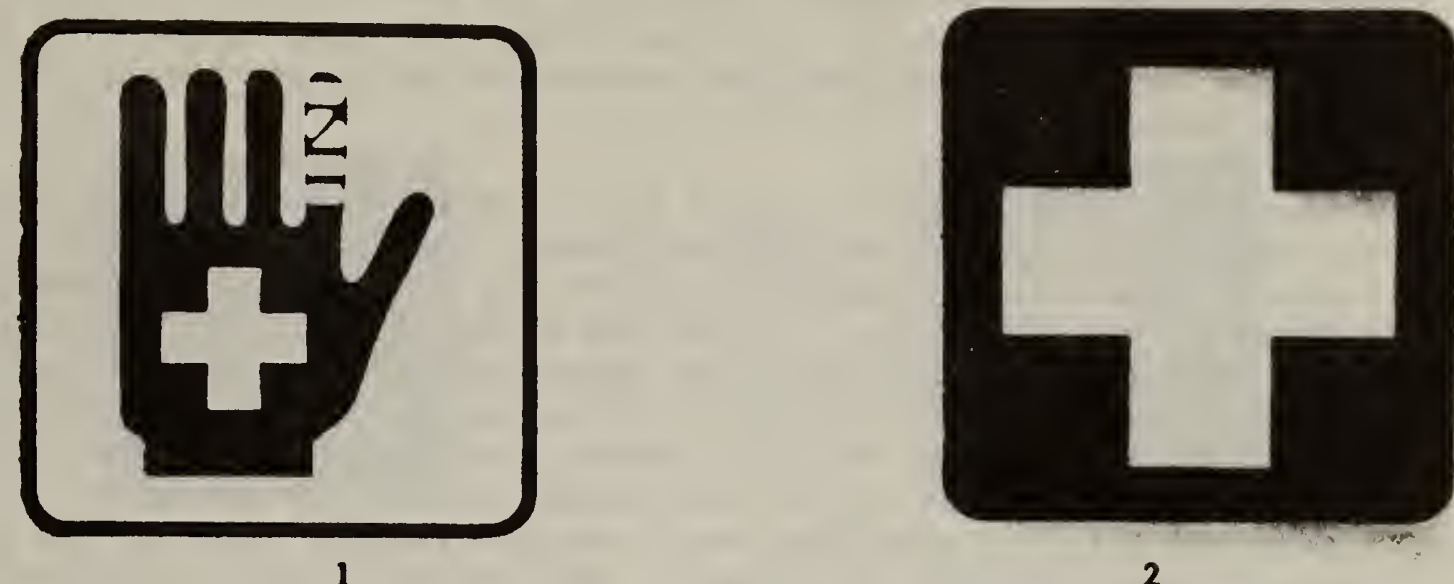

2

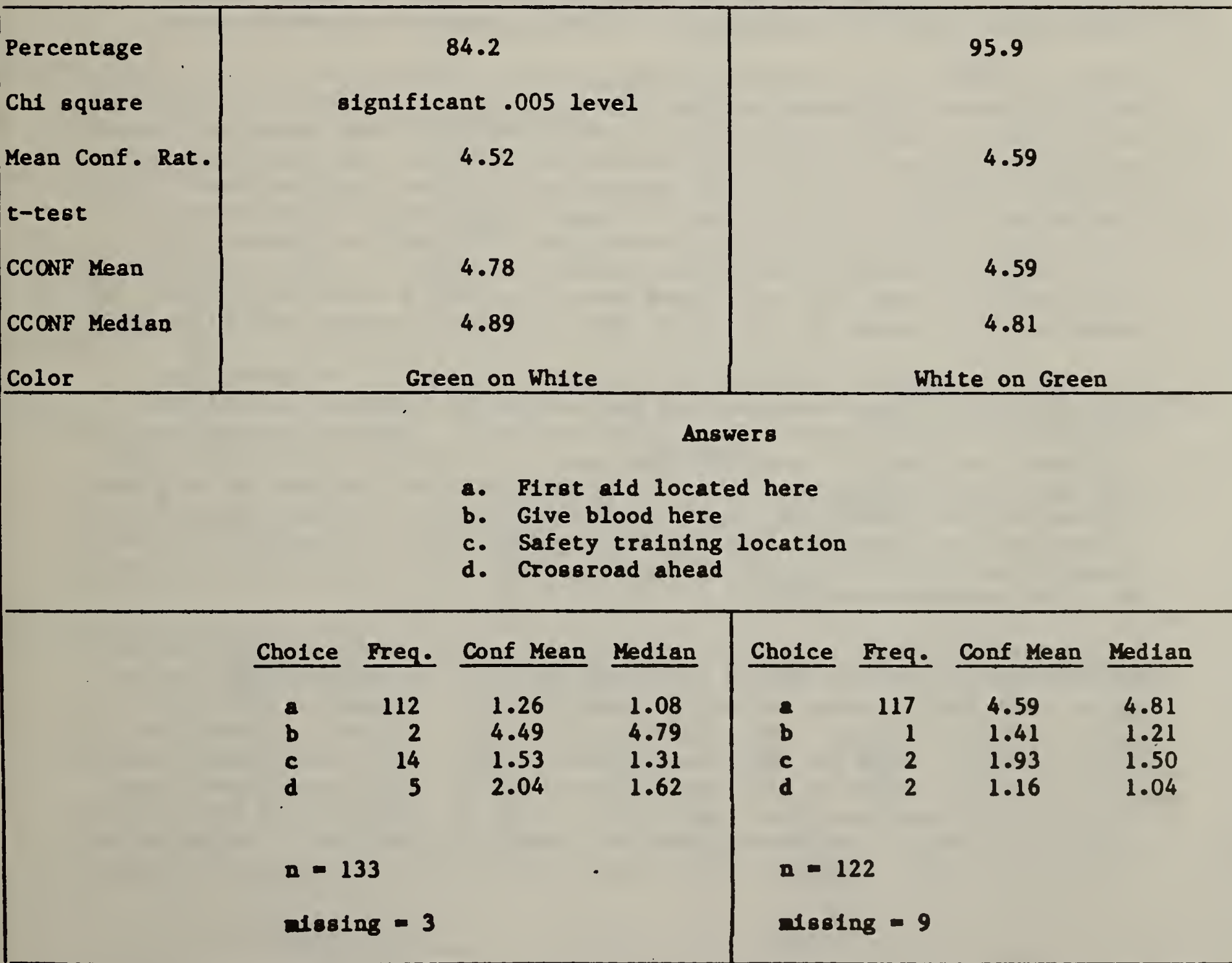


confidence rating was somewhat similar (1.93). Because the white cross and green background is frequently used at mines to indicate the safety office and its activities, a few miners commented that the color of the first aid sign should perhaps be red. On the other hand, this color might lead to confusions with the "Red Cross" society (as opposed to the green cross of the National Safety Council).

Image 2 for Safety Shower, figure 33, was more successful than image 1 in terms of the measures used. Image 2 was identified correctly by 86.9 percent, while image 1 was only identified by 65.5 percent of those participating. This difference was significant. While the confidence rating for image 2 was higher ( 4.32 versus 4.00 ), this still was relatively low. Image 1 received a fairly high percentage (18.8) of choices for answer d, "sprinkler system control" while image 2 received only 9.3 percent for this choice. Mean confidence ratings for " $d$ " were 3.11 and 1.33 respectively. In addition, seven percent of the participants selected "watch out for falling objects" for image 1 and "locker room location" for image 2. The somewhat poor performance of these symbols may be attributable to the relative infrequency of safety showers within mines themselves, as opposed to mills or chemical processing areas.

Similar comments may be made for Eyewash, figure 34, although the two images for this referent performed somewhat better. Image 1 was correctly identified by 91.3 percent while image 2 , a more abstract version, was identified correctly by only 68.5 percent. This difference was significant. The rather low mean confidence ratings, 4.32 and 3.90 respectively, may indicate the miners' relative unfamiliarity with this concept. Image 2 received a number of answers (23.8 percent) for "eye irritant," which also had a mean confidence rating of 2.54. Only 2.4 percent selected this answer for image 1. About 5-6 percent of the miners indicated that both images meant "wear eye protection". Again, eyewashes are more common in processing areas rather than mining/production areas.

Both Fire Extinguisher, and Fire Hose and Reel, figure 35, received high percentages of correct answers ( 96.2 percent and 92.3 percent) as well as reasonably high confidence ratings ( 4.86 and 4.62 ). Fire extinguisher received 2.6 percent choices for "gasoline pump location," although this answer also received a low confidence rating (1.35) suggesting that the majority of miners did not consider this to be a reasonable alternative. For "fire hose and reel" confusions were related to "hot radiator located here" ( 4.2 percent) and "high pressure area" (2.3 percent). Both images, however, performed well in terms of the three performance measures.

Fire Alarm Call Point, figure 36, however, appears to be both an unclear and unnecessary referent for mining applications. Neither image was well understood, with image 1 being correctly identified by 56 percent of the miners and image 2 by 64.3 percent. Both images received low confidence ratings also, 3.60 and 3.82. These two images work almost as well for "noise hazard" (answer c) with image 1 receiving 29.6 percent responses for this choice, and image 2 receiving 33.3 percent. Mean confidence ratings for noise hazard were 2.86 and 3.05 respectively. The images appear to communicate the idea of noise but not the message of "call point". In conversations with miners and safety personnel, 
P1gure 33

Safety Shower Location
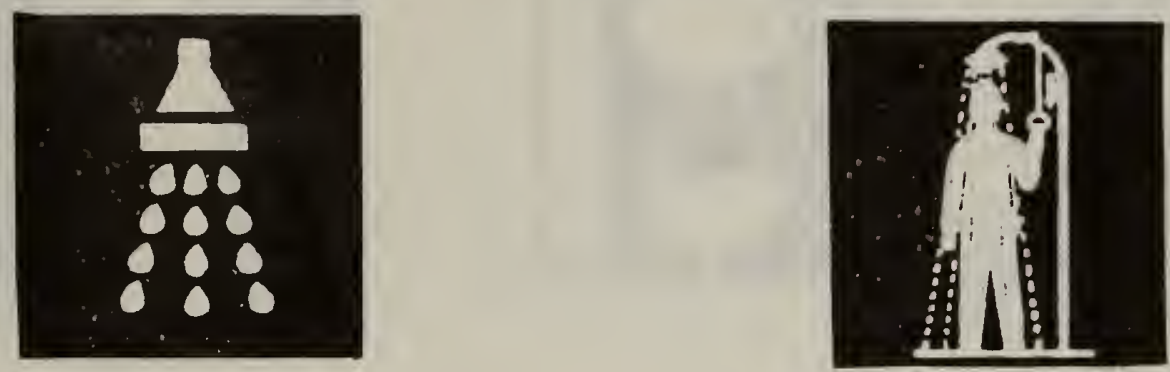

1

2

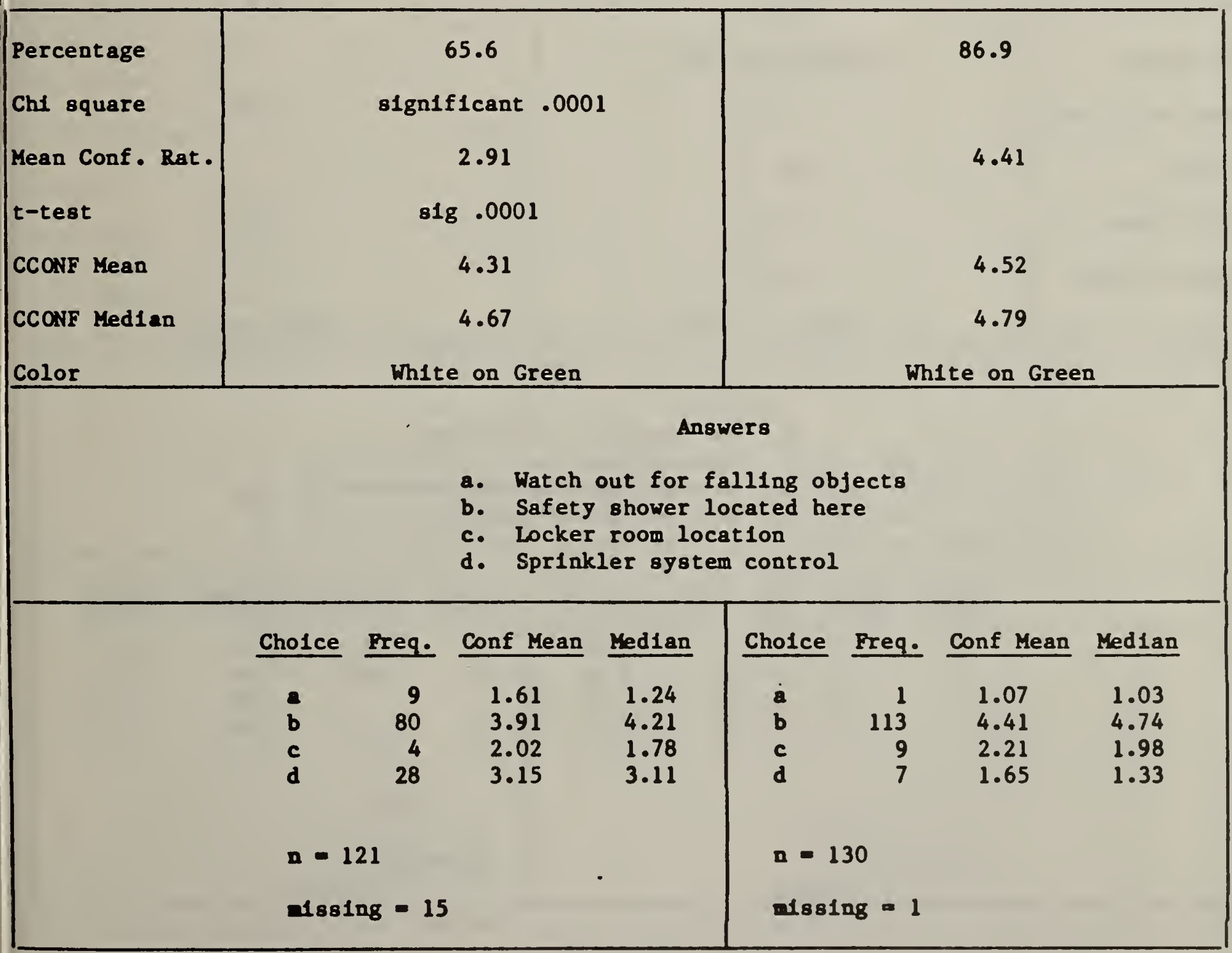


Figure 34

Eyewash Location
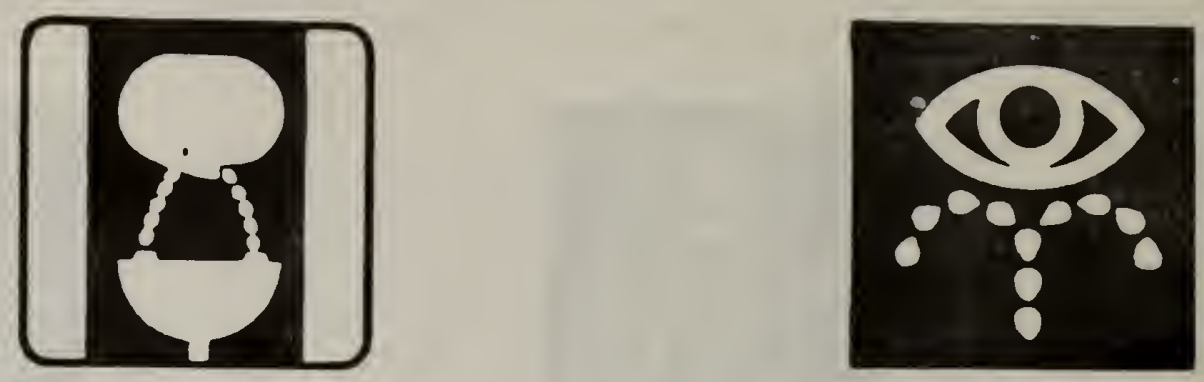

1

2

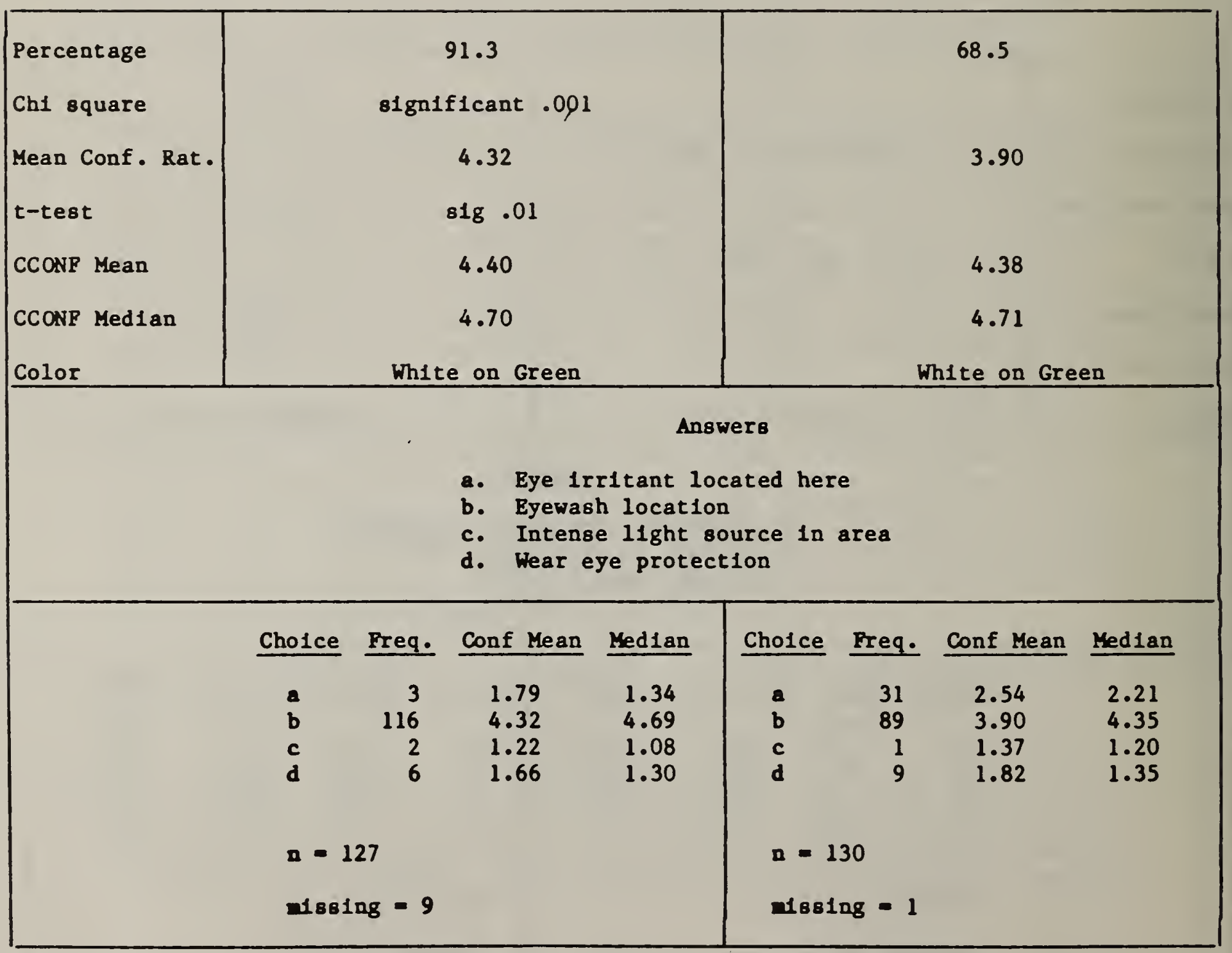


P1gure 35

P1re Ext1ngulsher Location

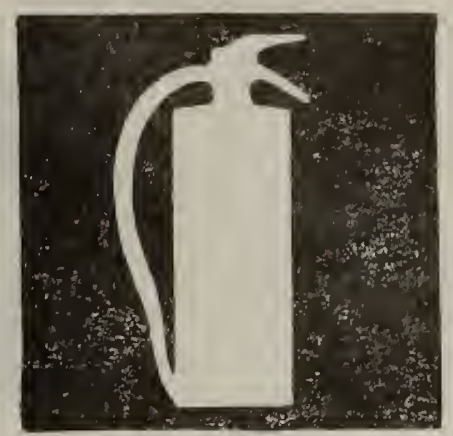

1
Fire Bose and reel

Location

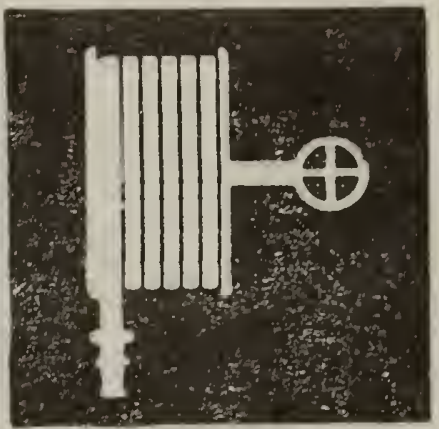

2

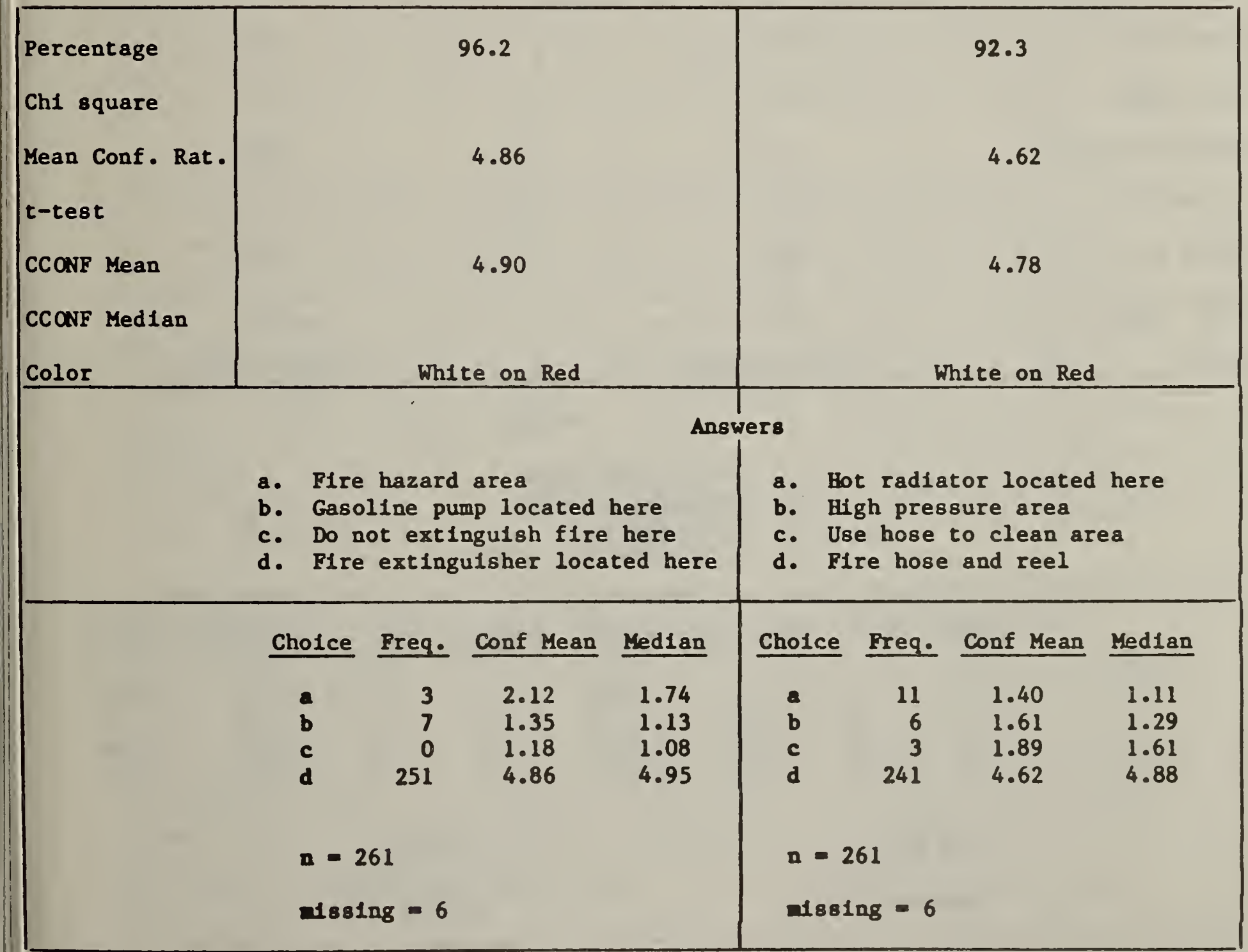


F1gure 36

P1re Alarm Call Point
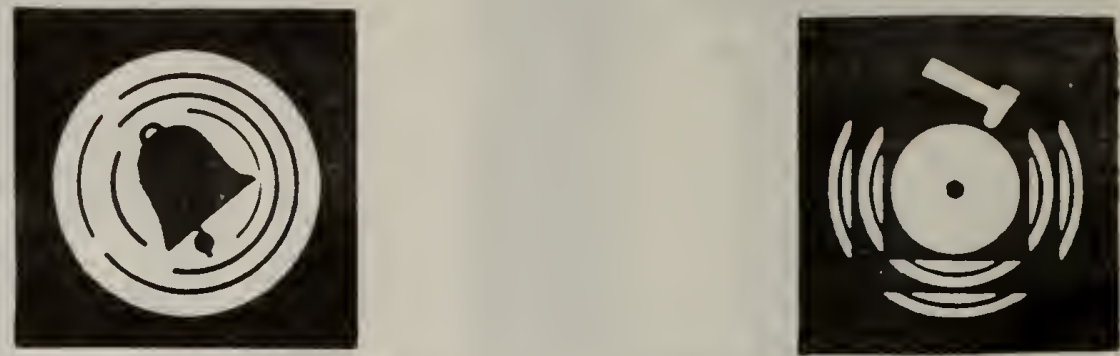

1

2

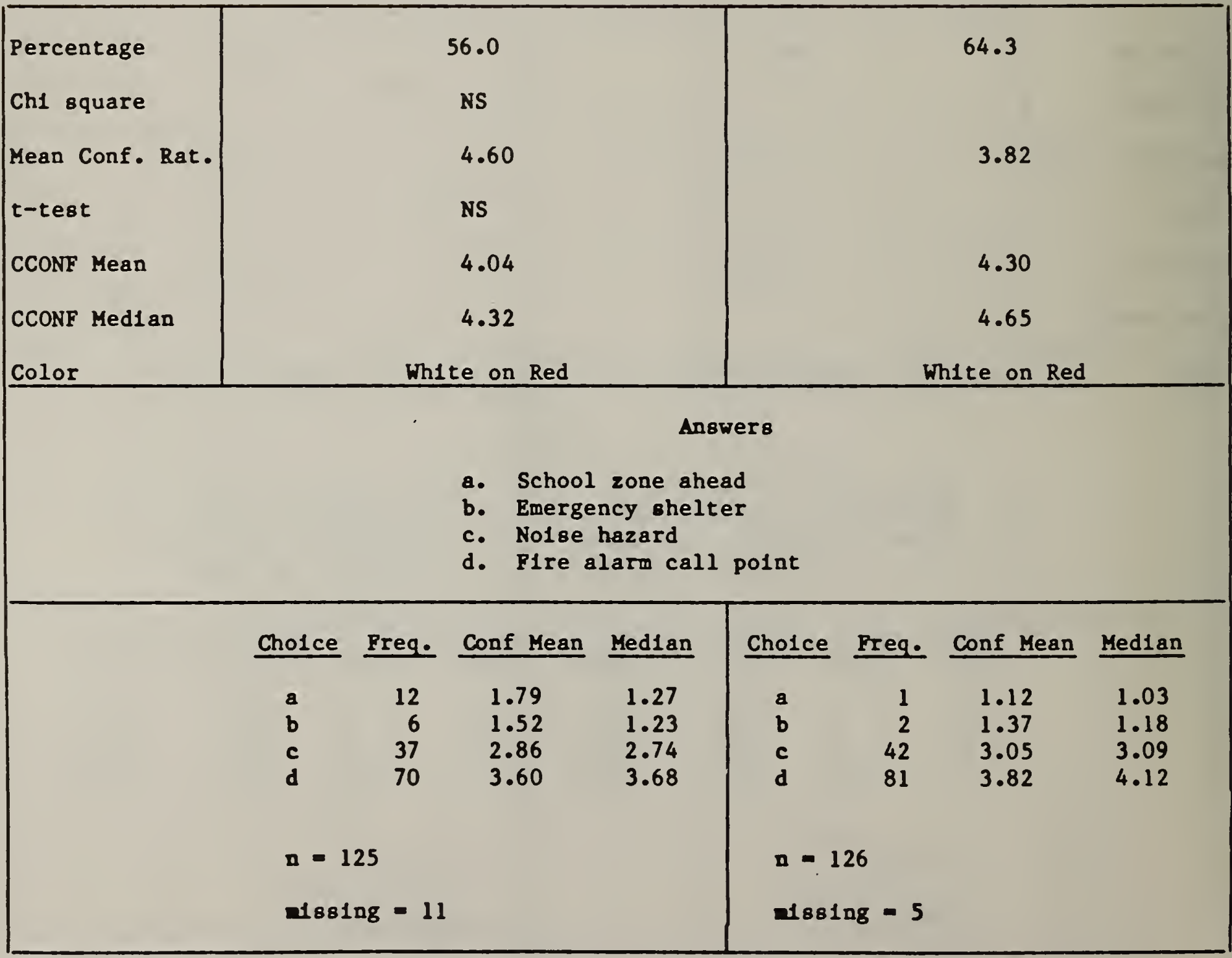


this referent did not appear to be as necessary as one for "alarm location" - a message for which the two images tested are not really appropriate.

\subsubsection{Egress Related Symbols}

All mines are required by MSHA to have "exit ways" clearly marked. At this point, only word signs are required, so that there would be no need to "unlearn" a set of symbol signs. The possibility thus exists for researching the feasibility of different symbol signs for egressways and selecting the one that performs best. As a result, four images were studied for the referents Exit and Emergency Exit, with the implicit assumption that both messages could indicate an exit way from the mine to the outside.

For the referent Exit, figure 37, there was a large and significant difference between the two images studied. Image 1 was correctly identified by 72.1 percent and received a mean confidence rating of only 3.78. Image 2, however was identified by 91.5 percent of those participating and received a confidence rating of 4.35. Image 1 also received 27.1 percent responses for "no passageway, dead end" - an opposite meaning. This answer also got a mean confidence rating of 2.49. This critical confusion suggests that image 1 should not receive further consideration as an "exit" marker. Image 2 received only 4.6 percent responses for this wrong answer with a mean confidence rating of 1.38 .

The two images studied for Emergency Exit, figure 38, also elicited similar differences, with image 1 performing significantly better than image 2 . Image 1 , a privately copyrighted symbol (Yanone, 1979), was identified correctly by 89.3 percent of those participating, and given a relatively low confidence rating of 4.18 . Image 2 , however, received an even lower confidence rating (3.34) and a low percentage of correct responses ( 55.7 percent). Both images received a number of responses for "do not run" ( 9.2 percent for image 1 , and 19.7 percent for image 2, with confidence ratings of 1.72 and 2.20 respectively). A sizable number of people (20.5 percent) also selected answer d, "no way out" as their choice for image 2. This critical confusion received a mean confidence rating of 2.13 . Image 2 clearly does not convey the message of "emergency exit" successfully to those people who participated in this study. Furthermore, of the four exit images studied, image 2 of Figure 37 appears to be the most successful. It received the highest percentage of correct answers, highest confidence rating, and lowest number of confusions.

In addition, a version very similar to this has been proposed to ISO for consideration as an "exit - emergency exit" symbol by the Japanese (1980).

The two images studied for No Exit, figure 39, were not particularly successful in terms of percentage correct and mean confidence rating, with image 1 receiving 81.1 percent correct resposes and a mean confidence rating of 4.29 , and image 2 receiving 69.5 percent and a rating of 4.00 . Neither symbol thus was particularly effective in communicating the message of No Way Out or No Exit. Confusions for image 1 arose primarily for answer b, "keep door closed" (13.4 percent, mean rating 2.48) while those for image 2 were related primarily to answer d, "no running", (21.9 percent, and 2.43). The relatively poor performance of symbols for this message, also seen in other NBS studies, may 
P1gure 37

Exit

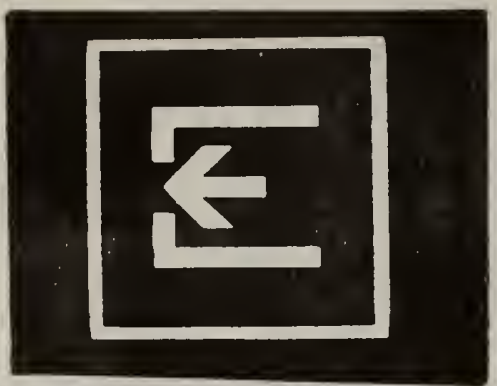

1

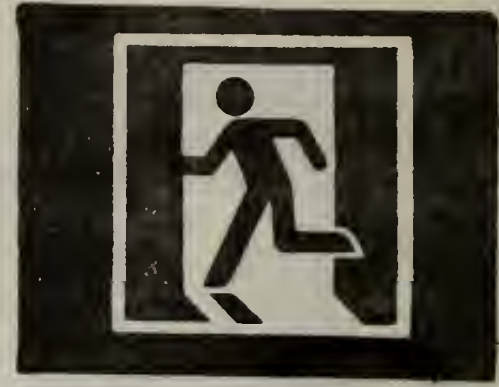

2

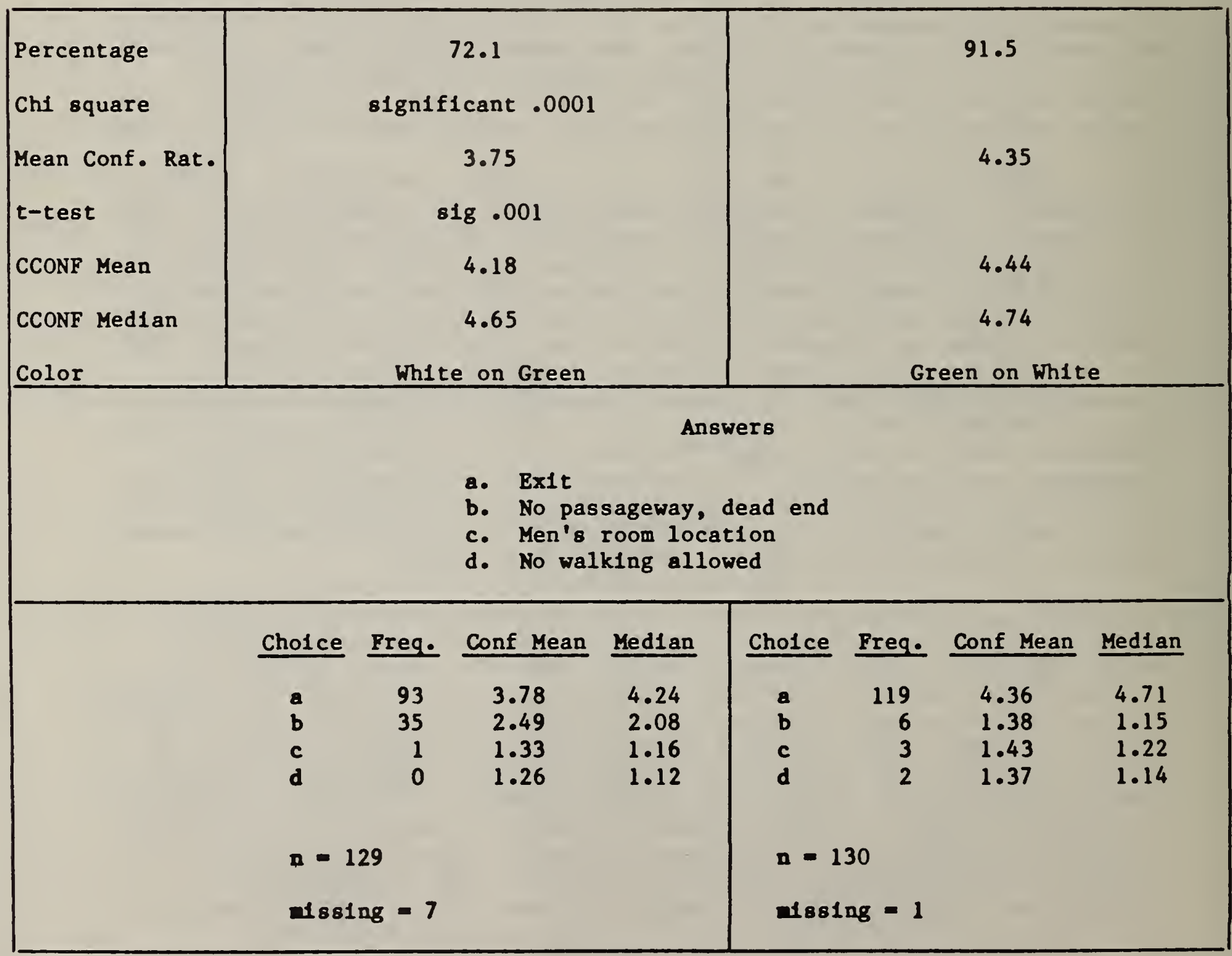




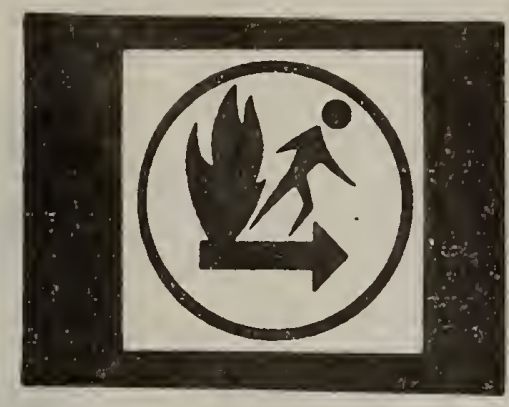

1

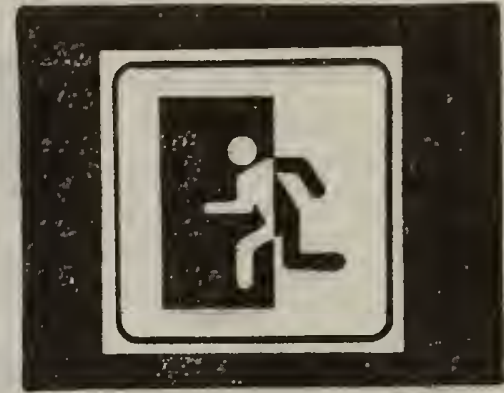

2

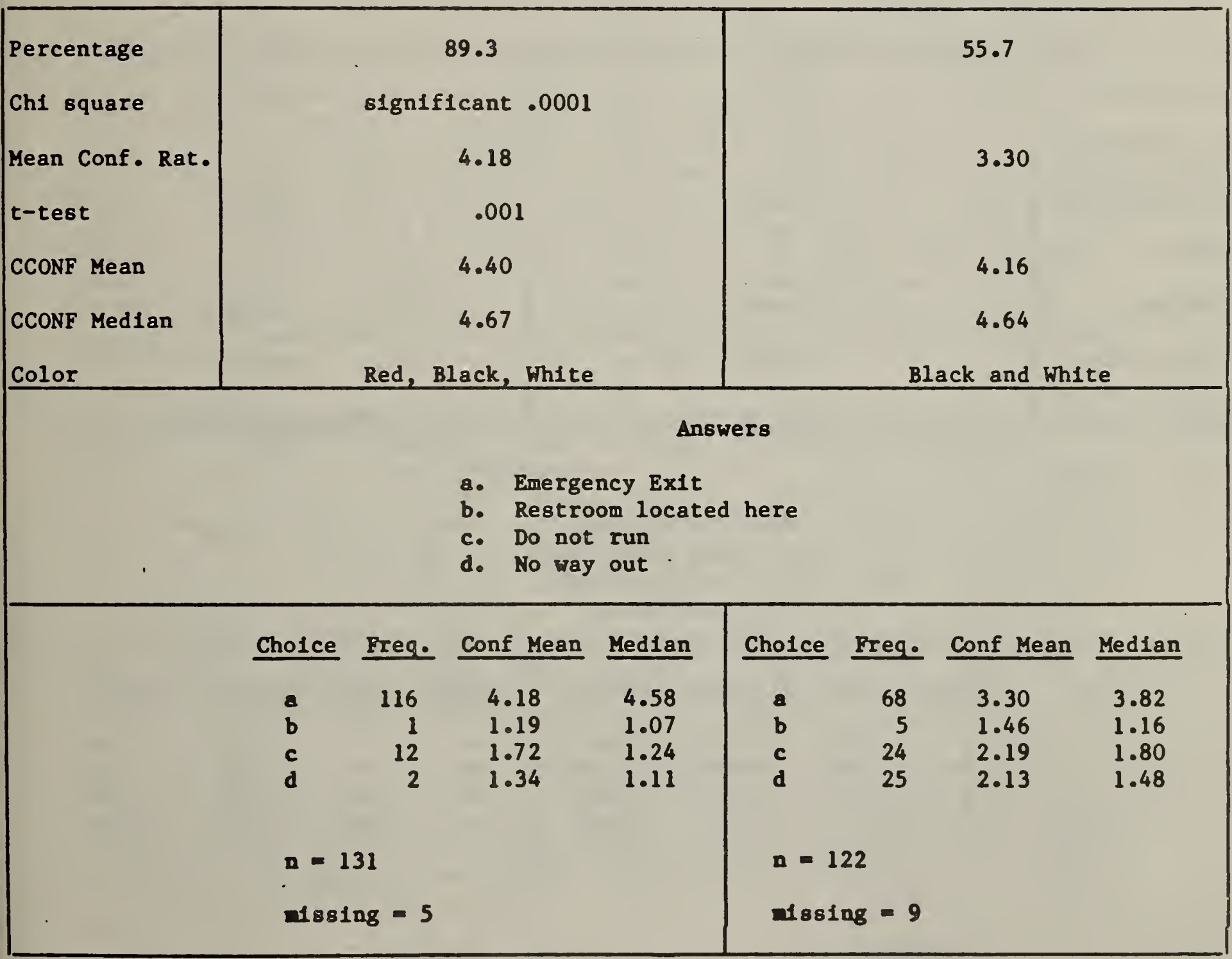


Figure 39

No Exit
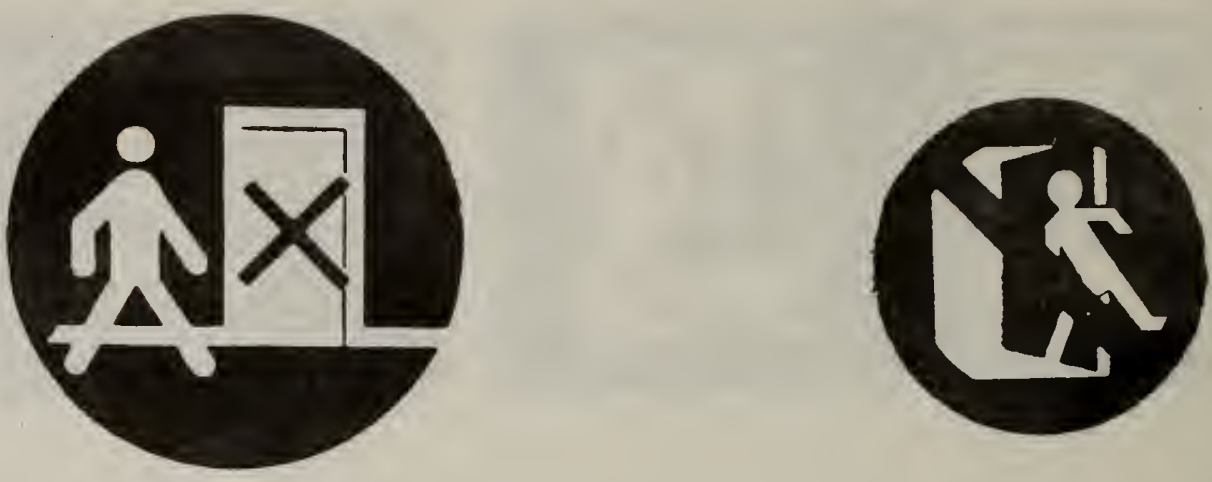

1

2

\begin{tabular}{|c|c|c|c|c|c|c|c|c|}
\hline $\begin{array}{l}\text { Percentage } \\
\text { Chi square } \\
\text { Mean Conf. Rat. } \\
\text { t-test } \\
\text { CCONF Mean } \\
\text { CCONF Median } \\
\text { Color }\end{array}$ & & $\begin{array}{r}8 \\
\text { Wh1 }\end{array}$ & $\begin{array}{l}1.1 \\
4.29 \\
4.46 \\
4.71 \\
\text { te on Red }\end{array}$ & & & White & $\begin{array}{r}4.48 \\
4.75 \\
\text { Black, Re }\end{array}$ & 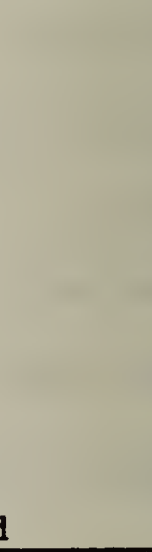 \\
\hline & \multicolumn{8}{|c|}{$\begin{array}{l}\text { Answers } \\
\text { 1s way } \\
\text { or closed } \\
\text { ay out } \\
\text { Ing }\end{array}$} \\
\hline & $\begin{array}{l}\text { Chotce } \\
\text { a } \\
b \\
\text { c } \\
d \\
n=1 \\
=188\end{array}$ & $\begin{array}{r}\text { Freg. } \\
7 \\
17 \\
103 \\
0 \\
27 \\
\text { ng }=9\end{array}$ & $\begin{array}{c}\text { Conf Mean } \\
1.43 \\
2.48 \\
4.29 \\
1.28\end{array}$ & $\begin{array}{l}\text { Median } \\
1.12 \\
2.19 \\
4.65 \\
1.09\end{array}$ & $\begin{array}{l}\text { Choice } \\
a \\
b \\
c \\
d \\
n=1 \\
1881\end{array}$ & 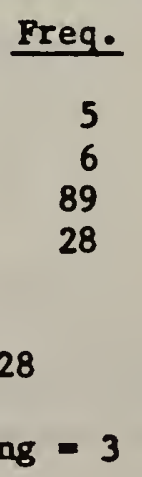 & $\begin{array}{c}\text { Conf Mean } \\
1.48 \\
1.58 \\
4.00 \\
2.43\end{array}$ & $\begin{array}{l}\text { Median } \\
1.14 \\
1.29 \\
4.57 \\
2.04\end{array}$ \\
\hline
\end{tabular}


well indicate a situation in which the positive message Exit is more appropriate and communicative than the negative. Of course, Exit signs are also a far more common occurrence in buildings and facilities than No Exit signs. Whatever the reason, NBS has been unsuccessful in locating a graphic image for No Exit that is understood by more than 70-80 percent of those responding.

On the other hand, the two images for Do Not Enter, figure 40, were more successful. Image 1 was identified correctly by 93.8 percent of the miners and received a mean confidence rating of 4.43. Image 2, which was significantly different from image 1 , received only 80.5 percent correct responses and a mean confidence rating of 3.89. This image also received 16.3 percent responses for "wear protective gloves". In contrast to "no exit", "no entrance, keep out, restricted area" is a common message in industrial and mining situations. The better performance of this message may reflect a greater familiarity with the idea of "do not enter."

The two remaining referents, Keep Door Open, figure 41, and Keep Door Closed, figure 42, were intended to symbolize a common mining situation of opening and closing off segments of the mine after passing through them. These messages are also required by the CFR (Title 30, 1980). The symbol for Keep Door Open received higher percentages of correct answers than "keep door closed". For both referents, however, the blue and white version performed significantly better than the red and white version, according to the $\chi^{2}$ statistics. Image 1 for "door open" which consisted of a red door on a white background received 89.7 percent correct responses and a confidence rating of 4.23. Image 2, consisting of a blue door on a white background, was identified correctly by 96.8 percent and received a mean confidence rating of 4.38. Both images received about 2-4 percent responses for "not an exit", although the mean confidence ratings were low for this choice. Both versions, differing only in color, appeared to communicate the intended message, although the confidence ratings were relatively low compared with the high percentages of correct responses.

Similar differences in performance were found for the two images for Keep Door Closed, which again differed in color, although the overall percentage of correct responses was lower than for Keep Door Open. Image 1, a white door on a blue background, was identified correctly by 83.1 percent of the participants, and received a (low) confidence rating of 3.98. Image 2, however, showing a white door on a red surround, received only 71.1 percent correct responses, and a mean confidence rating of 3.89. This image had a large number ( 15.6 percent) of choices for the answer Emergency Exit and for the answer Keep Door Open ( 12.8 percent). These two choices also received mean confidence ratings of 2.44 and 1.86. The percentage of selection for these two choices and mean for the answer Emergency Exit and for the answer Keep Door Open (12.8 percent). These two choices also received mean confidence ratings of 2.44 and 1.86 . The percentage of selection for these two choices and mean confidence ratings was lower for image 1. The reasons for the differences in performance are not clear. It may be that some participants saw the arrows as pointing to the opening - indicating a direction of travel - with the red indicating emergency. Whatever the reason, these confusions occur much less frequently with a blue background. Neither of these two referents appeared particularly successful, 


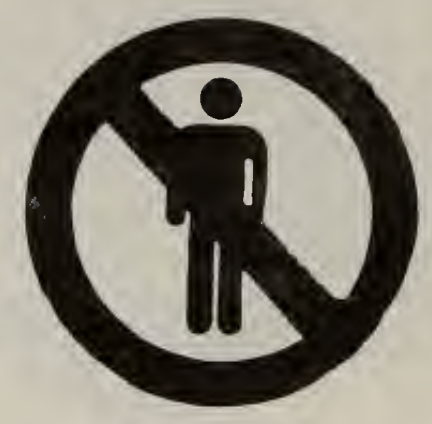

1

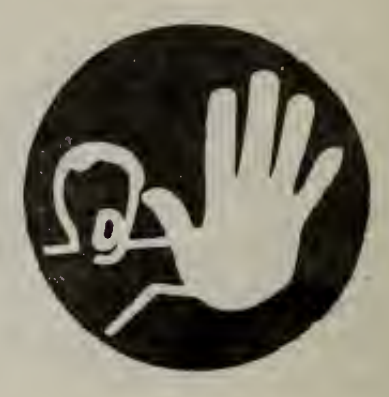

2

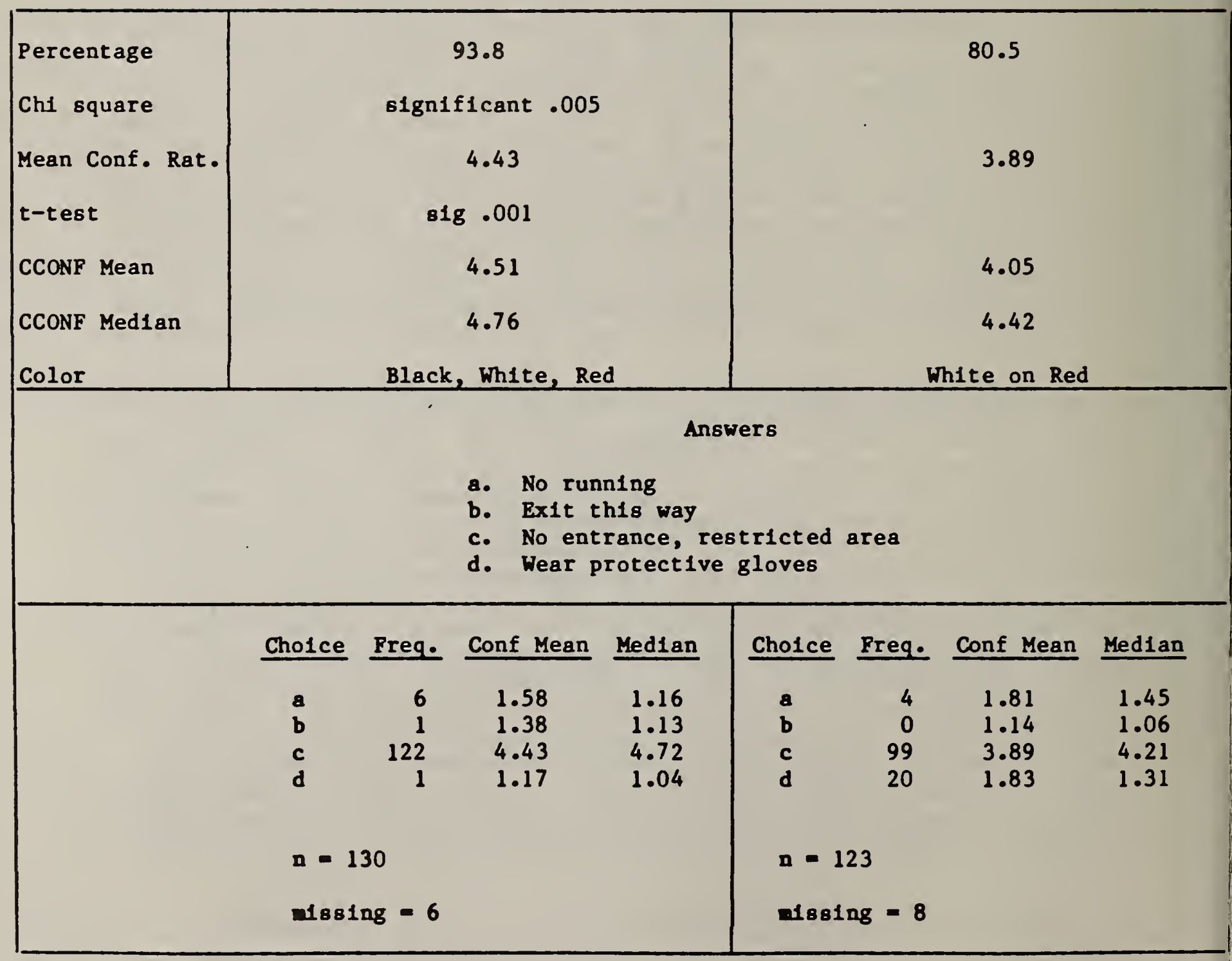


Figure 41

Keep Door Open

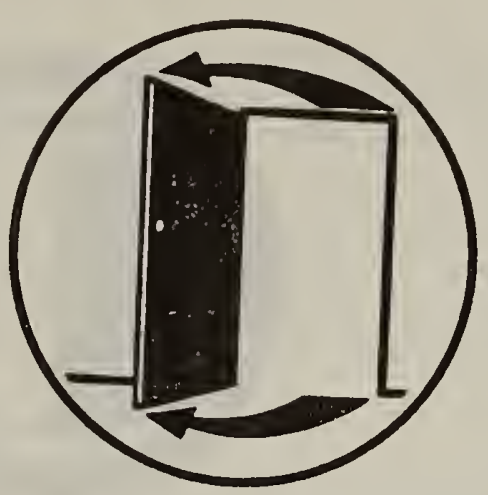

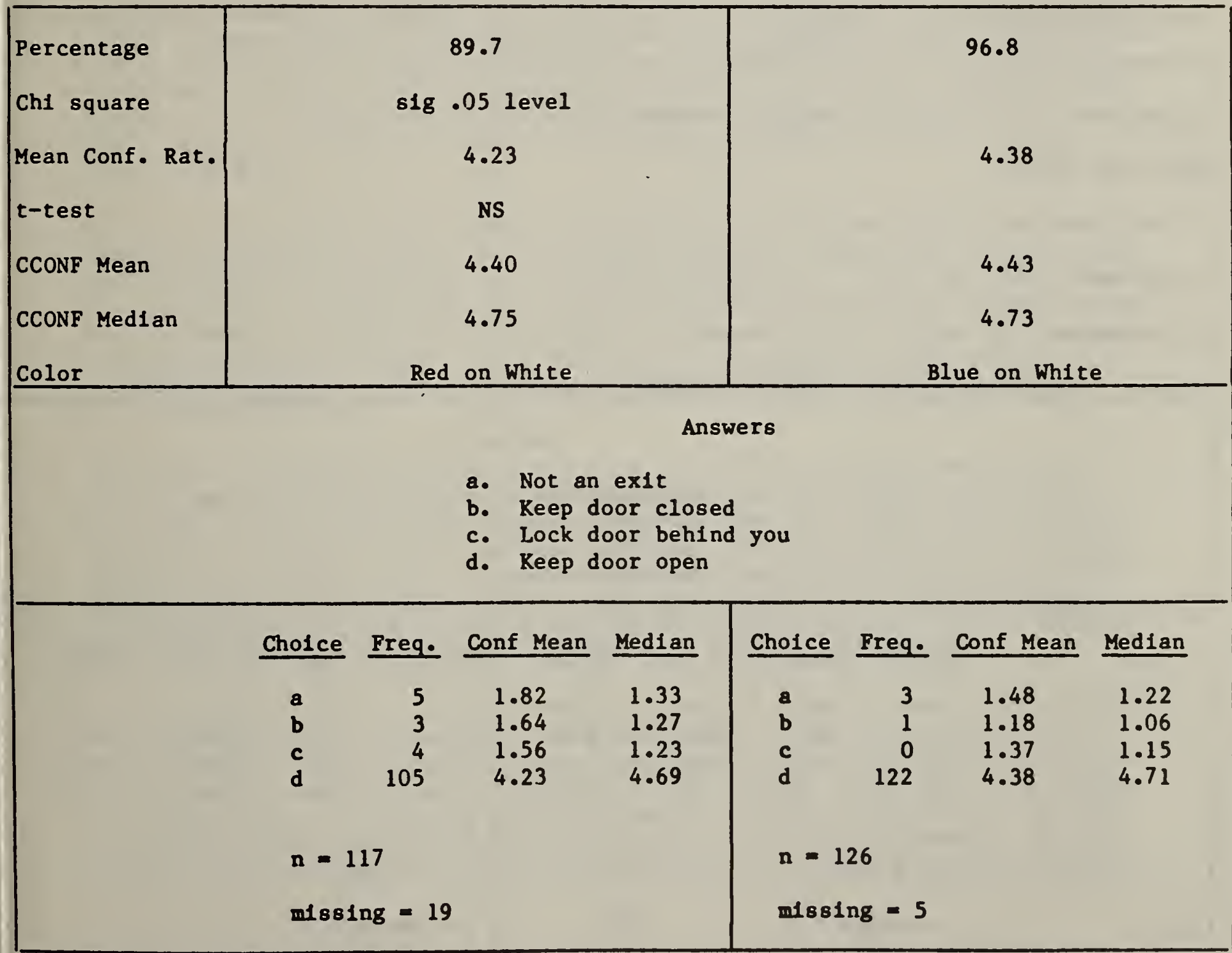




\section{Figure 42 \\ Keep Door Closed}

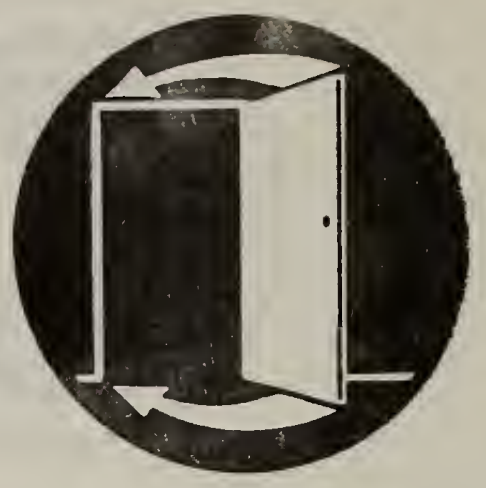

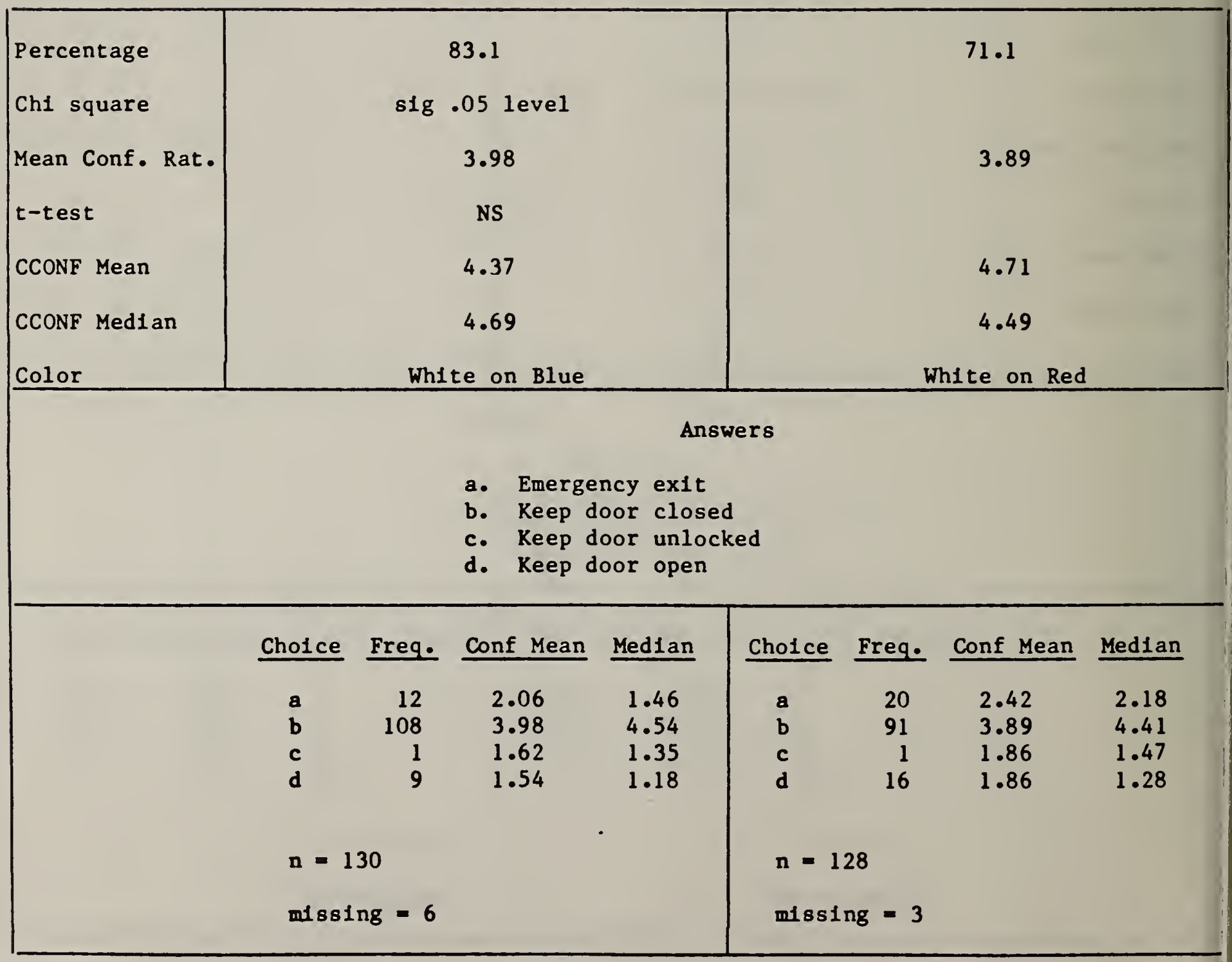


as miners often indicated puzzlement at the imagery. On an actual door, however, they might be much more successful.

\subsection{SURROUND SHAPE AND COLOR DATA}

Data on the perceived hazardousness of surround shape were collected from 268 miners. Data were excluded from the final statistical analysis where a miner failed to follow directions and rate each surround differently - e.g., by giving one or more shapes the same rating. About 30-50 miners failed to rate each surround differently, leaving about 214-228 people with statistically usable data. (The typical "incorrect" response was to give two or three shapes the same ranking, but not to give all 6 shapes the same rank.) Data were also collected on the most appropriate background color for the shape ranked as number one.

The rankings of 1-6 given for each surround shape were summed for each interior image for each sites. Table 15 presents the overall rank sums for each of the surround shapes for all referents (or interior images). The same data are presented graphically in figure 43. This figure also presents the overall ordering of surround shapes in terms of perceived hazardousness, with 1 representing most hazardous and 6 representing least hazardous. Tables 16-20 present the individual rank sum totals for each site as well as the overall rank sum total and mean rank. Table 16 presents site data for Explosion; table 17 for Entanglement; table 18 for Poison; table 19 for General Warning; and table 20 for Surround Alone.

Data were also collected on the perceived safety of surround shapes associated with two images for safety - First Aid and Hard Hat. These data are presented in tables 21,22 and 23, and are included in figure 43. It is not clear, however, whether the miners followed the instructions to rate these shapes according to safety, or continued to rate them for hazardousness. These two shapes were always presented last, while the hazard shapes were presented first, but in differing orders. (The only limitation was that the surround alone was never presented first).

The data on the perceived hazardousness of surround shape were analyzed for statistical significance using Kendall's coefficient of concordance for all data obtained for each interior image (General Warning, Poison, Entanglement, Explosion, surround alone, Hard Hat and First aid) for all subjects. A similar analysis was performed for a subset of about 50 subjects from the various oil shale sites. This analysis revealed that differences in the ranks for the surround shape were statistically significant (beyond the .05 level for the oil shale personnel and beyond the .001 level for the whole sample.)

Figure 43 demonstrates clearly that for the hazard warning symbols, the diamond is ranked lowest (is perceived as most hazardous for all images except surround alone). The octagon is a very close second, while the circle is consistently ranked sixth (as least hazardous in all cases). Generally the triangle is ranked third, the inverted triangle fourth, and the square fifth. Furthermore, there is a clear difference between the two shapes ranked as first and second (most hazardous) and the remaining shapes--with a very large difference 
Table 15. Ranking Data for Hazard Symbols - Totals for All Sites

\begin{tabular}{|c|c|c|c|c|c|c|c|}
\hline Referent & & & & & & & $\mathrm{N}$ \\
\hline General Warning & 561 & 887 & 573 & 739 & 979 & 755 & 214 \\
\hline Poison & 569 & 928 & 598 & 831 & 947 & 852 & 225 \\
\hline Entanglement & 573 & 861 & 590 & 796 & 981 & 861 & 222 \\
\hline Explosion & 580 & 883 & 628 & 843 & 927 & 927 & 228 \\
\hline Surround & 631 & 991 & 534 & 775 & 998 & 775 & 224 \\
\hline Sum & 2914 & 4550 & 2923 & 3984 & 4832 & 4170 & 1113 \\
\hline Mean Rank & 2.62 & 4.09 & 2.63 & 3.58 & 4.34 & 3.75 & \\
\hline Rank Order & 1 & 5 & 2 & 3 & 6 & 4 & \\
\hline
\end{tabular}


Table 16. Ranking Data for Explosion - Totals for Each Site

\begin{tabular}{|c|c|c|c|c|c|c|c|}
\hline $\begin{array}{l}\text { Surround } \\
\text { Shape }\end{array}$ & & & & & & & $\mathbf{N}$ \\
\hline BC & 89 & 97 & 62 & 128 & 101 & 132 & 29 \\
\hline BT & 138 & 235 & 202 & 229 & 280 & 239 & 63 \\
\hline WED & 110 & 165 & 99 & 148 & 147 & 150 & 39 \\
\hline EM & 48 & 80 & 52 & 89 & 82 & 90 & 21 \\
\hline os & 195 & 306 & 213 & 249 & 317 & 316 & 76 \\
\hline Sum & 580 & 883 & 628 & 843 & 927 & 927 & 228 \\
\hline Mean Rank & 2.54 & 3.87 & 2.75 & 3.70 & 4.07 & 4.07 & \\
\hline Rank Order & 1 & 4 & 2 & 3 & 6 & 6 & \\
\hline
\end{tabular}


Table 17. Ranking Data for Entanglement - Totals for Each Site

\begin{tabular}{|c|c|c|c|c|c|c|c|}
\hline $\begin{array}{l}\text { Surround } \\
\text { Shape }\end{array}$ & & & & & & & $\mathrm{N}$ \\
\hline BC & 62 & 97 & 66 & 96 & 93 & 111 & 25 \\
\hline BT & 117 & 217 & 158 & 233 & 282 & 232 & 59 \\
\hline WED & 112 & 165 & 101 & 141 & 164 & 136 & 39 \\
\hline EM & 53 & 79 & 55 & 72 & 101 & 81 & 21 \\
\hline os & 229 & 303 & 210 & 254 & 341 & 301 & 78 \\
\hline Sum & 573 & 861 & 590 & 796 & 981 & 861 & 222 \\
\hline Mean Rank & 2.58 & 3.88 & 2.66 & 3.59 & 4.42 & 3.88 & \\
\hline Rank Order & 1 & 5 & 2 & 3 & 6 & 4 & \\
\hline
\end{tabular}


Table 18. Ranking Data for Poison - Totals for Each Site

\begin{tabular}{|l|c|c|c|c|c|c|c|}
\hline \multicolumn{1}{c|}{$\begin{array}{c}\text { Surround } \\
\text { Shape }\end{array}$} & $\bigotimes$ & $\square$ & $\square$ & D & 0 & $\nabla$ & N \\
\hline BC & 78 & 102 & 62 & 109 & 100 & 116 & 27 \\
BT & 135 & 231 & 174 & 236 & 249 & 214 & 59 \\
WED & 115 & 179 & 99 & 159 & 164 & 145 & 41 \\
EM & 39 & 76 & 51 & 82 & 92 & 80 & 20 \\
OS & 202 & 340 & 212 & 245 & 342 & 297 & 78 \\
Sum & 569 & 928 & 598 & 831 & 947 & 852 & 225 \\
Mean Rank & 2.53 & 4.12 & 2.66 & 3.69 & 4.21 & 3.79 & \\
Rank Order & 1 & 5 & 2 & 3 & 6 & 4 & \\
\hline
\end{tabular}


Table 19. Ranking Data for General Warning - Totals for Each Site

\begin{tabular}{|c|c|c|c|c|c|c|c|}
\hline $\begin{array}{l}\text { Surround } \\
\text { Shape }\end{array}$ & & & & & & & $\mathrm{N}$ \\
\hline BC & 80 & 122 & 79 & 108 & 122 & 119 & 30 \\
\hline BT & 121 & 216 & 145 & 204 & 269 & 200 & 55 \\
\hline WED & 115 & 165 & 107 & 153 & 178 & 143 & 41 \\
\hline EM & 59 & 75 & 49 & 64 & 92 & 81 & 20 \\
\hline os & 186 & 309 & 193 & 210 & 318 & 212 & 68 \\
\hline Sum & 561 & 887 & 573 & 739 & 979 & 755 & 214 \\
\hline Mean Rank & 2.62 & 4.14 & 2.68 & 3.45 & 4.57 & 3.53 & \\
\hline Rank Order & 1 & 5 & 2 & 3 & 6 & 4 & \\
\hline
\end{tabular}


Table 20. Ranking Data for Surround Alone - Totals for Each Site

\begin{tabular}{|c|c|c|c|c|c|c|c|}
\hline $\begin{array}{l}\text { Surround } \\
\text { Shape }\end{array}$ & & & & & & & $\mathrm{N}$ \\
\hline BC & 84 & 120 & 58 & 116 & 121 & 110 & 29 \\
\hline BT & 151 & 247 & 138 & 223 & 260 & 199 & 58 \\
\hline WED & 119 & 183 & 100 & 142 & 164 & 132 & 40 \\
\hline EM & 56 & 90 & 42 & 72 & 103 & 78 & 21 \\
\hline os & 221 & 351 & 196 & 222 & 350 & 256 & 76 \\
\hline Sum & 631 & 991 & 534 & 775 & 998 & 775 & 224 \\
\hline Mean Rank & 2.82 & 4.42 & 2.38 & 3.46 & 4.46 & 3.46 & \\
\hline Rank Order & 2 & 5 & 1 & 4 & 6 & 4 & \\
\hline
\end{tabular}


Table 21. Ranking Data for First Aid - Totals for Each Site

\begin{tabular}{|c|c|c|c|c|c|c|c|}
\hline $\begin{array}{c}\text { Surround } \\
\text { Shape }\end{array}$ & & & & & & & N \\
\hline BC & 76 & 89 & 69 & 114 & 99 & 120 & 27 \\
\hline B T & 192 & 185 & 180 & 241 & 296 & 266 & 60 \\
\hline WED & 165 & 103 & 166 & 130 & 130 & 146 & 40 \\
\hline EM & 51 & 62 & 56 & 93 & 70 & 88 & 20 \\
\hline OS & 253 & 217 & 292 & 325 & 231 & 299 & 77 \\
\hline Sum & 737 & 656 & 763 & 903 & 726 & 919 & 224 \\
\hline Mean Rank & 3.29 & 2.93 & 3.41 & 4.03 & 3.24 & 4.10 & \\
\hline Rank Order & 3 & 1 & 4 & 5 & 2 & 6 & \\
\hline
\end{tabular}


Table 22. Ranking Data for Hard Hat - Totals for Each Site

\begin{tabular}{|c|c|c|c|c|c|c|c|}
\hline $\begin{array}{l}\text { Surround } \\
\text { Shape }\end{array}$ & & & & & & & $\mathrm{N}$ \\
\hline BC & 75 & 91 & 53 & 98 & 98 & 110 & 25 \\
\hline BT & 169 & 204 & 216 & 238 & 234 & 241 & 62 \\
\hline WED & 140 & 144 & 155 & 113 & 138 & 150 & 40 \\
\hline EM & 59 & 74 & 64 & 83 & 71 & 90 & 21 \\
\hline os & 224 & 253 & 260 & 282 & 272 & 305 & 76 \\
\hline Sum & 667 & 766 & 748 & 814 & 813 & 896 & 224 \\
\hline Mean Rank & 2.98 & 3.42 & 3.34 & 3.63 & 3.63 & 4.0 & \\
\hline Rank Order & 1 & 3 & 2 & 5 & 5 & 6 & \\
\hline
\end{tabular}


Table 23. Ranking Data for Safety Information Symols - Totals for All Sites

\begin{tabular}{|c|c|c|c|c|c|c|c|}
\hline $\begin{array}{l}\text { Surround } \\
\text { Shape }\end{array}$ & & & & & & & $\mathrm{N}$ \\
\hline Hard Hat Sum & 667 & 766 & 748 & 814 & 813 & 896 & 224 \\
\hline First Aid Sum & 737 & 656 & 763 & 903 & 726 & 919 & 224 \\
\hline Sum & 1404 & 1422 & 1511 & 1717 & 1539 & 1815 & 448 \\
\hline Mean Rank & 3.13 & 3.17 & 3.37 & 3.83 & 3.43 & 4.05 & \\
\hline Rank Order & 1 & 2 & 3 & 5 & 4 & 6 & \\
\hline
\end{tabular}




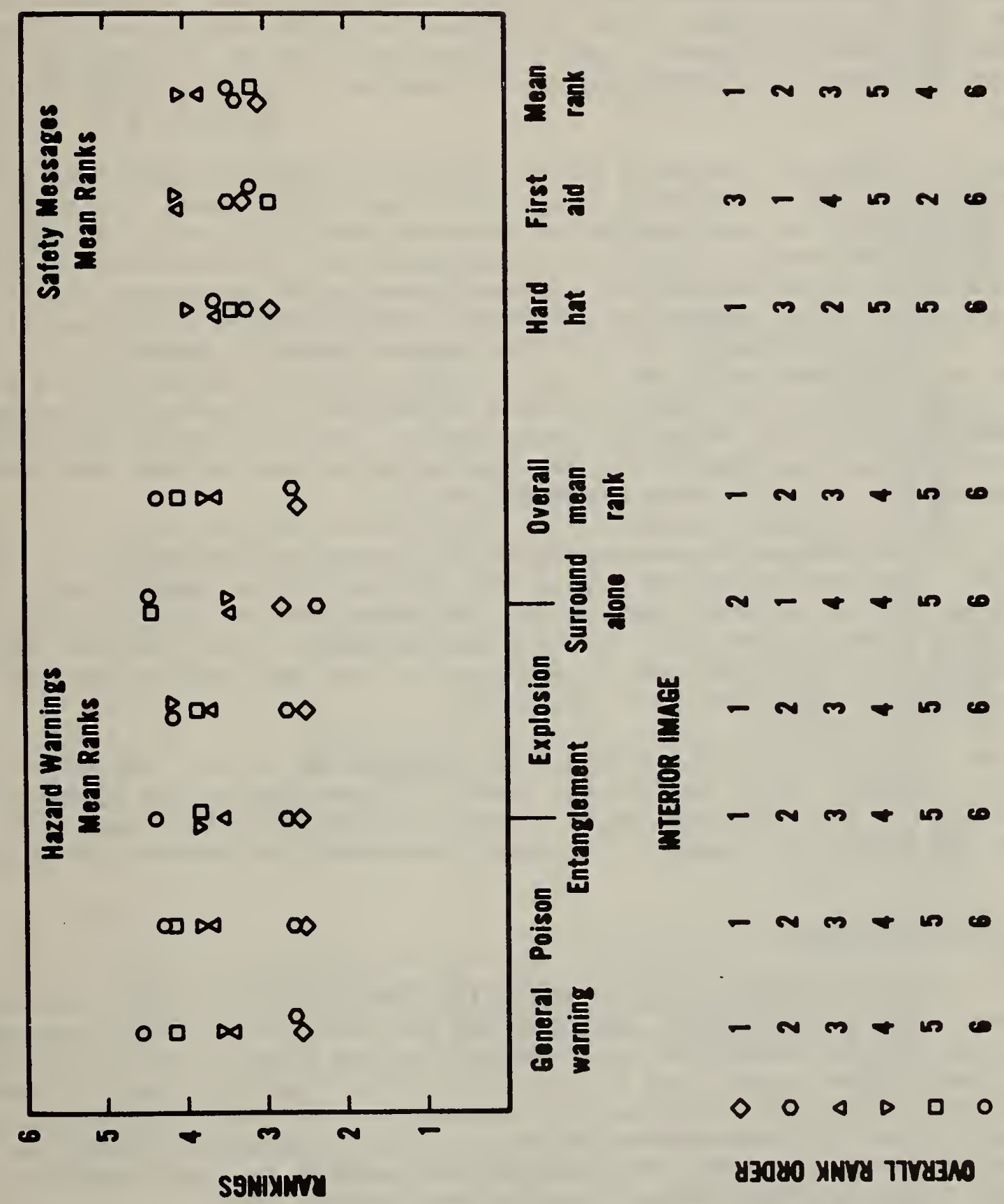

Figure 43. Rated hazardousness of surround shape 
between the shapes ranked as first and sixth. The rank ordering of surround shapes for hazard warning is reasonably consistent from interior image to interior image.

The data on surround shape for the two safety messages are less clear cut. The rankings are clustered more closely together--but with rather different patterns for the two interior images. Thus the diamond is ranked number one for Hard Hat while the square is ranked first for First Aid. Use of the Kendall coefficient of concordance indicated that the differences in ranks are significant, however.

In addition, the colors selected as most appropriate for the background color were tabulated. This tabulation appears as a set of histograms in figure 44, and indicates that red was selected as the most appropriate color by the majority of miners for poison, explosion, entanglement, and surround alone. Yellow was selected as the first choice for general warning and was second for all other messages, except poison for which black was the second most frequent choice. Orange was selected by the third largest number of miners for all hazards except poison, where white was the third choice. Except for the poison image, black, white, blue, and green were selected for hazard-warning symbols by almost equally small numbers of participants. The color choice data, then, tend to reinforce the common workplace stereotypes of red, yellow, and orange as appropriate colors for hazard warning symbols.

As with surround shape, color stereotypes for the two safety images are less clear cut. For hard hat in particular, the percentages are fairly evenly divided across colors with black, orange, and white seen as slightly less appropriate, and green, yellow, red, and blue somewhat more. For first aid, however, the preference is split between red and green as most appropriate, with a much lower percentage choice for the other colors.

Since the cross for first aid tends to be presented in red for "red cross" or green for "safety", these preferences seem to follow existing use of colors. Conversely, the lack of a similar stereotype for "wear hard hat," may well reflect the absence of standardized symbolic messages for personal protective gear.

\subsection{SITE DIFFERENCES}

Table 24 presents overall information for the five different sites. Generally performance was quite similar, with mean age and score being about the same with a few notable exceptions. As noted earlier the ANOVA for score, (reflecting the mean number correct out of a possible forty) indicated that the two $B C$ sites were significantly different with a mean score of 27-28 compared with the overall mean of 31-32. These two sites tended to be younger while the BT sites tended to be older. The data will be examined in some detailed to see which symbols, if any, caused problems for specific sites.

A chi square analysis of the frequency of correct response for each referent for each testing site indicated about 11 to 12 symbols where significant differences between testing site occurred. For group 1 and 2 these symbols included: 


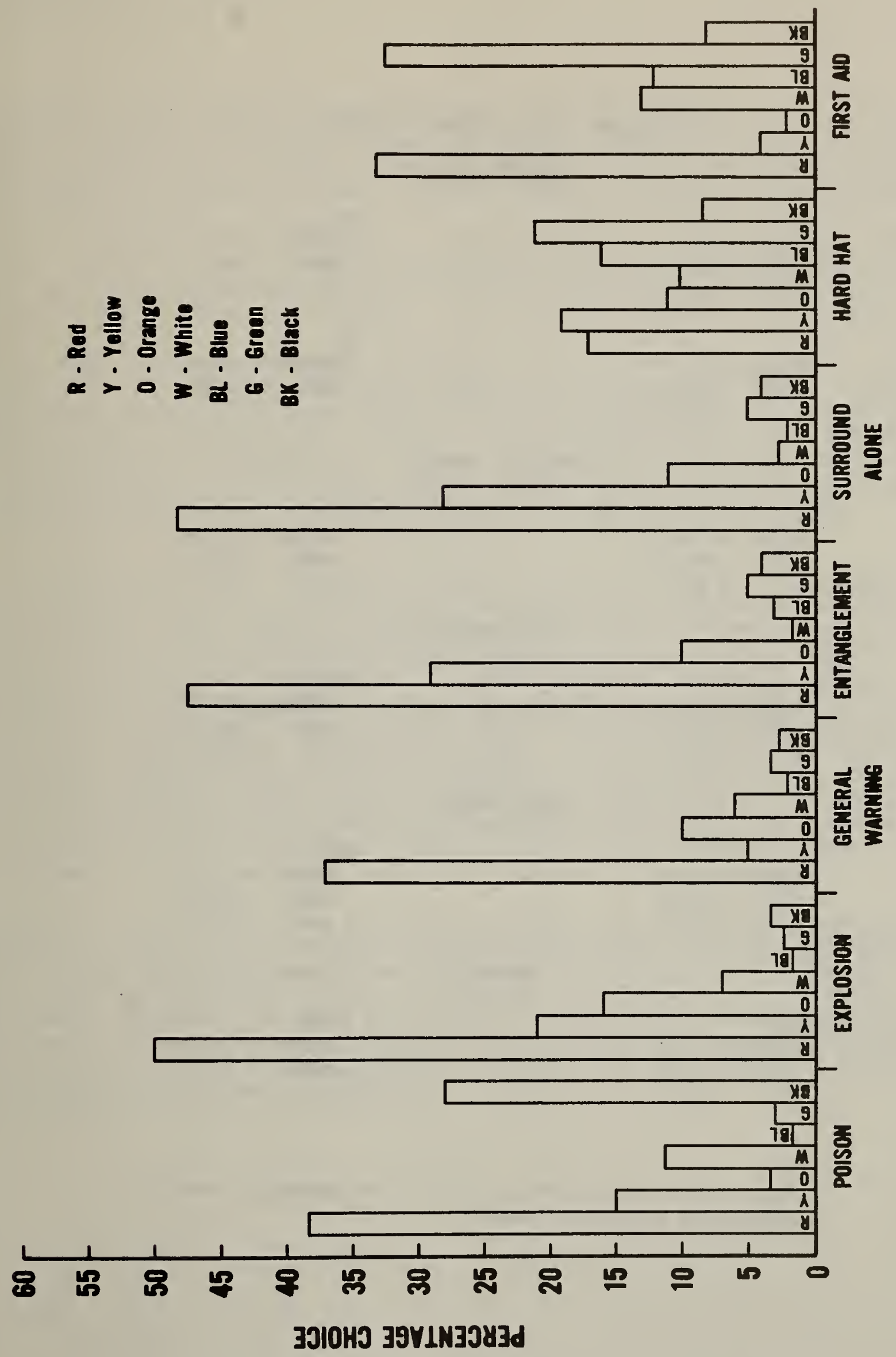

Figure 44. Preferred background color for selected symbols 
Table 24. Site Comparison Data

EASTERN GOAL

$$
\begin{aligned}
\text { EMI } & \\
\operatorname{SCORE} & =32.9 \\
\mathrm{AGE} & =34.8 \\
\mathrm{~N} & =10 \\
\mathrm{BCl} & \\
\mathrm{SCORE} & =27.7 \\
\mathrm{AGE} & =31.3 \\
\mathrm{~N} & =26
\end{aligned}
$$

EM2

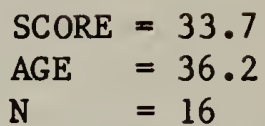

$\mathrm{BC} 2$

$$
\begin{array}{ll}
\text { SCORE } & =28.6 \\
\mathrm{AGE} & =29.8 \\
\mathrm{~N} & =24
\end{array}
$$

OPEN PIT COPPER

$$
\begin{aligned}
\mathrm{BTI} & \\
\mathrm{SCORE} & =33.5 \\
\mathrm{AGE} & =34.9 \\
\mathrm{~N} & =36
\end{aligned}
$$

SAND \& GRAVEL

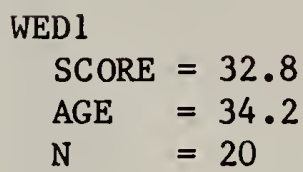

OIL SHALE

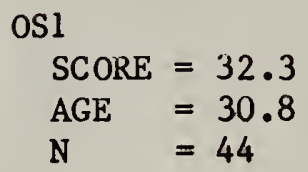

TOTAL

$$
\begin{array}{ll}
\mathrm{SCORE} & =31.3 \\
\mathrm{AGE} & =34.2 \\
\mathrm{~N} & =136
\end{array}
$$

BT2

$$
\begin{array}{ll}
\mathrm{SCORE} & =31.5 \\
\mathrm{AGE} & =42.2 \\
\mathrm{~N} & =35
\end{array}
$$

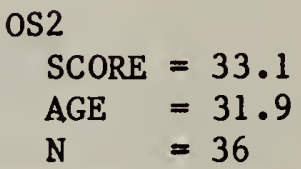

OVERALL

$$
\begin{array}{ll}
\text { SCORE } & =33.2 \\
\text { AGE } & =30.8 \\
\mathrm{~N} & =20
\end{array}
$$

$$
\begin{aligned}
\text { TOTAL } & \\
\text { SCORE } & =31.7 \\
\text { AGE } & =34.9 \\
\mathbf{N} & =131
\end{aligned}
$$

* Mean number correct for a total of 40 symbals. Thus, 40 represents a perfect "score". 
Flammable, Laser, Radiation, Pinch, Keep Door Closed, Emergency Exit, and No Exit. In group 1 , additional symbols for which statistically significant site differences occurred included: Corrosion, Poison, Shower, Exit and Respirator. For group 2, differences occurred for Cut, Eyewash, No Entrance and Entanglement.

Table 25 presents the percentages of correct response for each symbol for each site. Table 26 presents the mean confidence rating data for each symbol for each site. As can be seen from these tables, the differences between sites are often, but not always attributable to the poorer performance of the BC site.

A chi square analysis indicated significant (at or beyond the .05 level) site differences in frequency of correct response for the following Group 1 symbols: Flammable, Corrosion, Poison, Keep Door Closed, Safety Shower, Exit, Emergency Exit, No Exit, and Respirator. Similar significant differences were also calculated for the following Group 2 symbols: Flammable, Laser, Cut, Keep Door Closed, Eyewash, Emergency Exit, No Exit, No Entrance, and Entanglement. Significant site differences (at or beyond the .05 leve1) occurred for Laser, Radiation and Pinchpoint, which were seen by a11 participants.

Site differences can be examined in greater detail in table 25. Performance in terms of percentage of correct response for the group 1 symbols will be discussed first. In six cases, poorer performance is generally attributable to the BC site, with percentages of correct response as much as 20-50 percent lower. This included symbols for: Flammable, Radiation, Eyewash, No Exit, Poison, Pinch, and Close Door. (Percentages for these last three were also lower at the WED site). Other group 1 symbols for which individual site performance was markedly poorer included Exit (EM). On the other hand, for Laser, WED and OS performed about 30 percent better; for Corrosion OS alone received a perfect score; for Safety Shower, BT and OS were some 20-50 percent better; and for Exit and Respirator, WED was 20-30 percent better than the other sites. In no case however, was the performance of the BC group noticeably above the group mean.

Similar differences occurred for group 2 symbols. The BC site performance was poorer for Pinch, Laser, Keep Door Closed, Eyewash, Exit, No Exit, and Entanglement while the WED performance was poorer for Cut. The EM site performance was better for Flammable and Laser, while the os performance was better for Flammable, Radiation, No Exit, and No Entrance. In several cases BC performance was above the group mean. (Forklift, Do Not Touch, Foot Protection) Performance of the BT site was distinguished in that it was rarely above or below the group mean, for both sets of symbols. 
Table 25. Percentage of Correct Response for Each Site Group 1 Group 2

\begin{tabular}{|c|c|c|c|c|c|c|c|c|c|c|}
\hline $\begin{array}{c}\text { Number of } \underline{S}_{S} \\
\text { Site }\end{array}$ & $\begin{array}{l}\mathrm{N}=10 \\
\mathrm{EM} 1\end{array}$ & $\begin{array}{l}\mathrm{N}=26 \\
\mathrm{BCl}\end{array}$ & $\begin{array}{l}\mathrm{N}=36 \\
\mathrm{BT} 1\end{array}$ & $\begin{array}{l}\mathrm{N}=44 \\
\mathrm{OS} 1\end{array}$ & $\begin{array}{l}\mathrm{N}=20 \\
\text { WED 1 }\end{array}$ & $\begin{array}{l}\mathrm{N}=16 \\
\mathrm{EM} 2\end{array}$ & $\begin{array}{l}\mathrm{N}=24 \\
\mathrm{BC} 2\end{array}$ & $\begin{array}{l}\mathrm{N}=35 \\
\mathrm{BT} 2\end{array}$ & $\begin{array}{l}\mathrm{N}=36 \\
\mathrm{OS} 2\end{array}$ & $\begin{array}{l}N=20 \\
\text { WED2 }\end{array}$ \\
\hline \multicolumn{11}{|l|}{ Symbol } \\
\hline Flammable & 0.80 & 0.18 & 0.63 & 0.68 & 0.45 & 0.81 & 0.54 & 0.56 & 0.82 & 0.63 \\
\hline Laser & 0.00 & 0.09 & 0.19 & 0.42 & 0.44 & 0.81 & 0.13 & 0.40 & 0.36 & 0.10 \\
\hline Radiation & 0.50 & 0.08 & 0.32 & 0.56 & 0.42 & 0.47 & 0.17 & 0.37 & 0.54 & 0.20 \\
\hline Explosion & 0.80 & 0.81 & 0.91 & 0.98 & 1.00 & 0.81 & 0.91 & 0.91 & 1.00 & 0.90 \\
\hline Electrical & 1.00 & 0.80 & 1.00 & 1.00 & 1.00 & 0.60 & 0.29 & 0.59 & 0.45 & 0.70 \\
\hline Corrosion & 0.80 & 0.73 & 0.80 & 1.00 & 0.89 & 0.81 & 0.54 & 0.79 & 0.74 & 0.65 \\
\hline Poison & 1.00 & 0.77 & 0.97 & 0.93 & 0.82 & 0.73 & 0.86 & 0.74 & 0.85 & 0.90 \\
\hline Fork Lift & 1.00 & 0.84 & 0.97 & 0.98 & 1.00 & 0.94 & 1.00 & 0.88 & 0.94 & 1.00 \\
\hline Slip & 0.80 & 0.75 & 0.91 & 0.88 & 0.74 & 1.00 & 1.00 & 0.97 & 1.00 & 1.00 \\
\hline Fall & 1.00 & 0.85 & 1.00 & 1.00 & 0.89 & 1.00 & 0.79 & 0.91 & 0.97 & 0.90 \\
\hline Overhead & 0.90 & 0.64 & 0.63 & 0.65 & 0.95 & 1.00 & 0.96 & 0.97 & 1.00 & 0.95 \\
\hline Gen. Warning & 0.63 & 0.52 & 0.38 & 0.60 & 0.60 & 0.78 & 0.50 & 0.71 & 0.66 & 0.75 \\
\hline Trip & 1.00 & 0.88 & 1.00 & 1.00 & 0.95 & 0.93 & 0.71 & 0.71 & 0.85 & 0.95 \\
\hline Pinch Point & 1.00 & 0.67 & 0.91 & 1.00 & 0.83 & 0.88 & 0.45 & 0.91 & 1.00 & 0.95 \\
\hline Hot Surface & 0.89 & 0.85 & 0.80 & 0.92 & 0.89 & 1.00 & 0.96 & 0.91 & 1.00 & 1.00 \\
\hline Crush & 0.70 & 0.88 & 0.71 & 0.72 & 0.72 & 0.94 & 0.91 & 0.82 & 0.94 & 0.95 \\
\hline Sud.Pres.Release & 0.90 & 0.77 & 0.94 & 0.95 & 0.85 & 0.33 & 0.36 & 0.47 & 0.17 & 0.20 \\
\hline Cut/Sever & 0.80 & 0.76 & 0.94 & 0.84 & 0.71 & 0.94 & 0.96 & 0.94 & 1.00 & 0.50 \\
\hline Door Open & 1.00 & 0.80 & 0.97 & 1.00 & 0.68 & 1.00 & 0.96 & 0.94 & 1.00 & 0.95 \\
\hline Do Not Touch & 0.90 & 0.84 & 0.97 & 1.00 & 1.00 & 0.87 & 0.96 & 0.81 & 0.91 & 0.95 \\
\hline Door Closed & 1.00 & 0.73 & 0.91 & 0.90 & 0.58 & 0.86 & 0.42 & 0.76 & 0.67 & 0.95 \\
\hline Hard Hat & 1.00 & 0.88 & 0.97 & 1.00 & 1.00 & 0.94 & 0.96 & 0.97 & 1.00 & 1.00 \\
\hline Ear Protect. & 1.00 & 0.85 & 1.00 & 1.00 & 0.95 & 1.00 & 0.92 & 0.94 & 1.00 & 0.90 \\
\hline Eye Protect. & 1.00 & 0.92 & 0.97 & 1.00 & 0.95 & 1.00 & 0.96 & 0.89 & 1.00 & 1.00 \\
\hline Foot Protect. & 0.78 & 0.92 & 0.86 & 0.86 & 1.00 & 1.00 & 1.00 & 0.97 & 0.97 & 0.95 \\
\hline Hand Protect. & 1.00 & 0.88 & 0.91 & 0.92 & 0.95 & 1.00 & 0.96 & 0.91 & 0.97 & 0.95 \\
\hline No Smoking & 1.00 & 0.84 & 0.94 & 1.00 & 0.95 & 1.00 & 0.96 & 0.91 & 1.00 & 1.00 \\
\hline No Open Flame & 1.00 & 0.81 & 0.97 & 1.00 & 1.00 & 0.93 & 0.96 & 0.91 & 0.97 & 0.95 \\
\hline First Aid & 0.80 & 0.76 & 0.86 & 0.88 & 0.90 & 0.93 & 0.95 & 0.97 & 1.00 & 0.95 \\
\hline Safety Shower & 0.44 & 0.33 & 0.79 & 0.83 & 0.58 & 0.75 & 0.78 & 0.89 & 0.97 & 0.85 \\
\hline Eyewash & 1.00 & 0.68 & 0.94 & 1.00 & 0.95 & 0.94 & 0.42 & 0.66 & 0.71 & 0.85 \\
\hline Exit & 0.30 & 0.63 & 0.78 & 0.72 & 0.95 & 1.00 & 0.78 & 0.91 & 0.94 & 0.95 \\
\hline Emerg. Exit & 1.00 & 0.92 & 0.94 & 1.00 & 0.95 & 0.77 & 0.40 & 0.50 & 0.40 & 0.39 \\
\hline No Exit & 1.00 & 0.50 & 0.83 & 0.89 & 0.95 & 0.69 & 0.46 & 0.68 & 0.94 & 0.65 \\
\hline No Entrance & 1.00 & 0.83 & 0.97 & 1.00 & 0.85 & 0.87 & 0.70 & 0.67 & 0.97 & 0.85 \\
\hline Extinguisher & 1.00 & 0.88 & 1.00 & 0.95 & 0.95 & 0.94 & 1.00 & 0.94 & 1.00 & 0.95 \\
\hline Hose \& Reel & 0.90 & 0.80 & 0.94 & 0.97 & 0.95 & 1.00 & 0.88 & 0.91 & 0.97 & 0.85 \\
\hline Alarm Call Pt. & 0.50 & 0.54 & 0.57 & 0.69 & 0.33 & 0.67 & 0.43 & 0.68 & 0.71 & 0.70 \\
\hline Ent anglement & 0.90 & 0.65 & 0.79 & 0.84 & 0.89 & 1.00 & 0.75 & 0.94 & 0.97 & 0.95 \\
\hline Respirator & 0.56 & 0.76 & 0.50 & 0.76 & 0.95 & 0.71 & 0.75 & 0.85 & 0.82 & 1.00 \\
\hline
\end{tabular}


Table 26. Mean Confidence Rating Data for Correct Answers for All Subjects at Each Site

Group 1

Group 2

\begin{tabular}{|c|c|c|c|c|c|c|c|c|c|c|}
\hline Site & EM1 & $\mathrm{BC} 1$ & BT1 & OS 1 & WED 1 & EM2 & $\mathrm{BC} 2$ & BT2 & OS2 & WED2 \\
\hline \multicolumn{11}{|l|}{ Symbol } \\
\hline Flammable & $4 \cdot 10$ & 2.93 & 3.97 & 3.29 & 3.39 & 4.25 & 3.42 & 4.00 & 4.22 & 4.37 \\
\hline Laser & 1.89 & 2.92 & 2.52 & 2.62 & 3.17 & $2 \cdot 50$ & 1.81 & 3.67 & 2.80 & 2.33 \\
\hline Radiation & 3.00 & 2.29 & 3.00 & 3.48 & 3.17 & 3.27 & 2.28 & 3.58 & 3.43 & 2.27 \\
\hline Explosion & 4.33 & $4 \cdot 38$ & 4.60 & 4.57 & 4.79 & 4.00 & 4.29 & 4.44 & 4.77 & 4.72 \\
\hline Electrical & 4.60 & 4.48 & 4.91 & 4.78 & 4.89 & 3.75 & 3.14 & 3.93 & 3.38 & 4.17 \\
\hline Corrosion & 4.67 & 4.65 & 4.78 & 4.76 & 4.84 & 4.25 & 3.44 & 4.21 & 4.31 & 4.38 \\
\hline Poison & 4.70 & 4.17 & 4.94 & 4.67 & 4.78 & 3.69 & 4.10 & 4.00 & 4.29 & 4.72 \\
\hline Fork Lift & 4.70 & 4.47 & 4.75 & 4.67 & 4.95 & 4.69 & 4.57 & 4.71 & 4.71 & 4.90 \\
\hline Slip & 4.00 & 4.15 & 4.73 & 4.31 & 4.44 & 4.69 & 4.65 & 4.91 & 4.74 & 4.80 \\
\hline Fall & 4.60 & 4.57 & 4.82 & 4.56 & 4.79 & 4.47 & 4.05 & $4 \cdot 34$ & 4.47 & 4.67 \\
\hline Overhead & 4.56 & 4.19 & 4.22 & 3.85 & 4.84 & 4.81 & 4.35 & 4.91 & 4.47 & 4.85 \\
\hline Gen. Warning & 1.80 & 2.76 & 3.10 & 2.18 & 3.89 & 3.18 & 2.82 & 3.37 & 3.00 & 3.89 \\
\hline Trip & 4.50 & 4.59 & 4.94 & 4.79 & 4.84 & 4.07 & 3.53 & 4.26 & 4.34 & 4.42 \\
\hline Pinch Point & 4.80 & 3.70 & 4.54 & 4.46 & 4.68 & 4.19 & 3.06 & 4.30 & 4.57 & 4.79 \\
\hline Hot Surface & 4.12 & 4.50 & 4.33 & 4.05 & 4.56 & 4.56 & 4.47 & 4.44 & 4.66 & 4.70 \\
\hline Crush & $3 \cdot 30$ & 3.77 & 4.29 & 3.90 & 4.71 & 4.50 & 3.65 & 4.19 & 4.39 & 4.68 \\
\hline Sud.Pres.Release & 3.80 & 3.95 & 4.54 & 4.12 & 4.42 & 2.75 & 2.61 & 3.26 & 2.65 & 2.00 \\
\hline Cut/Sever & $4 \cdot 10$ & 4.37 & 4.46 & 3.78 & 4.33 & 4.62 & 4.29 & 4.64 & 4.47 & 3.82 \\
\hline Door Open & 4.50 & 4.20 & 4.47 & 3.97 & 4.10 & 4.57 & 4.05 & 4.44 & 4.54 & 4.20 \\
\hline Do Not Touch & 4.50 & 4.68 & 4.69 & 4.36 & 4.89 & 4.13 & 4.45 & 4.50 & 3.97 & 4.68 \\
\hline Door Closed & 3.80 & 4.00 & 4.38 & 3.90 & 3.53 & 4.00 & 3.05 & 4.14 & 3.77 & 4.50 \\
\hline Hard Hat & 4.50 & 4.25 & 4.79 & 4.68 & 5.00 & 4.44 & 4.67 & 4.84 & 4.53 & 4.68 \\
\hline Ear Protect. & 4.40 & 4.38 & 4.94 & 4.76 & 5.00 & 4.81 & 4.25 & 4.65 & 4.83 & 4.95 \\
\hline Eye Protect. & 4.50 & 4.57 & 4.76 & 4.68 & 4.89 & 4.56 & 4.33 & 4.76 & 4.56 & 4.80 \\
\hline Foot Protect. & 3.20 & 4.78 & 4.06 & 3.75 & 4.89 & 4.75 & 4.57 & 4.70 & 4.69 & 4.84 \\
\hline Hand Protect. & $4 \cdot 30$ & 4.68 & 4.67 & 4.15 & 4.79 & 4.56 & 4.32 & 4.75 & 4.50 & 4.74 \\
\hline No Smoking & 5.00 & 4.75 & 4.82 & 5.00 & 4.79 & 5.00 & 4.76 & 4.93 & 4.85 & 5.00 \\
\hline No Open Flame & 4.90 & 4.54 & 4.97 & 4.82 & 5.00 & 4.75 & 4.67 & 4.68 & 4.61 & 4.84 \\
\hline First Aid & 3.89 & 4.64 & 4.58 & 4.49 & 4.63 & 4.71 & 4.41 & 4.64 & 4.39 & 4.95 \\
\hline Safety Shower & 3.60 & 3.35 & 3.70 & 4.24 & 4.23 & 4.44 & 3.45 & 4.77 & 4.42 & 4.79 \\
\hline Eyewash & 3.67 & 3.58 & 4.67 & 4.29 & 4.84 & 4.25 & 3.11 & 4.14 & 3.74 & 4.26 \\
\hline Exit & 2.80 & 3.87 & 4.09 & 3.29 & 4.68 & 4.06 & 4.00 & 4.58 & 4.31 & 4.83 \\
\hline Emerg. Exit & $4 \cdot 10$ & 4.04 & 4.57 & 4.34 & 4.68 & 3.29 & 2.81 & 3.58 & 2.68 & 3.22 \\
\hline No Exit & 4.00 & 4.20 & 4.48 & 4.08 & 4.63 & 1.67 & 3.33 & 4.25 & 4.37 & 4.00 \\
\hline No Entrance & 3.90 & 4.20 & 4.64 & 4.46 & 4.53 & 4.29 & 3.18 & 3.77 & 3.94 & 4.33 \\
\hline Extinguisher & 4.90 & 4.76 & 4.97 & 4.77 & 5.00 & 4.75 & 4.80 & 4.90 & 4.86 & 4.95 \\
\hline Hose \& Ree1 & $4 \cdot 30$ & 4.05 & 4.70 & 4.85 & 4.74 & 4.80 & $4 \cdot 60$ & 4.68 & 4.66 & 4.40 \\
\hline Alarm Call Pt. & 3.30 & 3.21 & 3.85 & 3.60 & 3.72 & 3.60 & 2.95 & 4.03 & 3.94 & $4 \cdot 32$ \\
\hline Entanglement & 3.30 & 3.85 & 4.42 & 3.55 & 4.84 & 4.50 & 3.94 & 4.61 & 4.61 & 4.47 \\
\hline Respirator & $4 \cdot 10$ & 4.45 & 3.84 & 4.12 & 4.33 & $4 \cdot 38$ & 4.09 & 4.67 & 4.56 & 4.63 \\
\hline
\end{tabular}


5. DISCUSSION

\subsection{COMPARISON WITH PREVIOUS RESULTS}

At least fifty-five of the symbols studied with miners were also assessed with both industrial personnel and naive participants by Collins et al., (1982). As noted earlier, the industrial study utilized both a definition procedure and preference choices. Table 27 presents a comparison of the results from the two studies. This table identifies the symbol, provides the percentage of correct responses for both industrial and naive personnel from the earlier study, the percentage preference for these two groups of participants, the percentage correct responses from the miners, and their mean confidence ratings. Correlation coefficients were determined for dat'a from industrial-naive participants (0.73), mining-naive participants $(0.72)$, and industrial-mining participants $(0.81)$. These coefficients exclude data for No Exit and Fire Alarm Call Point for which severe scoring problems emerged with the definition data from the earlier experiment. When data for hazard warning symbols only are considered, the correlation coefficient between industrial and mining personnel jumps to 0.87 .

Despite changes in response procedure, there was thus reasonably good agreement in the percentage of correct responses for common symbols from the two studies. It is particularly interesting to note that the correlation coefficient for both miners and industrial personnel with the nalve data were so similar. This suggests that differences in the data between miners and industrial personnel may be due more to population differences than to methodological differences between the two studies. (The naive people and the industrial personnel used the definition style response form; the miners used the multiple-choice form). Generally, however, symbols which were correctly identified by miners were also correctly identified by industrial personnel. Differences in performance exceeded 10 percent in 13 cases with miners performing better in 7 cases and worse in 6 cases. The most noticeable discrepancy occurred for the Radiation symbol with which the industrial personnel appeared to be more familiar.

\subsection{FACTORS WHICH APPEAR TO AFFECT SYMBOL EFFECTIVENESS}

Review of the data obtained from both the mine and industrial personnel suggest some factors which appear to affect symbol effectiveness, as measured by the various understandability assessment procedures. In both studies, the very abstract symbols performed poorly. They received low percentages of correct responses, large percentages of critical confusions, low confidence ratings, and were rarely selected as the "preferred" symbol. Schiff (1980) confirms that very abstract symbols are poor communicators of information. Examples of abstract symbols in the present study include Radiation, Laser, General Warning, and the arrow and open box for Exit. Of course, one reason for the existence of these abstract symbols is that these concepts do not readily lend themselves to pictographic representations. Since these symbols do not have good initial understandability, they appear to require further training and/or an auxiliary word message. The data suggest further, that existing informal training for the Radiation and Laser symbols has not been particularly effective. For example, the Radiation symbol was one of the few symbols actually observed 
Table 27. Comparison with Previous Symbol Research

Symbol

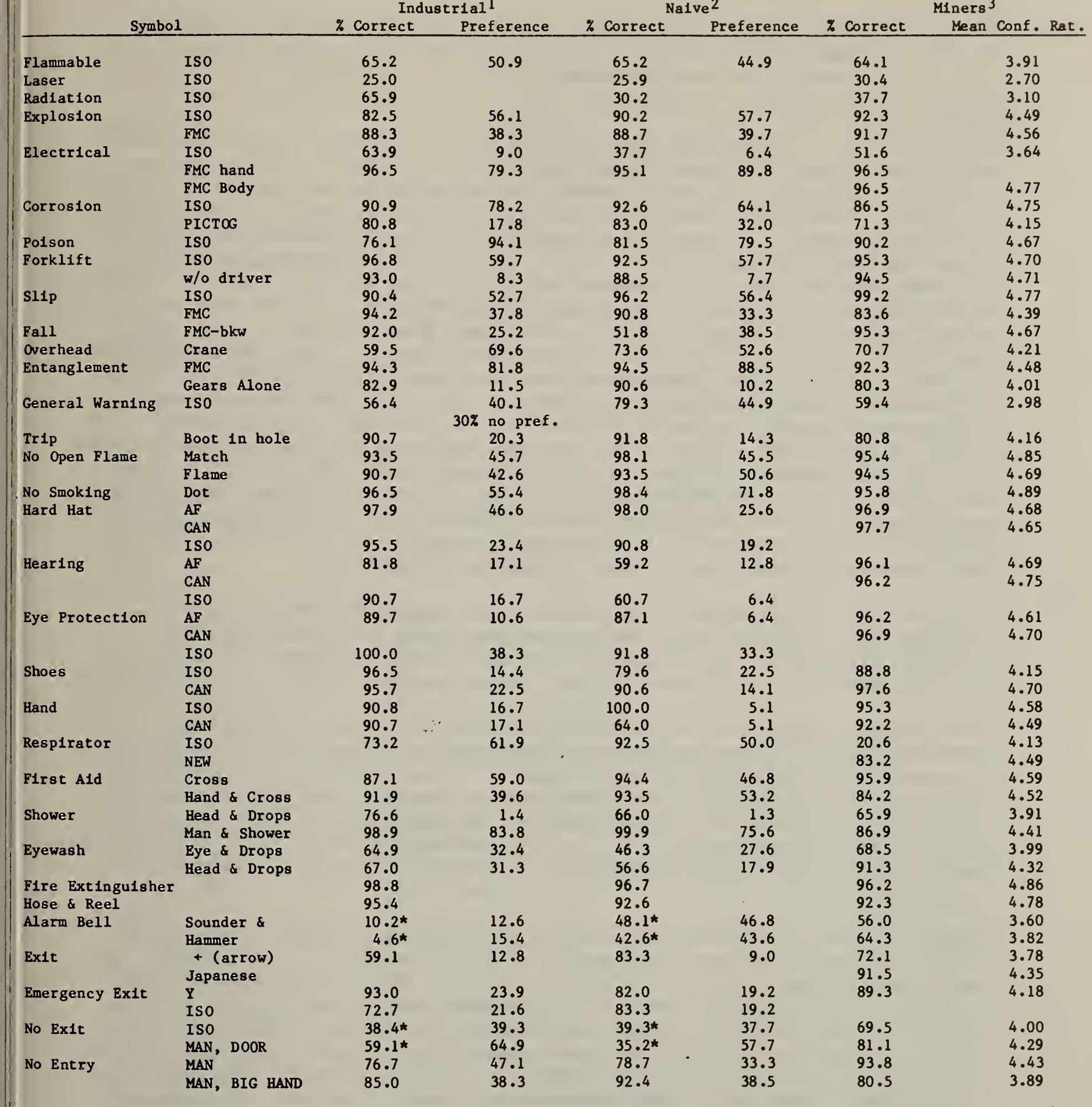

* Scoring problems with definition data arose here.

$1 \mathrm{~N}=$ about 86 to 94 participants

$2 \mathrm{~N}=$ about 53 to 61 participants

$3 \mathrm{~N}=$ about 131 to 135 participants 
during the site visits. Yet, it had very poor identification performance. On the other hand, the informal training for First Aid, another abstract, but widely used symbol, has been reasonably effective - suggesting that abstract symbols can be learned, if presented frequently and appropriately enough.

Tables 28 and 29 present the image content for the symbols, ordered according to the percentage of correct responses (lowest to highest). It can be seen from these tables that although several of the very abstract symbols were among the poorest performing symbols, several pictorial or representational symbols did equally poorly. In particular, version 2 of Sudden Pressure Release performed as badly as Radiation and Laser. Other poorly performing examples included version 2 for Exit, Poison, and Trip which, although representational in nature, do not appear to communicate their messages as effectively as the group 1 image. For group 1, poorly understood, but representational images included Overhead Hazard, Crush, Cut, and Entanglement. These differences suggest that the pictorial image should relate to ideas and messages with which the intended audience is familiar. Thus, version 2 of the Sudden Pressure Release image appears to depict bright light or welding hazard, judging by the number of miners who selected this answer. Similarly the Overhead Hazard image which shows a hammer and stone falling is a more common occurrence for many mines than a crane load breaking and falling. (Yet, this latter image could be appropriate in a processing plant where overhead loads are common.) Likewise the Crush image showing the whole body being crushed may depict roof fall or low clearance to miners accustomed to working underground.

Differences in performance among the various representational or pictorial versions of a referent reinforce the need to assess each image with the intended audience. Simply drawing a picture is not sufficient to ensure that it will communicate its message to the user as well as it does to the designer.

Nevertheless, symbols which proved to be effective in terms of initial understandability in the present study generally included those symbols showing a person with a hazard or a piece of gear. The more representational symbols usually received a high percentage of correct responses and higher mean confidence ratings. Examples in which the more representational image performed better than the more abstract one, include Safety Shower (2)* Exit (2), Entanglement (2), Slip (2), Emergency Exit (1), Eyewash (1), Posion (1), Electricity (1), and Trip (1).

Familiarity with the underlying concept also appears to affect performance. The most obvious examples of lack of familiarity include: Safety Shower, Eyewash, Laser, General Warning, and Fire Alarm Call Point. Examples of signs relating to these messages were rarely observed during the site visits. On the other hand, the data suggest that a number of the ISO hazard warning symbols, also used on the DoT-UN hazardous materials transport placards, are somewhat familiar to the miners. For Poison, Corrosion, Flammable and Explosion, the ISO image received a higher percentage of correct answers and a generally

* The number in parentheses refers to the image number as given in figures 6 to 42 . 
Table 28. Image Content--Ordered According to Percentage Correct Responses Group 1

$\underline{\text { Referent }}$

Laser

Radiation

Alarm Call

Flammable

General Warning

Shower

Respirator

Overhead

Exit

Crush

Entanglement

No Exit

Cut/Sever

Door Closed

Slip

First Aid

Corrosion

Pinch

Foot

Sud. Pres. Rel.

Emergency Exit

Door Open

Poison

Eyewash

Explosion

Hot Surface

Hand

Hose

No Entrance

Fall

Fork Lift

No Open Flame

Do Not Touch

No Smoking

Electrical

Ear

Extinguisher

Head

Eye

Trip
Content

Abstract--resembles sun beam

Abstract --3 blades

Bell Ringing

Picture of Flame

Abstract--!

Surround Shape

Shower Head \& Drops

Head, Gas mask

Hook, crane load, broken strap

Arrow, broken rectangle

Mangled hand, rectangle, arrow

Gears alone

Man, door, $\mathbf{x}$,

Severed hand, pointed object

Open door, wall, arrows

Foot \& Squiggle

Hand, bandage, cross

Pictures of test tubes, bar, hand being eaten away

Hand, rollers

Two shoes

Upper body, steam

Man, arrow, flame

Open door, wall, arrows

Skull and crossbones

Head, drops toward eye

Abstract Exp.

Hand, radiating surface

One glove

Coiled hose, knob

Standing man

Man, falling back, ledge

Man and truck

Circle, slash, lit match

Hand, surface

Circle, slash, lit cigarette

man, wire, lightning bolt

Ear protectors, head

Extinguisher--Pictorial

Hat Alone

Goggles, head

Man, falling forward, object
口

$\Delta$

$\Delta$

0

0

$\square$

0

ㅁ

$\Delta$

口

0

0

$\Delta$

$\square$

$\square$

$\square$

0

口

0

$\Delta$

$\theta$

$\theta$

$Q$

0

0

0

口 
Table 29. Image Content--Ordered According to Percentage Correct Responses Group 2

Referent

Laser

Sud. Pres. Rel

Radiation

Electricity

Emerg. Exit

General Warning

Flammable

Alarm C.P.

Eyewash

No Exit

Door Closed

Corrosion

No Entrance

Trip

Poison

Respirator

Shower

Pinch

Cut

No Touch

Crush

Exit

Fall

Hot Surface

Explosion

Entanglement

Hose

Fork Lift

No Open Flame

Hand

No Smoking

First aid

Ear

Extinguisher

Eye

Door Open

Foot

Head

Overhead

Slip
Content

Surround Shape

Abstract

Head--Explosion Toward Eye

Abstract

Abstract Lightning Bolt

Bicolor person, door

Abstract !

Picture of flame

Alarm ringing, hammer

Eye, drops

Person, open door

Open door, arrows toward wall 0

Drops, hand eaten away

Person w/big hand 0

Boot in hole 0

Person, clouds, lungs, starry eyes

Head, new respirator

Man pulling shower chain, drops

Hand rollers

Pointed object, foot

Finger, surface

Rectangle, $\downarrow$, falling man

Person, open door, wall

Person, diving forward, surface

Hand, radiating surface

Object being blown apart

Hand in gears

Coiled hose

Truck alone

Circle, slash, flame

Two gloves

Lit cigarette

Cross

Ear protection alone

Pictorial extinguisher

Eye glasses alone

Open door, arrows, away from wall 0

One shoe w/laceholes 0

Hat, head

Hammer, rock, downward motion

Person falling, level surface
$\Delta$

0

$\Delta$

$\Delta$

$\Delta$

$\Delta$

$\Delta$

$\square$ 0

0

ㅁ

$\square$

口

0

ㅁ

口

$\square$

$\square$

$\Delta$

口

$\Delta$

0

0

0

口

0

口

0

0

$\Delta$ 
higher mean confidence rating. The only ISO image for which this statement does not hold is the one for Electrical where the more representational picture, including a person and the hazard, performed better.

Another instance of probable familiarity includes the use of the circle and slash for prohibition. Early research by Brainard et al. (1961) indicated that their subjects were unfamiliar with this concept. Use of this approach in highway signing over the last 20 years, however, has clearly improved the effectiveness of the prohibition symbolization. All the prohibition symbols except one (no exit, version 2) were correctly identified by 90 percent or more of the miners responding. Similar results were found for industrial personnel. It remains, however, a graphic convention which must be learned. Dewar (1976) also pointed out that the prohibitory slash may obscure the symbol underneath, particularly if this symbol has a large amount of graphic detail. The prohibition symbols studied in the present experiment were relatively simple images such as No Smoking, Do Not Touch, Do Not Enter, representing noncomplicated messages.

As noted in previous NBS reports (Lerner and Collins, 1980a; Collins et al., 1982), messages related to egress appear to be difficult to symbolize effectively. Although one image for Emergency Exit and Exit each was identified correctly by more than 89 percent of the participants, the confidence rating for each image was relatively low (4.18 and 4.35). Both symbols for No Exit were identified correctly by only 75-77 percent of those responding. The better performance data for the Exit symbols suggest that it may be possible to use the Exit symbol as the basis for the No Exit symbol, and thus improve performance. This message, however, does not appear to be as familiar as the exit message.

\subsection{SURROUND SHAPE AND BACKGROUND COLOR DATA}

Contrary to expectations, variations in surround shape do affect the perceived hazardousness of a safety symbol. Although it was hypothesized that the six different surround shapes might well be ranked the same during part II of the present experiment, clear, statistically significant differences (using the Kendall coefficient of concordance) emerged between the six shapes. Furthermore, variations in interior image had little effect upon the overall ranks. Thus, regardless of whether a poison, explosion, entanglement, or general warning image were presented, the diamond and octagon were ranked as most hazardous and the square and circle as least.

The consistency in the rank orders is perhaps even more surprising since the miners had already participated in part $I$. In this portion of the experiment, hazard warning images were presented within triangles, squares, or once, a circle. The diamond and octagon were never presented as surround shapes in any portion of part $I$. The persistence, then, of the diamond and octagon as the most "hazardous" shapes suggests that the widespread use of these shapes for highway signs has been "learned" by the miners. These two shapes were ranked as more indicative of hazard, despite immediately prior familiarization with the triangle or square as hazard surround shapes. 
Based upon these data, the diamond can be recommended as a good surround shape for hazard warnings. It was most often ranked as most hazardous, is in conformance with existing U.S. highway practice for warning signs, and does not limit interior image area as does the ISO triangle. It is also used in the DoT-UN hazardous materials transport signs. The octagon may be best reserved by DOT to indicate "stop", along with the inverted triangle for "yield". The latter does not appear to indicate hazard as forcefully as the diamond, and again limits the interior image size. The circle clearly indicated hazardousness least of the six shapes studied, although the square was a close second. The square does allow more room for the interior image, particularly in comparison with the 2 triangular shapes, but the consistently high (non-hazardous) rankings suggest that this shape is not the most effective to warn of the presence of a hazard.

A study by Cochran, Riley and Douglass (1981), confirms that the diamond and octagon, as well as the inverted triangle are among the most effective warning shapes. These authors examined nineteen different geometric shapes for warning labels using the method of paired comparisons. Black and white shapes were viewed without interior images. Sixty-six subjects were asked to chose which sign of a pair best depicted "warning". The shapes that best represented warning were the inverted triangle, diamond, octagon, and triangle. "In general, shapes with corners with sharper appearing points apparently are more frequently recognized as warning shapes" (p. 397). Shapes which were less preferred for warning are "more simple looking, less irregular, and resting on a solid base, giving them the appearance of being in equilibrium" (p. 397). The authors point out that the influence of traffic signs can be seen in the results, with the shapes for the following (traffic) signs predominating - inverted triangle, octagon, hexagon, and diamond.

Although Cochran et al. (1981) comment that the invented triangle performed best, it was not significantly different from the diamond, octagon, or hexagon, nor was it preferred to these shapes. These four shapes thus appear to be about equally successful in indicating hazard warning. In conjunction with the present study, then, these data support the contention that neither the circle nor the square indicate hazard warning information as successfully as the other shapes studied.

The color data obtained in the present study also tend to reinforce existing warning sign practice. The primary colors selected by the miners for hazard warning - red and yellow - are currently widely used for industrial and highway warning signs (ANSI Z53.1, 1979; DoT, 1979). All of the hazard warning symbols studied in Part I of the present experiment were presented with yellow, white, or red background colors. Although red was less frequently presented as the background color, it was selected by the majority of the miners for 4 of the 5 warning images studied in Part II. Only once, for general warning, was yellow selected more frequently. These data suggest that the existing ANSI practice of using red for "danger" and yellow for "caution" (a lesser degree of hazard) continues to be appropriate. Miners, at least, appear to recognize these sterotypes. Collins et al. (1982) also noted comments from industrial personnel about the need to use red and yellow colors with various hazard symbols. They 
also noted that color does not appear to affect understandability but may contribute to the overall effectiveness of the symbol.

Along these lines, another study examined the attention-getting properties of color, surround shape, and word legend for four traffic signs. Adams and Hsu (1981) were concerned with the extent to which changes could be made to the coding details without these changes being detectable. Each sign was presented to fifty subjects in its original form, and with either the color, shape, or legend changed - for a total of sixteen signs, under degraded viewing conditions. The results indicated that color appeared to be the most salient dimension, followed by shape, and then by word legend. The word legend did not appear to be particularly noticeable for the exposure conditions of this experiment. The authors concluded that both color and shape can contribute to more rapid sign recognition.

The two studies reviewed above, plus the data from the present study suggest strongly that surround shape and color can communicate additional useful information about the presence of a hazard to a potential user. These cues can reinforce the information given by the interior image. Although the effect of such cues was not studied for a word sign, they appear useful for purely symbolic signs - the focus of the present investigation.

\subsection{DISCUSSION OF SITE DIFFERENCES}

Reasons for the site differences in performance are not particularly clear. The site with the poorest performance, the BC site, was an eastern U.S. coal mine, but so was the EM site which was characterized by much better performance. Miners at the BC site appeared to have much more difficulty with the testing situation, however. Their data sheets were characterized by greater failure to do the confidence rating portion of the experiment. They also appeared to be less familiar with some of the symbols related to chemical processing--safety shower, eyewash, corrosion, and poison-as well as the equipment-hazard symbols-pinch, cut, and entanglement. The abstract symbols for radiation and laser also appeared to be unfamiliar. Many of these concepts may not have been necessary for their site. Both the OS 2 and EM 2 groups contained several safety professionals which may have improved their overall performance. The BT site, was characterized by older, but very experienced personnel, two opposing factors which might both decrease and increase performance. The BC site was characterized by much younger personnel with less mining experience--factors which might also lead to poorer symbol recognition.

The symbols for which significant performance differences emerged are primarily the hazard and egress symbols. Failure to comprehend these symbols could lead to greater likelihood of an accident and injury. The personal protective gear symbols, on the other hand, appeared to elicit relatively similar performance from all groups. For those concepts for which problems seem to occur, (particularly the common hazards of flammable, corrosion, poison, entanglement, pinch, and cut), additional training and supplementary word signs may be required. Again, focus on the young inexperienced miner appears appropriate. 


\subsection{SELECTION OF A PRELIMINARY SYMBOL SET}

The data on symbol understandability obtained in both the present experiment and the previous industrial symbols experiment (Collins et al. 1982) were used to select a set of symbols which best conveyed the intended referent. A series of decision rules was generated for making this initial selection. While these rules are somewhat arbitrary, they seem to represent the best approach based upon the available data. These rules were used for selecting the interior graphic image. These images were then combined with the appropriate background/ surround shape as determined from part 2 of the present research.

A reasonable minimum selection criterion is that a symbol be understandable. ISO has suggested an understandability criterion of at least 85 percent correct responses, using a definition procedure, and no more then five percent critical confusions. The good correlation between data obtained with the definition procedure and with the multiple choice procedure suggests that an 85 percent cut-off figure can also be appropriate for the data obtained in the present experiment. A more stringent criterion could, of course, be used to exclude more symbols from consideration. In this experiment, however, a selection was made for all referents. The seven symbols which do not meet the understandability criterion are identified with an asterisk. These particular symbols require further training and/or accompanying word legends to ensure comprehension. It should be noted the majority of these symbols also performed poorly in the industrial symbols project.

If both images met the minimum understandability criterion, then the image which performed better statistically was selected. This performance was measured by either the chi square test for the frequency of correct responses or the t-test for confidence ratings. If the two symbols could not be discriminated by these two statistical measures, then the image with the higher percentage of correct responses was selected. A minimum difference between percentages correct was required to avoid basing the choice on spurious differences. A minimum difference of five percent was required, since this corresponds to approximately plus or minus two standard errors ${ }^{1}$ of the mean, or an approximate 95 percent confidence interval.

If the two images still could not be discriminated, the next decision rule involved correspondence with existing symbol standards. Conformance with these standards appears useful once the understandability criteria are met. In particular, the ISO set (DIS 5864.3, 1978), which is also used for the DoT/UN hazardous materials transport placards, appears to be a useful guide for hazardwarning symbols. These symbols already appear upon containers and trucks which serve mining facilities. As a result, many miners are incidentally exposed to them. Similar weight is given to the DoT (1979) set and the Treasury Board

1 The standard error for the percentage correct measure can be estimated by using the normal approximation to the binomial curve. Based upon this relationship, the standard error of the proportion of items correct is estimated by $\sqrt{\mathrm{NPQ} / \mathrm{N}}$ (where $\mathrm{N}$ is the number of subjects per group, $\mathrm{P}$ is the proportion of correct answers, and $Q$ is the proportion of incorrect answers). 
of Canada Federal Identity Program (1980) as miners may again be more likely to be exposed to these symbols. The goal of an understandable set of symbols is likely to be defeated if numerous different symbols are used for the same message. Consequently, if a symbol from existing standards meets the understandability criterion, then extensive graphic redesign appears unwise.

Nevertheless, the graphics approach embodied in the DoT (AIGA, 1974, 1979) symbols, an approach similar to that used by FMC (1978) and the Canadian Treasury Board standard $(1980)$ is finding wide use in the United States. As a result, weight was also given to this approach, particularly as its simplicity may also come closer to meeting eventual legibility criteria.

The various decision rules used in selecting each symbol, its image content, and referent message are given in table 30. Illustrations of the symbols selected for each message are given in section 8 (Handbook).

Thus, the decision rules utilized are the following:

1) The symbol should meet the understandability criterion of 85 percent correct identification and 5 percent or fewer critical confusions (oppositeto-correct answers).

2) There should be statistically significant differences between symbols - $\chi^{2}$ for frequency of correct answers, t-test for mean confidence rating for correct answers, and the standard error of the mean as a supplement for percentage correct.

3) There should be conformance with ISO (DoT/UN), Canadian or DoT symbol standards, with more weight given to ISO for hazard warning and more weight given to the Canadian for personal protective gear.

4) There should be fewer than five percent critical confusions with an incorrect choice alternative.

5) There should be overall conformance of graphic imagery with other members of the same set.

In six cases, the recommended image content differs from that given in Collins et al., (1982). Because the Canadian set of symbols had not been issued at the time this earlier study was done, its Personal Protective gear symbols consequently were not studied. The image content of the Canadian set is very similar to the ISO set, except that the graphic approach is simpler and more in line with the DoT (AIGA, 1979) series of symbols. Similarly for Overhead Hazard, Exit/Emergency Exit, and Trip, new symbols were included in the present study. They were chosen to be: more relevant to mining in the first case; to include symbols from a laboratory legibility study in the second case; and to depict triping over an object in the third case. In each case, the "new" symbol performed better according to the decision rules outlined above. In two other cases, Explosion and No Entry, results from the two studies did not coincide. For Explosion, although miners performed better for both images, their performance was markedly better (10 percent) for the ISo version - lending 
Table 30. Prel1minary Selection of Images

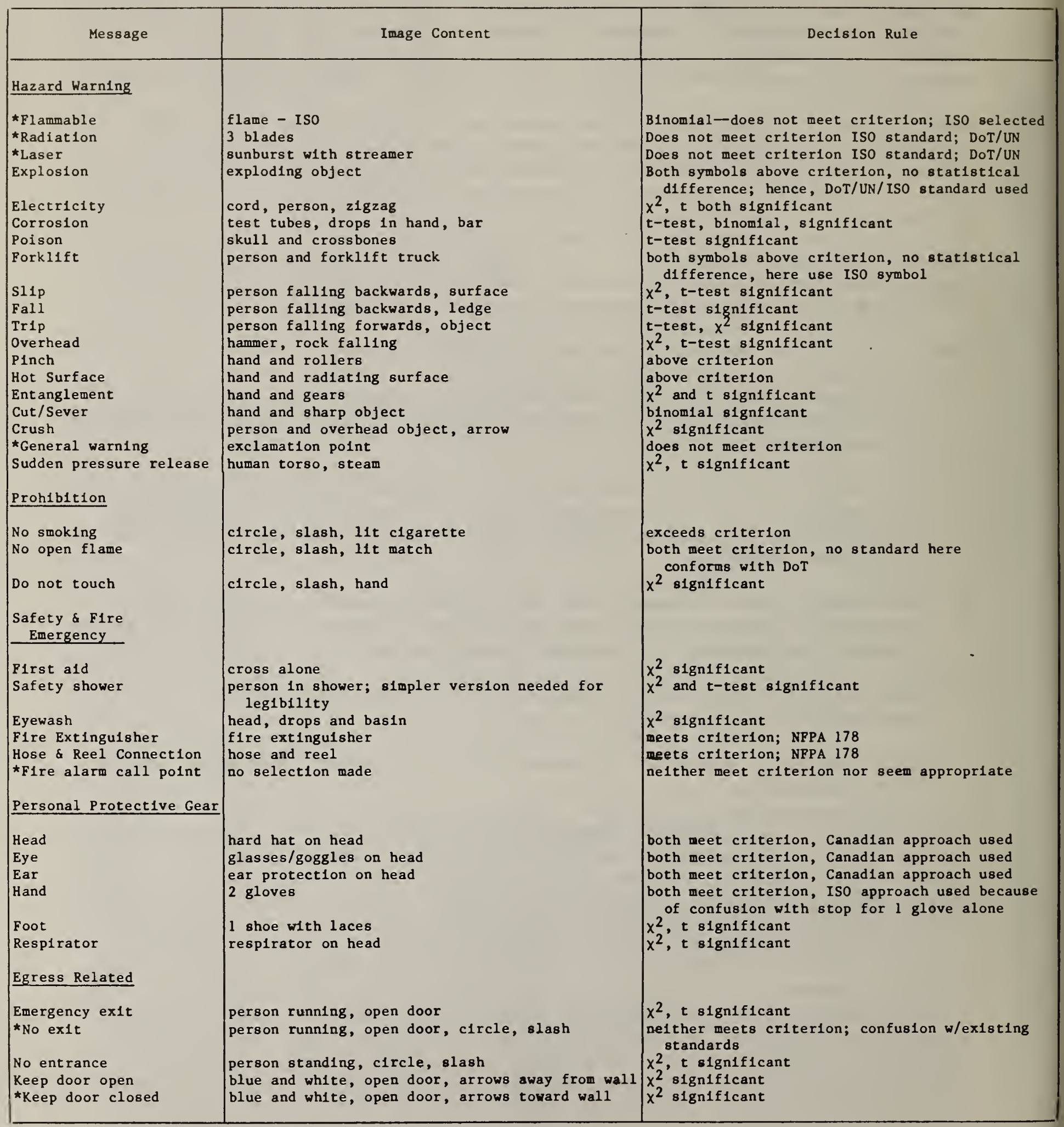

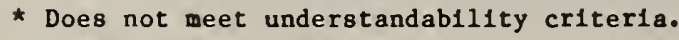


support to the idea that miners may well be more familar with explosive and blasting hazards. For No Entry the miners also gave a higher percentage of correct responses (93.8 vs 76.7 percent) to the "circle, slash, standing man" approach. Furthermore, during the actual study, presentation of the "man with big hand" image was often greeted with snickers and laughter--suggesting that this image might not be taken seriously.

As noted earlier, several symbols which had not performed well with industrial personnel continued to do poorly with miners. In particular, these included Flammable, Radiation, Laser, General Warning, Fire Alarm Call Point, and No Exit. The performance of Sudden Pressure Release imagery, which was not used in the earlier study, could be improved perhaps by the inclusion of a bursting hose. Corrosion, which barely met the criterion, appears to be a concept with which some miners are unfamiliar. Various images for Flammable succeed in communicating messages of fire successfully, but often with the idea that "fire is permitted" or "is actually present." This may be an instance where surround shape plays a role - people have become accustomed to seeing a circle and slash for prohibition. When it is not present, they assume that no prohibition exists--hence, "fires permitted," an incorrect (double-negative) answer selected by 20 percent of the participants. Use of a specified surround shape for hazard warning, such as the diamond, might lessen these confusions. Also, a "permissive" surround shape, such as the green circle used in some Canadian provinces (Dewar, 1976), might be appropriate in cases where an action is permitted. For example, DoT (AIGA, 1979) recommends a circle with a cigarette, but no slash, in those places where smoking is permitted. Whatever the reason, the flammable hazard idea appears to be difficult to convey with existing imagery.

In every study of safety symbols conducted to date at the National Bureau of Standards, symbols proposed for No Exit were poorly understood. The present study is no exception. This appears to be a difficult message to communicate with either words or symbols. The best approach might be to select a symbol for Exit and combine it with the circle and slash - and then restrict its use to those situations where a user might legitimately confuse an interior door with an exit. Problems of the circle and slash obscuring the message, or simply being ignored, have also been noted by Dewar (1976) who recommended using the positive approach whenever possible. It appears more useful to present users with positive information -- go this way, this way out, exit here -to guide their path, particularly during an emergency. Hence, development of an effective, legible Exit symbol might well be the best approach.

Finally, Fire Alarm Call Point is simply an unclear referent. In neither study were symbols for this message at all effective. This referent, which is intended to mean the place where an alarm is turned in, seems to be confused with the alarm (or noise) itself. Since various combinations of the approaches call point alone, sounder alone, and call point plus sounder - can be used, it may be best to develop warning systems, procedures, and accompanying symbols, on an individual mine basis. Certainly miners and industrial personnel do not appear to discriminate between the various intended messages and do not separate the idea of "call point" from that of "alarm". 
In this section a set of symbols was recommended for use in mining applications. To determine the effectiveness of these symbols an in-mine evaluation of symbol signs at 2 mines was conducted. This evaluation will be presented in section 6. Suggestions for further graphic refinement and additional research on legibility and conspiculty are given in section 7. A Handbook for using symbol signs in mines is given in section 8 . 


\section{IN-MINE SYMBOL SIGN EVALUATION}

\subsection{SELECTION OF SYMBOL SIGNS}

The effectiveness of a subset of the "effective" symbols recommended in section 5.5 was evaluated during a 3-month in-mine evaluation at two sites in the Eastern United States. One facility (LL) was an underground limestone mine, currently undergoing renovation, while the other (EM) was an underground coal mine and preparation plant. This latter site had participated in the initial evaluation. (See section 4. )

Based on the results of the understandability and perceived hazardousness evaluations, and discussions with the mine safety personnel, a set of 20 symbols was selected for the in-mine evaluation. This set included messages for the following categories: Hazard Warning, Personal Protective Gear, First Aid, Fire Equipment Location, and Egress. Several sets of 19 12-in. by 12-in. signs were then fabricated of impact-resistant plastic material with three holes in the top and in the bottom, to facilitate ease of mounting.

Figure 45 presents the 20 symbol signs as fabricated. (The Exit symbol was fabricated in 2 directions of travel.) Only one symbol which was poorly understood in the initial study was included in the in-mine evaluation. This symbol, Flammable Hazard, was needed to indicate the location of certain combustible materials. The No smoking symbol does not adequately convey this message, although it effectively conveys the idea of no smoking.

Symbol surround shape and color were used to code the different message categories. The hazard warning symbols were all shown within the diamond, rather than the triangle currently suggested by the ISO TC 80 draft standard (ISO, 1978). The diamond, in addition to being perceived in the initial study as "most hazardous", also allows a greater area for the interior image, and is consistent with the DoT (1979) practice. Otherwise, the surround shapes were in accordance with the ISO recommendations. The recommendations of the ISO draft (1978) and the ANSI 253.1 (1979) standard were followed for the color specifications. As a result, the hazard warning signs consisted of a black image on a yellow surround, within a black diamond. Symbols for personal protective gear were fabricated as white images on a solid blue disc. Safety and exit messages consisted of white images on a solid green square, while fire equipment messages consisted of white images on a solid red square. Prohibition messages consisted of a black image on a white background with a red circle and diagonal slash. It should be noted that the symbols tested in the initial study followed these guidelines, with the exception of the diamond for hazard warning.

\subsection{EVALUATION OF SYMBOL SIGN EFFECTIVENESS}

\subsubsection{Evaluation Procedures}

Several different evaluations were performed at the two facilities to determine the overall effectiveness of the symbols when installed as signs. This evaluation included selection of relevant messages and symbols, determination 


\section{BAZARD WARNING STMBOLS}
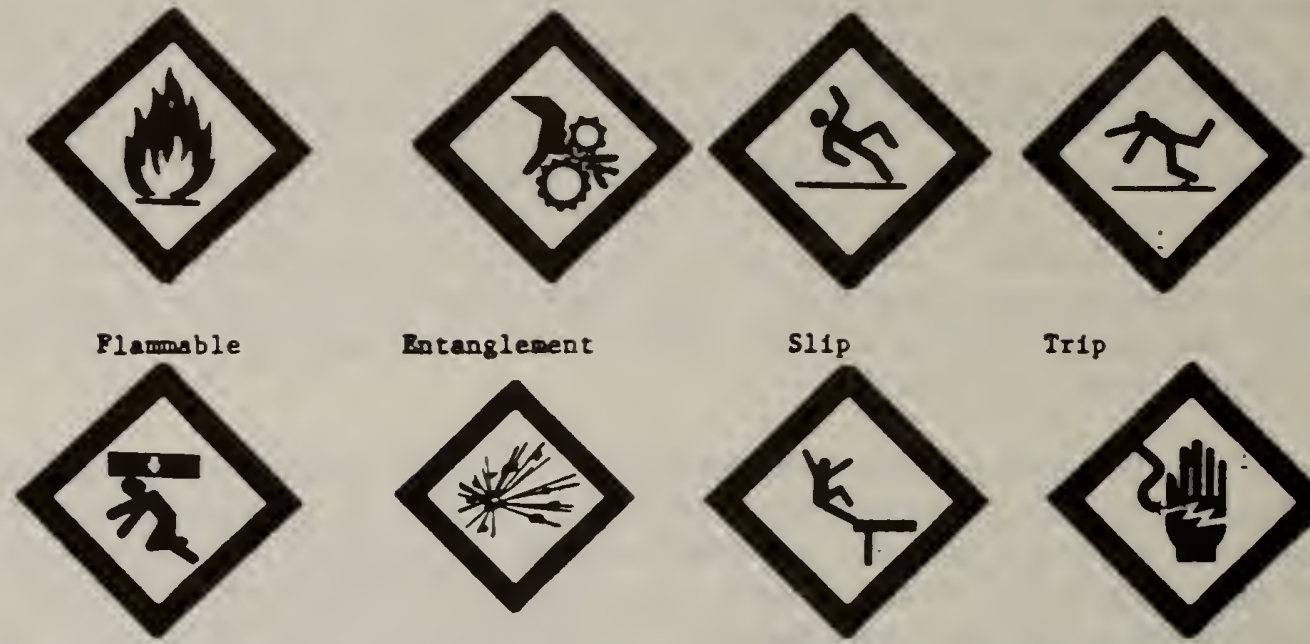

Explosion
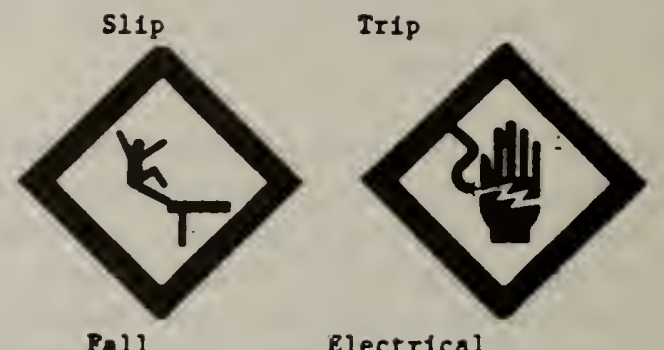

Electrical

PERSONAI PROTECTIVE GEAR

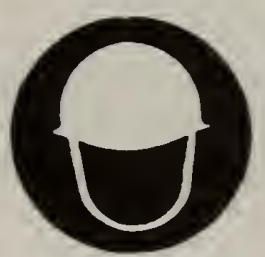

Bard Hat

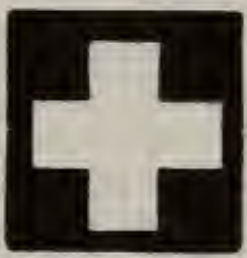

First A1d

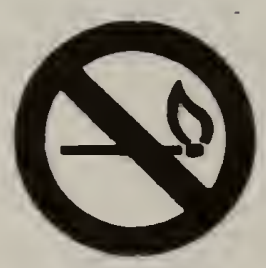

No Open Plame

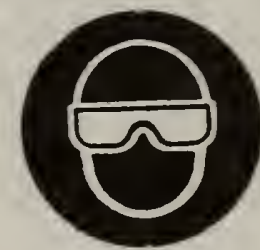

Safety Glasses

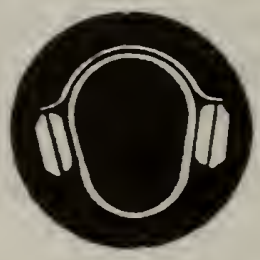

Ear Protection

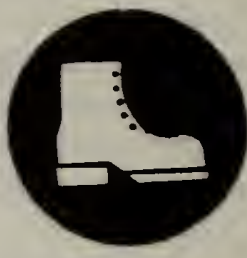

Safety Shoes

SAFETY AND EGRESS

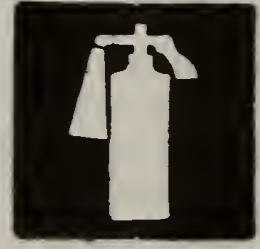

F1re Ertinguisher

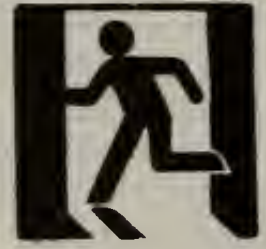

Bxit

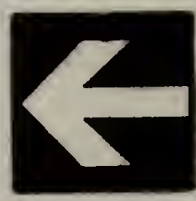

Arrow (w1th ExIt)

\section{PROAIBTION}

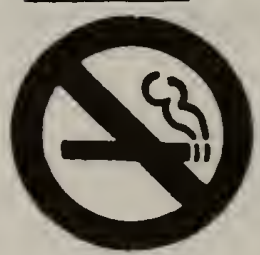

Do Smak108

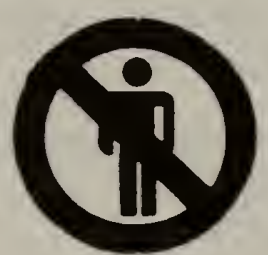

Wo Admittance (No Entry)

Figure 45. Symbols fabricated as signs for in-mine evaluation 
of appropriate location, and assessment of visibility, durability, contrast, vandalism, and theft. It also included further assessment of the understandability of the final set of 40 symbols recommended in section 5.5 at both sites. In addition, an evaluation of the confusions between members of the symbol subset and the conspicuity of the symbols actually installed was made for the LL site.

\subsubsection{Evaluation of Understandability--Both Sites}

A total of 99 people at the two sites participated in an evaluation of the understandability of the final set of symbols. This set included some hazard warning symbols within a diamond surround (see figure 45). This evaluation was intended to determine if unexpected changes in understandability had occurred for the final symbol set. The same multiple choice response form used in the initial study was used, so that the results would be comparable (see Appendix for form.)

At the LL site, 11 participants were shown the final set of 40 symbols. All groups of participants at the LL site also completed the evaluation of the perceived hazardousness of the set of six surround shapes for different interior images. This evaluation simply replicated the procedures from the initial study, and was designed to determine whether any unexpected differences in rated hazardousness arose at the LL site. (See section 4 for a full description of the procedure and rationale.)

Data from the initial evaluation for the EM site were presented in section 4. The additional in-mine testing consisted of an evaluation of the final symbol set, as tested at the LL site, using the multiple-choice procedure with 88 participants during weekly training sessions. The symbol signs had been installed at the site during these sessions so that the miners should have been familiarized with some of the symbol signs.

The data on symbol understandability are presented in table 31. The percentage of correct answers for each symbol is presented, along with mean confidence rating data for the correct choice alternative from the multiple choice procedure. Visual inspection of the data in table 31 indicates that the majority of symbols were well understood, with most symbols being correctly identified by more than 90 percent of those participating.

Inspection of the percentage correct data revealed that only six symbols were correctly identified by fewer than 80 percent of the participants. These included: Flammable, Radiation, General Warning, Laser, Safety Shower, and Fire Alarm Call Point. The most marked difference from the data collected in the initial study was that the percentage correct for the final symbol set was higher for 23 of the 40 symbols studied, with perfect scores in 9 cases. The confidence ratings were generally lower, however. The performance of only one symbol - Flammable - was noticeably poorer (greater than 10 percent lower) than in the initial study. Others which performed somewhat more poorly (between 5 and 10 percent) included the redrawn Explosion symbol, General Warning, Sever, Hearing Protection, and Safety Shower. The poorer performance of the Explosion symbol was most likely attributable to its new configuration. 
Table 31. Percentage Correct and Confidence Rating Data for Final Symbol Set for Both Sites

\begin{tabular}{|c|c|c|c|c|}
\hline Symbol & Correct $\mathrm{N}$ & Response $\mathrm{N}$ & \% Correct & $\begin{array}{c}\text { Mean } \\
\text { Confidence } \\
\text { Rating } \\
\text { Correct } \\
\text { Answer }\end{array}$ \\
\hline Flammable & 44 & 94 & $* * 46.8$ & 3.58 \\
\hline Radiation & 37 & 92 & 40.2 & 2.83 \\
\hline *Laser & 23 & 74 & 31.1 & 2.24 \\
\hline *Explosion & 71 & 83 & ** 85.5 & 3.23 \\
\hline Electrical & 99 & 99 & 100.0 & 4.72 \\
\hline Corrosion & 91 & 99 & 91.9 & 4.69 \\
\hline Poison & 96 & 98 & 97.9 & 4.75 \\
\hline Fork Lift Truck & 98 & 98 & 100.0 & 4.83 \\
\hline Slip & 98 & 99 & ** 98.9 & 4.54 \\
\hline Fali & 98 & 99 & 98.9 & 4.42 \\
\hline Overhead Hazard & 99 & 99 & 100.0 & 4.58 \\
\hline *General Warning & 36 & 68 & ** 52.9 & 2.09 \\
\hline $\operatorname{Trip}$ & 99 & 99 & 100.0 & 4.72 \\
\hline Pinch & 99 & 99 & 100.0 & 4.49 \\
\hline Hot Surface & 88 & 96 & 91.7 & 4.05 \\
\hline Crush & 94 & 98 & 95.9 & 4.17 \\
\hline \multicolumn{5}{|l|}{ Sudden Pressure } \\
\hline Release & 90 & 95 & 94.7 & 3.88 \\
\hline Sever & 82 & 99 & $\star * 82.8$ & 4.32 \\
\hline Ent anglement & 84 & 95 & $\star \star 88.4$ & 3.99 \\
\hline Do Not Touch & 94 & 96 & 97.9 & 4.04 \\
\hline No Smoking & 98 & 99 & 98.9 & 4.97 \\
\hline No Open Flame & 99 & 99 & 100.0 & 4.89 \\
\hline Head Protection & 96 & 98 & 97.9 & 4.48 \\
\hline Hearing Protection & 89 & 97 & ** 91.8 & 4.39 \\
\hline Eye Protection & 95 & 98 & 96.9 & 4.57 \\
\hline Foot Protection & 90 & 96 & $\star * 93.8$ & 4.21 \\
\hline Hand Protection & 97 & 97 & 100.0 & 4.32 \\
\hline \multicolumn{5}{|l|}{ Respiratory } \\
\hline Protection & 77 & 95 & $\star \star 81.0$ & 3.93 \\
\hline First Aid & 93 & 97 & 95.9 & 4.46 \\
\hline Safety Shower & 78 & 99 & $\star * 78.8$ & 4.30 \\
\hline Eye Wash & 83 & 91 & 91.2 & 3.65 \\
\hline Fire Extinguisher & 99 & 99 & 100.0 & 4.83 \\
\hline Hose \& Reel & 98 & 99 & 98.9 & 4.77 \\
\hline Fire Alarm & 53 & 98 & 60.2 & 3.18 \\
\hline Exit & 96 & 96 & 100.0 & 4.20 \\
\hline Emergency Exit & 79 & 94 & $\star \star 84.0$ & 3.76 \\
\hline No Exit & 85 & 97 & 87.6 & 3.95 \\
\hline Do Not Enter & 93 & 94 & 98.9 & 4.10 \\
\hline Keep Door Open & 82 & 89 & ** 92.1 & 3.46 \\
\hline Keep Door Closed & 85 & 93 & 91.4 & 3.66 \\
\hline
\end{tabular}

* Symbols characterized by 10 or more participants failing to respond to any choice alternative.

** Symbols receiving a lower percentage of correct responses than in the Initial study. 
Its increased similarity to the Laser symbol will be discussed in detail in 6.4.1. The poor performance for the Safety Shower symbol may have occurred because such showers are rarely used at either site, so that this symbol was interpreted as indicating the location of the changing room. Although the Flammable symbol was not well understood during the initial study, its even poorer performance here is of concern. The only change in the configuration from the initial study was the use of a diamond surround shape, rather than a triangle. This change did not decrease performance for the other hazard warning symbols, however. Some of the participants did suggest that this symbol should be red to indicate emergency. Whatever the reason, the Flammable Hazard symbol continues to be poorly understood, with many miners interpreting it as indicating that fire is permitted or present.

Nevertheless, the data given in table 31 confirm that the majority of the symbol set was correctly identified. Because the symbol signs had been installed at both sites during the understandability evaluation, this may have resulted in slightly better performance than that obtained during the initial study. In addition, the performance of the EM site had been somewhat above the group mean for the initial testing, so that the improvement in performance seen for the final symbol set might represent the generally better performance of this site, and not be applicable to all miners.

The data on the perceived hazardousness of surround shape were in general agreement with those from the Phase I study. Table 32 presents these data. It demonstrates that the diamond was always ranked as "most hazardous", while the circle was generally ranked as the least hazardous. The data also indicate that the triangle or the octagon was generally ranked as second-most hazardous. These data confirm that the diamond is viewed as indicating the highest degree of hazard for the various sites studied.

\subsection{SYMBOL SIGN INSTALLATION}

The majority of the symbol signs were installed by mine personnel during September 1982. Tables 33 and 34 present the signs installed at that time and their location at the two sites. Signs were generally mounted about 4-6 feet (1-2m) above the ground, or directly above exit doors or entry ways. Where an equipment hazard was marked, such as Electrical or Entanglement, the sign was mounted as close to the hazard as possible, again preferably at eye level or within the normal line of sight.

\subsubsection{Specific Signs at the LL Site}

A number of unexpected problems arose during the mounting process at the LL site. The rib walls generally proved to be both too crumbly and brittle to mount the signs directly, so that they were mounted on nearby constructed areas. This procedure was followed for the signs within the bulkhead rooms, gas mixing stub area, fueling areas, fan-door entry-way, and in the shop. The Exit signs, arrows, and No Entry (to the quarry area), however had to be suspended from the wire mesh located just below the roof by long wires. This allowed them to be placed about 4-6 feet above the ground, while keeping them out of the way of traffic within the facility. Unfortunately, they were not 
Table 32. Ranking Data for Surround Shapes for Hazard Symbols - LL Site

\begin{tabular}{|c|c|c|c|c|c|c|c|}
\hline $\begin{array}{l}\text { Surround } \\
\text { Snape }\end{array}$ & & & & & & & $\mathrm{N}^{*}$ \\
\hline General Warning & 14 & 15 & 15 & 17 & 24 & 20 & 5 \\
\hline Poison & 32 & 51 & 45 & 49 & 68 & 49 & 14 \\
\hline Entanglement & 36 & 49 & 47 & 36 & 59 & 49 & 13 \\
\hline Explosion & 30 & 47 & 50 & 52 & 55 & 60 & 14 \\
\hline Surround & 27 & 55 & 46 & 41 & 62 & 42 & 13 \\
\hline Sum & 139 & 217 & 203 & 195 & 268 & 220 & 59 \\
\hline Mean Rank & 2.36 & 3.68 & 3.44 & 3.30 & 4.34 & 3.73 & \\
\hline Rank Order & 1 & 4 & 3 & 2 & 6 & 5 & \\
\hline
\end{tabular}

* $\mathrm{N}$ represents the number of people who responded to each individual item. 
Table 33. Sign Location and Luminance Measurements -- LL Site

\begin{tabular}{|c|c|c|c|c|c|}
\hline Message & Location & Luminance-B & Luminance-D & Contrast & Contrast (Lab) \\
\hline First $\mathrm{Aid}^{1}$ & Shop & $27.8 \mathrm{fL}$ & $3.7 \mathrm{fL}$ & 0.87 & 0.86 \\
\hline Electrical ${ }^{2}$ & Shop & 14.1 & 0.9 & 0.94 & 0.90 \\
\hline Eye Prot. 3 & Shop/Grinder & 25.0 & 3.7 & 0.85 & 0.90 \\
\hline Fire Exting 4 & Shop & 27.7 & 7.0 & 0.75 & 0.76 \\
\hline Exit 1 & In Mine & 17.1 & 2.2 & $0.87 *$ & 0.84 \\
\hline Arrow 1 & In Mine & 13.8 & 0.9 & $0.93 *$ & 0.84 \\
\hline No Admit. 5 & In Mine & 15.4 & 5.5 & $0.64 *$ & 0.77 \\
\hline No Smoking 5 & Gas stub B drift & 16.3 & 3.5 & 0.78 & 0.76 \\
\hline Flammable $e^{2}$ & Same & 9.7 & 1.4 & 0.86 & 0.93 \\
\hline No Admit. 5 & Ventilator & 10.1 & 2.9 & $0.71 *$ & 0.77 \\
\hline Entanglement ${ }^{2}$ & Air Tugger D & 16.4 & 1.1 & 0.93 & 0.92 \\
\hline Extinguisher ${ }^{4}$ & Bulkhead Rm D & 3.0 & 1.0 & 0.67 & 0.76 \\
\hline First Aid 1 & Same & 17.8 & 2.1 & 0.88 & 0.86 \\
\hline No Smoking 5 & Outside fueling & 56.1 & 13.7 & 0.76 & 0.76 \\
\hline Hard Hat $^{3}$ & Gate & 43.7 & 5.2 & 0.88 & 0.90 \\
\hline Eye Prot. 3 & Gate & 39.2 & 5.0 & 0.87 & 0.90 \\
\hline Safety Shoe $^{3}$ & Gate & 39.1 & 4.4 & 0.89 & 0.87 \\
\hline
\end{tabular}

* These measurements were made by cap lamp and flashlight, and represent approximations only, due to the difficulty in holding both light source and meter steady.

1 - White and Green - Colors apply to both table 33 and 34

2 - Yellow and Black

3 - White and Blue

4 - White and Red

5 - White, Red, and Black 
Table 34. Sign Location and Luminance Measurements - EM Site

\begin{tabular}{|c|c|c|c|c|c|}
\hline Message & Location & Luminance-B & Luminance-D & Contrast & Contrast (Lab) \\
\hline Exit 1 & Training room & $36.2 \mathrm{fL}$ & $8.4 \mathrm{fL}$ & 0.77 & 0.84 \\
\hline Arrow 1 & Training room & 60.7 & 14.9 & 0.75 & 0.84 \\
\hline Fire Ext 4 & Interior room & 14.4 & 3.3 & 0.77 & 0.76 \\
\hline Fire Ext. 4 & Entranceway & 35.2 & 8.6 & 0.76 & 0.76 \\
\hline Eye Prot.3 & Over grinder & 37.1 & 5.0 & 0.87 & 0.90 \\
\hline Slip 2 & Over greaser & 38.0 & 5.0 & 0.89 & 0.90 \\
\hline No Admit. 5 & Outside Warehouse & 41.1 & $9.4(13.9) * *$ & $0.77(0.66)$ & $0.77 *$ \\
\hline Flammable 2 & Outside Warehouse & 33.5 & 2.7 & 0.92 & 0.93 \\
\hline No Smoking 5 & Outside Warehouse & 56.8 & 12.2 & 0.78 & $0.76 *$ \\
\hline Hard Hat ${ }^{3}$ & Outside Warehouse & 58.7 & 10.1 & 0.83 & 0.90 \\
\hline Trip 2 & Inside Warehouse & 17.8 & $2.5(3.5) * *$ & $0.86(0.80) * *$ & 0.92 \\
\hline No Admit . 5 & Outside Warehouse & 40.3 & 9.1 & 0.77 & $0.77 *$ \\
\hline Safety Shoes $^{3}$ & Prep Plant & 7.4 & 1.6 & 0.78 & 0.87 \\
\hline Hard Hat ${ }^{3}$ & Prep Plant & 7.4 & $1.6(4.6) * *$ & $0.78(0.36)$ & 0.90 \\
\hline $\operatorname{Trip}{ }^{2}$ & Prep Plant & 3.7 & 0.3 & 0.92 & 0.92 \\
\hline Overhead ${ }^{2}$ & Prep Plant & 2.5 & 0.5 & 0.8 & 0.92 \\
\hline Overhead 2 & Outside P. Plant & 59.5 & 15.4 & 0.74 & 0.92 \\
\hline Overhead ${ }^{2}$ & Near Loading Area & 37.4 & $7.8(16.8) * *$ & $0.79(0.55)$ & 0.92 \\
\hline No Open Flame 5 & Main Shaft Entry & 3.8 & 0.8 & 0.79 & $0.76^{\star}$ \\
\hline No Smoking 5 & Main Shaft Entry & 4.8 & 1.1 & 0.77 & $0.76^{*}$ \\
\hline
\end{tabular}

\footnotetext{
* Contrast between white surface and red circle and slash measured.

** Contrast between image and dirty area of surface measured.

1 - White and Green - Colors apply to both table 33 and 34

2 - Yellow and Black

3 - White and Blue

4 - White and Red

5 - White, Red, and Black
} 
as stationary as desirable. In the shop areas, signs were placed above the location of the safety equipment to be marked, again just at eye level. Signs for Personal Protective gear (Hard Hat, Safety Shoes, and Safety Glasses) were secured with wire to the front gate at the entrance to the facility. A No Smoking sign was placed just below the fuel tanks in an outside location with a Flammable Hazard sign to be added later. At the time of installation, all signs were clearly visible under cap illumination or daylight (exterior) illumination. Figure 46 presents selected photographs of the various signs as installed.

\subsubsection{Specific Signs at the EM Site}

Signs were installed by the safety personnel in above-ground areas only. No signs were installed underground because mine personnel felt that existing word signs were adequate, and because relatively few signs were actually used there. Symbol signs were mounted in the main shaft entrance area, training room, warehouse, heavy equipment repair area, processing plant, and refuse area. The location of signs is given in table 34. Since all the signs were above ground, these were no problems with mounting the signs to the mine walls or roof. Signs were generally mounted directly to the room wall or surface about 4-6 feet above the ground. Signs were also mounted directly above equipment hazards, as appropriate. See figure 47 which presents typical photographs of the signs after installation. Unlike the LL site, the EM site had an existing word-sign system, so that the symbol signs functioned as a supplement, to attract attention.

\subsection{SIGN EVALUATION}

The evaluation of the signs as installed used two different approaches. The first approach was the visual and photographic inspection of the signs, discussions with safety personnel, and measurement of sign luminance for contrast calculations. A short on-site test was also administered to personnel at the LL site to assess any confusions between the symbols in the set and to determine if the signs were conspicuous.

\subsubsection{Evaluation of Physical Characteristics}

At both sites, a number of procedures were used to evaluate the physical performance of the signs during the 3-month installation period. These included visual and photographic inspections of the signs, measurements of sign luminance, calculations of sign contrast at the site and in the NBS laboratory, and discussions with safety personnel.

The signs were inspected in October and December 1982. No problems of fading, deterioration, or poor legibility were observed. In addition, no problems of vandalism, theft or similar destruction were encountered. A few problems with dust and dirt build-up were noted after 3 months, particularly in some areas at the EM site, such as the preparation plant and refuse areas. Exterior signs, which had been subjected to normal weathering and dust, appeared to be in excellent shape, with no problems in legibility. Figure 47 reveals that these signs were still legible at that time. Build-up of a static electric charge on the plastic material of the signs may have caused fine dust particles 

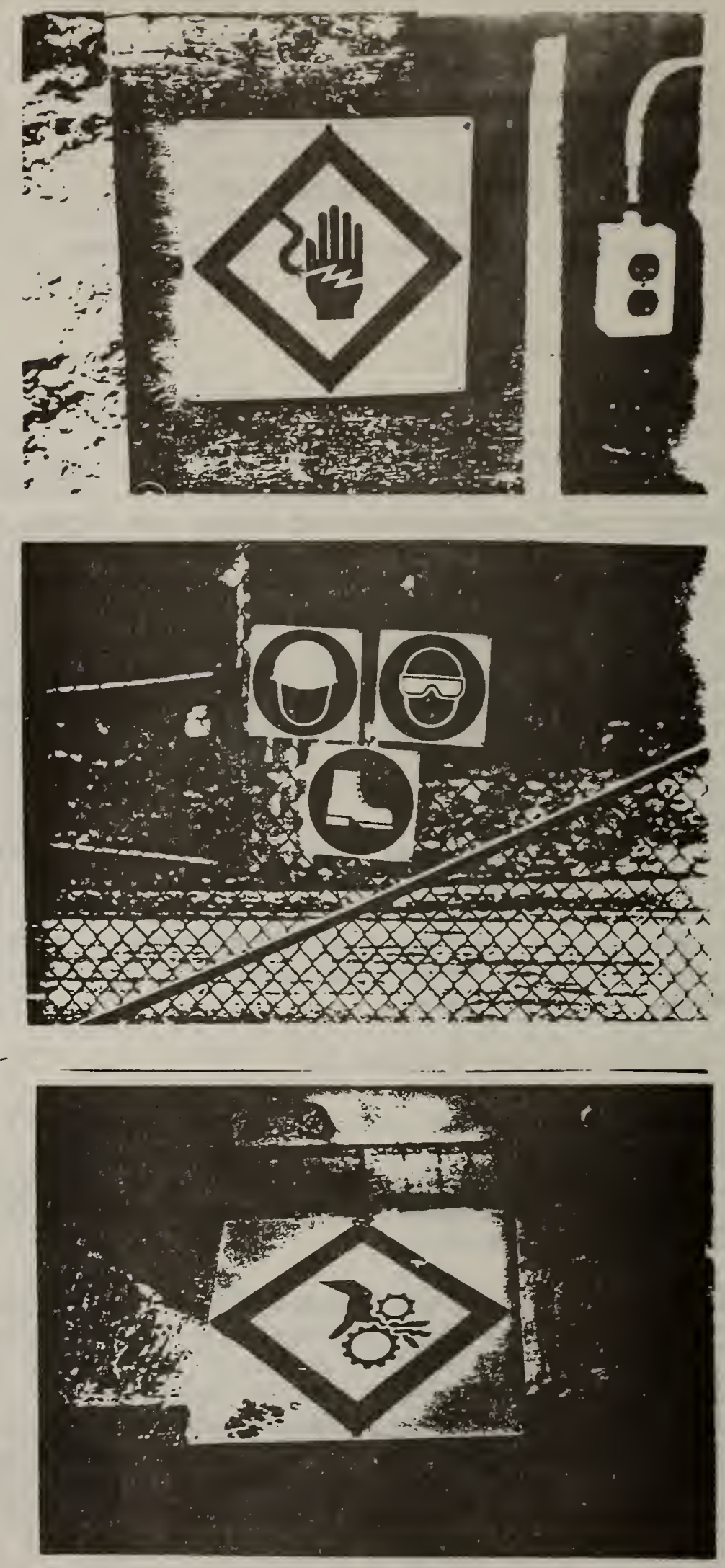

Figure 46. Photographs of symbol signs as installed at the Lit site 

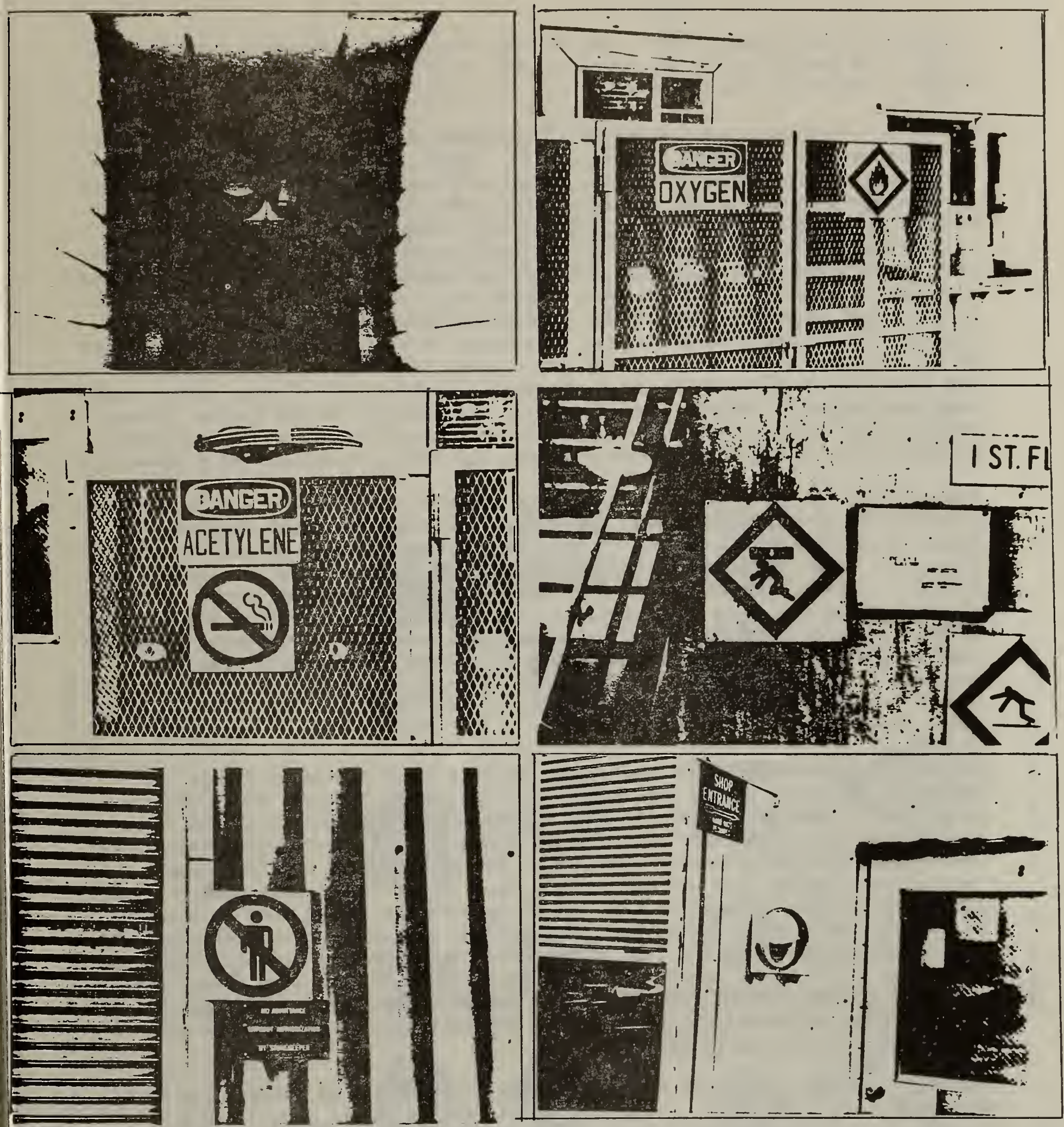

Figure 47. Photographs of symbol signs as installed at the EM site 
to adhere to the sign surface. The surface was easily cleanable, however. No problems of fading, rust, or corrosion were encountered at either site, for either exterior or interior signs.

During the December visit, a series of luminance measures was taken, from which the contrast for each sign was calculated. These calculations and measurements are also given in tables 33 and 34 , along with comparison calculations from laboratory measurements at NBS on clean signs under fluorescent lighting. (Light sources at the mines included daylight, fluorescent, incandescent, and high pressure sodium.) The calculations generally confirm that little or no reduction in contrast occurred during the testing period, except where coal dust had accumulated on some of the EM signs. These signs were still legible, however. It should be noted that some of the underground measurements at the LL site were only approximations due to the difficulty of making luminance measurements by cap lamp, which is both unsteady and creates large specular reflections. Cap illumination appeared to be an adequate illuminant for viewing underground signs--although it did not provide general illumination to the space. Consequently, use of retroreflective materials would be advisable to maximize the conspicuity of a sign (particularly as the cap lamp is moved around a space).

Discussions with mine personnel uncovered few problems. They did note, however, the need for a mirror-image exit symbol for locations where the direction of travel goes from left to right, as well as the right to left direction shown in figure 46. Such signs were subsequently installed at the LL site. Safety personnel also noted the problem of dust build-up, which they attributed to static electricity on the signs. In addition, they felt that underground signs should be self-luminous or retroreflective to maximize detection. Personnel at the EM site strongly felt that symbol-plus-word signs would be the most effective approach for safety signs.

\subsubsection{On-Site Evaluation Form--LL Site}

The on-site evaluation test used at the LL site is presented in figure 48. This form consisted of two portions -- a confusion evaluation, and a conspicuity evaluation. Twenty-two symbols which seemed most applicable to mining operations were depicted on this form, along with a list of short definitions (more definitions than symbols were provided.) In the confusion portion, people matched each symbol with a short definition. In the conspicuity portion, people indicated if they had seen each of the 22 symbols, by rating them on a scale of 1 to 5, where 1 meant that they had seen the symbol and 5 that they had not. The 22 symbols shown on the form deliberately included a number of symbols not installed at the site, to see if people would claim to have seen them. Administered after the initial installation of symbol signs, the on-site evaluation form provided an additional check on the effectiveness of the symbols in communicating the desired message.

Table 35 presents confusion and conspicuity data for the 22 symbols including the 12 actually installed at the time of testing at the LL site. Table 35 presents the confusion data first, in terms of the percentages of correct and incorrect matches; and the conspicuity data second, in terms of mean rating and standard deviation. For example, the symbol, Flammable, was correctly 
Table 35. Confusion/Conspicuity Data

Confusion

Conspicuity

\begin{tabular}{|c|c|c|c|c|c|c|}
\hline Message & $\mathrm{N}^{1}$ & $\%$ Correct & $\%$ Incorrect & Mean Rating & ST. Dev. & $\mathrm{N}$ \\
\hline- Corrosion** & 37 & 78.4 & $M=10.8 ; I, T, C, X=2.7$ & $4 \cdot 15 * * *$ & 1.46 & 20 \\
\hline Crush** & 36 & 88.9 & $C=8 \cdot 3 ; z=2.8$ & 4.21 & 1.28 & 19 \\
\hline Fall** & 37 & 86.5 & $Z=8.1 ; J=5.4$ & 4.16 & 1.31 & 19 \\
\hline -Poison** & 36 & 100.0 & & 3.58 & 1.76 & 19 \\
\hline -Slip** & 36 & 94.4 & $C, F=2.8$ & 3.79 & 1.51 & 19 \\
\hline -Ear Prot.** & 37 & 86.5 & $G=10.8 ; E=2.7$ & 3.16 & 1.69 & 19 \\
\hline -Eye Prot. & 37 & 100.0 & & 2.40 & 1.77 & 20 \\
\hline I-Electrical & 35 & 91.4 & $T=5.7 ; 0=2.8$ & 3.58 & 1.73 & 19 \\
\hline- Exit & 37 & 89.2 & $V=8.1 ; U=2.7$ & 2.84 & 1.74 & 19 \\
\hline I-Entangle & 34 & 91.2 & $A=8.8$ & 3.78 & 1.65 & 18 \\
\hline (-Explosion** & 37 & 56.8 & $T=35.1 ; H=5.4 ; Z=2.7$ & 3.88 & 1.49 & 17 \\
\hline -Flammable & 36 & 88.9 & $\star K=5.6 ; A, W=2.8$ & 2.74 & 1.62 & 19 \\
\hline -First Aid & 36 & 91.7 & $I=5.6 ; T=2.8$ & 1.94 & 1.35 & 17 \\
\hline -Extinguisher & 37 & 97.3 & $M=2.7$ & $2 \cdot 10$ & 1.68 & 19 \\
\hline -Head Prot. & 36 & 97.2 & $Q=2.8$ & 2.60 & 1.71 & 20 \\
\hline J-No Entry & 37 & 89.2 & $V=11.1$ & 2.84 & 1.66 & 19 \\
\hline -No Exit** & 36 & 58.3 & $U=16.7 ; Z, J=8.3 ; T, R, B=2.8$ & 4.33 & 1.10 & 18 \\
\hline 1-No Flame & 36 & 86.1 & $0, K=5.6 ; S=2.8$ & 2.56 & 1.54 & 18 \\
\hline -No Smoking & 36 & 97.2 & $U=2.8$ & 2.68 & 1.56 & 19 \\
\hline I-Radiation** & 34 & 88.2 & $T=5.9 ; P, Q=2.9$ & 3.84 & 1.66 & 19 \\
\hline$-T r i p \star *$ & 36 & 80.6 & $\mathrm{~B}=8.3 ; \quad=5.8 ; C, B=2.9$ & 4.05 & 1.32 & 19 \\
\hline A-Foot Prot. & 34 & 91.2 & $E=5.9 ; B, L=2.9$ & 2.57 & 1.73 & 21 \\
\hline
\end{tabular}

P=Fire Extinguisher

T=Laser Hazard

M=Eyewash location

* Letter refers to letters which identified the symbol message on the matching form, and which are given in the first columen of this table.

** Refers to symbol signs not installed at the time of testing.

*** The rating scale used 1 to Indicate that the sign had been seen; 5 that it had not. Thus, a low rating means that the 81 ga was probably seen.

$1_{\mathrm{N}}$ refers to the number of people who completed each answer. 
matched with definition " 0 " by 88.9 percent (of the 36 people who made the match). It was incorrectly matched with " $K$ ", Explosion, by 5.6 percent, and with both "A", Corrosion, and "W", No Open Flame, by 2.8 percent. Flammable also received a mean rating of 2.74 with a standard deviation of 1.62 , from the 19 people who completed the conspicuity portion.

Thirty-seven people completed the confusion portion of on-site evaluation form. Their data indicated that the Explosion symbol was identified correctly by only 53 percent of those responding with major confusions arising with the message, Laser. The high number of confusions seen for the Explosion symbol, not seen in the initial understandability data is most likely due to an unintentional change in the graphic configuration of this symbol during the sign fabrication process. Figure 46 demonstrates that the reconfigured symbol now has a strong horizontal directional component, not unlike the common Laser symbol. Furthermore, No Exit was identified correctly by only 58 percent of the participants with major confusions arising with symbols for No Entry, Trip, and Entanglement. Some of these confusions may have arisen because the extreme graphic complexity of the No Exit symbol resulted in the loss of critical detail on the photocopied test form. Such loss of detail could also occur as the result of dust or smoke for an installed sign, and suggests that this symbol should be redrawn and simplified. Confusion of No Exit with No Entry also arose in the initial data, probably due to the graphic similarity of these two symbols (see section 4). Furthermore, the No Exit concept does not appear to be a familiar one (Collins and Lerner, 1982). The Corrosion symbol was identified correctly by only 78 percent of the participants, with confusions arising with Eyewash. Here subjects may have been indicating the action to take after encountering a corrosive chemical.

The data on the conspicuity of the symbols, also contained in table 35 were somewhat less clear-cut. Only 19 people attempted to complete this form, with many people indicating that they had not been underground or had not been in a position to see the signs. The conspicuity data indicated that the 12 signs actually installed at the site received generally low numerical ratings, indicating that they had, in fact, been seen. (The rating scale instructions called for the use of a 1 if the sign had been seen, 5 if it had not. Signs actually installed at the site generally received mean ratings below 3.) In particular, signs located in heavily traveled areas such as the main gate, the shop and the underground entry typically received lower numerical ratings (indicating that the signs were conspicuous.) Only the Entanglement and Electrical symbols, located in underground bulkhead rooms, received somewhat high ratings. The Poison symbol, which was not installed at the site, received a high rating, despite its perfect score on the confusion portion of the form. Although the limited number of people responding to this portion of the form makes it difficult to draw firm statistical conclusions, the data do suggest that those signs that were installed were seen and remembered.

In summary, the data suggest that the original Explosion symbol should be used, rather than the modified version, and that the No Exit symbol should not be used where it could be interpreted as No Entry. Despite the confusions for a few symbols, the data indicate strongly that the majority of the symbols were well understood, and not confused with other symbols within the set of symbols 
selected for the LL facility. In particular, symbols for Protective Gear, General Safety, Ex1t, and F1re Equipment were well understood, as were most of the Hazard Warning symbols. The consplcuity data further suggest that the symbols were successful in attracting attention. In summary, the data given in table 35 indicate that symbol signs installed at the LL site were generally well understood and successful in attracting attention, thus fulfilling their intended purpose.

\subsubsection{Comments from the EM Evaluation}

Comments during the evaluation of $81 \mathrm{gn}$ understandab1lity at the EM site (see 6.2) included a number of suggestions by the miners particlpating in the test1ng. There was a feeling that some signs should be red to reflect danger or high levels of hazard, but that the yellow sucessfully indicated caution. Some miners felt that the F1rst A1d and Exit signs should be red rather than green because these represent emergency conditions. (Note that some code recommendations are in conflict over the use of red and green for these s1tuations, as we11). The miners generally felt that the prohibition c1rcle and slash were quite effective. As far as specific symbols were concerned, they did not think the redrawn Explosion symbol was at all effective, along with the General Warning symbol. They suggested that the Hard Hat should be redrawn to resemble a miner's hard hat (with a cap-lamp connection) and not look like an "upside-down soup kettle". The Fire Alarm symbol was not considered to be effective, nor was the alternate Exit symbol showing an arrow (see f1gure 37 ). Many of the miners expressed a $11 \mathrm{k} 1 \mathrm{ng}$ for the No Smok1ng and Entanglement symbols, however. Some miners also suggested that a few carefully chosen words could 1ncrease the effectiveness of the symbol signs, an opinion shared by their safety and training personnel.

\subsection{GENERAL CONCLUSIONS FROM THE ON-SITE EVALUATION}

In general, the overall good understandab1l1ty of the symbol signs demonstrated by the different evaluation procedures suggests that the symbols signs installed communicate reasonably effectively. The data suggest that the symbol signs were generally well understood and conspicuous enough to be seen and remembered even by visitors on tours through a site. These data indicate that the symbol signs were effective in communicating information and attracting attention. They were also effect1ve in terms of physical parameters such as contrast, durability, and general visibility.

Although the problems which occurred for Individual symbols, such as Flammable and Explosion, have already been discussed, two additional points can be made. The first is that the rather small change made in the graphic configuration of the Explosion symbol had a large effect upon 1ts understandability. This suggests that any new symbol introduced to a site, or any change to an existing symbol should be evaluated with the miners at that site. Secondly, the problems with the Flammable symbol might be lessened by the use of a surround shape (such as diamond), which can indicate "hazard" as well as the circle and slash indicate "prohibition". Use of a red background color to indicate danger, energency, or stop might also lessen confusions with "fire permitted". 
Other problems occurred where the message was too complex for a single symbol to represent it. This is particularly true for situations which vary over time, represent more than one hazard or require both a prohibition and a hazard message. Examples of such signs would include: Blasting in Progress, Flammable/ Explosive Area, or Blasting, No Admittance. Discussions with mine personnel indicated that they felt that some combined word/symbol signs would be advisable, either as a training aid (while people learned the meaning of the symbols) or as supplementary information. In this format, the symbol would be used to transmit information about the presence of a hazard, and to attract the user's attention, while the word message would provide additional information. Such signs have the potential of being very cluttered, which might obscure the intended message, however. As a result, such signs require an evaluation of the legibility of the overall sign layout to determine if the symbol is still conspicuous and if the addition of words has cluttered the message beyond recognition.

While the mounting problems have already been addressed, it should be noted that simply affixing a sign to a mine wall is sometimes easier said than done. Signs suspended by wires from the roof are subject to movement from ventilation air or passing equipment. Yet, the signs could not be attached to the walls because they crumbled. A stationary pole-mounted sign may be the best solution if it can be kept out of the way of mobile equipment. Other problems occurred when the space was not big enough for the sign, forcing it to be mounted below or beside the hazard. Clearly, having signs in a variety of sizes is desirable, as well as in a format with an adhesive backing for marking equipment hazards.

One side benefit of the symbol signs is that where word and symbol signs of comparable size were displayed together, the symbol sign was visible at a greater distance (see figure 49 which shows this effect for the Personal Protective Gear and No Open Flame/No Smoking signs.) In this respect, the symbol signs are more conspicuous than their word counterparts, and hence have the possibility of receiving greater attention.

Thus, the testing program indicated that when chosen appropriately, symbol signs are an effective means of communicating safety and hazard information. Symbols for personal protective gear, safety equipment, fire equipment, prohibition and egress appear to be adequate in their present format. These symbols are well understood and appear to be both legible and conspicuous. Thus, the recommendations for supplementary word signs are most applicable to the hazardwarning signs. It is this class of messages for which changing conditions, restrictions, and supplementary information may be needed on the sign. With these exceptions, the symbol signs emerged as generally effective during the on-site testing at both mine sites. 

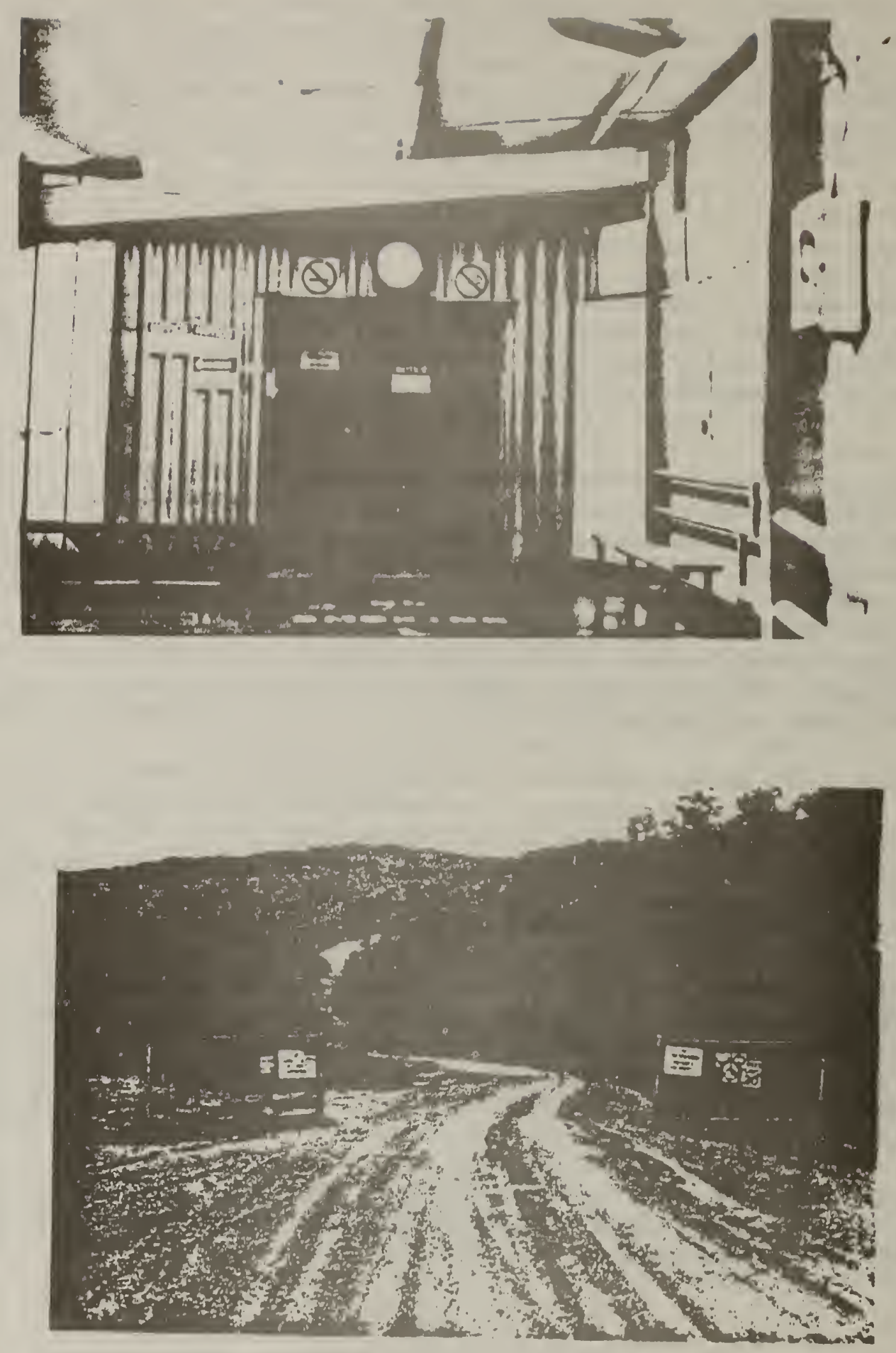

Figure 49. Photographs comparing symbol signs with adjacent word signs 


\subsection{SUGGESTIONS FOR IMPROVEMENT IN SYMBOLS}

A number of recommendations can be made for improving symbol sign effectiveness, based on data from the initial testing and the in-mine evaluation. A major needed improvement to the set of symbols selected in 5.5 is the need for a consistent graphic style in both image content and surround shape. The latter will be discussed in 7.2. Both the AIGA (1979) and Follis and Hammer (1979) emphasized the need for an integrated, internally consistent graphic style within a particular set of symbols. Needless to say, the symbols presented in. and Handbook were drawn from a variety of sources which depicted no single, consistent graphic style. As a result the final selections require graphic redesign and refinement to bring the set to a more consistent format. Even the symbols used in the in-mine testing require some graphic modification for consistency and legibility (see Figure 45).

Based upon all the research. to date, the following changes in image content can be suggested. These changes also include suggestions given by individual miners during the debriefing following part 1 of the present study (see appendix). 1) Where possible, follow the ISO/DoT/UN format for Hazard Warning symbols, but simplify the imagery using fewer details and bolder graphics. 2) Try to include a person with the hazard where possible. Where the hazard is more likely to be initiated by only a part of the body, showing the hand with the hazard appears effective. For this reason, the Electrical Hazard symbol might show the wire with the hand rather than the whole body. However, for Slip, Trip and Fall, the whole body is immediately affected, and hence is depicted. 3) For Sudden Pressure Release, a hose or connection should be shown rupturing. 4) Both the Safety Shower and Eyewash images require some refinement. For safety shower, the image should be greatly simplified with a more universal person. The handbook presents an initial attempt at simplification and reduced detail. For Eyewash, the drops should be shown approaching the eye rather than the nose. 5) For Eye Protection, it might be more effective to show glasses rather than an eye mask. The Respirator symbol also should use the same head as the other symbols. 6) The Exit and No Exit symbols should be redrawn to provide consistency between the two without unnecessary detail. 7) The Keep Door Open/Closed symbols should be made more massive, to resemble mine doors rather than ordinary doors. 8) The original explosion symbol, showing an object blowing apart, should be used. Other suggestions include increasing the legibility and graphic consistency of the whole set.

\subsection{SURROUND SHAPE AND COLOR}

The results of part 2 of the present experiment indicate that the diamond should be seriously considered as a plausible surround shape for hazard warnings. Therefore the hazard warning symbols should be redrawn with the diamond. Use of the diamond is consistent with the MUTCD (DoT, 1979) and created no problems during the in-mine testing. (The diamond is, however, inconsistent with ISO and EEC recommendations.) Other results indicate that the circle and slash are reasonably well understood for prohibition. This convention appears to be effective, provided that the interior image is not overly detailed. The 
use of a square for safety and circle for protective gear did not elicit comment. These shapes were fudged as less hazardous and therefore appear more appropriate for safety information as opposed to hazard warning messages. Furthermore, unlike the dlamond for hazard warning, there appears to be no reason not to follow exlsting ISO/Canadian practice for the surround shape for the safety and egress messages.

As far as color 18 concerned, there appears to be agreement among miners that red and yellow 1ndicate hazard. Th1s is in 11ne with current ANSI 235.1 (1979) recommendations in which red is used for danger and yellow for caution. As a result, it appears reasonable that color coding be used to indicate the level of hazard--with red reserved for those situations where there is a high probabllity of personal infury or death as well as extensive property damage, and yellow used for those situations where a lesser degree of injury or property damage might result. Again, because existing color conventions do not appear contradictory for the other categories of safety symbols, the ISO recommendations appear valld. These include: solid green background and white 1mage for safety Information, including egress; red circle and slash, white background, and black image for prohibition; solid blue background and white image for personal protective gear; and solid red background with white image for fire fighting equipment. Color should not be used as the sole indicator of a hazard/safety message due to the prevalence of red-green color deficlencles, however.

\subsection{CRITERIA FOR EVALUATING SYMBOL EFFECTIVENESS}

Schiff (1980) commented that use of symbols that "naturally suggest their referents or connotatives correspond to thelr referents are important considerations" (p. 340). Thus, a symbol is likely to be more effective if 1 t begins with a reasonable degree of understanding or meaningfulness to the intended audience. As a result, throughout the present report, the major criterion for determining the effectiveness of a symbol has been understandability. Understandability was arbitrarlly defined as a certain percentage of correct answers on a multiple choice response form. Clearly, this is not the only criterion by which effectiveness may be measured. Understandabllity 1tself may be affected by a number of factors. Context is one of the most 1mportant. Something that one expects to see is 11kely to be more understandable than an unexpected object. Testing a symbol in context, as on a piece of machinery or near a potential hazard would certainly be expected to increase 1ts apparent understandability (Cahill, 1975). In some respects, testing a symbol out of context can be considered a "worst case" approach. Symbols wh1ch perform well under these conditions should continue to be effective when appropriately located. Although use of a multiple cholce procedure will 1tself provide some context through the varlous cholce alternatives, performance could also be impalred because a miner did not understand, or agree with, the choices given for a symbol. Yet, numerous problems are encountered in scoring a definition-style approach for assessing symbol comprehension. These were discussed by Collins et al. (1982) and Lerner and Collins (1980a). This latter approach also assumes a certain verbal dexterity on the part of the participants. Finally, it should be remembered that correct identification of a symbol does not necessarily mean that safe behavior will follow. 
In addition to understandability, however, other criteria for assessing the effectiveness of a given set of symbols should also be considered. First and foremost is that of legibility. Mining is typically a dirty, dusty operation in which low light levels and poor visibility can occur. As a result, any set of safety symbols should be evaluated for legibility under degraded viewing conditions, to maximize the likelihood of being seen under field conditions. Other criteria include discriminability (or minimizing confusion between symbols within a set), and behavior (or determining that the symbolic message results in the appropriate actions). Determining the correct size of a symbol for both good legibility and conspicuity is also critical.

Throughout the preceding paragraphs, understandability was treated as though it were a clearly defined entity. Because it is not, a criterion of 85 percent correct responses was set as an arbitrary cut-off value below which a symbol could be said not to communicate. Similarly, a criterion of 5 percent critical confusions was also suggested to eliminate those symbols for which substantial misconceptions and inversions exist. These values were adopted from recommendations by standards groups and previous studies. Although they appear reasonable, the criteria are by necessity arbitrary and subject to discussion. For example, adoption of more lenient or stringent criteria is certainly possible. Conceivably, the level of hazard or potential danger to the user could also be used as an index by which to set a criterion for selection. Symbols for more dangerous situations could require a higher percentage correct, for example, before they are used as the sole hazard-warning message. More lenient criteria could be selected if training were provided, or additional verbal material added, or if workers were familiarized with the symbols and the possible hazards. Selection of an acceptable criterion cut-off appears to depend on the criticality of the message, as well as on opportunitles for training or providing additional verbal material.

Certainly for those symbols which do not meet the 85 percent correct criterion, additional information for the user appears necessary. In addition, perhaps the graphic rendition of such symbols should be changed, in the hopes that a more effective design might emerge. (Four of the seven symbols which did not meet the understandability criterion are incorporated in existing standards which could make any graphic change more difficult.)

\subsection{DEVELOPMENT OF A SET OF RECOMMENDED SYMBOLS}

One problem in the development of a set of symbolic safety messages is the size and extent of the message set. The 40 messages studied in the present experiment represent common mining hazards and safety messages. Generic symbols which depicted a class of potentlal hazards on safety messages were selected for study. Many others exist, however. Furthermore, subsets of messages exist within a single referent. For entanglement, for example, the symbol could depict the most vulnerable body part (finger, hand, foot, leg, etc.) as well as different equipment types. While it appears more efficient to use a single symbol to communicate a generic hazard, instances may arise where more specificity is desirable. However, the use of many, very specific images depicting a set of limited messages may potentially confuse the user, who is forced to distinguish between very similar images. The end concern must always 
be for the users and the effectiveness of the symbolic message in communicating with them. A set of guidelines for the graphic development and user evaluation of a proposed symbol at a given site might well be a good solution. Determining the effectiveness of every proposed message/symbol combination was clearly beyond the scope of the present study. Instead, the messages that appeared to be most critical from the sources given earlier were studied in the hope that this information, albeit limited, would prove useful to those concerned with mine safety symbols.

Despite the many problems in developing and evaluating a set of safety symbols noted in earlier portions of this report, the present study successfully 1dentified symbols for 34 safety messages which meet the understandability criteria. The generally good agreement with the data obtained by Collins et al. (1982) in their study of industrial safety symbols suggests that a set of symbols has been identified which can successfully communicate safety information to a wide variety of industrial and mining personnel.

The task is not yet complete. Decisions remain about selecting the best surround shape and color for hazard warning symbols, because of conflicts with existing national and international standards. Some 1mages also require graphic modification as well as integration into a consistent set. The final set should then be evaluated with an appropriate mining audience to ensure that unexpected confusions do not arise, and that legibility problems are minimized. The issue of legibility raises the issue of size for symbols. Because all guidelines for symbol size appear to be derived from letter legibility (see section 8 ), a measure such as minimum critical detail or strokewidth should be developed for specifying symbol size. Once these and other issues have been settled, then the overall effectiveness of the symbol within a word sign format, such as the one recommended by ANSI Z35.1 (1972), should also be assessed to determine overall conspiculty and legibility. In addition, a study similar to the one conducted by Laner and Sell (1960) which demonstrated that safety posters effectively increased safe behavior, should be conducted. A critical research issue in workplace signage is that of determining if people notice and follow the recommendations given by safety signs and symbols.

Nevertheless, the evaluation given in the preceeding pages appears to allow the selection of a reasonably effective set of hazard pictorials and safety information symbols. The conclusions are still based on a limited sample of subjects, but the good correlations with the earlier study, with a different group of participants, provides at least some assurance that the symbols selected should be reasonably understandable. The data obtained in the present study suggest that the symbols discussed in section 5 can be used as the basis for developing a final set of safety symbols not only for mines but for other industrial applications as well. 


\section{HANDBOOK FOR USING SYMBOL SIGNS IN MINES}

\subsection{INTRODUCTION}

Because symbol signs can be perceived more rapidly and accurately than word signs, the U.S. Department of Transportation (1979) uses them on the highways. Symbols often require less space on a sign than a comparable word message, so that symbol signs can be larger, command more attention, and be more legible under poor viewing conditions (Forbes, Gervais and Allen, 1963; King, 1975). Finally, of course, symbols communicate information without the use of words, a desirable attribute if the audience does not read English well. Because symbols can communicate essential information rapidly and accurately, without the use of words, they have many advantages for use in modern, mechanized mining operations.

As a result, the National Bureau of Standards (NBS) undertook an evaluation of the effectiveness of symbol signs in mines, under a contract supported by the U.S. Bureau of Mines (J011-3020). This research was designed to determine if safety symbols were understood by miners and were effective as mine safety signs. In this research, two sets of symbols for mine-safety and hazard-warning messages were evaluated with miners at 8 different mines in the United States. Based on this evaluation, a set of mine safety symbols was developed. This set of symbols was further evaluated for understandability during an in-mine testing program at two mine sites in the Eastern United States. This testing program evaluated confusions among the symbols and determined if the symbols installed in the mine were seen and remembered. The in-mine testing program also evaluated the physical parameters of the signs such as durability and contrast, in addition to determining the opinions of mine-safety personnel about symbol sign effectiveness.

Based upon the various evaluations of mine safety symbols, a number of suggestions can be made for using symbol signs in mines. These suggestions are intended to be helpful to the mine safety officer who is confronted with symbol signs for the first time, and must decide when and how to use them. Because not all aspects of sign use were evaluated by NBS, many of the suggestions are drawn from sign design handbooks, voluntary standards (both national and international), and the Manual of Uniform Traffic Control Devices (MUTCD), of the Department of Transportation (DoT, 1979). These suggestions are only guidelines, and are, in no sense, regulations or standards. Rather, they are intended to serve as a framework for helping anyone who wishes to institute a symbol sign system at a mine site. They are intended to supplement the individual safety officer's own experience, when using a relatively new type of sign at a mine site.

\subsection{CURRENT STANDARDS FOR SYMBOL SIGNS}

There is no standard, voluntary or regulatory, for using safety symbols in workplaces or on products in the United States. The American National Standards Institute (ANSI) has a (voluntary) standard for word signs, the Z35.1 (1972) "Specifications for Accident Prevention Signs", and another for safety colors, the 253.1 (1979), "Safety Color Code for Marking Physical Hazards". 
Both standards are now being revised by the 2535 committee on Safety Colors and Signs. This committee is also drafting a standard for safety symbols. The Occupational Safety and Health Administration regulation section 1910 (CFR 29, 1981) now specifies only the symbol for slow moving vehicles, having deleted specific reference to the radiation and biohazard symbols. It does specify the radiation symbol for use at construction sites in section 1926 (1981), however. It also specifies the meaning of safety colors in line with the ANSI 253 recommendations. The Mine Safety and Health Administration (MSHA) in CFR 30 (1980) provides no specific recommendations for the use of symbols or safety colors, although it does list situations which require signs.

As a result, because safety symbol signs are an innovative means of communicating safety and hazard information, the following suggestions are given for thelr use at mine sites. Before providing specific suggestions for using symbol signs at a mine site, it should be noted that the MUTCD (DoT, 1979) is probably the best guidebook to use for signing mine haulageways and roads. The MUTCD provides guldance on symbol signs, word signs, placement, size (as a function of roadway speed), color, mounting procedures, and general information about road signs. These guldelines represent one of the best compilations of traffic sign information, and are applicable for road signs on mine sites.

The suggestions given in the present Handbook apply to other, non-roadway, areas on a site such as the main faclilties, preparation plants, shops and maintenance/repalr areas, and permanent underground installations.

The philosophy expressed by DoT in the MUTCD about the properties of effective traffic control devices and signs is applicable to any system of safety signs. The MUTCD notes that signs should meet the following five requirements:

Fulfill a definite need.

Command attention.

Communicate a clear and simply stated meaning.

Command the user's respect.

Provide adequate response time.

To meet these requirements, attention should be paid to factors such as: sign design, placement, maintenance, and uniformity. In the following pages, suggestions for using these factors are given as guidance for developing and installing an in-mine safety symbol sign system.

\subsection{SELECTION OF SYMBOL SIGNS}

The initial decision about which situations require safety signs should be based on the MSHA (1980) code requirements. Table 36 presents a 1 ist of MSHA sign messages. Although MSHA does not require symbol signs for any of these messages, the data obtained by the NBS-BoM symbol research suggests that at least 11 of the messages could be effectively communicated by symbols. These messages are marked in table 36 with an asterisk. In addition, the symbol research suggested an additional 20-25 safety and hazard warning messages for which symbol signs could also be used. 
Table 36. Mine Safety Messages from the Code of Federal Regulations

General Message

*No Entry,

Restricted Entry

Hazard, Danger

(general)

* No Smoking

*No Open Flame

*Explosive

Blasting Switch,

Safety Switch

Burn Rate of Fuse

*Flammable Liquid

Compressed Gas

Hazardous Material

*Toxic Material

*Location of Fire-Fighting

Equipment

Location of Self-Rescuer

*Electrical Danger

Electricity Lock-Out

Electricity Disconnect

Traffic Control

\section{$\underline{\text { Relevant Citations }}$}

$55.3-5,55.6-103,56.3-5,57.6-103$

$57.3-5,57.5-28,56.6-103,57.20-20$, $57.21-43,75.303,75.1711-3,77.1303(\mathrm{~g})$

$55.20-11,56.20,57.20-11,75.303$

$55.4-2,55.6-110,55.8-5,56.4-2$, $56.6-110,56.8-5,57.4-2,57.6-110$, $57.8-5,77.1102$

$55.4-2,55.8-5,56.4-2,56.8-5,57.4-2$, $57.8-5,77.1102$

55.6-20(i), 55.6-43, 55.6-159(b), $56.6-20(\mathrm{i}), 56.6-43,56.6-159(\mathrm{~b})$, $57.6-20($ i $), 57.6-29,57.6-43,57.6-159(\mathrm{~b})$, $77.1301(c)(9), 77.1301(e), 77.1302(c)$

$77.1303(\mathrm{hh})$

$77.1303(v)$

$77.1103(a)$

$75.1106-3$

$55.16-4,56.16-4,57.16-4,77.208(c)$

$55.20-12,56.20-12,57.20-12$

$55 \cdot 4-23,56.4-23,57.4-23$

$75.1712-2(f), 75.1714-2(g)$

$55.12 .21,56.12-21,57.12-21,77.511$

$55.12-16,55.12-17,56.12-16,56.12-17$, $57.12-16,57.12-17,75.511,77.501$

$75.601,75.809,75.904,77.600$

$55.971,56.971,57.971,77.1600(\mathrm{~b})$

* Symbols exist for these messages 
Table 36. (Cont1nued)

\section{GENERAL MESSAGE}

Traffic Control

Train Crossing

Parked Vehicle Hazard

Projection from Vehicle

Men Working (in shaft)

Emergency Stop (hoist)

Speed (holst)

Maximum Load (holst)

Unsafe Equ1pment

*Fall Hazard

Obstruction

*Egress

*Keep Door Open/Closed

Shelter Hole

Reduced Clearance

Reduced Overhead Clearance

\section{RELEVANT CITATIONS}

$55.971,56.971,57.971,77.1600(\mathrm{~b})$

$55.9-59,56.9-59,57.9-59$

$55.9-68,56.9-68,57.9-68,77.1607(0)$

$55.9-49,56.9-49,57.9-49,77.1607(t)$

$55.19-107,56.19-107,57.19-107$,

$55.19-108,56.19-108,57.19-108$

$55 \cdot 19-13,56 \cdot 19-13,57.19-13$

$77.1908(k)$

$77.1402-2$

$55.9-73,56.9-73,57.9-73$

$55.11-12,56.11-12,57.11-12$

$57.9-104$

$57.11-51(b), 75.1704,77.1101(c)$

$55.21-57,56.21-57,57.21-57$

$57 \cdot 9-111$

$55.9-83,56.9-83,57.9-83,75 \cdot 1403-8(\mathrm{~b})$, $77.1600(\mathrm{c}), 77.1605(\mathrm{~h})$

$55.9-60,56.9-60,57.9-60,55.11-10$, $56.11-10,57.11-10,75.1403-10(\mathrm{c})$, $77.1600(c)$ 
Table 37 categorizes these safety messages in 5 different categories: Hazard Warning, Mandatory Action, Prohibition, Egress location, and Safety and Fire Equipment Location. These categories are typically communicated by the use of both color and surround shape. These provide additional information about the message. (For the handbook, Keep Door Open/Closed is categorized as mandatory action, as this message appears to be more a required action than egress-related.)

Hazard warning messages are used to warn of the presence of a hazard, and, if possible, to indicate the consequences of encountering the hazard. This category includes both danger and caution messages, such as "Danger, blasting in progress", or "Caution, slippery floor ahead".

Mandatory action messages are used to indicate required actions. This category primarily includes protective gear messages, such as "Wear Hard Hat", but could also include other required actions, (such as "Keep door open/closed").

Prohibition messages indicate forbidden or prohibited actions, in other words, something that must NOT be done. This category includes messages such as "No Smoking in this area".

The egress category includes messages related to Exit or passage through a door or exitway. This category also includes some prohibitory messages related to exit, such as No Exit.

Safety and Fire Location messages indicate the location of safety and emergency equipment. For example, a typical safety message might be "Eyewash located here", while a fire equipment message might be "Fire extinguisher location".

Figure 50 presents a series of symbols suggested for messages within each of these categories. (These symbols were found to be understood by a large number of miners during the NBS research on mine safety symbols.)

\subsection{FABRICATION OF THE SYMBOL SIGNS}

The following suggestions for symbol sign configuration, color, and size are given for fabricating the signs. These suggestions assume that the symbols have been determined to be effective with the miners at the site, through use of an evaluation procedure such as that given in Section 8.5. A symbol consists of an interior image plus a surround shape. The images shown should be in accordance, as closely as possible, with the images shown in figure 50. A typical example is given in figure 51.

\subsubsection{Color and Surround Shape}

The following suggestions are given for using surround shape and color with each of the message categories. The physical specifications for the symbol sign colors should be those specified by ANSI Z53.1 (1979). This standard provides the specifications for each color, in a format familiar to most sign manufacturers, and is a good way to ensure that "red" is the correct "red". The colors have been specified to yield the best possible color discrimination for all people, including those with color vision deficiencies. 
Table 37. Categories of Safety Messages Used in the Handbook

HAZARD WARNING

Corrosion

Polson

Explosion

Electrical

S11p, Tr1p, Fal1

Sudden Pressure Release

MANDATORY ACTION

Safety Shoes

Safety Glasses

Hand Protection

PROHIBITION

No Smoking

SAFETY AND FIRE EQUIPMENT LOCATION

First Ald

Eye Wash

Fire Hose \& Reel

EGRESS LOCATION

Ex1t

No Exit
Fork11ft

Entanglement

Pinch, Cut/Sever

Overhead

Crush

Hot Surface

Hard Hat

Ear Protection

Keep Door Open/Closed

Do Not Touch

No Open Flame

Safety Shower

Extinguisher

No Entrance 


\section{HAZARD WARNING SYMBOLS}

ELECTRICAL

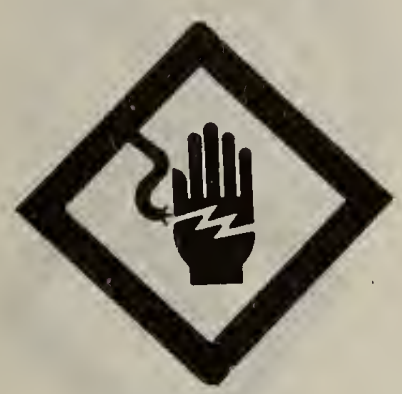

FALL

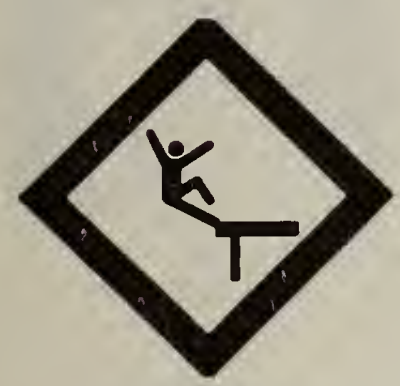

ENTANGLEMENT

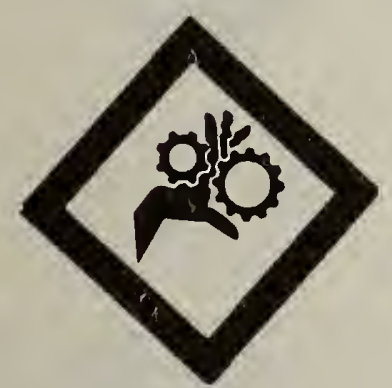

EXPLOSION

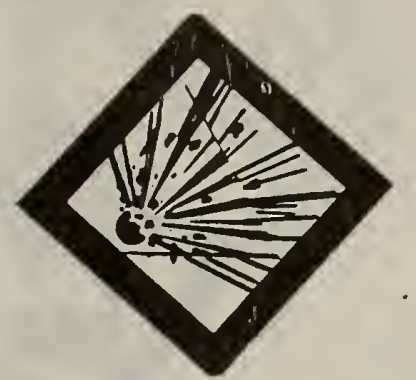

SLIP

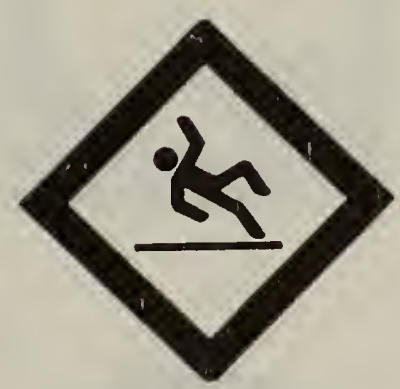

CRUSH

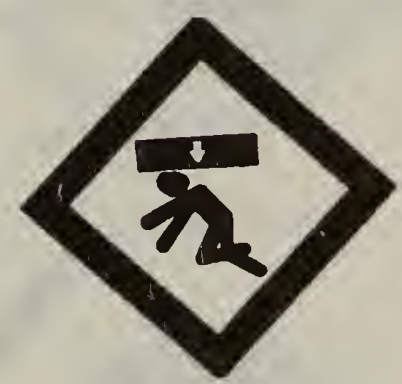

FLAMMABLE

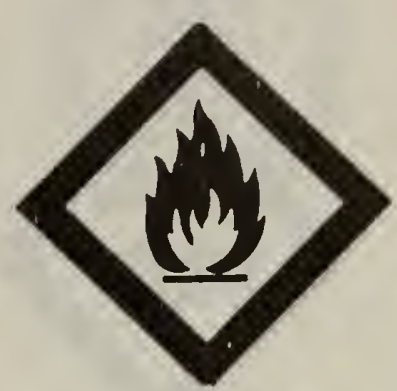

TRIP

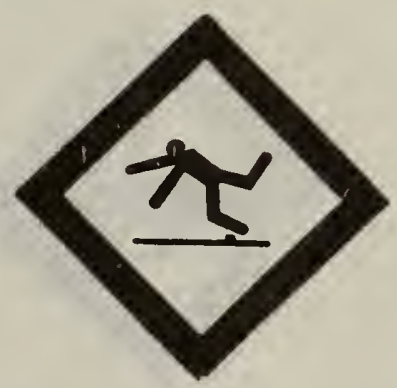

POISON

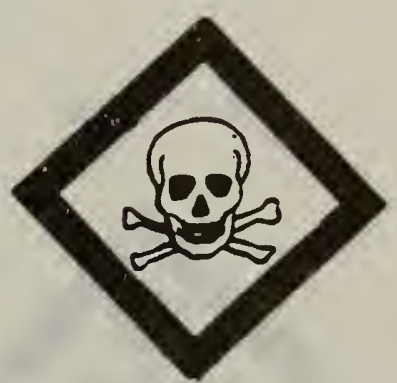

Figure 50. Symbols suggested for safety messages 
ADDITIONAL HAZARD WARNING SYMBOLS

CORROSION

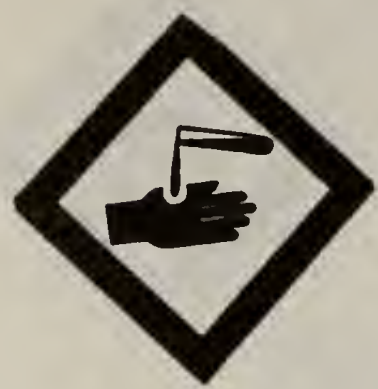

CUT/SEVER

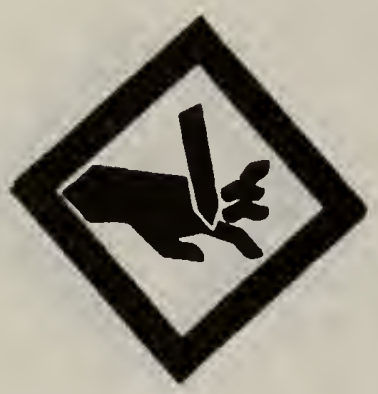

HOT SURFACE

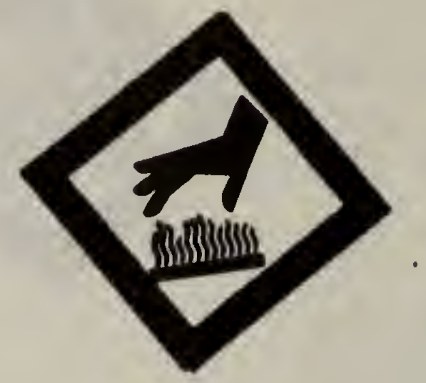

PINCH POINT

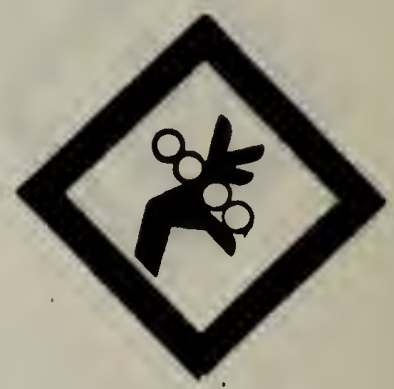

TO BE USED ONLY AFTER TRAINING OR WITH SUPPLEMENTARY WORD MESSAGES

RADIATION

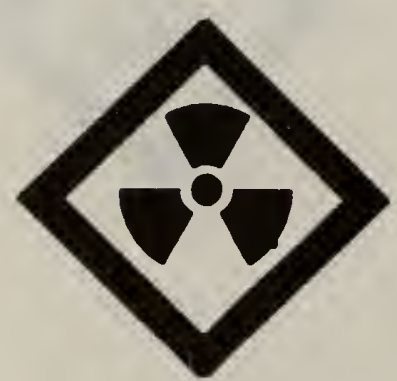

LASER

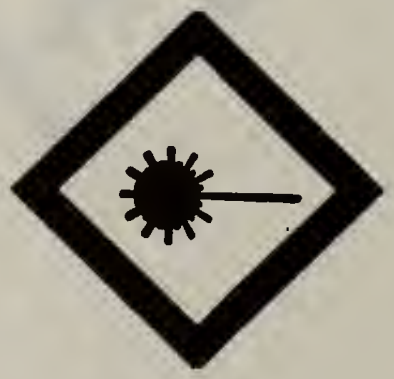

Figure 50. (continued) 
PROHIBITION

NO SMOKING

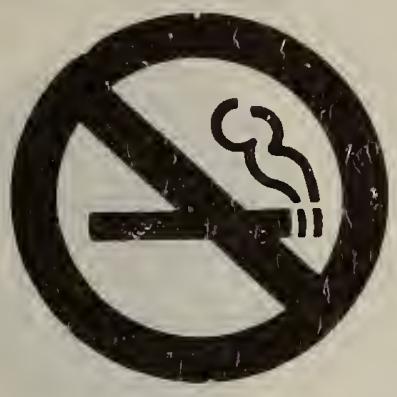

EXIT

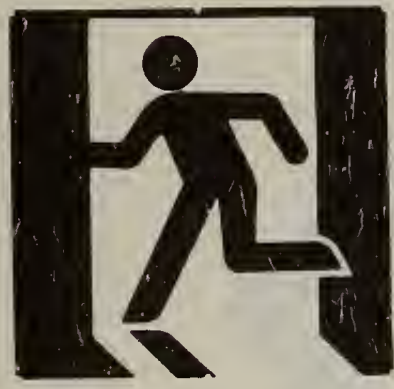

NO EXIT

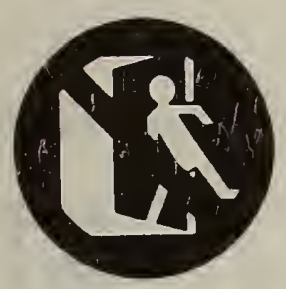

KEEP DOOR OPEN

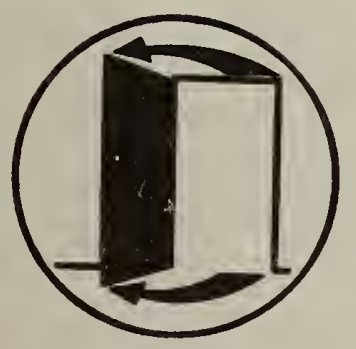

NO OPEN FLAME

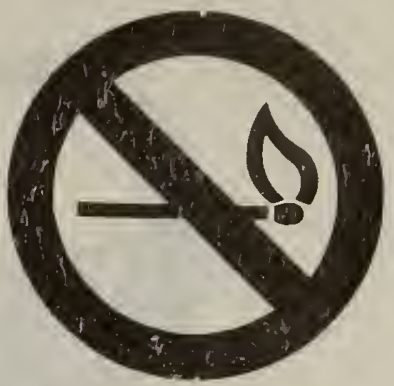

EGRESS-LOCATION

DIRECTIONAL ARROW

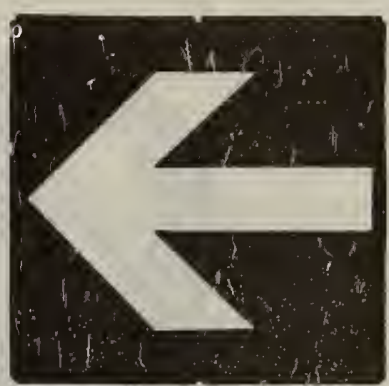

NO ENTRY

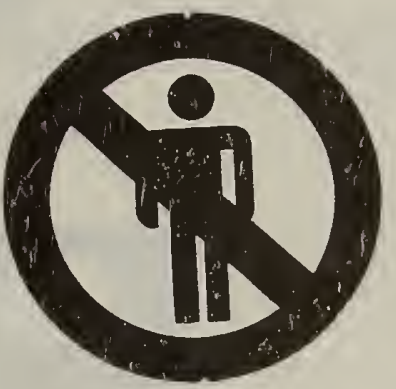

KEEP DOOR CLOSED

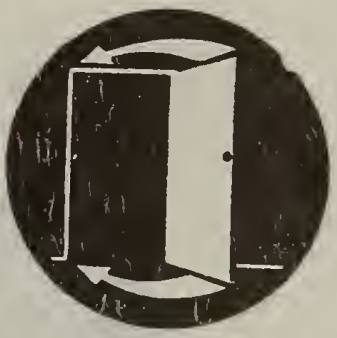

Figure 50. (continued)
DO NOT TOUCH

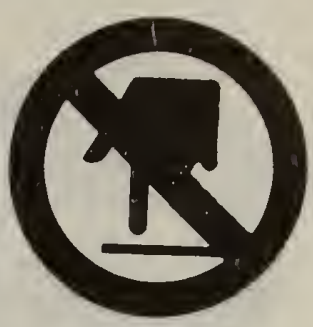


(MANDATORY ACTION)

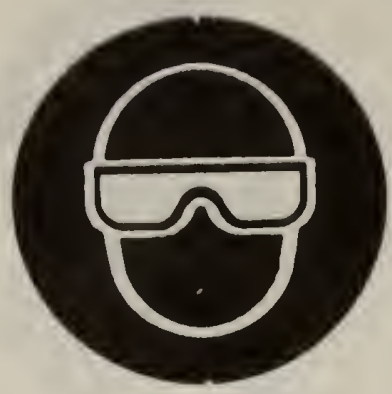

SAFETY GLOVES

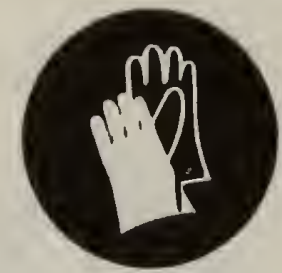

KEEP DOOR OPEN
EYE PROTECTION

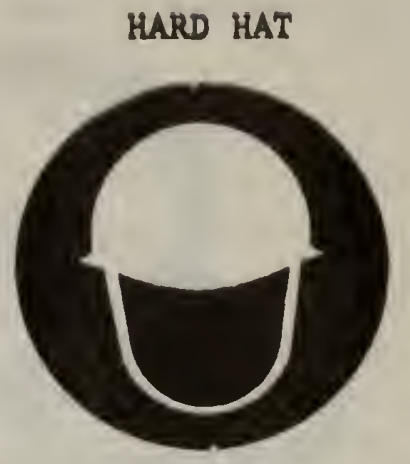

SAFETY SHOES

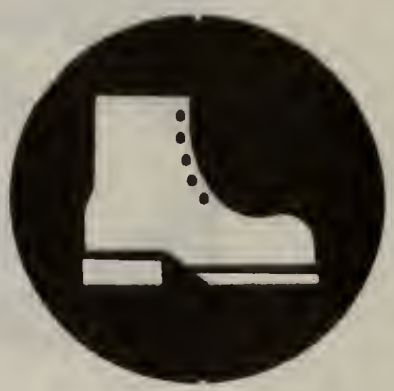

SAFETY AND FIRE EQUIPMENT LOCATION

FIRST AID

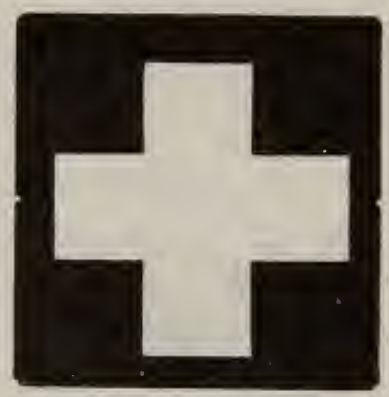

FIRE EXTINGUISHER

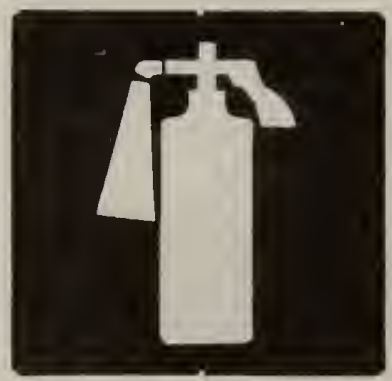

EYEWASH

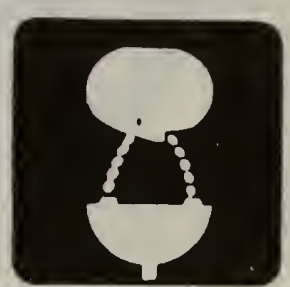

FIRE HOSE AND REEL

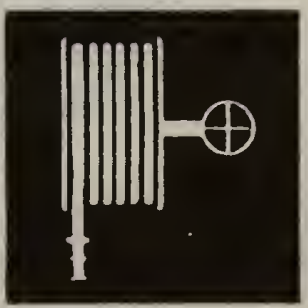

EAR PROTECTION

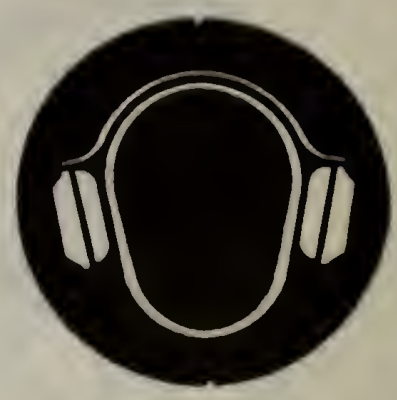

SAFETY SHOWER

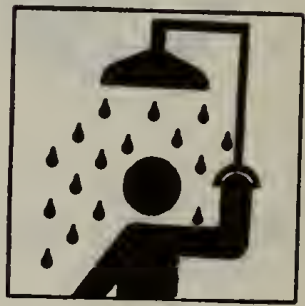

F1gure 50. (continued) 


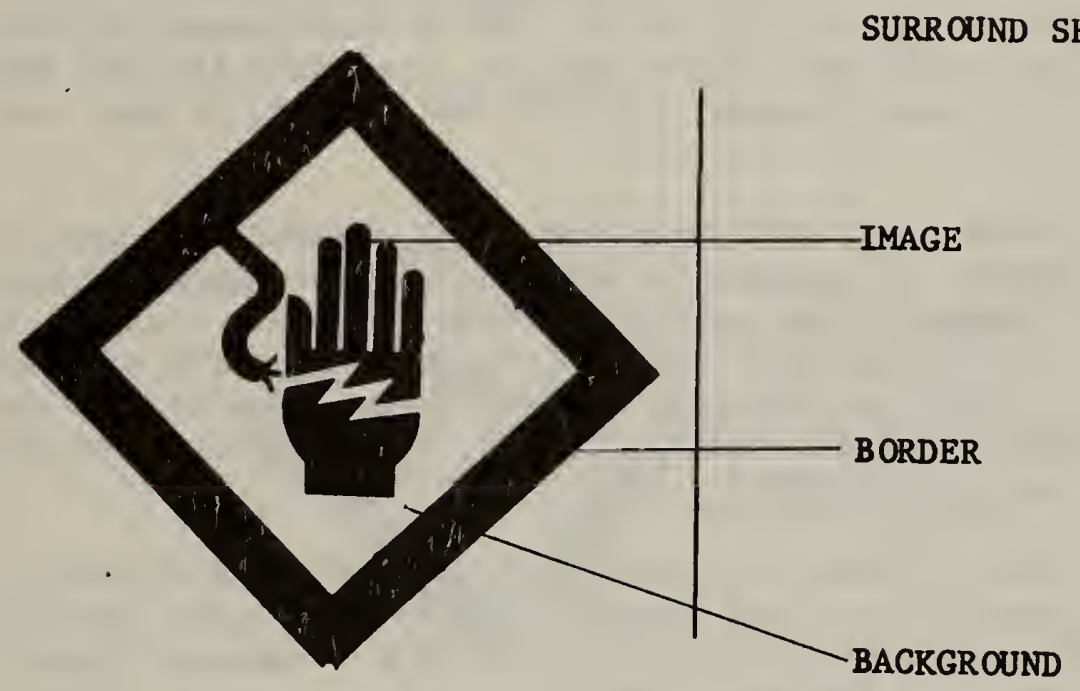

Figure 51. Typical symbol configuration 
The 253 standard also provides the following meanings for safety colors. Red means Danger or Stop; Yellow means Caution; Green means Safety and Location of F1rst Ald and Safety Equipment; Blue means Information; and Orange designates dangerous parts of machines or energized equipment. Specifications are also given for white, black, grey, purple, and brown, although these colors are not given specific safety meanings.

If a safety officer is relying on color to communicate a sense of urgency or danger, he/she should be aware that this message can be lost under certain energy-efficient light sources (which have become very popular due to their low maintenance costs.) Under high intensity discharge lights such as low pressure sodium (LPS) high pressure sodium (HPS), or clear mercury, red colors of ten appear brown, thus eliminating color as a coding dimension. To avold this problem, the sign should be self-1lluminated, the sign color should be modifled, or the lighting system should be changed. Using fluorescent colors which are correctly identifled under most light sources, including LPS and HPS is one way of modifying the color (Jerome, 1977; Glass, Howett, Lister, and Collins, 1983).

Four types of surround shape are suggested. The diamond is suggested for hazard-warning symbols, in accordance with the MUTCD recommendations. A square (or rectangle) is suggested for safety and fire equipment location symbols. A circle is suggested for mandatory or required actions, while a circle and 8 lash are suggested for prohibited actions. (These suggestions are in line with the ISO (1978) recommendations for safety symbols, except for hazard-warning, which is in accordance with the MUTCD.)

Hazard warning symbols should be centered within a diamond shape. (If, for some reason, the symbols are used on equipment to be shipped outside the U.S., the hazard warning symbol should be shown within a triangular shape for conformance with the 1977 EEC Directive).

Two background colors are suggested for use on hazard warning signs in accordance with the recommendations of the ANSI 235 standard (and suggestions made by miners during the in-mine symbol evaluation). The current ANSI standard identifies two levels of hazard: Danger and Caution. Danger is used when the hazard is likely to result in death or severe injury. Caution is used if the hazard is likely to result in injury or damage of a less serious nature. If the hazard is in the Danger category, a red backgound color should be used, with a white 1mage and a thin white border around the background. See figure 52. If the hazard is less serious, it is in the Caution category. A yellow background should be used with a black image and thin black border. The use of yellow as a cautionary color is widely recognized, and is recommended by DoT (1979).

Prohibition symbols should consist of black images on a white background, centered within a red circle and slash. The slash should go from upper left to lower right at a 45 degree angle (DoT, 1979). See figure 52. 
HAZARD WARNING

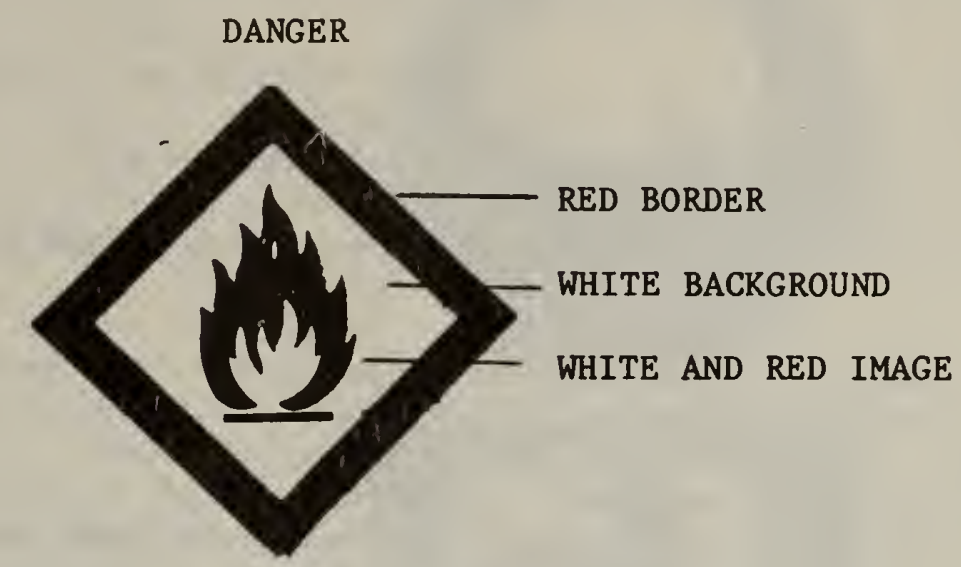

CAUTION

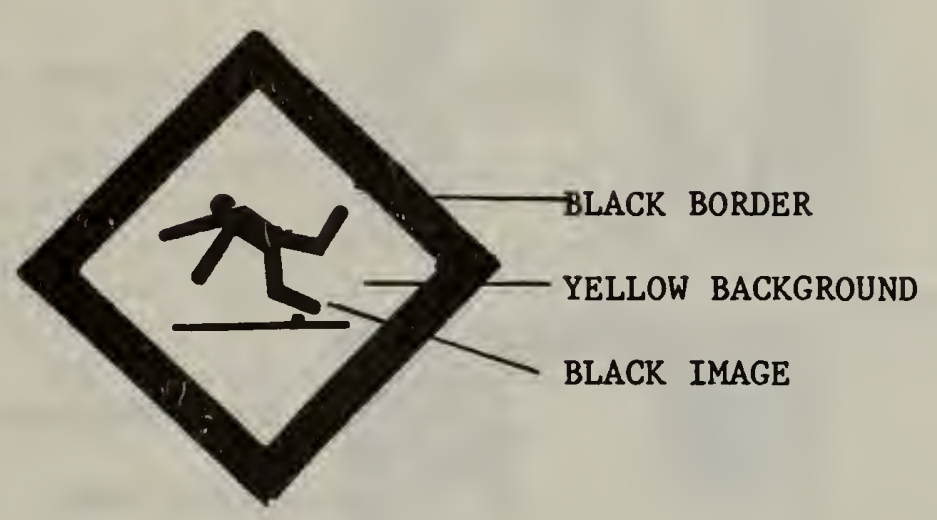

PROHIBITION

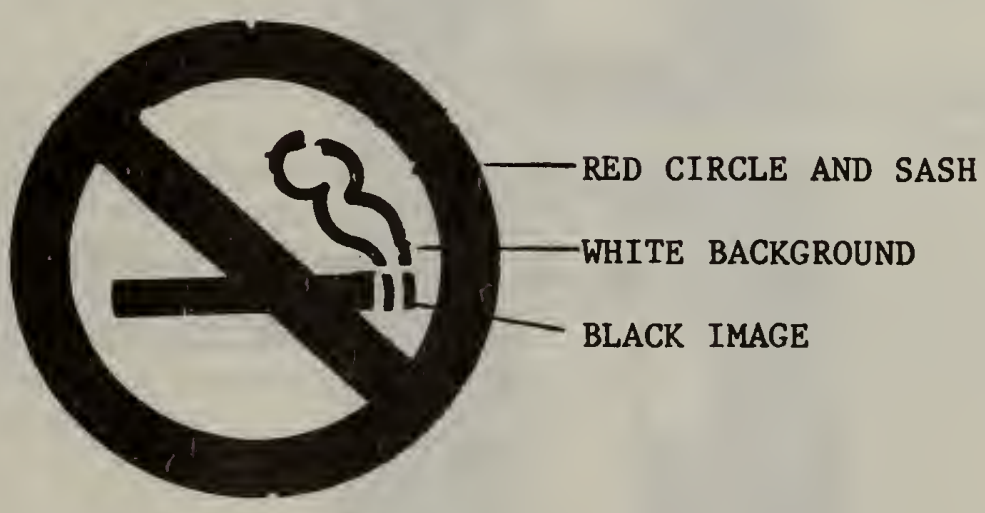

Figure 52. Examples of symbol configuration for each category 
MANDATORY

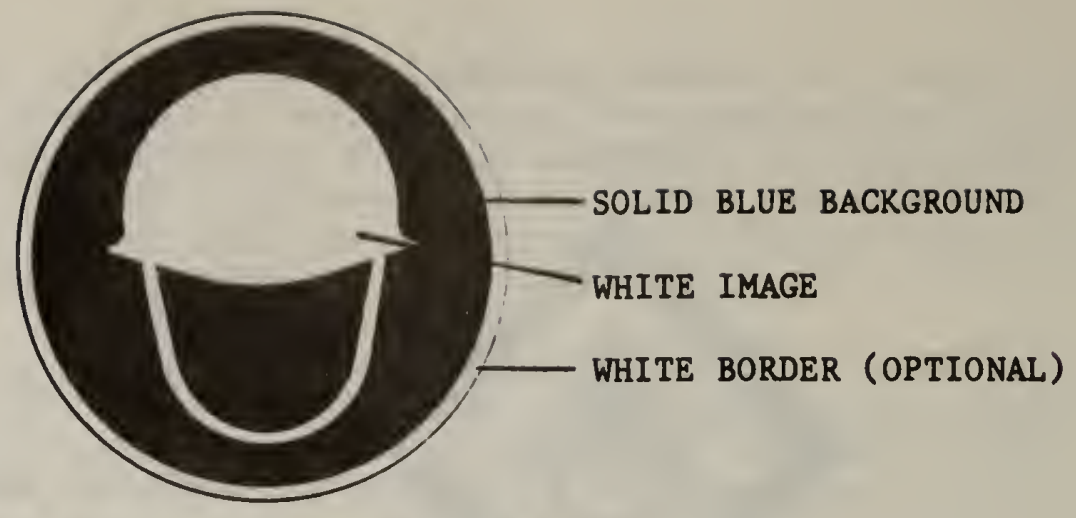

EGRESS

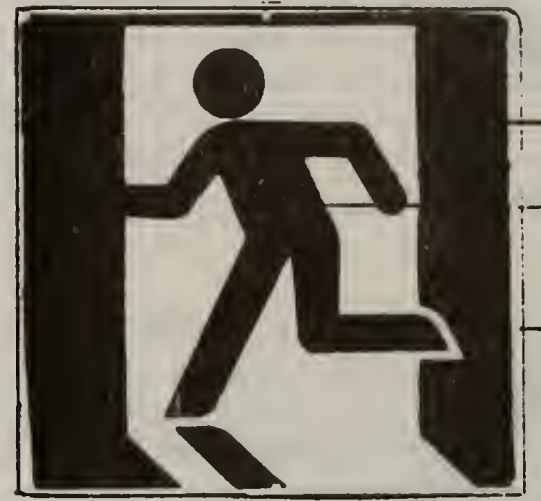

SOLID GREEN BACKGROUND

WHITE IMAGE (OR GREEN IMAGE ON WHITE DOORWAY)

- WHITE BORDER (OPTIONAL)

Note: No Exit should follow requirements for Prohibition

SAFETY INFORMATION

FIRE INFORMATION
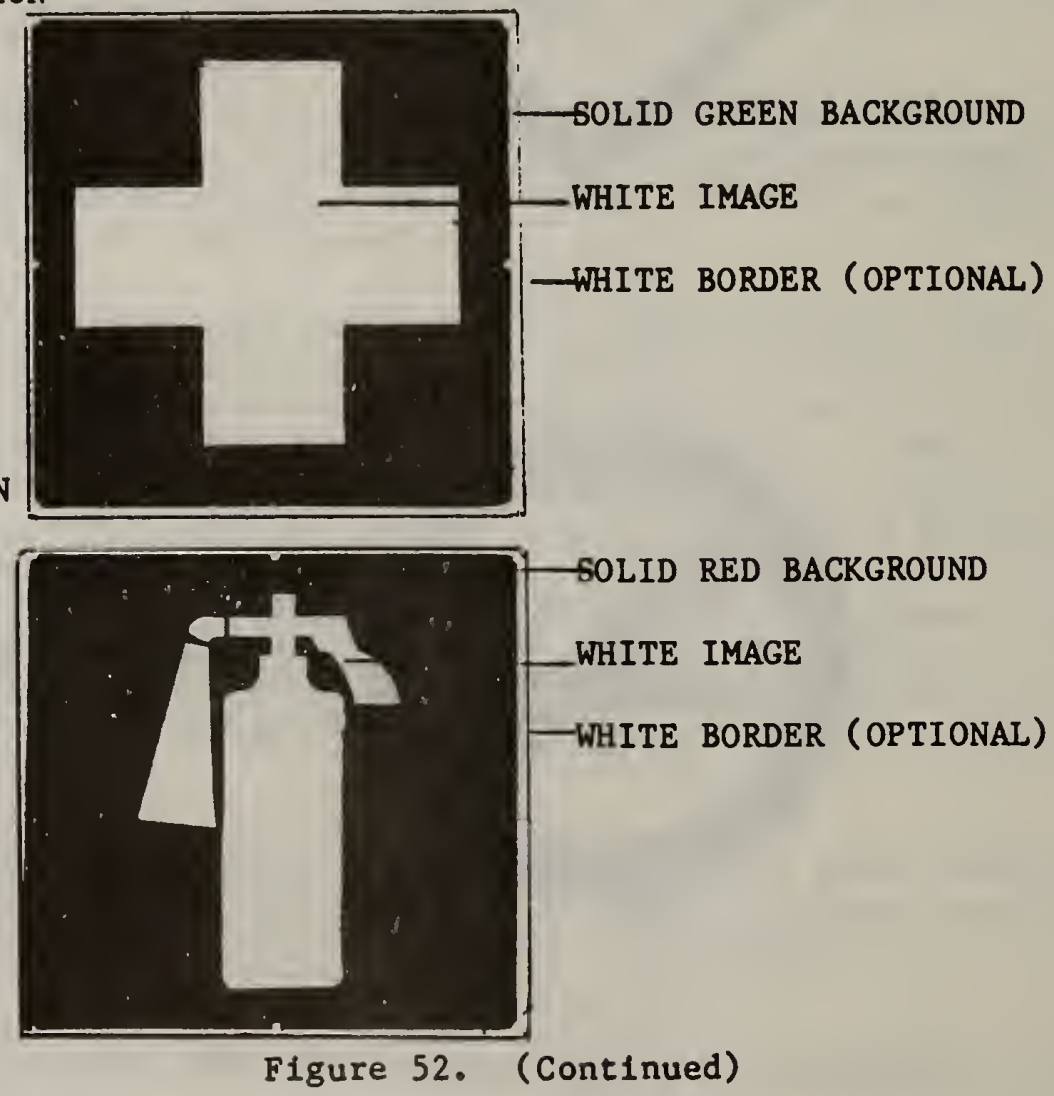
Mandatory action symbols should consist of white images centered on a solid blue circle or disc (ISO TC 80, 1978). See figure 52. (The Keep Door Open symbol should reverse the colors.)

The Exit symbol should consist of a white image on a square green background similar to the general safety messages (AIGA, 1979). See figure 52 . The No Exit and No Entry symbols should follow the recommendations for the prohibition category, with a black image on a white background surrounded by a red circle and slash.

Symbols for safety equipment location should consist of a white image centered on a square green background. Thus, the First Aid cross should be a white cross on a green square. (This avoids confusions with the "green cross for safety" theme of the National Safety Council, or the "red cross" for the Red Cross Society.) Symbols for fire emergency equipment should consist of a white image on a red background. See figure 52 .

\subsubsection{Sign Material}

Sign material should be durable and easily cleaned. A variety of materials is availible from sign manufacturers including steel, aluminum, porcelain, and various plastics. Choice of sign material will depend on the environment in which the sign will be located, and the desired sign life. In preparation and processing plants, corrosion and rust become a significant factor, while in other areas, dust and dirt must be considered (so that the sign must be easy to clean). Some colors will also fade after exposure to the weather or corrosive chemicals. Consultation with a sign manufacturer about the best material for a particular location is suggested.

The MUTCD recommends the use of reflectorized or illuminated signs so that the same colors and shape are seen by both day and night. Retroreflective materials are also available from sign manufacturers. These materials reflect light on the sign from headlights or cap lamps. They should be used underground or where night operations are in progress, because they increase the visibility of the sign at night and under low lighting levels.

In addition, a schedule of periodic inspection and maintenance is necessary. For the signs to be effective in getting people's attention and reminding them of safe behaviors, the signs must be legible. Equipment should not be parked or positioned so that it obscures any safety sign. Build-up of layers of dust will also eliminate any benefit from using signs. In areas where corrosive chemicals are used, signs may require frequent replacement, while signs in dusty areas will require periodic cleaning. The purpose of the signs is to get the miner's attention and communicate information; they must be clean and in reasonable repair to do this.

\subsubsection{Size}

The recommendations for sign legibility which are given in the MUTCD and ISO standards were developed from, and apply primarily to, the visibility of letters in words. They are designed to ensure that a letter or word be recognizable. 
No simllar research appears to exist for symbols, probably because of the difficulty in specifying the critical detall (comparable to letter helght or strokewidth) for symbols. As a result, it is difficult to specify how large a symbol must be to be seen and be effective.

The MUTCD (DoT, 1979) was consulted for recommendations for highway symbols. The MUTCD guldelines for symbol size assume a given sign size, typically a square, $18,24,30$, or 36 inches high. The longest dimension of the symbol is then specifled as being 83.3 percent (Brooks, personal communication) of the sign helght. For a 24-1n. sign, the dimension would be 20-1n; and for a 30-1n. sign, the dimension would be 25-1n. Using DoT's rule of thumb of 1-in. of letter helght visible at 50 feet, the 18-1n. sign as a whole should be visible at 900 feet. Assuming that the visibility of a symbol 1 s somewhat equivalent to that of a letter of the same helght, the 15-1n. symbol should be recognizable at 700-750 feet and should be highly visible. Safety signs avallable from three catalogues came $1 \mathrm{n}$ a range of $10 \mathrm{ln}$. by $12 \mathrm{ln}$; $8 \mathrm{ln}$. by $12 \mathrm{ln}$; 8 1n. by 8 1n.; as well as $20 \mathrm{ln}$. by $24 \mathrm{ln}$; $24 \mathrm{ln}$. by $24 \mathrm{ln}$; $30 \mathrm{ln}$. by $30 \mathrm{ln}$. and larger. Symbol signs tested in the in-mine evaluation were $12 \mathrm{ln}$. by $12 \mathrm{ln}$. $81 \mathrm{gns}$, a size which seemed to provide more-than-adequate leglbility for the relatively short viewing distances used. Unless a relatively small area is involved, the sign should probably not be smaller than 8 in. square.

If the symbol 18 used to 1ndicate a general hazard, then 1 must command attention, and should probably be bigger than the minimum visibility requirements for letters would suggest. Suggestions for minlmum symbol size developed by the Treasury Board of Canada (1980), In agreement with Sm1th's (1979) recommendations, and ISO suggest1ons $(1980 \mathrm{~b} ; 1982)$, are presented in table 38 . It should be noted that the suggestions given in those sources are based on research on letter, rather than symbol, visibility. In practice, the best procedure may be to determine, simply by looking at the sign, that it is legible at all reasonable viewing distances. Nevertheless, Smlth (1979) suggests that for good legibllity, a letter should be about $0.84-1 \mathrm{n}$. high to be viewed at 10 feet and 2.1-in. high at 25 feet. The use of the DoT recommendations of 1-in. for every 50 feet of viewing distance (a recommendation within Smith's values for 90 percent, but not 100 percent legibility) would result in even smaller letters. These various recommendations are intended to ensure that a letter or word be recognizable 90 to 100 percent of the time. Certalnly, the symbol should never be smaller than these recommendations for letters, regardless of the application. The smaller detalls of many of the symbols will be lost, however, even if these recommendations are followed. Again, the safety offlcer's best judgement is needed. He/she must first determine the distance at which the sign will typlcally be seen, and size the symbol so that it is clearly legible at this distance.

\subsection{SIGN PLACEMENT}

\subsubsection{S1gn Location}

General recommendations call for symbols to be placed within the normal line of sight with a variation of $+/-15$ degrees (ISO, 1982). Thus a sign located $10 \mathrm{~m}(32.8 \mathrm{ft})$ from a viewer could be about $2.5 \mathrm{~m}(8.2 \mathrm{ft})$ above or below the 
Table 38. Minimum Sizes Suggested for Symbols by the Treasury Board of Canada*

$\begin{array}{cc}\begin{array}{l}\text { Viewing } \\ \text { Distance }\end{array} & \begin{array}{l}\text { Symbo1 } \\ \text { Size }\end{array} \\ 3-6 \mathrm{~m} & 40 \mathrm{~mm} \\ 6-9 \mathrm{~m} & 60 \mathrm{~mm} \\ 9-12 \mathrm{~m} & 80 \mathrm{~mm} \\ 12-15 \mathrm{~m} & 100 \mathrm{~mm} \\ 15-18 \mathrm{~m} & 120 \mathrm{~mm} \\ 18-24 \mathrm{~m} & 160 \mathrm{~mm} \\ 24-30 \mathrm{~m} & 200 \mathrm{~mm} \\ 30-36 \mathrm{~m} & 240 \mathrm{~mm} \\ 36-48 \mathrm{~m} & 320 \mathrm{~mm} \\ 48-60 \mathrm{~m} & 400 \mathrm{~mm} \\ 60-72 \mathrm{~m} & 480 \mathrm{~mm} \\ 72-90 \mathrm{~m} & 600 \mathrm{~mm}\end{array}$

Note: The values are based on viewing under good light conditions and viewing angles which do not exceed 10 degrees.

* The values are given by the Treasury Board of Canada standard (1980), and are not based on research performed by NBS. They are given only as a guide for absolute minimum symbol size. 
normal line of sight. The line of sight depends, of course, on whether the person is seated or standing, in a mine-haulage truck or shuttle car. Signs located more than 30 degrees above the line of sight are very unlikely to be seen (Follis and Hammer, 1979). The recommendations mean that a sign should probably be located about 5 to 7 feet from the ground, unless extremes of haulage vehicles are operating in the area. In addition, these suggestions do not apply if the area is sprayed with chemlcals to reduce dust. Signs should then be mounted above the sprayed area so that they can remain legible.

Any sign such as the Exit symbol which shows obvious directional characteristics should be mounted so that its direction is appropriate. The Exit symbol should generally be used with an arrow, to reinforce the direction of travel.

The location of the sign in relation to the hazard or safety action is also critical. The nature of the message on the safety sign should determine its placement. The DOT MUTCD recommends placing prohibition or mandatory action signs at the place where the recommended action is to occur. Hazard warning signs, however, should be placed some distance before the hazard to warn users that they are approaching a hazardous situation so that they can take appropriate action (Treasury Board of Canada, 1980). The DoT manual suggests distances of 250 feet for low-speed zones, and 1500 feet for high-speed highways. While these distances are probably too long for many mining applications, particularly those within buildings, placing of the sign some distance before the hazard is encountered appears wise. This would allow the user time to avoid the hazard and take proper precautions.

Thus for most mining situations, the sign should be visible before the hazard is encountered to allow people to react properly. Equipment hazards, however, should probably be indicated on the equipment itself. (Most equipment is currently shipped by the manufacturer with warning labels already in place.) A number of guidelines for labels and symbols for product safety have been published, including the FMC (1978) and Westinghouse (1981) handbooks. Their recommendations are quite useful for marking or labeling possible hazards on equipment which does not already have warning labels.

Signs for prohibited actions, such as No Smoking, should be carefully placed only in the areas for which the prohibition applies. Simllarly, mandatory action signs, such as Hard Hat Required, should be used only where the restriction applies. Thus, ear protectors are typically required only in certain designated high noise areas, not a whole site (unlike safety shoes).

A number of different approaches may be selected to mark a hazardous situation. Table 39 presents signs that could be used to indicate the presence of a corrosive chemical. The sign may warn of a hazard, indicate the consequences of the hazard, require protective gear, prohibit touching the hazard, or indicate first aid measures. The safety officer should determine which sign approach best fits the particular situation. More than one symbol/sign may be used depending on the desired safe behavior. 
Table 39. Different Symbolic Information for a Single Hazard

\section{HAZARD:CORROSION}

DESCRIPTIVE

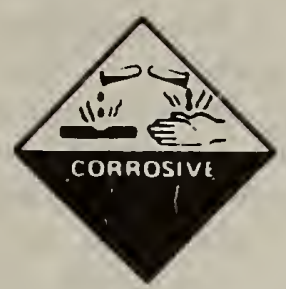

CONSEQUENCES
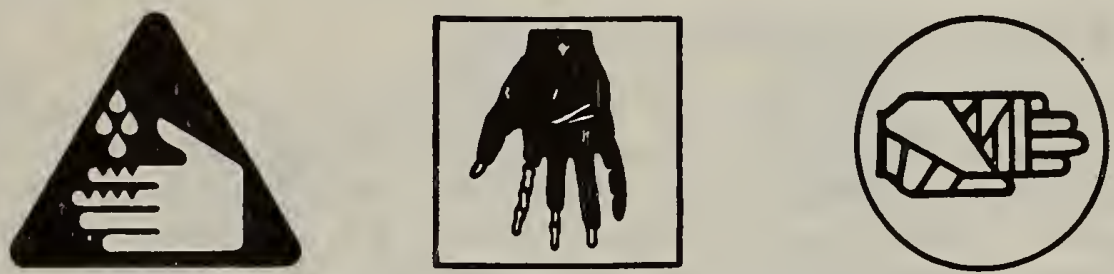

\section{PROTECTIVE}

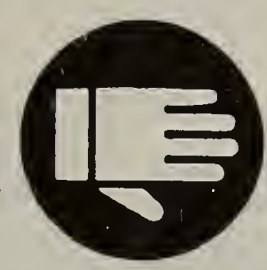

\section{PROHIBITION}
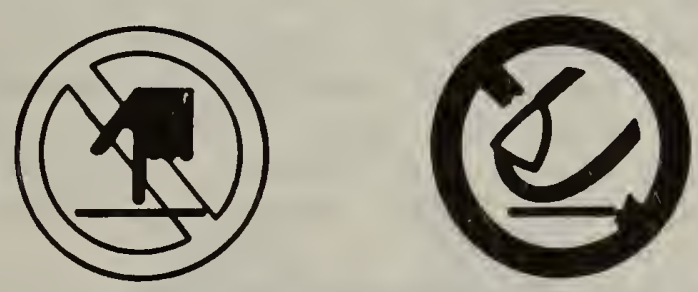

\section{FIRST AID}
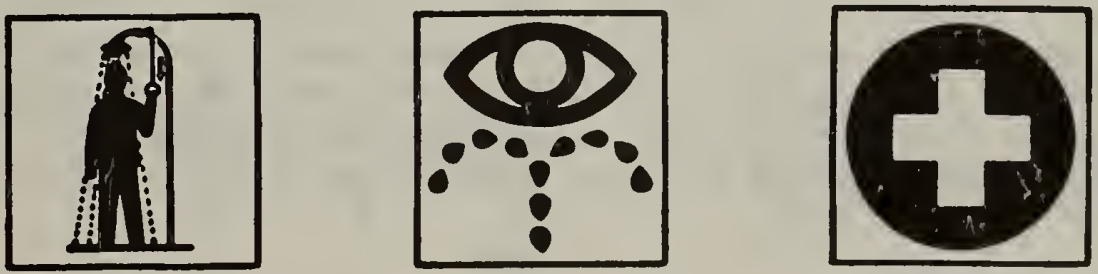


\subsubsection{Number of Signs}

It is important that the safety officer exercise his/her best judgement in using signs. Oversigning can be as harmful as undersigning, because the important messages may be lost in general visual clutter. Thus, the MUTCD (DoT, 1979 , p. 2, A.3) noted that "care should be taken not to install too many signs. A conservative use of regulatory and warning signs is recommended as these signs, if used to excess, tend to lose their effectiveness." The Treasury Board of Canada (1980) commented that "the number of symbols placed in any one facility should be strictly limited to those that are absolutely necessary. This principle increases the effectiveness of the symbols displayed and prevents visual confusion" ( $p .18)$. These cautionary statements are intended to warn against a common tendency to mark everything in sight and thus lose the attention-getting value of the safety sign. The safety officer should only use signs for situations where the likelihood of injury, particularly serious infury, is great, or where certain behaviors must or must not occur.

\subsection{SYMBOL EVALUATION--SUGGESTED PROCEDURES}

The symbols presented in figure 50 were evaluated for understandability with as many as 360 miners from 11 different sites in the U.S. While this represents a reasonably large number of people, it certainly does not represent all possible miners. Since many of these symbols are new, they may be unfamiliar to at least some miners at a site. As a result, it is suggested that the understandability of the symbols be determined for miners at a site, before symbol signs are used there. A good mechanism for determining symbol understandability could be a short test given during the safety or training session.

While there are many ways of determining the understandability of a set of symbols, two testing procedures can be suggested. In the first procedure, miners are asked to define the meaning of the symbols. In the definition procedure, the miners are shown slides or reproductions of the symbols. Each individual miner is asked to write down a short definition of no more than 10 words of the meaning of the symbol. (This procedure should take no more than one-half hour for the symbols shown in figure 50.) After collecting all the answer sheets, the safety/training officer should then discuss the meaning of each symbol, and note any problems that seem to arise. The officer should then score the answers as right or wrong. If more than 15 percent of the miners get the answer wrong for a particular symbol, then the meaning of the symbol should be discussed further at the next meeting. If this symbol is used on a sign, it should be accompanied by a short, clear explanatory word message.

The second procedure is suggested as an alternative method, if the time for scoring the definitions is likely to be a problem. (Scoring problems can arise because of difficulties in reading handwriting, and in being certain of what a person meant by a particular answer. Yet, the definition procedure allows the identification of many possible wrong answers that might arise for a particular symbol. As such, it provides more information than the matching procedure, although is more time-consuming.) In the matching procedure, a form such as that given in table 40 could be used. This form contains all the symbols 

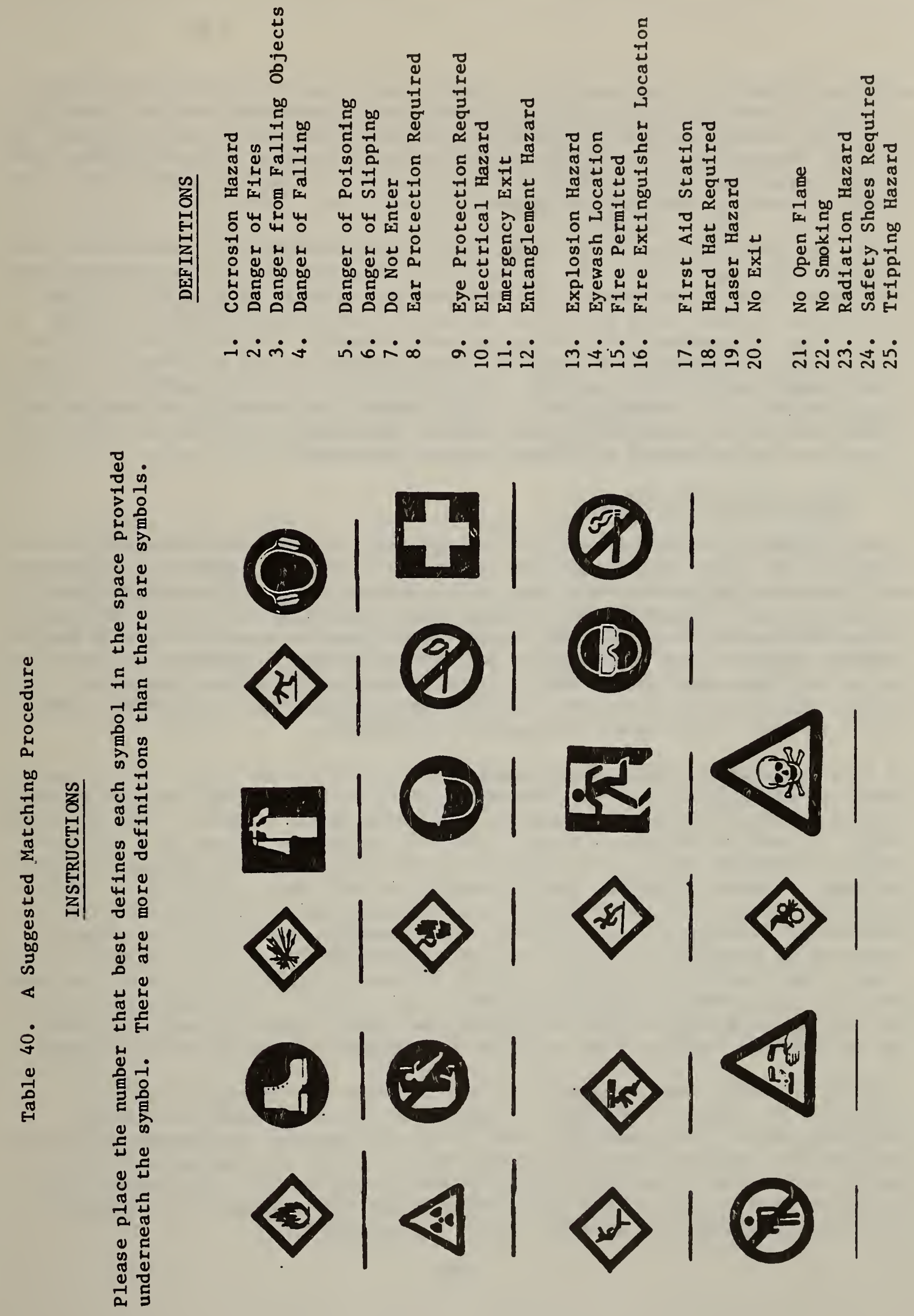
given in figure 50. The miners are asked to match each symbol with one (and only one) of the short definitions given at the right. There are more definitions than symbols so that the process of elimination cannot be used to make matches. The definitions deliberately include some common confusions that have arisen in previous testing, such as Fire Permitted for the Flammable Hazard symbol (as well as the correct answer).

Again, the miners are asked to complete the form 1ndividually, without talking to each other, and hand it in. As in the first method, the correct answers for each symbol are then discussed, and any problems noted. If more than 15 percent of the answers for a particular symbol are wrong, then further training and the use of supplementary word signs are indicated. Periodic retesting is a good 1dea, particularly if there is large turnover in the workforce. If a miner cannot read or write English, these various evaluation procedures are inappropriate. The training officer might conduct oral evaluation sessions, by asking each miner, individually, to explain what each symbol means. Additional training or multi-lingual signs may also be indicated.

\subsection{ADDITION OF WORD MESSAGES}

Symbol signs can be used to attract attention and communicate information rapidly. There are some situations, particularly hazard s1tuations, for which word slgns may be more approprlate, or for which both symbol and word signs should be used. Add1tional word messages may be particularly useful in providing information about actions to take in response to specific hazards or in defining the extent of the hazard. The in-mine symbol sign evaluation suggested that the other categorles of symbols-mpohiblted action, mandatory action, safety and fire equipment location, and egress-may be somewhat less $11 k e l y$ to require additional explanatory information.

If word messages are used, they should be short and to the point. Foll1s and Hammer (1979) suggest that word messages should be as short as possible so that they can be read quickly and mean the same thing to all viewers. Thus the word "Stop" is used for highways, rather than "All drivers must come to a full stop, before proceeding through the upcoming intersection", or some similarly lengthy statement. The word message should communicate information such as the probable consequences of the hazard, how to avold the hazard, or the duration of a restriction. Examples might include: the Flammable symbol with the phrase "combustible materials in area"; the Entanglement symbol with the phrase "keep fingers away from moving parts"; the Ear Protection symbol with the phrase "ear protection required for exposures greater than 1 hour". The symbol is used to get the user's attention and communicate the kind of hazard or action, while the word phrase explains what to do or what happens if the hazard 18 1gnored.

In addition, word messages should be used for symbol signs which are poorly understood by miners at the site. Examples of likely candidates include: Radiation, Laser, and Flammable. The MUTCD, for example, recommends the use of supplementary word messages for symbols which are not well understood for a period of at least three years after initial installation. When symbols are inftially used at a site, use of an accompanying word message to facilitate learning the symbols may also be a valid recommendation. 
It is important, however, to avoid lengthy word messages. The American Hospital Association (1979) recommends no more than 26 characters per line, and no more than 16 words on a sign. The FMC manual (1978) recommends a format in which only 19 characters are used per line. It suggests further that messages be limited to no more than 3 to 5 lines of type. Although such recommendations have not been researched for their impact on legibility, they do represent the best judgement of a number of sign designers. Long messages simply cannot be read in the time necessary to react to the sign and avoid the hazard or perform the required action.

\subsection{GENERAL RECOMMENDATIONS}

Table 41 summarizes a number of the general suggestions presented in this Handbook for using symbol signs at mine sites. These suggestions are intended to be helpful to the safety officer who wishes to use symbols and signs to communicate safety information. They provide general guidelines for selecting and locating safety symbol signs when combined with the symbols given in figure 50.

In conclusion, the Department of Transportation uses symbols on the highways because they communicate rapidly and accurately. Words are used only as a supplementary, training device or to provide directional guidance. The same approach appears valid for mines sites, because, when chosen appropriately, symbols can communicate safety and hazard information effectively. The preceeding sections have presented three phases of research on symbol signs which demonstrate the general feasibility of using symbol signs at mine sites. The handbook has presented some general considerations and guidelines for actually installing these symbol signs. 
Table 41. General Suggestions for Using Safety Symbols at Mine S1tes

Use DoT "Manual of Uniform Traffic Control Devices" for mine road signs.

- Use symbol signs to attract attention and communicate information rapidly.

- Avold oversigning--use signs to indicate the 1mportant safety messages.

- Be sure that background color and surround shape correspond to message category:

$$
\begin{aligned}
& \text { Hazard Warning--Danger--Red--Diamond Surround } \\
& \qquad \text { Caution--Yellow--Diamond Surround } \\
& \text { Mandatory Action--Blue--Circle (Disk) Surround } \\
& \text { Prohib1tion--Red--C1rcle and Slash Surround } \\
& \text { Egress--Green--Square (Rectangle) Surround }
\end{aligned}
$$$$
\text { Equipment Location--Safety--Green--Square (Rectangle) Surround }
$$$$
\text { F1re--Red--Square (Rectangle) Surround }
$$

- Use reflective materials for underground and night operations.

- Locate warning signs before the hazard and all other signs as close to the desired action as possible.

- Be sure that signs are legible at intended viewing distances.

- Place signs within normal line-of-sight.

- Be sure that directional signs agree with actual direction of travel.

- Institute regular sign maintenance and replacement program.

- Evaluate symbol understandability with miners--Provide supplemental training or word messages if necessary.

- Keep word messages short and to the point. 


\section{REFERENCES}

1. Adams, A. S. and Hsu, L. T., The Coding of Symbol Signs, Hazard Prevention, 1981, Mar/Apri1, 17, 5-7.

2. American Hospital Association, Signs and Graphics for Health Care Facilities. Chicago, IL, American Hospital Association, 1979.

3. American Institute of Graphic Arts (AIGA), Symbol Signs. Report prepared for the Department of Transportation. DOT-OS-40192, November 1974.

4. American Institute of Graphic Arts (AIGA), The Development of Passenger/ Pedestrian Oriented Symbols for Use in Transportation-Related Facilities, U. S. Department of Transportation. DOT-RSPA-DPB-40-79, 1979.

5. American National Standards Institute (ANSI). Safety Color Code for Marking Physical Hazards, New York: ANSI 253.1, 1979.

6. American National Standards Institute (ANSI). Specifications for Accident Prevention Signs, New York: ANSI Z35.1, 1972.

7. Brainard, R. W., Campbell, R. J., and Elkins, E. H., Design and Interpretability of Road Signs, Journal of Applied Psychology, 1961, 45, 130-136.

8. Brooks, T. Personal Communication, January, 1983.

9. Bureau of Labor Statistics, Occupational Injuries and IIlnesses for 1978, USDL 79-788; and Work Related Deaths for 1978, USDL 79-787, Nov. 7, 1979.

10. Cahil1, M. C., Interpretability of Graphic Symbols as a Function of Context and Experience Factors, Journal of Applied Psychology, 1975, 60, 376-580.

11. Cah111, M. C., Design Features of Graphic Symbols Varying in Interpretability, Perceptual and Motor Sk111s, 1976, 42, 647-653.

12. Canadian Standards Association, Signs and Symbols for the Occupational Environment, Can. 3-Z-321-77, September 1977.

13. Cochran, D. J., Riley, M. W., and Douglass, E. I., An Investigation of Shapes for Warning Labels. Proceedings of the Human Factors Soclety, 1981, pp. 395-399.

14. Code of Federal Regulations, Title 29, Labor, Chapter XVII--Occupational Safety and Health Administration, Section 1910-144 to 1910-153; Section 126,1981 , p. 254-262.

15. Code of Federal Regulations, Title 30, Mineral Resources, Parts 0-199, Mine Safety and Health Administration, July 1980. 
16. Code of Federal Regulations, Title 49--Transportation, Parts 100-199, Hazardous Mater1als Transport Labels, January 1974.

17. Collins, B. L., The development and evaluation of effective symbols. Washington, D.C.: National Bureau of Standards, Buldding Sclence Series 141, May 1982.

18. Collins, B. L., Lerner, N. D., Plerman, B. C., Symbols for Industrial Safety. Washington, D.C.: National Bureau of Standards, NBSIR 82-2485, Apri1 1982.

19. Collins, B. L. and Lerner, N. D., Assessment of Fire Safety Symbols, Human Factors, $1982,24,75-84$.

20. Collins, B. L. and Lerner, N. D., An Evaluation of Exit Symbol Visibility. Washington, D.C.: National Bureau of Standards, NBSIR 83-2675, Apr11 1983.

21. Department of Transportation, Federal H1ghway Administration, Manual on Uniform Traffic Control Devices (MUTCD). Title 23, CRR. WashIngton, D.C., 1979 .

22. Dewar, R. E., "The Slash Obscures the Symbol on Prohibitive Traffic Signs," Human Factors, 1976, 18, 253-258.

23. Dewar, R. E., E11s, J. G., and Mundy, G., Reaction Time as an Index of Traffic S1gn Perception, Human Factors, 1976, 18(4), pp. 381-392.

24. Dewar, R. E. and Swanson, H. A., Recognition of Traffic Control Signs. National Academy of Sclences, NRC, H1ghway Research Board, 1972, 414, 16-23.

25. Dreyfuss, H., Symbol Sourcebook. New York: McGraw H111, 1972.

26. Easterby, R. S. and Haklel, S. R., Safety Labelling of Consumer Products-Interim Report on Shape and Colour Coding of Signs, AP Report No. 56, Applied Psychology Department, University of Aston in Birmingham, Gosta Green, Birmingham, England, March 1977 (a).

27. Easterby, R. S. and Haklel, S. R., Safety Labelling of Consumer Products-Shapes and Colour Code Stereotypes in the Design of Signs, AP Report 75, Applied Psychology Department, University of Aston in Birmingham, Gosta Green, B1rmingham, England, December 1977 (b).

28. Easterby, R. S. and Hakiel, S. R., Safety Labelling and Consumer Products: Field Studies of Sign Recognition, AP Report 76, Applied Psychology, Department, University of Aston, Birmingham, England, December 1977 (c).

29. Easterby, R. S. and Hakiel, S. R., Field Testing of Consumer Safety Signs: The Comprehension of Pictorially Presented Messages, Applied Ergonomics, $1981,12,143-152$. 
30. Easterby, R. S. and Zwaga, H. J. G., Evaluation of Public Information Symbols, ISO Tests. 1975 Series, AP Report 60, Applied Psychology Department, University of Aston in Birmingham, Gosta Green, Birmingham, England, March 1976.

31. Ells, J. G. and Dewar, R. E., Rapid Comprehension of Verbal and Symbolic Traffic Sign Messages, Human Factors, 1979, 21, 161-168.

32. European Economic Community, Council Directive, Safety Signs at Places of Work, Journal of the European Communities, 25 July 1977, P. L229/ $12-\mathrm{L} 229 / 20$.

33. European Economic Community, Commission of the European Communities, Safety and Health Commission for the Mining and Extractive Industries, The Harmonisation and Application of Safety Signs at Work in Coal Mines, Luxembourg, 1979.

34. Follis, J. and Hammer, I., Architectural Signing and Graphics. New York: Whitney Library of Design, 1979.

35. Forbes, T. W., Gervais, E., and Allen, T., Effectiveness of Symbols for Lane Control Signals, Highway Research Board Bullet1n, 1963, 244, 16-29.

36. FMC, Product Safety Signs and Labels. Santa Clara, California, FMC, 2nd Ed., 1978 .

37. Freedman, M. and Berkowitz, M. S., Preliminary Report on Laboratory and Pilot Field Testing: Testing Criteria and Techniques of Evaluation for Passenger/Pedestrian Oriented Symbols for Use in Transportation Related Facilities, DOT-OS-60071. FIRL No. C4448, January 1977.

38. Freedman, M., Berkowitz, M. S., and Gallagher, V. P., Symbol Signs: Testing Criteria and Techniques of Evaluation Passenger/Pedestrian Oriented Symbols for Use in Transportation Related Facilities, Interim Report, U.S. DoT, September 2, 1976.

39. Glass, R. A., Howett, G. L., Lister, K., and Collins, B. L., Some Criteria for Colors and Signs in Workplaces. Washington, D.C.: National Bureau of Standards, NBSIR 83-2694, April 1983.

40. Green, P., Development of Pictographic Symbols for Vehicle Controls and Displays," Society of Automotive Engineers: Technical Paper (Warrendale, PA), \#790 383, February-March 1979.

41. Green, P. and Pew, R. W., Evaluating Pictographic Symbols: An Automotive Application, Human Factors, 1978, 20, 103-114.

42. Griffith, D. and Actkinson, T. R., International Road Signs:

Interpretability and Training Techniques, U.S. Army Research Institute for the Behavioral and Social Sciences - Report 1202, September 1978. 
43. Heard, E. A., Symbol Study - 1972, Society of Automotive Engineers, Automotive Engineers Congress, Detro1t, MI, February 25 - March 1, 1974, 740-304.

44. Hulbert, S., Beers, J,, and Fowler, P. Motorists' understanding of traffic control devices. Fall Church, Va: AAA Foundation for Traffic Safety, March, 1979.

45. International Organization for Standardization (ISO), Equipment for Fire Protection and Fire Fighting Safety Signs, Geneva: ISO, Draft Proposal DP 6309, ISO/TC $21 / \mathrm{SC} / 1,1978$.

46. International Organization for Standardization (1S0), Safety Colours and Safety Signs, Geneva: 1S0, Draft Standard, D1S 3864.3, ISO/TC 80, 1978.

47. International Organization for Standardization, (ISO), TC 145, Graphic Symbols Part 1-Rules for the presentation of graphic symbols; General Principles. Geneva: ISO, Revision of ISO 3461, N115E, 1980(a).

48. International Organization for Standardization (ISO), TC 125/SC1, ISO/DIS 7001. Procedure for the Development of Public Information Symbols. Geneva, 1980(b).

49. International Organization for Standardization (ISO), Draft Technical Report 7239. Development and Application Principles for Public Information Symbols. Geneva: ISO, TC145, 1982.

50. Janda, H. F. and Volk, W. N., Effectiveness of Varlous Highway Signs, Nat1onal Research Counc1l - Highway Research Board Proceeding 8, 1934, 14, 442-447.

51. Japanese Proposal of P1ctograph Regarding ISO/TC21/SC1 N25, DP6309 Safety Sign No. 4, "Emergency Exit," May 1980.

52. Jerome, C. W., The Rendering of ANSI Safety Colors. Journal of the Illuminating Engineering Society, 1972, 6, 180-183.

53. Johnston, A. W., Cole, B. L., Jacobs, R. J., and Gibson, A. J. Visibility of traffic control devices: Catering for the real observer. Ergonomics $1976,19,591-609$.

54. King, L. E., A Laboratory Comparison of Symbol and Word Roadway Signs, Traffic Engineering and Control, 1971, 12, 518-520.

55. King, L. E., Recognition of Symbol and Word Traffic Signs, Journal of Safety Research, 1975, $7,80-84$.

56. Kirsh, I., and Guthrle, J., The Concept and Meaningfulness of Functional Literacy, Reading Research Quarterly, 1977-78, 485-507.' 
57. Laner, S. and Sell, R. G., An Experiment on the Effect of Specially designed safety posters, Occupational Psychology, 1960, 34, 153-169.

58. Lerner, N. D. and Collins, B. L., The Assessment of Safety Symbol Understandability by Different Testing Methods, Washington, D.C.: National Bureau of Standards, NBSIR $80-2088,1980(a)$.

59. Lerner, N. D. and Collins, B. L., Workplace Safety Symbols, Washington, D.C.: National Bureau of Standards, NBSIR 80-2003, 1980 (b).

60. Mackett-Stout, J. and Dewar, R., "Evaluation of Public Information Signs," Human Factors, 1981, 23, 139-151.

61. Mine Safety and Health Administration, MSHA Mine Injuries and Worktime Quarterly, January-December, 1980 and 1982 .

62. Mine Safety and Health Administration, Injury Experience in Coal Mining, MSHA IR $1122,1979$.

63. Modley, R. and Myers, W. R., Handbook of Pictorial Symbols. New York: Dover Publications, 1976.

64. National Fire Protection Administration, (NFPA), Standard Symbols for Fire Fighting Operations. Boston, MA: NFPA 178, 1980.

65. National Safety Council, Accident Facts, Final Condensed Edition, Chicago, IL: National Safety Council, 1981.

66. National Safety Council, Accident Facts: 1979 Edition, National Safety Council, Chicago, 1979.

67. Nutheme Co., Illustrated Safety Signs, Skokie, IL: Nutheme, 1975.

68. Rubin, M. L. and Walls, G. L., Fundamental of Visual Science. Springfield, Illinois: Charles C. Thomas, 1969.

69. Schiff, W., Perception: An Aplied Approach. Boston: Houghton, Mifflin, 1980 .

70. Sharry, J. A. (Ed.), Life Safety Code Handbook. Boston, National Fire Protection Association, 1978.

71. Shepich, T. J., Schlick, D. P., and Thirumalai, K., Mandatory Safety and Health Traning of New Miners, MSHA, IR 1082, 1978.

72. Smith, S. L., Letter size and Legibility, Human Factors, 1979, 21, 661-670.

73. Smith, G. and Weir, R., "Laboratory Visibility Studies of Directional Symbols Used for Traffic Control Signals," Ergonomics, 1978, 21, 247-252. 
74. Soclety of Automot1ve Engineers (SAE), Safety S1gns--SAE J115a. Warrendale, PA: SAE, June 1979.

75. SPSS (Stat18tical Package for the Social Sciences), New York: McGraw-H111, 1975.

76. Standards Association of Austral1a, The Design and Use of Graphic Symbols and Public Information Standards, Part 3, Test Procedures for Evaluating Graphic Symbols and Symbol S1gns, Australian Standard, AS 2342, Part 3, 1980.

77. Treasury Board of Canada, Graphic Symbols for Public Areas and Occupational Environment8, Ottawa, Canada, July 1980.

78. Walker, R. E., Nicolay, R. C., and Stearns, C. R., Comparative Accuracy of Recognizing American and International Road S1gns, Journal of Applied Pyschology, $1965,49,322-325$.

79. Washington Post, "Reading and Writing Gap W1dening as Needs Out-distance Sk111s in U.S.", September 9, 1979, p. 12.

80. Westinghouse Electr1c Corporat1on, Product Safety Label Handbook. Trafford, PA: Westinghouse, 1981.

81. Wiegand, D. and Glumm, M. M., An Evaluation of P1ctographic Symbols for Controls and Displays in Road Vehicles, Technical Memorandum 1-79, U. S. Army Human Engineerlng Laboratory, February 1979.

82. Yanone, A. G., "Fire Exit" Symbol, Copyright 1979.

83. Zwaga, H. J.G., and Boersema, T. Evaluation of a Set of Graphic Symbols. The University of Utrecht, The Netherlands: Psychological Laboratory, Report \#28, July 1981 . 


\section{Yellow Jackets* Reviewed}

1. Mantrip accident/injuries - January 1978 - January 1979

2. Electrical injuries in coal - 1974-79

3. Electrical fatalities at M/NM mines - 1972 - August 1977

4. Back injuries $M / N M$ 1977-1970

6. Pinch point injuries M/NM 1978 - June 1979

7. Handtool injuries $\mathrm{M} / \mathrm{NM}$ - 1977-1979

8. Conveyor injuries $\mathrm{M} / \mathrm{NM}-1975-1976$

9. Slusher accidents M/NM 1975-1977

10. Machinery accidents M/NM 1975 - September 1976

11. Near fatal accidents M/NM 1975-1976

12. Forecasts of fatality rates, conditional totals 1981-1985

13. Surface fatalities M/NM 1972-1975

14. Injury comparison - surface mine/NM, S\& G 1978 - November 1979

15. Truck haulage related fatalities surface coal - 1978-1976

16. Injury hazard comparison in different coal seam heights

17. Surface coal mine injury experience - key to accident prevention

18. Fall or rib, roof, face accidents - underground coal

19. Criteria for selecting mines for special attention

* Publications of the HSAC Branch of MSHA 


\section{APPENDIX A. MINERS' COMMENTS DURING SYMBOL DEBRIEFING}

Fork11ft--perfer the one showling the man in the forkl1ft--forkl1ft with man shows operational unit--the other could mean park forkl1ft here

Safety Shower--man in shower 1s better; more real1st1c; more abstract symbol 1s no good; looks l1ke a sprinkler system

Corrosion--more abstract symbol 1s not good; ISO symbol shows two things (hand and metal); ISO symbol shows corrosion to metals as well as hand

Exit--Arrows and squares take too long to flgure out; requires thought; 1 t looks like a dead end; could mean "creep that way"; looks $11 \mathrm{ke}$ a football fleld

Flammable--confusion: because clrcle, slash and flame mean "no flre", therefore flame alone must mean "f1re"; could mean f1re permitted; need for a symbol to indicate permission; perhaps use person and flames to indicate fire hazard

No Smoking--11ke the use of c1rcle and slash to mean "no"

F1re alarm--sounder or horn better for f1re alarm; bell no good; both look like "nolse hezard"

Ear protectlon--protectors on head better; more defined; protectors by themselves require you to stop and think; look 11ke an arch without the head

Entanglement--hand in gears good--many groans when sl1de shown

Electricity--ISO symbol means lighting strike here; man and electric1ty good

Sudden pressure release--head w1th explosion (1mage 2) looks like welding; like and arc; guy looks like he's wearing a welding mask; 1mage 1 looks like flash burns, bolling water, may indicate steam release; really needs pipe or hose to show rupture and steam escaping

Hard hat--hat by itself doesn't look like hard hat, looks like turtle, or upside-down soup kettle; hat on head looks like military hat--perhaps show attachment for cap lamp

Cut/Sever--foot image perhaps too drastic for the message "cut"

Door open--do not 11ke

Overhead load--rocks and hammer better for underground mines or shop or construction--hammer gives idea of falling-crane means hoisting

Safety gloves--gloves with cuffs can cause problems in underground mines 
Hot Surface--plate and flames should be red--need to indicate radiant, not direct heat; need to show hand with flat palm (looks like guy is something up)

Pinch Point--graphic--get attention

No Exit--" $\mathrm{X}$ " over door is not good as " $\mathrm{X}$ " is the word "exit"--the other symbol is vague and unclear

Fall from elevation--backward fall provides idea of helght

Crush--hand crush shows damage; whole body can also indicate low clearance

No open flame--don't set fires; match better, more universal, flame looks like campfire

Safety glasses--glasses on man look like both safety glasses and goggles

General Warning--do not like--seems dumb--baseball field ahead--does not make sense--poor

Respirator--ISO image perhaps better for chemical processing--image 2 better, looks more like what is worn--is not a whole face piece--perhaps make smaller

Poison--skull and crossbones better; more familiar--has been used for years-the other is better for bad or polluted atmosphere;

Explosion--ISO Image--like fragments--idea that something has blown-up perhaps need bomb with fuse-the other explosion symbol is better

Slip--legs alone looks like debris, upset can of oil

First Aid--green cross for safety--red for red cross

Trip--could be confused with running--perhaps show hard hat falling off--man and object better, indicates message--perhaps show foot being caught

Fire Extinguisher--change nozzle

Emergency Exit--man and flame--run fast from fire--two tone man--disappearing man, theft, integrated schools

Do Not Touch--make slash over finger narrower--looks like electrical emergency button or high pressure valve; circle and slash works well

Eyewash--head and drops is better--perhaps add drops on face

Safety shoes--ISO (two shoes) Image is too delicate, need laces to look like boots, dumb, like dress boots or rubber boots; Canadian symbol--like eyelets, but show safety, steel toe 
MrefllAA iner, 8.001

\begin{tabular}{|c|c|c|c|}
\hline $\begin{array}{l}\text { U.0. DEPT. OF COMM. } \\
\text { BIBLIOGRAPHIC OATA }\end{array}$ & $\begin{array}{l}\text { 1. PUBLICATION OR } \\
\text { REPORT NO. }\end{array}$ & 2. Performing Orgen. Report No. & J. Publlention Date \\
\hline SHEET (See In struetiona) & NBSIR $83-2732$ & & June 1983 \\
\hline
\end{tabular}

4. TITLE AND SUBTITLE

Use of Hazard P1ctorlals/Symbols in the Minerals Industry

3. AUTHOR(S)

Belinda Lowenhaupt Collins

6. PERFORMING ORGANIZATION (If Jolnt or other then NBS, see In atruet/on s)

MATIONAL BUREAU OF STANDARDS

DEPARTMENT OF COMMERCE

WASHINGTON, D.C. 20234

9. SPONSORING ORGANIZATION NAME ANO COMPLETE AODRESS (Stret, Clty, Stote, ZIP)

U.S. Bureau of Mines

Columbla Plaza

2401 E Street, N.W.

Washington, D.C. 20241

10. SUPPLEMENTARY NOTES

[] Document descrlbes a computer prosram; SF-185, FIPS Software Summary, 10 attached,

11. ABSTRACT (A 200-word or less foctuol summery of most sisnifleant information. If documens Includes a s/enlfleans blbllogrophy or llserature supvey, mention it here)

This report documents a mult1-phase research effort on the evaluation of the effectiveness of safety symbols and hazard plctorlals for use in mining and milling operations. In the first phase, applicable codes and standards were revlewed, along with documentation of typical mining hazards, to determine relevant safety messages. In the second phase, site visits were made to elght mine sites to document existing sign practice and common mining hazards. In the third phase, the effectiveness of two sets of symbols for 40 different safety messages was evaluated with 267 miners from ten sites at disparate geographical locations. This evaluation also included an assessment of the effectiveness of six different symbol surround shapes and colors. Symbols which were most effective were those which depicted both the person and the hazard or protective gear, and which were more representational rather than highly abstract. Use of a dlamond to indlcate hazard-warning is also recommended. Based upon this research, a set of 40 symbols are suggested for further graphic refinement, additional evaluation, and eventual use. A subject of 20 of these symbols was selected for in-mine evaluation at two mine sites. This evaluation determined that the symbol signs were generally well-understood, consplcuous, durable, and leglble. A handbook which provides suggestions for using symbol signs at mine sites concludes the report.

12. KEY WORDS (Six to tweive entries; alphabetical order; capitalize only proper names; and separate key words by semicolons) communication; hazard; mining; pictogram; safety; signs; standards; symbols; visual alerting; warnings

13. AVAILABILITY

Unlimited

[ For Official Distribution. Do Not Release to NTIS

$\square$ Order From Superintendent of Documents, U.S. Government PrInting Office, Washington, D.C. 20402.

14. NO. OF PRINTED PAGES

Order From National Technlcal Information Servlce (NTIS), Springfield, VA. 22161

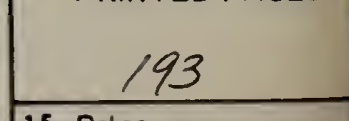

15. Price 

